\title{
USING HIGH-PROBABILITY REQUEST SEQUENCES TO INCREASE SOCIAL INTERACTIONS IN YOUNG CHILDREN WITH AUTISM
}

\section{DISSERTATION}

\author{
Presented in Partial Fulfillment of the Requirement for \\ the Degree Doctor of Philosophy in the Graduate \\ School of The Ohio State University
}

\author{
By \\ Sunhwa Jung, M.A. \\ $* * * * *$ \\ The Ohio State University \\ 2003
}

Dissertation Committee:

Approved by

Professor Diane Sainato, Advisor

Professor William Heward

Professor Ralph Gardner

Advisor

Rebecca Morrison, Ph. D. 


\begin{abstract}
The importance of children's development and learning in the early years has been strongly emphasized in practice and research. To date, a variety of empirically validated strategies in early childhood special education and applied behavior analysis have been developed. Among the variety of effective instructional strategies, the highprobability request sequence has been demonstrated as an antecedent and non-aversive procedure, which is well incorporated into classroom routines. Few studies on the use of the high-probability request sequence have addressed the social behaviors of young children with autism with peers in their natural environment.

The inclusion of young children with disabilities is increasing, and building meaningful social relationships between children with and without disabilities is one of the most important goals of inclusion. Due to the substantial social skill deficits of children with autism, facilitating social interactions has been a critical issue in educational research. Among a variety of social interaction interventions, peer-mediated strategies are the most frequently used and have shown the strongest empirical support for social outcomes. However, it is noted that these strategies focus on peer training to initiate with children with autism, and often yield prompt-dependent behavior and
\end{abstract}


limitations in generalization and maintenance. Few studies have been implemented to teach social behaviors children with autism as well as the typically developing peers.

The purpose of this study was to investigate an effective strategy to increase social interactions of children with autism in the children's typical classroom environment. The high-probability request sequence intervention was first delivered to the peers as a model and then delivered to the target children. The intervention was implemented using the children's favorite play materials during a center time in an inclusive classroom.

The specific dependent variables of interest were the percent correct responses to the low-probability requests, and number of intervals of social initiations and responses toward other children. The effects of the intervention on these variables were monitored using a single subject multiple baseline design across subjects. In addition, measures of procedural integrity, accuracy and social validity were collected.

The results of this study indicated that all three children's compliant responding to low-probability requests and social initiations and responses increased during the intervention condition. Furthermore, the target children's social initiations and responses generalized with their peers and in generality settings. 
Dedicated to my parents 


\section{ACKNOWLEDGMENTS}

I wish to thank my advisor and mentor Dr. Diane Sainato who for the past four years has provided all the support, encouragement, and advice that I needed to live in a new world. Her knowledge, experiences, and time were endlessly offered to complete this research. Her willingness to help her students has been a model for me as a professor. Thanks also to Dr. Rebecca Morrison who has opened her school to me for research and always supported me with her knowledge and experiences. To Dr. William Heward who is truly committed to help his graduate students to do their best work, I express thanks for his valuable and thoughtful suggestions for this research. Thanks to Dr. Gardner for providing his insightful and practical suggestions. Also, I would like to thank Dr. Carol Ann Davis for her consultation throughout this research.

I appreciate the help of the parents, teachers, staff, and children of Oakstone Academy. In particular, Susan Snyder deserves a special thank you for her support with flexibility and patience and for making me feel welcome in her classroom. I am grateful to my two dedicated data collectors, Satcey Christenson and Juli Slack, who have maintained their commitment and enthusiasm for this research. Also many thanks to my

dependable colleagues, Yao Ma, Donna Vallerial, and Ya-yu Lo. Finally, I am grateful to my parents and brother for their love, support, and encouragement. 
VITA

March 1, 1964

1986

1993

1986-1988

1992-1998

1999-present
Born-Choongbook, Korea

B.A. Special Education, Ewha Womans University

M.A. Special Education, Ewha Womans University

Special Education Teacher in Kodug middle school, Seoul, Korea

Early Childhood Special Education Teacher; Educational Diagnostician; Administrator, Seoul Community Rehabilitation Center, Seoul, Korea

Graduate Administrative, Research, and Teaching Associate, The Ohio State University

\section{PUBLICATIONS}

Jung, S., Kim, S., Kim, S., Hwang, S., Lee, S., Cho, H., \& Lee, J. (1999). The curriculum for small parent group education in Seoul Community Rehabilitation Center: Doongji Gyosil. Seoul: Seoul Community Rehabilitation Center.

Cho, Y., Jung, S., Kim, H., \& Kang, O. (1994). The curriculum for preschoolers with special needs I. Seoul: Seoul Community Rehabilitation Center.

Cho, Y., Jung, S., Kim, H., \& Kang, O. (1994). The curriculum for preschoolers with special needs II. Seoul: Seoul Community Rehabilitation Center.

\section{FIELDS OF STUDY}

Major Field: Education 
TABLE OF CONTENTS

Page

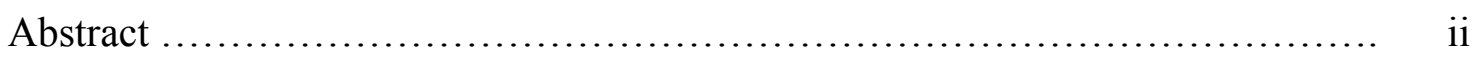

Dedication ................................................................. iv

Acknowledgement f...............................................................

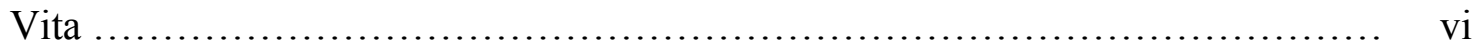

List of Tables .............................................................

List of Figures ............................................................ xii

Chapters:

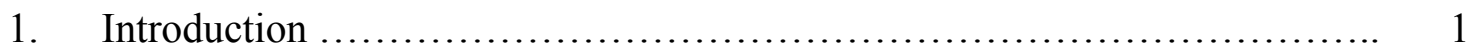

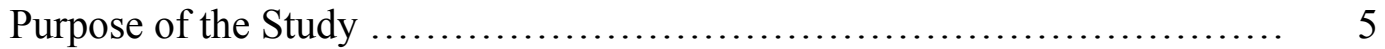

Research Questions ................................................. 7

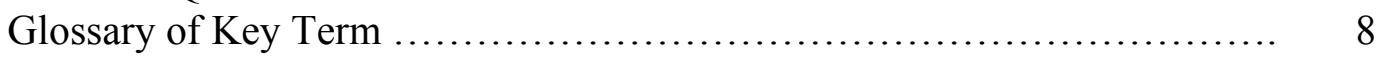

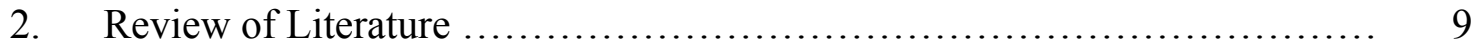

High-Probability Request Sequence ................................. 9

The Theoretical Explanations of the Effects of the High-Probability

Request Sequence ........................................... 11

Behavioral Momentum ....................................... 12

Basic Research Findings in Behavioral Momentum .................. 13

Behavioral Momentum in Basic Research and High-Probability

Request Sequence in Applied Research in Applied Research ........... 17

Applied Research Findings Using the High-Probability Request

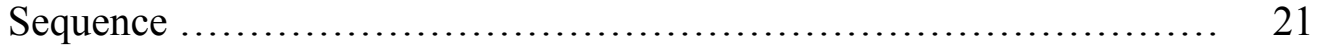

Summary of the Literature on High-Probability Request Sequence ...... 53

Social Interaction Interventions ................................... 55

Peer-Mediated Intervention ....................................... 57

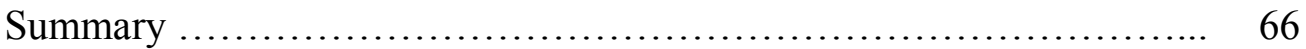




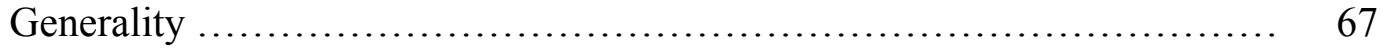

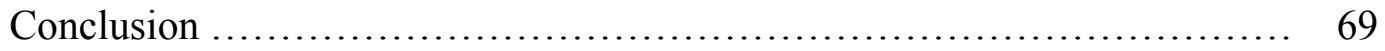

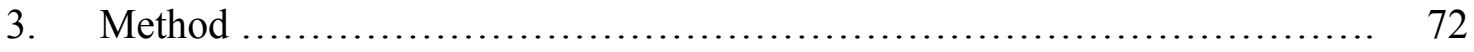

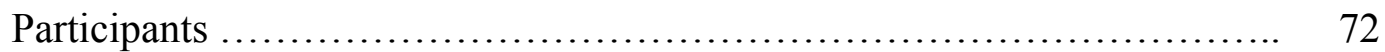

Experimenter .................................................... 77

Classroom Staff .................................................. 77

Research Setting ................................................. 77

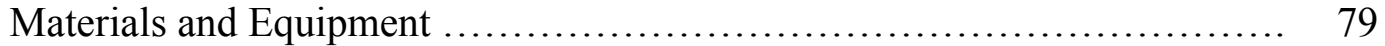

Definition and Measurement of Dependent Variables .................... 82

Definition of Dependent Variables ............................... 82

Measurement ................................................ 85

Procedures to Assess Believability of Data ............................ 85

Accuracy Measures ............................................ 86

Procedural Integrity ........................................... 88

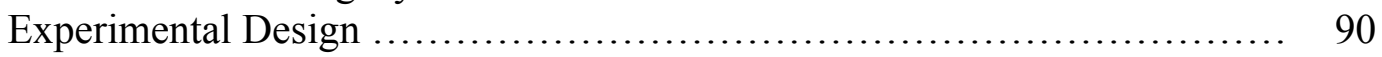

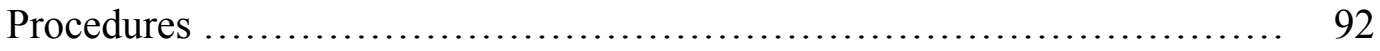

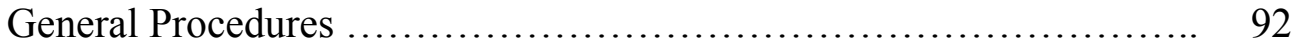

Normative Measurement ...................................... 93

Status Assessment of High-Probability and Low-Probability Request ... 94

Baseline ....................................................... 95

Low-Probability Requests Alone ............................... 96

High-Probability Request Sequence Using Embedded Peer Modeling ... 98

Low-Probability Requests Alone .................................... 100

Maintenance ..................................................... 101

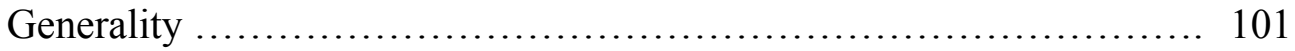

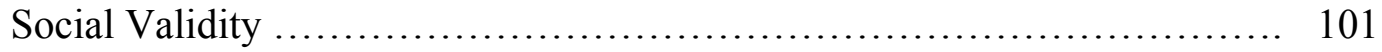

Intervention Goals .............................................. 102

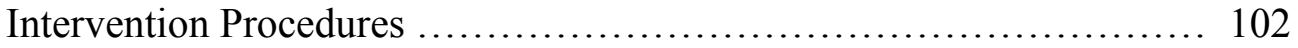

Intervention Outcomes ....................................... 103

4. $\quad$ Results ................................................................ 104

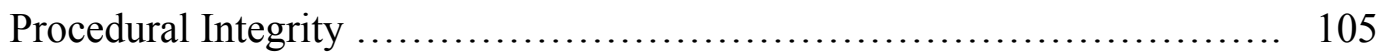

Procedural Integrity Checklist ................................ 105

Delivery of Low-Probability and High-Probability Requests .......... 107

Experimenter General Prompts ................................ 113

Accuracy Measures for Experimenter General Prompts .............. 121

Responses to High-Probability Requests ........................ 124

Peer Training .............................................. 127

Procedures to Ensure the Believability of Dependent Variables.................... 128

Dependent Variables............................................. 139 
Compliant Responding to Low-Probability Requests ................ 139

Social interactions in the intervention setting ........................ 146

Social interactions in the generality setting ........................ 164

Additional data on other behaviors ............................... 179

Social Validity ..................................................... 186

Intervention Goals.............................................. 186

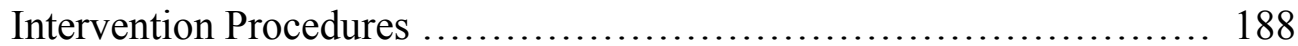

Intervention Outcomes ..................................... 190

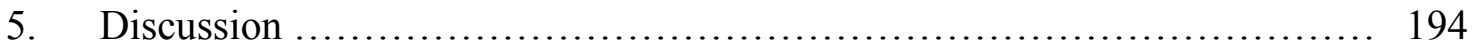

Limitations of the Study ......................................... 194

Research Questions ............................................. 195

Implications for Practice ..................................... 212

Directions for Future Research ................................. 214

Summary .................................................... 217

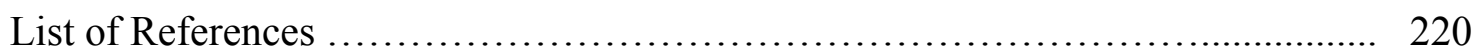

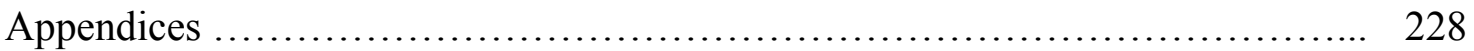

A. Data Collection Form ........................................... 228

B. Coding Manual ............................................... 234

C. Procedural Integrity Checklist ................................ 241

D. Parent and Teacher Questionnaire ............................. 247

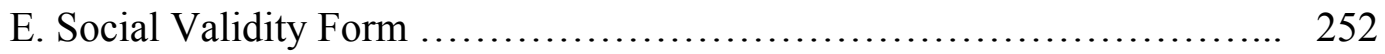

F. High-Probability and Low-Probability Request Assessment Form ........ 259

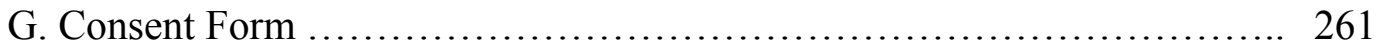

H. High-Probability and Low-Probability Requests .................... 267

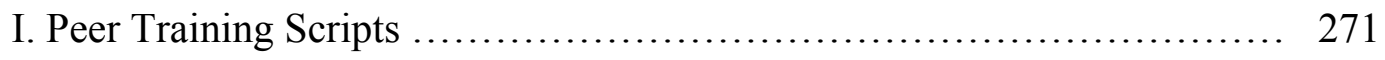




\section{LIST OF TABLES}

Table $\quad \underline{\text { Page }}$

2.1 Summary of studies on high-probability request sequence intervention ..... 23

2.2 Summary of studies on peer-initiation intervention $\ldots \ldots \ldots \ldots \ldots \ldots \ldots \ldots \ldots$

2.3 Summary of studies on peer modeling ............................. 65

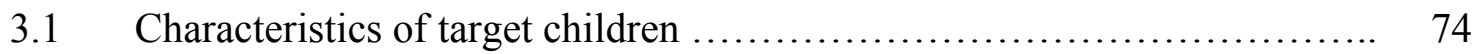

3.2 Examples of low-probability and high-probability requests for participants

3.3 Examples of a high-probability request sequence using embedded peer modeling

4.1 Summary of procedural integrity checklists completed and interobserver agreement calculated for procedural integrity checklists for participants in the intervention (I) and the generality setting $(\mathrm{G})$

4.2 The mean percentage of delivery of low-probability and high-probability requests and accuracy measures calculated for delivery of low-probability and high-probability requests

4.3 The mean number of intervals and range of experimenter general prompts for participants in the intervention (I) and generality setting $(\mathrm{G})$

4.4 Accuracy measures for experimenter general prompts for participants in the intervention (I) and generality setting $(\mathrm{G})$...

4.5 Accuracy measures for the target children and peers' responses (R), nonresposnes (NR), and noncompliance (NC) to low-probability and highprobability requests

4.6 Accuracy measures for social initiations (I) and responses (R) in the intervention setting 
4.7 Accuracy measures for social initiations (I) and responses (R) in the generality setting.

4.8 Accuracy measures for disruptive behaviors in the intervention (I) and generality settings $(\mathrm{G})$

4.9 The mean percentage and range of the target children's and peers' responses (R), nonresponses (NR), and noncompliance (NC) to lowprobability and high-probability requests

4.10 The mean number of intervals and range of the target children's social initiations (I) and responses (R) to the peer $(\mathrm{P})$ and the generality peer $(\mathrm{G})$ in the intervention settings.

4.11 The mean number of intervals and range of peers' social initiations (I) and $(\mathrm{R})$ to the target children $(\mathrm{T})$ and the generality peer $(\mathrm{G})$ in the intervention setting

4.12 The mean number of intervals and range of the target children's social initiations $(\mathrm{I})$ and responses $(\mathrm{R})$ to the peer $(\mathrm{P})$ and the generality peer $(\mathrm{G})$ in the generality setting

4.13 The mean number of intervals and range of peers' social initiations (I) and responses to the target children $(\mathrm{T})$ and the generality peer $(\mathrm{G})$ in the generality setting

4.14 The mean number of intervals and range of the target children's disruptive behaviors and self-stimulating behaviors in the intervention (I) and generality setting $(\mathrm{G})$

4.15 Summary of parent and teacher questionnaire

4.16 Summary of observed skills for the target children during intervention videotaped segments by the professionals in early childhood special education 


\section{LIST OF FIGURES}

Figures $\quad$ Page

$3.1 \quad$ Illustration of classroom .............................................. 78

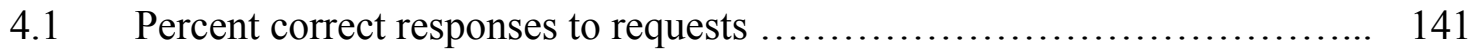

4.2 Number of intervals of social behaviors in the intervention setting ........ 147

4.3 Number of intervals of social behaviors in the generality setting ......... 166 


\section{CHAPTER 1}

\section{INTRODUCTION}

The importance of children's early development and learning has been strongly emphasized in practice and research (Sandall, McLean, Santos, \& Smith, 2000).

Providing effective early intervention for children with disabilities results in positive outcomes for these children and their families (Sandall et al., 2000). To date, a variety of empirically validated strategies in early childhood special education and applied behavior analysis have been developed. Efforts to expand the repertoire of instructional techniques available to practitioners continue to be a focus of research in early intervention (Davis \& Brady, 1993; Killu, 1999).

Inclusive educational placements have become more common for young children with disabilities. The increasing inclusion of young children with disabilities demands a broader variety of instructional strategies to accommodate the range of children's educational needs in early childhood settings. These instructional strategies need to be easily implemented, incorporated into instructional routines, use typical toys and 
materials, and be delivered in the child's natural classroom environment. Such strategies may help children to generalize their learned behaviors as well as increase the implementation of interventions by classroom teachers.

Among the variety of effective instructional strategies, the high-probability request sequence has received attention as an antecedent and non-aversive procedure (Davis \& Brady, 1993). The high-probability request sequence procedure has been demonstrated to be an effective instructional tactic to increase not only compliance but also specific skills such as language and social skills (Davis \& Brady, 1993; Davis, Brady, Hamilton, McEvoy, \& Williams, 1994; Davis, Brady, Williams, \& Hamilton, 1992; Davis \& Reichle, 1996; Davis, Reichle, \& Southard, 2000). The current Division for Early Childhood Recommended Practice Guidelines suggests the high-probability request procedure is one of the strategies that teachers can use to increase the complexity and duration of children's play, engagement, appropriate behavior, and learning (Wolery, 2000). In addition, researchers suggest that the high-probability procedure can be easily incorporated into classroom routines or existing intervention programs in preschools while at the same time accommodating a child's individual needs (Davis, 1995; Davis \& Brady, 1993; Davis \& Reichle, 1996; Davis et al., 1992, 1994; Davis et al., 2000; Killu 1999; Killu et al., 1998; Sanchez-Fort, Brady, \& Davis, 1995; Santos \& Lignugaris/Kraft, 1999). The high-probability request sequence does not require extra materials and can be used in a variety of contexts. Much of the research on the use of the high-probability request sequence intervention has focused on increasing compliance of school age- 
children and adults with disabilities (Santos, 2001). Few high-probability request sequence studies have addressed the social behaviors of young children with autism with peers in their natural environment (Davis et al., 1994).

Social relationships with peers are critical for child development. These relationships are formed when children have positive interactions with peers in the classroom and in the community (Frea, Craig-Unkefer, Odom, \& Johnson, 1999). Building meaningful social relationships between children with and without special needs is one of the most important goals of inclusion (Guralnick, 1999). However, young children with disabilities often do not have the prerequisite social skills to develop relationships.

Children with autism have substantial social interaction deficits. They rarely initiate interactions and are unlikely to exhibit spontaneous language, gestures, or eye contact before speaking (Zanolli, Daggett, \& Adams, 1996). Numerous researchers note that social interactions between children with autism and typically developing peers are unlikely to occur without systematic and planned social interventions even when they are placed together in inclusive settings (Brown \& Odom, 1995; Guralnick, 1999; Hundert \& Houghton, 1992; Kohler \& Strain, 1999).

Facilitating social interactions in young children with autism has been a critical issue in educational research. Researchers have developed a wide variety of interventions to increase social interactions of young children with autism (Kohler, Anthony, Steighner, \& Hoyson, 2001; Odom \& Strain, 1986; Odom \& Watts, 1991; Sainato, Goldstein, \& Strain, 1992; Zanolli et al., 1996). Among a wide variety of social skill interventions, peer-mediated strategies are the most frequently used and have shown the strongest 
empirical support for social outcomes (Rogers, 2000; Sasso, Peck, \& Garrison-Harrell, 1998; Zanolli et al., 1996). Peer modeling, as well as training peers to initiate to children with autism, can produce positive effects on children's generalized imitation of social behaviors (Kohler \& Strain, 1990; Kohler and Strain, 1999). In studies using peermediated strategies, children with autism typically responded to their peers, acting as confederates rather than initiating social behaviors toward the typically developing peers. Additionally, it is noted that these interventions often yield prompt-dependent behavior; limitations in generalization and durability of responding; and require extensive teacher involvement (Chandler, Lubeck, \& Fowler, 1992; Hundert \& Houghton, 1992; Odom, Chandler, Ostrosky, McConnell, \& Reaney, 1992; Sainato, Goldstein, \& Strain, 1992; Sasso, Peck, \& Garrison-Harrell, 1998). Children with autism need to learn to initiate to typical peers as well as respond to their initiations. Few studies have been implemented to improve the social initiations as well as the social responses of children with autism. A combination of the high-probability request sequence intervention and a peer-mediated intervention for both children with autism and typically developing children may help to facilitate children's social responses as well as social initiations while also helping children to maintain and generalize social interactions. Furthermore, facilitating social interactions embedded in the context of the classroom while encouraging engagement in appropriate play activities may help children extend spontaneous social interactions. Thus, children's social interactions may reap the benefits of the natural contingencies of ongoing reciprocal interactions in natural settings. 


\section{Purpose of the study}

The purpose of this study was to investigate a strategy to increase social interactions for children with autism in an inclusive setting. This study combined the strategies of high-probability requests intervention and peer-mediated interventions in order to build an effective strategy for increasing social interactions in the children's typical classroom environment. It was anticipated that by facilitating social initiations as well as responses with encouraging play within a given a context, children would be more likely to maintain and expand ongoing social interactions within the classroom.

This study sought to extend previous research by exploring the effectiveness of the high-probability request sequence intervention through application of the procedure to the social interaction skills of young children with autism. Although numerous studies have demonstrated the effectiveness of the high-probability request sequence intervention on compliant behaviors, few studies using the high-probability request sequence have been conducted to increase the social interactions of young children with autism (Davis et al., 1994).

In addition, this study extended the literature in the area of high-probability requests and peer mediated interventions to increase social interactions through combining two strategies. Peer-mediated interventions have demonstrated the effectiveness of training peers to initiate toward children with disabilities. In addition to training peers to interact with children with autism, facilitating the social initiations of children with autism toward typically developing peers may encourage ongoing interactions between the children. Furthermore, using peer modeling could provide children with autism the opportunity to observe and imitate their peers' social behaviors. 
Previous studies have demonstrated that friendship activities using songs and games increase social interactions among children by prompting greetings, complimenting, and affection behaviors (Brown, McEvoy, \& Bishop, 1991; Brown, Raglan, \& Bishop, 1989; Brown \& Odom, 1995; Cooper \& McEvoy, 1996; McEvoy, Twardosz, \& Bishop, 1990; Twardosz, Nordquist, Simon, \& Botkin, 1984). The intervention in this study included requests to prompt children to share greetings, compliment their friends, and display affectionate behavior and play interactions within a given context. Researchers note that friendship activities are more likely to obtain generalized social responding since the activities serve as multiple exemplars and include social behaviors that are more likely to evoke positive social interactions (McEvoy, Twardosz, \& Bishop, 1990). Thus, the intervention would increase generalized social interactions by including prompts adapted from friendship activities.

Finally, the social validity of the goals, procedures, and outcomes were assessed. Since developing effective instructions in inclusive settings for use in the classroom or other natural environments is an important goal, assessment of relevant consumers' opinions regarding the intervention was necessary. Surveys and questionnaires were used to obtain the opinions of parents and teachers regarding the validity of the intervention goals, the acceptability and usability of the procedures, and the outcomes.

As young children with autism are increasingly placed in inclusive environments, it becomes more important to develop strategies that can be used in these environments to increase their social relationships with their typically developing peers. The investigation 
of strategies such as the high-probability request sequence combined with a peermediated social interaction intervention may lead to the development of more effective strategies for use in classroom environments.

\section{Research Questions}

1. What are the effects of the use of high-probability request sequences with embedded peer modeling on complaint responding to low-probability requests to initiate social behaviors for young children with autism?

2. What are the effects of the use of high-probability request sequences with embedded peer modeling on the social interactions of young children with autism toward their typically developing peers?

3. What are the effects of the use of high-probability request sequences with embedded peer modeling on the social interactions of young children with autism toward their typically developing peers during generality sessions?

4. To what extent do parents and early childhood special education teachers find the intervention goals, procedures, and outcomes to be relevant, useful and effective for children with autism? 


\section{Glossary of Key Terms}

The following is a glossary of terminology used in this study.

behavioral momentum: persistence of behavior and its resistance to change following a change in reinforcement condition (Nevin, Mandell, \& Atak, 1983)

high-probability request sequence: a sequence of easy and favorite requests (i.e., highprobability requests) delivered immediately prior to a request that is not typically performed (i.e., low-probability request) (Davis \& Brady, 1993; Davis, 1995). high-probability requests: requests that a child consistently performs (Davis, 1995; Santos, 2001).

low-probability requests: requests that the child does not typically perform; thus, the probability of the child performing them is low (Davis, 1995; Santos, 2001).

Inter-prompt time (IPT): the interval of time between the reinforcement delivered for the previous request and commencing delivery of the next request 


\section{CHAPTER 2}

\section{REVIEW OF LITERATURE}

Research in early childhood special education and applied behavior analysis seeks to develop and extend effective instructional strategies for children with autism. Among the variety of effective instructional strategies, the high-probability request sequence has been demonstrated to be an effective instructional tactic to increase not only compliance but also specific skills such as language and social skills. Due to the substantial social skill deficits of children with autism, facilitating social interactions has been a focus of research for these children. This chapter reviews the literature on the high-probability request sequence intervention, including the theoretical explanation, behavioral momentum, and the application of the high-probability request sequence intervention to improve a variety of skills. A review of the literature on increasing social interactions of young children with autism using peer-mediated strategies is presented.

High-Probability Request Sequence

The high-probability request sequence has received attention as an effective instructional strategy to increase compliant behavior (e.g., Davis, Brady, Williams, \& 
Hamilton, 1992; Ducharme \& Wolering, 1994; Mace et al., 1988, etc.). Recently, the high-probability intervention has been expanded to improve other functional skills such as language and social skills for young children with disabilities (e.g., Davis, Brady, Hamilton, McEvoy, \& Williams, 1994; Davis \& Reichle, 1996; Sanchez-Fort, Brady, \& Davis, 1995; Santos \& Lignugaris/Kraft, 1999).

The high-probability request sequence intervention includes a sequence of easy and favorite requests (i.e., the high-probability requests) delivered immediately before a request that is not typically performed (i.e., the low-probability request) (Davis \& Brady, 1993; Davis, 1995). This strategy has been also referred to as "pre-task requests," or “interspersed requests." High-probability requests are those that a child consistently performs (Davis, 1995; Santos, 2001). Low-probability requests are requests that the child does not typically perform (Davis, 1995; Santos, 2001). The high-probability request procedure is performed as follows (Davis, 1995): (a) deliver a sequence of three to five high-probability requests at a rapid pace, (b) deliver praise for each performance of the high-probability requests, (c) deliver a low-probability request, and (d) deliver praise for the performance of the low-probability request.

Researchers note that the high-probability request sequence is a proactive, antecedent strategy that teachers, parents, and peers can effectively implement to promote a variety of appropriate behaviors in children with disabilities (Davis 1995; Davis \& Brady, 1993; Davis \& Reichle, 1996; Davis et al., 1992, 1994, 2000; Santos, 2001). Investigators who have implemented the high-probability request sequence note that it has many advantages as an instructional strategy in applied settings. For example, the 
high-probability request sequence does not require extra materials and can be easily incorporated into classroom routines, the home, or a variety of other contexts (Davis, 1995; Davis \& Brady, 1993; Davis \& Reichle, 1996; Davis et al., 1992,1994, 2000; Ducharme \& Worling, 1994; Killu, Sainato, Davis, Ospelt, \& Paul, 1998; Sanchez-Fort, Brady, \& Davis, 1995; Santos, 2001; Santos \& Lignugaris/Kraft, 1999).

\section{The Theoretical Explanations of the Effects of the High-Probability Request Sequence}

Although numerous studies have demonstrated the substantial effects of the highprobability request sequence procedure to promote appropriate behaviors, the effectiveness of the high-probability request sequence intervention has not been clearly explained. According to Singer, Singer, and Horner (1987) the reinforcement of compliance to pretask requests changes the valence of the target requests. That is, when movement from a positive valence condition (i.e. recess) to negative valence condition (i.e., work) is preceded by series of reinforced requests, the negative valence becomes weak or less discriminative. Horner, Day, Sprague, O’Brien, and Heathfield (1991) explained that the experience of compliance to preferred instructions following reinforcement may produce more opportunities to promote a generalized class (i.e., the same stimulus class) of compliance to instruction that includes less preferred activities.

As another interpretation of the effectiveness of the high-probability request sequence that has been used by most researchers who implemented the high-probability request sequence procedure, Mace and his colleagues (1988) suggested that the effectiveness of the high-probability request procedure can be explained by the behavioral momentum paradigm proposed by Nevin, Mandell, and Atak (1983). Mace et al. (1988) proposed that by delivering the high-probability request sequence immediately 
prior to issuing a low-probability request, the rates of response and reinforcement increased. Thus, compliance with instructions following the high-probability request sequence persisted when the low-probability request was delivered by establishing a momentum of compliant behavior. Most applied literature on the use of the highprobability request sequence has used the behavioral momentum model to interpret the effects of the high-probability request sequence procedures (e.g., Ardoin, Martens, \& Wolfe, 1999; Belfiore, Lee, Vargas, \& Skinner, 1997; Davis \& Reichle, 1996; Davis et al., 1992, 1994, 2000; Ducharme \& Worling, 1994; Harchick \& Putzier, 1990; Houlihan, Jacobson, \& Brandon, 1994; Killu et al., 1998; Mace \& Belfiore, 1990; Mace, Mauro, Boyajian, \& Eckert, 1997; McComas, Wacker, \& Cooper, 1998; Rortvedt \& Miltenberger, 1994; Sanchez-Fort et al., 1995; Santos \& Ligungaris/Kraft, 1999; Wehby \& Hollahan, 2000).

\section{Behavioral Momentum}

Behavioral momentum, proposed by Nevin et al. (1983), describes the persistence of behavior following a change in reinforcement conditions. Nevin and his colleagues applied Newton's laws of motion in physics to the study of changes in human behavior. Momentum in physics is the product of mass and velocity. That is, when a heavy body and a light body move at the same time, velocity differs in momentum. The velocity of the heavier body changes less than that of the lighter body when its movement is opposed by an external force.

Behavioral momentum is the product of response rate and resistance to change (Nevin et al., 1988). In the analogy by Nevin et al., behavioral velocity corresponds to response rate, and behavioral mass corresponds to resistance to change (i.e., response 
strength). Responses occur at a steady rate under constant conditions until affected by a new variable. This is parallel to a body persisting in motion until being affected by an external force. When the response rate is changed by a given variable, the change depends on the rate of reinforcement, much like the change in motion of a body depends on its mass. Thus, responding maintained by a relatively higher rate of reinforcement has greater resistance to change than responding maintained by less frequent reinforcement. Nevin (1996) noted that the metaphor of behavioral momentum includes two independent dimensions of behavior important to applied behavior analysis: the rate of responding that is established and maintained by the contingencies of reinforcement, and its resistance to change when responding is challenged or disrupted in some way. The applied behavior analysis may concern establishment of desirable and adaptive behavior and persistence of that behavior when the intervention is removed (Nevin, 1996). Mace and his colleagues (1990) stated the practical implications of the behavioral momentum metaphor in terms that practitioners attempt to overcome persistent maladaptive behavior patterns and build new patterns that will persist after intervention ends.

\section{Basic Research Findings in Behavioral Momentum}

Nevin and his colleagues (1983) proposed the behavioral momentum paradigm extending Nevin's early research (1974) examining the relationship between response strength and schedules of reinforcement. Nevin (1974) noted that in his experiment with pigeons response strength is relative resistance to change, and more frequently reinforced responding was less influenced by extinction. Nevin (1974) arranged multiple variableinterval variable-interval (multiple VI VI) schedules with different rates of reinforcement in two successive schedule components signaled by distinctive stimuli. The pigeons were 
trained to respond to one schedule of food reinforcement for pecking in the presence of one key color, and a different schedule in the presence of a second key color. After the pigeons responded to the schedules consistently, the response strength was examined by providing the procedures of response-independent food and extinction (the termination of food). The results indicated that the response rates were higher in the components with more frequent reinforcement, larger magnitude of reinforcement, shorter delay, and shorter ratio requirement of responding. In addition, the responding maintained by those components was less influenced by the procedure of response-independent food, and was more resistant to extinction than responding maintained by less frequent reinforcement, smaller magnitude of reinforcement, and high ratio requirements of responding. That is, greater relative resistance to change was established by more frequent reinforcement, larger, and less delayed reinforcers.

In the subsequent study, Nevin and his colleagues (1983) extended previous studies on the relationship between response strengths and schedules of reinforcement and examined behavioral momentum and response strength by training pigeons to peck a lighted key on two-component multiple variable-interval, variable-interval schedules of reinforcement. This study assessed resistance to change (i.e., response strength) based on behavioral momentum framework. When pigeons responded to different schedules, resistance to change was assessed by arranging a response-independent food procedure during periods between the two components on a variable time (VT) schedule and extinction. The results of the study indicated that resistance to change was greater under conditions with higher rates of reinforcement and relatively more rapid extinction was occurred in the component previously correlated with less frequent reinforcement. This 
study demonstrated the similarities between the momentum paradigm in physics and resistance of behavior change by applying the paradigm to the experiment with pigeons. The authors paralleled the momentum paradigm to free operant behavior by proposing that response rate is analogous to velocity and resistance to change is analogous to mass. On the basis of this analogy, they suggested that when performance occurs at the same rate in two different schedule components and one is less influenced by an external variable than the other, the response showing greater resistance to change may have greater mass. Behavioral mass is related to the tendency for responding to persist when conditions are altered, and behavioral velocity is related to the ongoing response rate. Thus, the results of the study supported the analogy that resistance to change is greater under conditions with higher rates of reinforcement after conditions of reinforcement were changed. In addition, the authors stated that response rates depended on contingencies between responses and reinforcer, and resistance to change depended on overall rate of reinforcement. They suggested that the velocity component of the behavioral momentum may be determined by operant, response-reinforcer contingencies, and the mass component may be determined by Pavlovian, stimulus-reinforcer contingencies.

By extending Nevin et al.'s study (1983) which proposed that resistance to change may have resulted from differential stimulus-reinforcer contingencies rather than the difference in frequency of reinforcement for key pecking, Nevin (1984) examined the determiners which contribute to resistance to change (behavioral mass). He hypothesized that stimulus-reinforcer contingencies affect behavioral mass in the Newtonian metaphor. Three pigeons were trained to peck keys on a six-component multiple schedules of food 
reinforcement arranged in successive pairs on three keys. The first component of all three keys with different colors (red-left, yellow-center, and green-right) had variable intervals of 120 -s. As the second component, a variable time of 24-s was correlated to the left key (white key), a variable-time of 120 -s to the center key (blue key), and extinction to the right key (orange). Thus, the red key in the first component would become associated with the highest reinforcement rates in the second component, and the green key in the first component would become associated with extinction (nonreinforcement) in the second component. Resistance to change was assessed by prefeeding, discontinuing food, and presenting free food after pigeons responded consistently to the baseline schedules. The results in baseline showed no consistent relations between response rates and Component 1 and Component 2. However, when resistance to change was assessed by prefeeding and extinction, Component 1 was related to reinforcement rate in Component 2. Thus, these findings indicated that stimulus-reinforcer contingencies affected resistance to change. According to results, the author suggested that response rate and resistance to change are influenced by reinforcement, however, their determiners may be separated.

On the basis of the study by Nevin et al. (1983), Mace and his colleagues (1990) attempted to apply basic research paradigms of behavioral momentum in a laboratory to adults with mental retardation in a naturalistic setting. They conducted two studies in a group home assessing resistance to change by providing edible reinforcers for sorting plastic dinnerware. In the first experiment, sorting responses were reinforced on a VI 60-s schedule and a VI 240-s schedule with a different color flatware for each schedule. Videotape was provided as the distracting stimulus to assess resistance to change. 
Response rates in baseline without distracting stimulus were similar in both schedules. While presenting a distracting stimulus (i.e., videotape) with the sorting task, response rates in both schedules decreased, and were higher with the color associated with the higher reinforcement schedule (VI 60-s). In the second experiment, a VI 60-s schedule of reinforcement was used as the first experiment. Additionally, response-independent reinforcers were provided on a VT 30-s schedule (i.e., a conc VI VT schedule) with different colors of flatware. During baseline condition, response rates were higher with the color associated with the VI 60-s schedule than with the color associated with the VI 60-s VT 30-s. When a videotape was presented as a concurrent distracting stimulus, overall responses at both colors decreased relative to baseline. However, response rates were higher with the color associated with the concurrent VI VT schedule than with the color of VI reinforcement in this condition. Thus, the authors suggested that resistance to change is independent of both response rates during baseline and response-reinforcer contingencies. The results of the study indicated that response strength (i.e., behavior persistence) is dependent upon the presence of a stimulus associated with the higher reinforcements, supporting the basic literature on nonhuman performance. This study supported premise that the behavioral momentum model can be applied to human behavior.

Behavioral Momentum in Basic Research and High-Probability Request Sequence in

\section{Applied Research}

Mace and his colleagues (1988) first described the high-probability request sequence in relation to the behavioral momentum metaphor. They applied the highprobability request sequence which indirectly manipulated the rate of reinforcement to 
establish momentum of compliance that may persist in compliance with a low-probability task. Mace et al. (1988) hypothesized that the velocity of a behavior was increased by delivering three requests that were likely to be performed and the mass was increased by delivering reinforcement for the performance of the high-probability requests (Davis, 1995). That is, when several high-probability requests were performed (i.e., increasing velocity), and subsequently reinforced for the performance of the requests (i.e., increasing mass), the momentum of behavior is established for low-probability requests. Although Mace et al. (1988) developed the high-probability request sequence intervention prompted by the behavioral momentum model, researchers have noted that there are some similarities and differences between basic research in behavioral momentum and applied research with the high-probability request sequence intervention.

Nevin (1996) stated that increased compliance with the low-probability request following the high probability procedure can be understood in relation to the procedures and findings of basic research. In terms of the momentum metaphor, the high-probability request sequences may be interpreted as establishing a high velocity of the response class of compliance. Reinforcers for compliance during the high-probability request sequence increase the mass-like aspect of compliance. The momentum effect results in making compliance to a low-probability request more likely.

On the other hand, Nevin (1996) noted that the high-probability request procedure differs in several ways from basic research on momentum, and some methods and findings of basic research may not be relevant to applied work on compliance. 
Additionally, some researchers have pointed out several issues to consider when interpret effects of the high-probability request sequence using behavioral momentum metaphor (Houlihan \& Brandon, 1996; Plaud \& Gaither, 1996)

First, in Nevin's momentum paradigm, the high-probability request sequence is considered as a dependent variable (i.e., measurement for resistance), and the lowprobability request as a disrupter (i.e., prefeeding or free feeding) while in applied research the low-probability request is considered as a dependent variable in common higher order response class (Houlihan \& Brandon, 1996; Nevin, 1996).

There is a difference in the schedules of reinforcement used in basic research and the application of the high-probability request sequence (Nevin, 1996; Houlihan \& Brandon, 1996; Plaude \& Gaither, 1996). On the behavioral momentum model multiple schedule components were used to maintain steady state behaviors whereas the highprobability procedure used one continuous schedule of reinforcement for compliance with each request (i.e., high-probability or low-probability). Nevin (1996) stated that two or more different schedule components are necessary to demonstrate a positive relation between resistance to change and rate of reinforcement.

Additionally, Nevin (1996) pointed out that the high-probability request sequence procedure does not show steady-state baseline response rate against which to evaluate the effect of a disrupter, for two reasons: "(a) the compliance response class is not a free operant, but is prompted by a discrete request and indeed is defined by correspondence between the request and action, and (b) the high-probability sequence is too brief to establish a reliable baseline" (Nevin, 1996, p. 541). 
The important contribution of the behavioral momentum paradigm is to separate the determiners of the velocity (i.e., response rate) and mass of the behavior (i.e., resistance to extinction) (Houlihan \& Brandon, 1996; Nevin, 1996; Plaud \& Gaither, 1996). However, Nevin (1996) has questioned whether compliance to the low-probability request after the high-probability request sequence is the result of the velocity of compliance, the mass of compliance, or both (i.e., momentum).

In terms of the behavioral momentum paradigm, an intervention to establish compliance with requests is successful when compliance occurs consistently during intervention (i.e., high velocity) and responding to requests persists in the appropriate situation when the intervention was withdrawn (Nevin, 1996). However, many studies have shown that responding to low-probability request was not maintained after the highprobability procedure ended (Nevin, 1996; Plaud \& Gaither, 1996).

Nevin (1996) suggested that the effectiveness of the high-probability request procedure can be understood within the framework of the momentum metaphor; however, translating the terms of the momentum metaphor into the high-probability request procedure should be done cautiously, and alternative accounts are possible.

On the other hand, Mace (1996) who first described behavioral momentum as the effects of the high-probability request sequence suggested some points for the relation between the high-probability request sequence procedures and behavioral momentum model. He stated that the generality for behavioral momentum is considered, although there are many procedural differences between Nevin's multiple schedule work with pigeons and the high-probability request sequence intervention of noncompliance with humans: (a) species generality which resistance to change is a positive function of rate of 
reinforcement with a variety of species, (b) procedure generality which the functional relationship between reinforcement and resistance to change has been shown across various reinforcement parameters such as different types of multiple schedules of reinforcement, different reinforcer amounts, and different reinforcer types; and (c) variations of the high-probability request sequence procedure have established effective procedures by examining the short inter-prompt intervals, and using higher quality reinforcers to enhance the effectiveness, and an experiment with a rat with a signaled fixed ratio (FR). Mace (1996) questioned if Nevin's findings were limited to pigeons using the multiple-schedule procedure or represent an example of a general functional relation between reinforcement and persistence that was included in the high-probability request sequence procedure. Moreover, he stated that the applications of behavioral momentum should be done in terms of a general behavioral relation. Mace (1996) suggested that studies on strengthening the persistence of desirable behavior and weakening the persistence of undesirable behavior will be more needed by coordinating basic and applied research.

\section{Applied Research Findings Using the High-Probability Request Sequence}

Numerous studies on the use of high-probability request sequences have demonstrated the effectiveness of promoting appropriate behaviors in a variety of contexts that include compliance with request routines, medication taking, transition activities, self-care routines, communications, and social interaction. Many of those studies have applied the high-probability request sequence to increase compliance, and 
recently have been extended to increase other functional skills in a variety of settings. Table 2.1 provides a brief overview of applied research on the high-probability request sequence.

\section{Early applications of the high-probability request sequence}

Early studies on the use of the high-probability request sequence or interspersed requests have been conducted by extending the strategies that previous researchers have suggested (Carr, Newsome, \& Binkoff, 1976; Engleman \& Colvin, 1983). Carr and his colleagues (1976) decreased the self-injury of a child with psychosis by embedding the requests to follow directions within descriptive statements. The child's selfdestructive behavior decreased by delivering the story in an animated and cheerful manner prior to request mands. Similarly, Engleman and Colvin (1983) suggested an antecedent intervention by preceding a difficult request with a rapid series of short, simple requests and reinforcing compliance with the less demanding requests.

On the basis of Engleman and Colvin's suggestion (1983), Singer, Singer, and Horner (1987) examined the effects of using pretask requests to increase compliance during transitions from recess to work. Pretask request intervention was implemented with four elementary students with severe disabilities who had extensive histories of noncompliance to teacher requests after each of three recess periods (morning, noon, and afternoon). Pretask requesting consisted of delivering three to five requests that had a high probability of compliance (e.g., "Give me five") immediately prior to requests with a low probability of compliance (i.e., "Go to group now"). Compliance resulted in praise, and if compliance did not occur within 3-s, the request was repeated in a firm voice and 


\begin{tabular}{|c|c|c|}
\hline Study & Ardoin, Martens, \& Wolfe(1999) & $\begin{array}{l}\text { Belfiore, Lee, Vargas, \& } \\
\text { Skinner (1997) }\end{array}$ \\
\hline $\begin{array}{l}\text { Subjects/ } \\
\text { Setting }\end{array}$ & $\begin{array}{l}3 \text { children attending a second } \\
\text { grade regular education classroom } \\
\text { During transitions in regular } \\
\text { elementary classroom }\end{array}$ & $\begin{array}{l}2 \text { children ages of } 14 \text { and } 15 \\
\text { years old in an alternative } \\
\text { school }\end{array}$ \\
\hline $\begin{array}{l}\text { Dependent } \\
\text { Variable \& } \\
\text { Measurement }\end{array}$ & $\begin{array}{l}\text { Percentage of compliance to low-p } \\
\text { instructions } \\
\text { Latency to compliance }\end{array}$ & $\begin{array}{l}\text { Latency to initiate low- } \\
\text { probability problem }\end{array}$ \\
\hline $\begin{array}{l}\text { Independent } \\
\text { Variable/ }\end{array}$ & $\begin{array}{l}\text { High-p } 3 \text { condition } \\
\text { Fading conditions(HIP-2, HIP-1) }\end{array}$ & $\begin{array}{l}\text { Interspersal of single-digit } \\
\text { problems with multiple-digit } \\
\text { problems }\end{array}$ \\
\hline Trainer & Teacher & Experimenter \\
\hline $\begin{array}{l}\text { Experimental } \\
\text { Design }\end{array}$ & A multielement design & A reversal $(\mathrm{ABAB})$ design \\
\hline Results & $\begin{array}{l}\text { High-p request intervention and } \\
\text { fading procedures were effective } \\
\text { for two subjects, but was not } \\
\text { effective for one subject. Two } \\
\text { students' compliance maintained at } \\
\text { follow-up. }\end{array}$ & $\begin{array}{l}\text { High-p request intervention } \\
\text { decreased latency to initiate. }\end{array}$ \\
\hline Generality & No & No \\
\hline $\begin{array}{l}\text { Procedural } \\
\text { Integrity }\end{array}$ & Yes & Yes \\
\hline Social Validity & $\begin{array}{l}\text { Yes. The Intervention Rating } \\
\text { Profile-15 }\end{array}$ & No \\
\hline
\end{tabular}

Continued

Table 2.1: Summary of studies on high-probability request sequence intervention 
Table 2.1 (continued)

\begin{tabular}{|c|c|c|}
\hline Study & $\begin{array}{l}\text { Davis, Brady, Hamilton, } \\
\text { McEvoy, \& Williams (1994) }\end{array}$ & $\begin{array}{l}\text { Davis, Brady, Williams, \& } \\
\text { Hamilton (1992) }\end{array}$ \\
\hline $\begin{array}{l}\text { Subjects/ } \\
\text { setting }\end{array}$ & $\begin{array}{l}3 \text { children with severe } \\
\text { disabilities between ages of } 5 \\
\text { and } 6 \text { years old } \\
8 \text { typical peers as training } \\
\text { peers( } 4 \text { ) and generalization } \\
\text { peers(4) } \\
\text { Regular integrated play settings } \\
\text { Regular school campus }\end{array}$ & $\begin{array}{l}2 \text { boys with behavior disorders } \\
\text { and severe disabilities ages of } 7 \\
\text { years old and } 5 \text { years old } \\
\text { Special needs preschool classroom }\end{array}$ \\
\hline $\begin{array}{l}\text { Dependent } \\
\text { Variable \& } \\
\text { Measurement }\end{array}$ & $\begin{array}{l}\text { Responses to low-p requests } \\
\text { (e.g., "Share the toy.") } \\
\text { Peer interactions } \\
\text { Duration, event recording }\end{array}$ & $\begin{array}{l}\text { Percentage of responses to low-p } \\
\text { requests (e.g., "Come here.") } \\
\text { Event recording }\end{array}$ \\
\hline $\begin{array}{l}\text { Independent } \\
\text { Variable/ } \\
\text { Trainer }\end{array}$ & $\begin{array}{l}\text { High-p intervention; prompt- } \\
\text { removal procedure } \\
\text { Experimenter \& teacher }\end{array}$ & $\begin{array}{l}\text { High-p intervention } \\
\text { Special education teacher }\end{array}$ \\
\hline $\begin{array}{l}\text { Experimental } \\
\text { Design }\end{array}$ & $\begin{array}{l}\text { A multiple baseline design } \\
\text { across subjects }\end{array}$ & $\begin{array}{l}\text { A multiple baseline design across } \\
\text { trainers }\end{array}$ \\
\hline Results & $\begin{array}{l}\text { Increased responses to low-p } \\
\text { requests } \\
\text { Generalized unprompted } \\
\text { initiations and interaction to } \\
\text { training peers and nontraining } \\
\text { peers in the training and } \\
\text { nontraining setting. } \\
\text { Compliance was maintained } \\
\text { after removing the intervention. }\end{array}$ & $\begin{array}{l}\text { Increase in responding to the low- } \\
\text { p requests } \\
\text { Generalized compliance to the } \\
\text { other adults } \\
\text { Compliance was maintained at } 4 \\
\text { weeks follow-up }\end{array}$ \\
\hline Generality & $\begin{array}{l}\text { Generalized compliance in } \\
\text { nontraining settings and children }\end{array}$ & $\begin{array}{l}\text { Generalized compliance across } \\
\text { trainers }\end{array}$ \\
\hline $\begin{array}{l}\text { Procedural } \\
\text { Integrity }\end{array}$ & Yes & Yes \\
\hline $\begin{array}{l}\text { Social } \\
\text { Validity }\end{array}$ & No & No \\
\hline
\end{tabular}

Continued 
Table 2.1(continued)

\begin{tabular}{|c|c|c|}
\hline Study & Davis \& Reichle (1996) & Davis, Reichle, \& Southard (2000) \\
\hline \multirow[t]{2}{*}{$\begin{array}{l}\text { Subjects/ } \\
\text { setting }\end{array}$} & $\begin{array}{l}4 \text { children with emotional- } \\
\text { behavioral disorders ages } 4 \text { and } \\
5 \text { years old), and } 3 \text { children as } \\
\text { intervention peers }\end{array}$ & $\begin{array}{l}2 \text { six year old boys with mental } \\
\text { retardation and with severe } \\
\text { challenging behavior during } \\
\text { transition times }\end{array}$ \\
\hline & $\begin{array}{l}\text { Play groups in day; elementary } \\
\text { classrooms }\end{array}$ & $\begin{array}{l}\text { During classroom transition times } \\
\text { in regular ed. Kindergarten } \\
\text { classroom and segregated } \\
\text { classroom }\end{array}$ \\
\hline \multirow[t]{2}{*}{$\begin{array}{l}\text { Dependent } \\
\text { Variable \& } \\
\text { Measurement }\end{array}$} & $\begin{array}{l}\text { Percentage of compliance to } \\
\text { low-p requests (e.g., "Hand } \\
\text { (peer) Soda.") }\end{array}$ & $\begin{array}{l}\text { Percentage of successful transition } \\
\text { (e.g., "Let's go to class.") }\end{array}$ \\
\hline & $\begin{array}{l}\text { MOOSES computer based } \\
\text { observation system }\end{array}$ & Event recording \\
\hline \multirow{2}{*}{$\begin{array}{l}\text { Independent } \\
\text { Variable/ } \\
\text { Trainer }\end{array}$} & $\begin{array}{l}\text { Variant and invariant high-p } \\
\text { request sequences }\end{array}$ & $\begin{array}{l}\text { High-p request sequence } \\
\text { preferred item as a distracter }\end{array}$ \\
\hline & Peers & Teacher/paraprofessional \\
\hline $\begin{array}{l}\text { Experimental } \\
\text { Design }\end{array}$ & $\begin{array}{l}\text { A combined multiple baseline } \\
\text { and reversal(ABCBC; ACBCB) }\end{array}$ & An alternating treatments design \\
\hline Results & $\begin{array}{l}\text { Increase in responses to social } \\
\text { requests in the invariant and } \\
\text { variant condition } \\
\text { Compliance was maintained in } \\
\text { the variant condition }\end{array}$ & Both interventions were effective. \\
\hline Generality & No & No \\
\hline $\begin{array}{l}\text { Procedural } \\
\text { Integrity }\end{array}$ & Yes & Yes \\
\hline $\begin{array}{l}\text { Social } \\
\text { Validity }\end{array}$ & No & $\begin{array}{l}\text { Yes. By using a survey and direct } \\
\text { observations of the teachers during } \\
\text { transitions }\end{array}$ \\
\hline
\end{tabular}

Continued 
Table 2.1(continued)

\begin{tabular}{|c|c|c|}
\hline Study & Ducharme \& Worling (1994) & Harchick \& Putzier (1990) \\
\hline $\begin{array}{l}\text { Subjects/ } \\
\text { setting }\end{array}$ & $\begin{array}{l}\text { A } 5 \text { year old boy and a } 15 \text { year } \\
\text { old girl with the mental } \\
\text { retardation and with } \\
\text { noncompliant behaviors } \\
\text { The family home }\end{array}$ & $\begin{array}{l}\text { A } 23 \text { year old woman with severe } \\
\text { mental retardation and a seizure } \\
\text { disorder } \\
\text { A community-based group home }\end{array}$ \\
\hline $\begin{array}{l}\text { Dependent } \\
\text { Variable \& } \\
\text { Measurement }\end{array}$ & $\begin{array}{l}\text { Compliance to low-p "do" (e.g., } \\
\text { "Stand up."), "don't" requests } \\
\text { (e.g., "Don't lie on the floor.") } \\
\text { Event recording }\end{array}$ & $\begin{array}{l}\text { Number of times took medication } \\
\text { and spit out the medication }\end{array}$ \\
\hline $\begin{array}{l}\text { Independent } \\
\text { Variable/ }\end{array}$ & $\begin{array}{l}\text { High-p intervention; high-p } \\
\text { request fading }\end{array}$ & High-probability requests \\
\hline Trainer & Parents & Group home staff \\
\hline $\begin{array}{l}\text { Experimental } \\
\text { Design }\end{array}$ & $\begin{array}{l}\text { A combination of } \mathrm{ABAB} \text { and } \\
\text { multiple baseline design across } \\
\text { subjects }\end{array}$ & An $\mathrm{ABAB}$ reversal design \\
\hline Results & $\begin{array}{l}\text { Increase in compliance to "do" } \\
\text { requests for both subjects. } \\
\text { No increases in compliance to } \\
\text { "don't" requests by subject } 2 \text {, and } \\
\text { increases in compliance to } \\
\text { symmetrical requests } \\
\text { Compliance was maintained } \\
\text { during the high-p request-fading } \\
\text { phase, and during the } 16 \text { weeks } \\
\text { follow-up }\end{array}$ & $\begin{array}{l}\text { Increase in the compliance to } \\
\text { taking medication and decreased } \\
\text { in vomit } \\
\text { Compliance was maintained after } \\
6 \text { month follow-up }\end{array}$ \\
\hline Generality & No & No \\
\hline $\begin{array}{l}\text { Procedural } \\
\text { Integrity }\end{array}$ & Yes & Yes \\
\hline $\begin{array}{l}\text { Social } \\
\text { Validity }\end{array}$ & $\begin{array}{l}\text { Yes. Questionnaire by parents } \\
\text { and therapists }\end{array}$ & No \\
\hline
\end{tabular}

Continued 
Table 2.1 (continued)

\begin{tabular}{|c|c|c|}
\hline Study & $\begin{array}{l}\text { Horner, Day, Sprague, O’Brien, } \\
\text { \& Heathfield (1991) }\end{array}$ & $\begin{array}{l}\text { Houlihan, Jacobson, \& Brandon } \\
\text { (1994) }\end{array}$ \\
\hline $\begin{array}{l}\text { Subjects/ } \\
\text { setting }\end{array}$ & $\begin{array}{l}\text { Study 1: } 3 \text { youths with severe } \\
\text { mental retardation between the } \\
\text { ages of } 12 \text { and } 14 \text {; in a group } \\
\text { home } \\
\text { Study } 2 \text { : a } 14 \text { year old boy with } \\
\text { moderate mental retardation with } \\
\text { a number of undesirable } \\
\text { behaviors }\end{array}$ & $\begin{array}{l}\text { A } 5 \text { year old boy with autism } \\
\text { During play and work time in a } \\
\text { special needs preschool } \\
\text { classroom }\end{array}$ \\
\hline $\begin{array}{l}\text { Dependent } \\
\text { Variable \& } \\
\text { Measurement }\end{array}$ & $\begin{array}{l}\text { Percentage of aggression or self } \\
\text { injury using an interval recording } \\
\text { Percentage of trials attempted to } \\
\text { complete task } \\
\text { A partial interval observation }\end{array}$ & $\begin{array}{l}\text { Percentage of compliance to low- } \\
\text { p requests(e.g., "Take the book } \\
\text { out of the box.") }\end{array}$ \\
\hline $\begin{array}{l}\text { Independent } \\
\text { Variable/ } \\
\text { Trainer }\end{array}$ & $\begin{array}{l}\text { Easy tasks; hard tasks; hard and } \\
\text { interspersed tasks } \\
\text { Experimenters and novel trainers }\end{array}$ & $\begin{array}{l}\text { High-p request sequence with } 5-\mathrm{s} \\
\text { and } 20-\mathrm{s} \text { IPT } \\
\text { Experimenter }\end{array}$ \\
\hline $\begin{array}{l}\text { Experimental } \\
\text { Design }\end{array}$ & $\begin{array}{l}\text { An } A B A B C B C D E \text { within-subject } \\
\text { reversal design }\end{array}$ & An alternating treatments design \\
\hline Results & $\begin{array}{l}\text { During interpersed task, } \\
\text { aggression and self-injury } \\
\text { decreased, trials attempted to } \\
\text { complete task increased. }\end{array}$ & $\begin{array}{l}\text { Increased in compliance with } 5-\mathrm{s} \\
\text { IPT, but no increase with } 20-\mathrm{s} \\
\text { IPT }\end{array}$ \\
\hline Generality & $\begin{array}{l}\text { Similar responding occurred with } \\
\text { new trainers and new hard tasks }\end{array}$ & No \\
\hline $\begin{array}{l}\text { Procedural } \\
\text { Integrity }\end{array}$ & Yes & No \\
\hline $\begin{array}{l}\text { Social } \\
\text { Validity }\end{array}$ & Yes & No \\
\hline
\end{tabular}

Continued 
Table 2.1 (continued)

\begin{tabular}{|c|c|c|}
\hline Study & $\begin{array}{l}\text { Kennedy, Itkonen, \& Lindquist } \\
\text { (1995) }\end{array}$ & $\begin{array}{l}\text { Killu, Sainato, Davis, Ospelt, \& } \\
\text { Paul (1998) }\end{array}$ \\
\hline $\begin{array}{l}\text { Subjects/ } \\
\text { setting }\end{array}$ & $\begin{array}{l}18 \text { and } 19 \text { year old students with } \\
\text { severe disabilities }\end{array}$ & $\begin{array}{l}3 \text { boys with developmental delays } \\
\text { and behavioral difficulties } \\
\text { between ages of } 4 \text { and } 5 \\
\text { a separate classroom }\end{array}$ \\
\hline $\begin{array}{l}\text { Dependent } \\
\text { Variable and } \\
\text { Measurement }\end{array}$ & $\begin{array}{l}\text { Occurrence of compliance to low- } \\
\text { p request (e.g., "Put away a } \\
\text { jacket.") } \\
\text { Event recording }\end{array}$ & $\begin{array}{l}\text { Responding to low-p request } \\
\text { (e.g., "Point to the block") } \\
\text { Disruptive behavior } \\
\text { Event recording }\end{array}$ \\
\hline $\begin{array}{l}\text { Independent } \\
\text { Variable/ } \\
\text { Trainer }\end{array}$ & $\begin{array}{l}\text { Interspersed requests } \\
\text { Social comments }(2 \mathrm{~s}) \\
\text { Social comments }(15 \mathrm{~s}) \\
\text { Experimenter }\end{array}$ & Experimenter/Paraprofessional \\
\hline $\begin{array}{l}\text { Experimental } \\
\text { Design }\end{array}$ & $\begin{array}{l}\text { Subject 1: ABACABACAC } \\
\text { Subject 2: ACABABAC } \\
\text { A multielement design using } \\
\text { A,B,C,D }\end{array}$ & $\begin{array}{l}\text { A multiple baseline design across } \\
\text { subjects }\end{array}$ \\
\hline Results & $\begin{array}{l}\text { Increase in compliance to the } \\
\text { low-p requests during the } \\
\text { interspersed requests and social } \\
\text { comments procedures } \\
2 \text {-s interval between social } \\
\text { comments and low-p requests } \\
\text { were more effective than } 15-\mathrm{s} \text {. }\end{array}$ & $\begin{array}{l}\text { Compliance in all subjects } \\
\text { increased with the first trainer, } \\
\text { and slightly increased with the } \\
\text { second trainer. } \\
\text { Compliance was maintained after } \\
\text { withdrawing the high-p request } \\
\text { sequence. } \\
\text { Disruptive behavior did not } \\
\text { increase }\end{array}$ \\
\hline Generality & No & $\begin{array}{l}\text { Generalized compliance to } \\
\text { secondary trainer }\end{array}$ \\
\hline $\begin{array}{l}\text { Procedural } \\
\text { Integrity }\end{array}$ & No & Yes \\
\hline $\begin{array}{l}\text { Social } \\
\text { Validity }\end{array}$ & No & Yes. By using a questionnaire \\
\hline
\end{tabular}

Continued 
Table 2.1 (continued)

\begin{tabular}{|c|c|c|}
\hline Study & Mace \& Belfiore (1990) & $\begin{array}{l}\text { Mace, Hock, Lalli, West, } \\
\text { Belfiore, Pinter, \& Brown (1988) }\end{array}$ \\
\hline $\begin{array}{l}\text { Subjects/ } \\
\text { setting }\end{array}$ & $\begin{array}{l}\text { A } 38 \text { year old woman with severe } \\
\text { mental retardation and with a } \\
\text { history of escape-motivated } \\
\text { stereotypic behavior } \\
\text { A university-affiliated group } \\
\text { home }\end{array}$ & $\begin{array}{l}\text { Study 1: A } 36 \text { year old man with } \\
\text { severe mental retardation; } \\
\text { a university affiliated group home } \\
\text { Study 2: A } 44 \text { year old male with } \\
\text { Down Syndrome } \\
\text { Study 3: The same subject as } \\
\text { Experiment } 2\end{array}$ \\
\hline $\begin{array}{l}\text { Dependent } \\
\text { Variable \& } \\
\text { Measurement }\end{array}$ & $\begin{array}{l}\text { Stereotypic touching } \\
\text { responses(STR) } \\
\text { Compliance with low-p requests } \\
\text { A continuous count within } 10-\mathrm{s} \\
\text { interval recording }\end{array}$ & $\begin{array}{l}\text { Study 1, 3: Compliance to low- } \\
\text { probability "do" and "don't" } \\
\text { Study 2: Compliance to low- } \\
\text { probability "do" } \\
\text { Continuous } 10 \text {-s interval }\end{array}$ \\
\hline $\begin{array}{l}\text { Independent } \\
\text { Variable/ } \\
\text { Trainer }\end{array}$ & $\begin{array}{l}\text { High-p request sequence } \\
\text { Attention control } \\
\text { Experimenters }\end{array}$ & $\begin{array}{l}\text { Study 1: A sequence of high- } \\
\text { probability commands } \\
\text { Study 2: A sequence of high- } \\
\text { probability commands } \\
\text { Study 3: Interprompt time(IPT) } \\
\text { Experimenter }\end{array}$ \\
\hline $\begin{array}{l}\text { Experimental } \\
\text { Design }\end{array}$ & $\begin{array}{l}\text { A multiple schedule design with } \\
\text { reversal components }\end{array}$ & $\begin{array}{l}\text { Study 1: A multielement design } \\
\text { Study 2: An ABAB reversal } \\
\text { design } \\
\text { Study 3: A multielement design } \\
\text { to compare 5-s and } 20 \text {-s IPTs }\end{array}$ \\
\hline Results & $\begin{array}{l}\text { Substantial increases in } \\
\text { compliance with low-p requests } \\
\text { and decreases in STR. }\end{array}$ & $\begin{array}{l}\text { Both experiments Study } 1 \text { and } \\
\text { Study } 2 \text { increased compliance. } \\
\text { Increase in compliance with } \\
\text { commands using 5-s IPT }\end{array}$ \\
\hline Generality & No & No \\
\hline $\begin{array}{l}\text { Procedural } \\
\text { Integrity }\end{array}$ & No & Yes \\
\hline $\begin{array}{l}\text { Social } \\
\text { Validity }\end{array}$ & No & No \\
\hline
\end{tabular}

Continued 
Table 2.1 (continued)

\begin{tabular}{|c|c|c|}
\hline Study & Mace et al.(1988)-continued & $\begin{array}{l}\text { Mace, Mauro, Boyajian, \& Eckert } \\
\text { (1997) }\end{array}$ \\
\hline $\begin{array}{l}\text { Subjects/ } \\
\text { setting }\end{array}$ & $\begin{array}{l}\text { Study 4: Two males with } \\
\text { moderate mental retardation aged } \\
\text { of a } 34 \text { year and } 45 \text { year } \\
\text { old/Bathroom in the group home } \\
\text { Study 5: The same subjects as } \\
\text { Experiment 4/Bathroom and } \\
\text { bedroom in the group home }\end{array}$ & $\begin{array}{l}2 \text { adolescent boys with moderate } \\
\text { mental retardation and with } \\
\text { noncompliance, severe } \\
\text { aggression, disruptive behaviors; } \\
\text { four male rats }\end{array}$ \\
\hline $\begin{array}{l}\text { Dependent } \\
\text { Variable \& } \\
\text { Measurement }\end{array}$ & $\begin{array}{l}\text { Study 4: Compliance latency } \\
\text { Event recording } \\
\text { Study 5: The time elapsed to } \\
\text { complete each of the three task } \\
\text { segments for taking a shower } \\
\text { Duration }\end{array}$ & $\begin{array}{l}\text { Frequency, percentage of } \\
\text { compliance to low-p instructors } \\
\text { (e.g., "Stand up") }\end{array}$ \\
\hline $\begin{array}{l}\text { Independent } \\
\text { Variable/ } \\
\text { Trainer }\end{array}$ & $\begin{array}{l}\text { Study 4: Command sequence; } \\
\text { Attention control } \\
\text { Study 5: High-p command } \\
\text { sequence; Contingency } \\
\text { management }\end{array}$ & $\begin{array}{l}\text { High-p treatment with praise, } \\
\text { food, or both } \\
\text { Experimenter }\end{array}$ \\
\hline $\begin{array}{l}\text { Experimental } \\
\text { Design }\end{array}$ & A multielement design & $\begin{array}{l}\text { Reversal designs replicated across } \\
\text { low-p instructions; An ABAB } \\
\text { reversal sequence }\end{array}$ \\
\hline Results & $\begin{array}{l}\text { Study 4: Decrease in latency to } \\
\text { compliance } \\
\text { Study 5: The high-p command } \\
\text { sequence was the most effective } \\
\text { and prompts, contingency } \\
\text { management respectively. }\end{array}$ & $\begin{array}{l}\text { Three experiments showed a } \\
\text { consistent relationship between } \\
\text { reinforcer quality and behavioral } \\
\text { momentum. }\end{array}$ \\
\hline Generality & No & No \\
\hline $\begin{array}{l}\text { Procedural } \\
\text { Integrity }\end{array}$ & Yes & No \\
\hline $\begin{array}{l}\text { Social } \\
\text { Validity }\end{array}$ & No & No \\
\hline
\end{tabular}

Continued 
Table 2.1 (continued)

\begin{tabular}{|c|c|c|}
\hline Study & $\begin{array}{l}\text { McComas, Wacker, \& Cooper } \\
(1998)\end{array}$ & Rortvedt \& Miltenberger (1994) \\
\hline $\begin{array}{l}\text { Subjects/ } \\
\text { setting }\end{array}$ & $\begin{array}{l}22 \text { month old boy with } \\
\text { developmental delays and severe } \\
\text { self-injurious behavior } \\
\text { In the subject's hospital room }\end{array}$ & $\begin{array}{l}2 \text { typically developing } 4 \text { year old } \\
\text { girls } \\
\text { In the home }\end{array}$ \\
\hline $\begin{array}{l}\text { Dependent } \\
\text { Variable \& } \\
\text { Measurement }\end{array}$ & $\begin{array}{l}\text { Percentage of compliance to the } \\
\text { low-p request(e.g., "Hold still") } \\
\text { A combination 10-s partial- } \\
\text { interval and event-recording } \\
\text { system }\end{array}$ & $\begin{array}{l}\text { Compliance during continuous } \\
10 \text {-s intervals (e.g., "Put your } \\
\text { glass in the sink.") }\end{array}$ \\
\hline $\begin{array}{l}\text { Independent } \\
\text { Variable/ } \\
\text { Trainer }\end{array}$ & $\begin{array}{l}\text { Differential reinforcement of } \\
\text { alternative behavior with escape } \\
\text { extinction(DRA/ESC EXT) } \\
\text { High-P/DRA.ESC EXT } \\
\text { Mother under direct supervision } \\
\text { from a therapist }\end{array}$ & High-p sequence; time out \\
\hline $\begin{array}{l}\text { Experimental } \\
\text { Design }\end{array}$ & A multiple schedule design & $\begin{array}{l}\text { A multiple baseline across } \\
\text { subjects design with an ABAB } \\
\text { within-subject design }\end{array}$ \\
\hline Results & $\begin{array}{l}\text { Increase in compliance, and the } \\
\text { difference between two } \\
\text { treatments increased over time. }\end{array}$ & $\begin{array}{l}\text { No increase in compliance with } \\
\text { high-p request sequence } \\
\text { Increase in compliance during } \\
\text { time out procedure }\end{array}$ \\
\hline Generality & No & No \\
\hline $\begin{array}{l}\text { Procedural } \\
\text { Integrity }\end{array}$ & Yes & Yes \\
\hline $\begin{array}{l}\text { Social } \\
\text { Validity }\end{array}$ & No & No \\
\hline
\end{tabular}

Continued 
Table 2.1 (continued)

\begin{tabular}{|c|c|c|}
\hline Study & $\begin{array}{l}\text { Sanchez-Fort, Brady, \& Davis } \\
\text { (1995) }\end{array}$ & Santos \& Lignugaris/Kraft (1999) \\
\hline \multirow[t]{2}{*}{$\begin{array}{l}\text { Subjects/ } \\
\text { setting }\end{array}$} & $\begin{array}{l}2 \text { children with severe and } \\
\text { moderate disability between ages } \\
\text { of } 8 \text { and } 4\end{array}$ & $\begin{array}{l}5 \text { preschoolers with } \\
\text { developmental delays }\end{array}$ \\
\hline & $\begin{array}{l}\text { Summer school classroom in an } \\
\text { integrated public school }\end{array}$ & $\begin{array}{l}\text { During center time activities in a } \\
\text { special preschool program }\end{array}$ \\
\hline $\begin{array}{l}\text { Dependent } \\
\text { Variable \& } \\
\text { Measurement }\end{array}$ & $\begin{array}{l}\text { Percentage of correct low-p target } \\
\text { responses(i.e., sign or words) }\end{array}$ & $\begin{array}{l}\text { Number of attempts to respond to } \\
\text { indirect requests } \\
\text { Number of correct responses to } \\
\text { indirect requests } \\
\text { A } 10 \text {-s interval recording system }\end{array}$ \\
\hline $\begin{array}{l}\text { Independent } \\
\text { Variable/ }\end{array}$ & High-p request sequence & High-p request sequence \\
\hline Trainer & Teacher, aide, experimenter & Experimenter \\
\hline $\begin{array}{l}\text { Experimental } \\
\text { Design }\end{array}$ & $\begin{array}{l}\text { A multiple baseline design across } \\
\text { low-p target words }\end{array}$ & $\begin{array}{l}\text { A multiple probe design across } \\
\text { subjects with intervention } \\
\text { withdrawal }\end{array}$ \\
\hline \multirow[t]{2}{*}{ Results } & $\begin{array}{l}\text { Increase in target words for both } \\
\text { subjects }\end{array}$ & $\begin{array}{l}\text { Attempts to respond and the } \\
\text { correct responses to indirect } \\
\text { requests in all subjects increased. }\end{array}$ \\
\hline & $\begin{array}{l}\text { One subject showed the use of } \\
\text { generalized words. }\end{array}$ & $\begin{array}{l}\text { Three of the subjects maintained } \\
\text { at the high level of attempts to } \\
\text { respond and correct responses to } \\
\text { indirect requests after the } \\
\text { intervention was withdrawn. }\end{array}$ \\
\hline Generality & $\begin{array}{l}\text { Inconsistent result in } \\
\text { generalization }\end{array}$ & No \\
\hline $\begin{array}{l}\text { Procedural } \\
\text { Integrity }\end{array}$ & Yes & Yes \\
\hline $\begin{array}{l}\text { Social } \\
\text { Validity }\end{array}$ & No & No \\
\hline
\end{tabular}

Continued 
Table 2.1(continued)

\begin{tabular}{|c|c|c|}
\hline Study & Singer, Singer, \& Horner (1987) & Wehby \& Hollahan (2000) \\
\hline \multirow[t]{2}{*}{$\begin{array}{l}\text { Subjects/ } \\
\text { setting }\end{array}$} & $\begin{array}{l}4 \text { students with moderate to } \\
\text { severe disabilities ranging in age } \\
\text { from } 7 \text { to } 10 \text { years. }\end{array}$ & $\begin{array}{l}\text { A } 13 \text { year old girl with learning } \\
\text { disability in math and written } \\
\text { language }\end{array}$ \\
\hline & A special education classroom & $\begin{array}{l}\text { During independent math work in } \\
\text { math class }\end{array}$ \\
\hline Dependent & Frequency of compliance to & Latency to engagement \\
\hline Variable \& & transition (recess to work) & Percentage of engagement \\
\hline Measurement & (e.g., "Go to work") & \\
\hline & & MOOSES \\
\hline $\begin{array}{l}\text { Independent } \\
\text { Variable/ }\end{array}$ & Pretask requesting & High-probability sequence \\
\hline Trainer & Special education teacher, aide & Neutral social comments \\
\hline & & Teacher \\
\hline \multicolumn{3}{|l|}{ Experimental } \\
\hline Design & $\begin{array}{l}\text { An } \mathrm{ABA} \text { and } \mathrm{BAB} \text { reversal } \\
\text { design }\end{array}$ & An ABABACB design \\
\hline Results & $\begin{array}{l}\text { Increase in compliance during } \\
\text { pretask requesting }\end{array}$ & $\begin{array}{l}\text { Effective in reducing the latency } \\
\text { to compliance but minimally } \\
\text { affected duration of engagement }\end{array}$ \\
\hline Generality & No & No \\
\hline $\begin{array}{l}\text { Procedural } \\
\text { Integrity }\end{array}$ & No & Yes \\
\hline $\begin{array}{l}\text { Social } \\
\text { Validity }\end{array}$ & No & No \\
\hline
\end{tabular}

Continued 
Table 2.1 (continued)

\begin{tabular}{|c|c|c|}
\hline Study & $\begin{array}{l}\text { Zarcone, Iwata, Hughes, \& } \\
\text { Vollmer (1993) }\end{array}$ & $\begin{array}{l}\text { Zarcone, Iwata, Mazaleski, \& } \\
\text { Smith (1994) }\end{array}$ \\
\hline \multirow[t]{2}{*}{$\begin{array}{l}\text { Subjects/ } \\
\text { setting }\end{array}$} & $\begin{array}{l}\text { A } 33 \text { year old female with } \\
\text { profound mental retardation }\end{array}$ & $\begin{array}{l}\text { A } 38 \text { year and a } 45 \text { year old male } \\
\text { with profound mental retardation } \\
\text { and SIB }\end{array}$ \\
\hline & & $\begin{array}{l}\text { Grounds of the facility at a day } \\
\text { program }\end{array}$ \\
\hline \multirow{4}{*}{$\begin{array}{l}\text { Dependent } \\
\text { Variable and } \\
\text { Measurement }\end{array}$} & Latency to self-injurious & Percentage of trials with SIB \\
\hline & behavior & $\begin{array}{l}\text { Percentage of compliance with } \\
\text { low-p and high-p instructions }\end{array}$ \\
\hline & Percentage of compliance & \\
\hline & Continuous $10-\mathrm{s}$ intervals & Continuous 10 s intervals \\
\hline \multirow{4}{*}{$\begin{array}{l}\text { Independent } \\
\text { Variable/ } \\
\text { Trainer }\end{array}$} & High-p request sequence & High-p sequence \\
\hline & High-p request sequence and & High-p + EXT \\
\hline & $\begin{array}{l}\text { Escape extinction } \\
\text { Escape }\end{array}$ & \\
\hline & Experimenter & Experimenter \\
\hline \multirow[t]{2}{*}{$\begin{array}{l}\text { Experimental } \\
\text { Design }\end{array}$} & ABCBD reversal design & $\begin{array}{l}\text { A multielement format(functional } \\
\text { assessment) }\end{array}$ \\
\hline & & ABCBC reversal design \\
\hline \multirow[t]{2}{*}{ Results } & $\begin{array}{l}\text { High-p plus extinction and } \\
\text { extinction alone procedures } \\
\text { were effective in increasing } \\
\text { compliance, decreasing SIB }\end{array}$ & $\begin{array}{l}\text { High-p alone was not effective in } \\
\text { SIB and compliance with low-p } \\
\text { request. }\end{array}$ \\
\hline & High-p alone was not effective & $\begin{array}{l}\text { High-p with extinction increased } \\
\text { compliance and decreased SIB. }\end{array}$ \\
\hline Generality & No & No \\
\hline Procedural & & \\
\hline Integrity & Yes & Yes \\
\hline Social & & \\
\hline Validity & No & No \\
\hline
\end{tabular}


with physical assistance. The pretask intervention resulted in substantial increases in compliance and decreases in aggression when a teacher asked the students to work after recess.

Mace and his colleagues (1988) first used the momentum metaphor proposed by Nevin et al. (1983) to increase the compliant behavior of four adults with mental retardation in a group home. They conducted five experiments that evaluated the effectiveness of the high-probability command sequence on increasing compliance to self-care routines by including a variety of variables such as the form of the lowprobability request (i.e., "do," "don't"), attention control, and the inter-prompt times (IPT).

In the first experiment, the effects of high-probability command sequence on compliance to low-probability “ do" (e.g., "Please put your lunch box away.") and “don't" (e.g., "Please don't leave your lunch box on the table.") commands were examined. The high-probability command sequence intervention resulted in an increase of the subject's compliance to both forms of the low-probability commands.

The second experiment was conducted to examine effects of positive attention alone on compliance "do" requests. Compliant responses increased after delivering the high-probability command sequence. However, compliance during the attention control session (i.e., the experimenter's comments) was not changed from the baseline levels. The authors suggested that the presentation of discriminative stimuli for high-probability behaviors may be critical in obtaining the momentum-like effects.

The third experiment was conducted to evaluate the appropriateness of the behavioral momentum analogy in applied settings. The high-probability command 
sequence was provided by 20 -s and 5 -s inter-prompt times (i.e., the time interval between the completion of the last high-probability command in the high-probability command sequence and the initiation of the low-probability command). The results demonstrated that the subject's compliance to low-probability "do" and "don't" commands was consistently higher with a 5 -s inter-prompt time than with the 20 -s inter-prompt time. The authors suggested that the momentum-like effects in the high-probability command sequence may be related to the temporal contiguity between the high-probability command sequence and the low-probability command. Thus, it may be critical that lowprobability commands be delivered immediately after the high-probability request sequence. Additionally, the authors suggested that the results of this experiment are predicted by the behavioral momentum analogy because the effects demonstrated in the 5-s IPT procedure may have been due to the higher rates of presentation of reinforcement in the 5-s IPT than in the 20-s IPT condition.

The fourth experiment was conducted using a multielement design to assess the effects of the high-probability command procedure to reduce the subject's latency to respond to commands. The subjects had self-care skills; however, they were very slow to respond to staff requests. The use of the high-probability command sequence decreased the subjects' latency to respond to the low-probability commands.

The fifth experiment was performed to reduce the time a subject spent taking a shower. Three independent variables, including contingency management, prompts, and the high-probability command sequence were compared using a multielement design. The high-probability command sequence was shown to be the most effective in reducing task duration; prompts were less effective, and contingency management was least 
effective among the three interventions. The authors suggested that it is possible to evoke behavior that affects reinforcement by manipulating the type of command issued so that a pattern of responding with a relatively high behavioral mass is established. Interpreting from a behavioral momentum framework, they suggested that increased compliance to low-probability commands following the high -probability request sequence may indicate resistance to change in the changed environmental conditions.

Subsequently, Horner and his colleagues (1991) used interspersed requests for adolescents with severe mental retardation who displayed aggression and self-injury to avoid difficult instructional situations in a residential setting. The authors examined the effects of interspersed requests on task completion, aggression, and self-injury during instruction. They interspersed three to five short, simple requests (e.g., following a "Do this" request) after about three training trials (e.g., sorting silverware from the dishwasher) and following any indication of resistance. Each interspersed request was followed by verbal praise, and the difficult task was presented within 5-s of completing the last interspersed request. The results demonstrated that the interspersed request intervention was effective at decreasing aggression and self-injury during instruction and at increasing attempts to complete task. In the second study with a child with moderate mental retardation in a self-contained classroom, the interspersed requests intervention resulted in a decrease in levels of aggression. The attempts to perform tasks increased during the intervention, and remained at high levels after the intervention phase.

On the basis of the early successful applications of high-probability request sequences, researchers have examined the effectiveness of the high-probability request intervention in promoting appropriate behaviors in a variety of contexts. 


\section{Applications of the High-Probability Request Sequences to Compliance}

Many students with developmental disabilities have shown difficulties with compliance to requests. Noncompliance to requests is considered a primary reason for children's exclusion from social interactions and learning opportunities (Davis et al., 1992). The high-probability request sequence has been employed as a nonaversive and antecedent procedure to deal with noncompliance of the population with developmental disabilities while preventing coercive interactions with parents and teachers (Singer et al., 1986).

Compliance with routine requests. In a replication of the study by Mace et al.(1988), Houlihan, and his colleagues (1994) examined the effects of the highprobability request sequence on compliance, and compared the effects of 5-s and 20-s inter-prompt times (IPT) with a noncompliant preschool-aged boy with autism. A sequence of three high-probability requests (e.g., "Look at me.") was provided either 5-s or 20-s prior to the delivery of a low-probability request (e.g., "Take the book out of the box."), and compliance to requests was followed by social reinforcement and tactile reinforcers. The results of the study demonstrated that compliance with low-probability requests increased during the high-probability request intervention with 5-s IPT, however, it did not show improvement over baseline levels with the 20-s IPT. Thus, this finding replicated the third experiment of Mace et al.'s study (1988) and supported the length of time between the high-probability request and the low-probability request as an important factor in the high-probability request intervention.

Concerning of the maintenance and generalization of compliance, Davis and her colleagues (1992) extended previous work by facilitating generalized compliance to 
adults who did not use the high-probability request sequence. The participants in the study were two boys with behavioral disorders and severe disabilities ages seven and five years old. The teachers rapidly delivered three to five high-probability requests (e.g., “Touch your head.") immediately prior to presenting each low-probability request (e.g., "Come here."). Verbal or gestural praise was provided for each response to a request. The results of the study indicated that the use of the high-probability request sequence increased compliance to low-probability requests. In addition, the use of multiple trainers resulted in generalized responding to low-probability requests with the fourth trainer for Subject 1 and with the third and the fourth trainer for Subject 2. Then the children's increased responding was maintained at follow-up sessions.

In addition to Davis et al. (1992), Ducharme and Worling (1994) attempted to maintain the effectiveness of the high-probability request sequence procedure. They hypothesized that stimulus fading after use of the high-probability request sequence could be one strategy for promoting long-term effects in compliance since previous studies (Horner et al., 1991; Mace et al., 1988; Singer et al., 1987) had shown that compliance to low-probability requests typically returned to baseline levels after the high-probability request sequence was withdrawn. The authors examined the effects of the highprobability request sequence procedure along with stimulus fading to maintain compliant behaviors. The high-probability request sequence intervention was implemented by the subjects' parents at home. Two children with developmental disabilities and noncompliant behaviors ages five and fifteen years old participated in this study. Fading procedures consisted of gradually decreasing the number of the high-probability requests delivered and increasing the delay in delivery between the high-probability and the low- 
probability requests. The results indicated that both children showed increases in compliance to low-probability requests after implementing the high-probability request sequence procedure. In addition, compliance was maintained at high levels for both subjects during the high-probability request fading phase, and compliance levels remained at high levels at 16 weeks later. This study extended the research on using high-probability request sequence by demonstrating the maintenance of low-probability behaviors without delivery of the high-probability request sequences. Additionally, this study demonstrated the effectiveness of the high-probability request sequences implemented by parents. Parents reported high levels of satisfaction with the intervention. As extension, Kennedy, Itkonen, and Lindquist (1995) compared the effectiveness of interspersed high-compliance requests and social comments as antecedents to increase compliance like Mace et al. (1988) included the attention control procedure (i.e., the experimenter's neutral or positive comments) in their study. Additionally, the authors evaluated the effects on compliance of the time interval between social comments and low-compliance requests. Two students with severe disabilities ages of eighteen and nineteen years old participated in two experimental sequences. In the first experiment, four high-compliance requests (e.g., "What's your name?") or four brief comments (e.g., "It's a beautiful day.") were delivered by 2-s interval prior to low-probability sequence (e.g., "Put away the jacket."). The second experiment compared interspersed requests and social comments within 2-s and 15-s interval procedures by using a multielement design. The results of the first experiment demonstrated that the two intervention procedures showed similar effects in increasing compliance, unlike the results of the study by Mace et al. (1988). The results of the second experiment showed that two subjects' compliance 
was slightly higher in the interspersed requests condition. In addition, the shorter time interval between social comments and low-compliance requests (i.e., 2-s) resulted in higher compliance than the 15 -s interval. The authors stated that the data should not be interpreted as meaning that social comments can replace the high-probability request sequence intervention, and that more research would be needed.

Another study that extends the literature examines the effects of a highprobability request sequence on compliance to low-probability requests and disruptive behavior in a classroom setting during typical activities and by using novel-trainer probes. Killu, Sainato, Davis, Ospel, and Paul (1998) implemented the high-probability request sequence intervention with preschoolers with developmental delays at an instructionally appropriate time during play routines. A multiple baseline design across subjects was used to evaluate the effects of the high-probability request intervention on children's compliance. Probes were used to assess the children's responses to the intervention with a second trainer. The results demonstrated that the high-probability request sequence increased compliant responding to requests and that the increased compliance was maintained after withdrawing the high-probability request sequence intervention. Compliance to requests from the second trainer slightly increased. Disruptive behavior did not sharply decrease due to the initial low baseline levels of challenging behavior. Despite the teacher's prediction, the use of the high-probability request sequence did not result in any increase of disruptive behavior. In addition, this study demonstrated that the high-probability request sequence can be integrated into an instructional routine and can be modified to meet the instructional needs of each child. 
Although many studies have demonstrated the effectiveness of the highprobability request sequence on compliance with routine requests, research by Rortvedt and Miltenberger (1994) showed mixed results. They implemented the high-probability request sequence procedure to increase compliance in two typically developing preschoolers with noncompliant behaviors to routine requests, and compared the effectiveness of the time-out and the high-probability request sequence procedure. The parents delivered a sequence of three high-probability requests (e.g., "Touch your nose."), immediately prior to the low-probability request (e.g., "Put your glass in the sink."). For the next phase, a time out procedure for noncompliance was provided as a comparison procedure after the second baseline. The results demonstrated that the high-probability request sequence procedure did not show an increase in compliance. Although the second subject's compliance with the low-probability requests increased slightly, it was difficult to implement the high-probability request sequence procedure since she was noncompliant with the high-probability requests in later sessions. However, the time out procedure resulted in increases in compliance for two subjects, and compliance was maintained at follow up sessions. The authors concluded that more research is needed concerning the feasibility of the high-probability request sequence intervention with typical children.

Regarding the results of the studies that failed to demonstrate the effectiveness of the high-probability request procedure, Mace, Mauro, Boyajian, and Eckert (1997) hypothesized that the high-probability request sequence intervention did not establish sufficient momentum to overcome the opposition force of the low-probability request. Thus, they suggested that the efficacy of the high-probability request treatment might be 
improved by using higher quality reinforcers for compliance to high-probability instructions. The authors implemented the high-probability requests sequence and evaluated its effectiveness under the different reinforcement conditions. The first experiment was conducted to assess the effects of the high-probability instructions on compliance with low-probability instructions (e.g., "Come over here," "Stand up," etc.) for two adolescent boys with moderate mental retardation who exhibited severe aggression and disruptive behaviors. Each low-probability instruction was delivered after requesting a sequence of three or four high-probability instructions. Compliance to each high-probability instruction was reinforced with praise, food or both, and compliance to each low-probability instruction was reinforced by praise across all high-probability requests. The results indicated that providing food or food and praise as a reinforcer for high-probability compliance increased compliance with low-probability instructions. The second experiment compared the effects of the high-probability treatment with praise and food on the resistance of compliance to change with repeated low-probability instructions. The first phase remained the same as the high-probability request sequence procedure in the first experiment (single low-probability instruction following highprobability request sequence) with the food reinforcement. In the second and fourth phase the high-probability compliance (five low-probability instructions following highprobability request sequence) reinforced with praise and the high-probability compliance reinforced with food were alternated. For both forms of the intervention, compliance to low-probability instructions was reinforced with praise. In the third phase, two forms of the high-probability treatment (with praise and with food) were alternated across sessions. The results indicated that providing food as a reinforcer to compliance to the 
high-probability requests produced greater compliance and compliance to successive low-probability requests persisted more when food, rather than praise, was provided as a reinforcer.

Compliance with prescribed medication routines/medical procedures. Some studies implemented the high-probability request sequence procedure to increase compliance to medical procedures. Harchik and Putzier (1990) examined the effectiveness of the high-probability request sequence intervention in increasing compliance with taking medication by adapting Singer et al.'s (1987) and Mace et al.'s (1988) procedures. The procedures were implemented by direct-care staff during their daily responsibilities. A 23-year-old woman with severe mental retardation and a seizure disorder who refused to take her medication participated in this study. Five highprobability requests (e.g., "Touch your nose.") were presented to the subject and praise and tokens were provided after the subject's compliance. Medication was presented immediately after compliance to the high-probability request sequence. The results of the study demonstrated that the subject's compliance with taking her medication increased and her vomiting decreased during the intervention. The effects of the high-probability request sequence procedure were maintained at the six-month follow up.

Another study used the high-probability request sequence to increase compliance with medical procedures. McComas, Wacker, and Cooper (1998) extended the use of the high-probability request sequence for compliance with the central venous line care for a toddler with developmental delays and severe self-injurious behavior (SIB). The participant received treatment for a short-bowel syndrome. Differential reinforcement of alternative behavior with escape extinction (DRA/ESC EXT) and the high- 
probability/DRA/ESC EXT were compared. The participant's mother implemented the interventions under direct supervision and with specific instructions from a therapist. During the high-probability request sequence phase, three high-probability requests (e.g., "Touch your head.") were delivered prior to a low-probability request (i.e., "Hold still.") along with DRA/ESC EXT. This study demonstrated that the high-probability request sequence resulted in increases in compliance to the medical procedure, and the difference between the two treatments increased over time.

Compliance with transition time. The ability to make transitions is one of the critical skills for a child's independence in a classroom (Ardoin, Martens, \& Wolf, 1999). In addition to the previous study for compliance to transition time directives by Singer et al. (1987), Ardoin et al. (1999) extended the study on the high-probability request sequence procedure used by a regular classroom teacher for second-grade typically developing children in a group (20 students in the classroom) in which three target children with a history of noncompliance in class were monitored. Using a multielement design, they evaluated the effects of the high-probability request sequence on transition instruction (e.g., "Get in quiet position.") along with fading procedures (i.e., high-p 2 and high-p 1). The results showed that high-probability request intervention and fading procedures were effective for two subjects. The effects of the intervention were maintained at two and three week follow-up points. However, the data of the third subject were inconclusive. The author provided several explanations for this subject's performance such as the teacher's low procedural integrity with this subject's sessions, the subject's loss of interest from the teacher's frequent use of the high-probability intervention without integrity in other times, and the subject's distraction by other 
activities (e.g., eating breakfast). These findings indicated that the high-probability request sequence would be an effective group-administrated school based intervention for increasing compliance in some students.

To increase successful transition for two kindergartners with mental retardation and severe challenging behavior during transition times, Davis, Reichle, and Southards (2000) compared the effects of the high-probability request sequence and the use of a preferred item as a distracter on the compliance with transitions of two six-year old boys with severe challenging behaviors and developmental disabilities by using an alternating treatment design. The interventionists (i.e., the teacher or paraprofessional) implemented the high-probability request sequence and a preferred item as a distracter immediately prior to a request to make a transition (e.g., "Let's go to class," "Time to go to group," etc.). The results indicated that the two interventions were effective in increasing successful transitions for both children. Additionally, the results of social validity measures for the two interventions assessed through teacher ratings indicated that both procedures were considered practical for use on a daily basis in the classroom.

Compliance with academic tasks. Extending the high-probability request sequence procedure to academic tasks, Belfiore, Lee, Vargas, and Skinner (1997) evaluated the effects of completing a sequence of three high-preference mathematics problems preceding a low-preference problem on latency for students to initiate working on a the low preference problem. In an alternative school setting, they presented three high-preference problems (i.e., 1-digit multiplication) to two students prior to delivery of the low-preference problem (i.e., one 3-digit multiplication). Unlike other high- 
probability intervention studies, the researchers did not provide verbal praise as the reinforcer for completing each high-preference problem. Results showed that both subjects' latency to initiate the low-preference tasks decreased during the intervention.

Using academic tasks, Wehby and Hollahan (2000) further extended the highprobability request sequence to an intervention with a child with a learning disability. They examined the effects of the high-probability request procedure with an elementary student on the latency and duration of compliance to requests for independent completion of math problems. After three successful high-probability requests (e.g., "Put your name on your paper."), the low-probability request (e.g., "Begin independent seat work.") was presented. Neutral social comments (e.g., "It is hot today.") were provided as a comparison in the same manner used for high-probability requests. Praise was provided for responding to each high-probability and low-probability request. Results indicated that the latency to compliance substantially decreased after presenting the highprobability request sequence, whereas the neutral social comment phases showed long latencies before compliance. However, the high-probability request sequence procedure had little effect upon the duration of engagement. Applications of High-Probability Request Sequences to Reduce Aggression, SelfInjury, and Stereotypic Behaviors

Researchers have attempted to reduce escape-motivated behaviors such as aggression, self-injurious behavior, or stereotypic behaviors as a collateral effect by increasing compliance with tasks. Mace and Belfiore (1990) noted that increases in compliance with task-related demands may have a collateral effect of reducing problem behaviors that are maintained by escape from demand. They suggested that compliance 
with task-related activities is functionally incompatible with escape or avoidance of these same activities. The authors conducted the high-probability request sequence intervention to decrease stereotypic touching responses (STR), and increase compliance with lowprobability requests (e.g., "Please hang up your coat.") of a 38-year-old woman with the severe mental retardation who engaged in repetitive, stereotypic touching of objects, and people. The experimental analysis was conducted to identify the function of the subject's STR which resulted in escape from task-related demands before implementing the highprobability request sequence. The use of a high-probability request intervention in which STR did not produce escape (i.e., escape extinction) resulted in substantial increases in compliance with low-probability requests and a collateral reduction in STR.

Whereas Mace and his colleagues (1990) examined the effects of the highprobability request intervention including escape extinction, Zarcone, Iwata, Hughes, and Vollmer (1993) evaluated the separate effects of the high-probability sequence procedure on the self-injurious escape behavior of a 33-year-old profoundly retarded woman. Using functional analysis, probable function of the subject's self-injurious behavior (SIB) was an escape from instruction. The high-probability request procedure was employed alone and with escape extinction, and finally escape extinction alone was implemented. When the high-probability request sequence alone was employed, latency to SIB increased initially but decreased and then remained low, and compliance to low-probability requests showed little improvement. When escape extinction was employed along with the high-probability request sequence procedure, latency to SIB increased. In the final phase, only the escape extinction procedure was effective in decreasing latency to SIB. The subject's compliance to low-probability requests was highest during the high- 
probability sequence with extinction condition and extinction alone. Based on the results, the authors suggested that increasing compliance alone may not compete with the opportunity to escape from the demand.

On the basis of the study by Zarcone et al. (1993), Zarcone, Iwata, Mazaleski, and Smith (1994) replicated the previous study to examine the separate effects of the highprobability request sequence and escape extinction on reducing the self-injurious escape behavior of two men with developmental disabilities and self-injurious behavior (SIB). They conducted a functional analysis assessment in which it was identified that SIB in the two males was maintained by negative reinforcement (i.e., escape from instructional task). They then evaluated the effects of the high-probability request sequence on SIB during the high-probability request procedure alone and with the extinction procedure. Results demonstrated that the rates of self-injury increased and percentage of compliance to high-probability and low-probability requests decreased during the high-probability request sequence procedure alone. The high-probability procedures with extinction resulted in a decrease in the rates of self-injury and increases in compliance. The authors suggested that intervention based on the use of positive reinforcement alone may not be effective if the escape contingency is allowed when another response competes with compliance and is maintained by escape. They described that although the density of positive reinforcement for compliance increased by using the high-probability request sequence, the effects on escape behavior may be limited, and other treatment options may be needed (e.g., using higher quality of reinforcers, modification of task-related parameters such as rate of instructions, duration of instructional sessions, and effort.). 
Applications of High-Probability Request Sequences to Promote Communication Skills

Investigators have prompted research that extends high-probability request sequence intervention to teaching procedures beyond simple compliance (Davis, 1995; Davis \& Brady, 1993; Davis \& Reichle, 1996; Davis et al., 1994; Killu, 1999; Killu et al., 1998; Sanchez-Fort, Brady, \& Davis, 1995; Santos, 2001; Santo \& Ligungaris/Kraft, 1999). They stated that the high-probability request procedure has potential in teaching applications such as communication and social responding.

In an extension of the previous studies using teaching applications, Sanchez-Fort and her colleagues (1995) incorporated the high-probability request sequence to teach word and sign communication targets to a preschooler with a moderate disability and an elementary child with a severe disability. The authors hypothesized that if a student does not use a communication function (i.e., the low probability behavior), the highprobability request sequences could increase the communication function by reinforcement following the communication attempts. Instructors dispersed the requests throughout the day in relevant conditions to the low-probability target responses (e.g., the word "help" while assisting the subject's seat belt, lunch, toileting, etc.). Both subjects showed increases in the use of the low-probability target words after implementing the high-probability request sequences. However, the generalization effects were inconsistent. One subject showed use of the untrained words, but another subject did not. The authors noted that the teaching procedure, which relied on fifteen or fewer trials distributed through the day, and training words were not enough to produce generalized effects.

Another study on communication skills published by Santos and Lignugaris/Kraft (1999) implemented high-probability request sequences for five preschoolers with 
developmental delays to increase responding to indirect requests that are common in inclusive early childhood settings. The authors hypothesized that responses to indirect questions would increase when the indirect question was asked immediately following a sequence of direct questions with delivery of contingent reinforcers. When the child engaged in play during the center time activities, the instructor delivered three direct questions (e.g., "What animal is this?") rapidly prior to each indirect request (e.g., "Hmm, I wonder what animal this is?"), and each correct response to request was verbally praised. The results demonstrated that attempts to respond and the correct responses to indirect requests in all subjects increased during the high-probability request sequence intervention. In addition, three of the five subjects maintained high levels of attempts to respond and correct responses to indirect requests after the intervention was withdrawn. Applications of High-Probability Request Sequences to Facilitate Social Interactions

Many strategies, including environmental arrangement, naturalistic approaches, teacher-mediated interventions, and peer-mediated interventions, have been developed to increase the social skills of young children with disabilities (Odom, et al., 1999). However, a few studies have focused on increasing social initiations of young children with disabilities. Researchers have demonstrated that the high-probability request sequence is among effective strategies to promote social initiations and social interactions of young children with disabilities.

Davis and her colleagues (1994) used the high-probability intervention to increase the social initiations and interactions of young children with disabilities. Three young children with severe disabilities who were socially withdrawn participated in the study. The high-probability request intervention was implemented during each participant's 
regular integrated play setting by the primary investigator, the children's teachers, and a graduate student in special education. The low-probability requests (e.g., "Give the toy to peer.") to initiate with peers were delivered after a series of high-probability requests. The results demonstrated that the target children increased their prompted and unprompted social behaviors with trained peers. In addition, the increased social initiations and interactions were generalized to nontrained peers in the training and nontraining settings. The increased social initiations and interactions showed maintenance for several months after withdrawal of the intervention.

In a subsequent study, Davis and Reichle (1996) extended previous research regarding high-probability request sequence by comparing the difference in responding to low-probability requests when high-probability requests were delivered in an invariant sequence or variant sequence. Zarcone et al. (1994) hypothesized that the repeated paring of high-probability requests with low-probability requests would give the highprobability requests the same aversive properties as the low-probability requests; the high-probability requests, thus, might become discriminative stimuli for noncompliance. On the basis of the study by Zarcone et al. (1994), Davis and Reichle (1996) hypothesized that this problem might be overcome by varying the order of highprobability requests. They implemented variant (i.e., the high-probability requests delivered in a different sequence) versus invariant high-probability request sequences (i.e., high-probability requests delivered in the same order) to increase compliance with social requests in young children with emotional-behavioral disorders. In addition, they examined whether young peers could implement the high-probability request sequences and result in increases in target social behaviors. Peer interventionists were prompted to 
maintain procedural integrity by whispering in the peer's ear or using hand gestures. During intervention, an intervention peer delivered the high-probability request sequence (e.g., "Point to the soda fountain.") immediately prior to the low-probability request (e.g., "Hand (peer) soda."), and the social peer responded to the target child with a statement extending the social interaction (e.g., "Thanks for the soda pop."). The results of the study demonstrated that the variant high-probability sequences were more effective than the invariant high-probability sequence, and young peers' interventions resulted in compliance with social requests. These findings indicated that the sequencing of the highprobability request sequence is critical to the effectiveness of the intervention strategy. Additionally, the intervention implemented by peers was effective; however, extensive teacher training and prompting were required.

\section{Summary of Literature on High-Probability Request Sequence}

By extending early applications, literature on the use of the high-probability request sequence has demonstrated its effects on a variety of subjects ranging from toddlers to adults and for persons with and without disabilities investigated compliance with routine requests, medication routines, transition time, academic tasks, reducing disruptive behaviors, and promoting communication skills and social interactions. Additionally, the high-probability request procedures have been successfully employed by teachers, paraprofessionals, and parents as well as by experimenters. Most of the studies on the use of the high-probability procedures have demonstrated their effectiveness in promoting appropriate behaviors; however, some studies have shown differential effects. McComas, Wacker, Peck, Golonka, Millard, and Richman (2000) noted that three general patterns of responding to low-probability requests in the 
applications of the high-probability procedure have been shown: (a) compliance to the low-probability requests increased when the high-probability request sequence was delivered (e.g., Mace et al., 1988; Mace \& Belfiore, 1990), (b) compliance with the lowprobability requests increased following compliance with the high-probability requests, and these effects were maintained without presenting high-probability requests across sessions (e.g., Davis et al., 1992, 1994; Killu et al., 1998; Santos \& Lignugaris/Kraft, 1999), and (c) the high-probability procedure did not increase compliance with lowprobability requests (e.g., Rortvedt \& Miltenberger, 1994; Zarcone et al., 1993, 1994). On the basis of some studies that have reported marginal improvements or no effects Mace and his colleagues (1997) attempted to enhance the effectiveness of the highprobability procedure by using a higher reinforcer. They suggested that varying the quality of reinforcement may increase the effectiveness of the high-probability procedure.

Research on the high-probability request sequence has methodologically extended previous studies. Mace and his colleagues (1988) and Houlihan and his colleagues (1994) examined the effects of varying the inter-prompt time between the delivery of reinforcement for the last high-probability request and the delivery of the low probability request. These studies indicated that the high-probability procedure was more effective with a shorter inter-prompt time (i.e., 5-s) than with longer inter-prompt time (i.e., 20-s). Davis and Reichle (1995) examined the use of variant versus invariant high-probability request sequence procedures and demonstrated that the presentation of high-probability requests in random order is more effective than using the same order each time during each trial. In addition, they demonstrated the effectiveness of the high-probability request sequence procedure implemented by peers. 
The high-probability procedure was compared to other procedures (i.e., social comments) to determine whether simply gaining and maintaining the attention of the individual would increase responding to low-probability requests. Mace et al. (1988) and Mace and Belfiore (1990) demonstrated that social comments did not produce increases in compliance to the low-probability requests; however, Kennedy et al. (1995) showed that two interventions (i.e., the high-probability procedure and social comments) resulted in the similar effects.

Many studies on the use of high-probability procedures have been implemented in clinical settings, group homes, homes, special education classrooms, and regular education classrooms. Recently, researchers have attempted to incorporate the highprobability request sequence into appropriate instructional contexts in natural environments (Ardoin et al., 1999; Davis et al., 1992; 1994; 1996; 2000; Killu et al., 1998; Sanchez-Fort et al., 1995; Santos \& Lignugaris/Kraft, 1999). They have prompted the extension of high-probability request sequence to improve a variety of functional skills in addition to compliant behaviors.

\section{Social Interaction Interventions}

Social relationships with peers are critical for children's development. Building meaningful social relationships between children with and without special needs is one of the most important goals of inclusion (Guralnick, 1999). These relationships are formed when children have positive interactions with peers in the classroom and in the community (Frea, Craig-Unkefer, Odom, \& Johnson, 1999). Moreover, positive 
interactions with peers is important for later adjustment, acceptance by others, and finally to one's quality of life (Guralnick, 1990). However, young children with disabilities often do not have the prerequisite social skills to develop relationships.

Children with autism have substantial social interaction deficits. The low frequency and quality of their social interactions is one of the most defining features of autism (McConnell, 2002; Rogers, 2000). They rarely initiate or respond to social interactions with their peers whereas typically developing children initiate or respond to social interactions with their peers most of the time (Koegel, Koegel, Frea, \& Fredeen, 2001). Children with autism are unlikely to exhibit spontaneous language, gestures, or eye contact before speaking (Zanolli et al., 1996). The lack of social skills and of positive social interactions in children with autism may hinder their long-term development of social behaviors, and this expands the developmental gap between children with autism and their typical peers (McGee, Morrier, \& Day, 1999). Numerous researchers note that social interactions between children with autism and typically developing peers are unlikely to occur without systematic and planned social interventions even when they are placed together in inclusive settings (Brown \& Odom, 1995; Guralnick, 1990, 1999; Hundert \& Houghton, 1992; Kohler \& Strain, 1999; Koegel et al., 2001).

Due to the substantial social skill deficits of children with autism, facilitating their social interactions has been a critical issue in educational research. Researchers have developed a wide variety of interventions to increase the social interactions of young children with autism (Kohler, Anthony, Steighner, \& Hoyson, 2001; Odom \& Strain, 1986; Odom \& Watts, 1991; Sainato, Goldstein, \& Strain, 1992; Zanolli et al., 1996). 
These interventions include environmental interventions (Ivory \& McCollum, 1999; Odom, Peterson, McConnel, \& Ostrosky, 1990; Sainato \& Carta, 1992), naturalistic interventions (McEvoy et al., 1988; Kohler et al., 2001), teacher-mediated interventions (McConnell, Sisson, Cort, \& Strain, 1991), and peer-mediated interventions (Goldstein, English, Shafer, \& Kaczmarek, 1997; Odom \& Strain, 1986; Odom \& Watts, 1991; Odom et al., 1985; 1987; 1992; 1999). Among a wide variety of social skill intervention strategies, peer-mediated strategies are the most frequently used interventions and have shown the strongest empirical support of social outcomes (Rogers, 2000; Sasso et al., 1998; Zanolli et al., 1996). Peer-mediated interventions include peer initiation training, peer modeling, and peers participating in group-oriented contingencies (Kohler \& Strain, 1990). This review on peer-mediated interventions focuses on peer initiation interventions and peer modeling.

\section{Peer-Mediated Interventions}

\section{Peer Initiation Interventions}

Interventions using peers as intervention agents train typically developing children to initiate play towards children with disabilities. Peers are cued by teachers to begin to interact with the target children around typical play materials and activities. Table 2.2 provides a brief overview of the studies on peer initiation interventions.

Odom, Hoyson, Jamieson, and Strain (1985) examined the effects of using peerinitiation intervention packages to increase the social interactions of three socially withdrawn children. The peer confederates were taught to initiate social behaviors toward the children with disabilities at the beginning of the intervention phase. During 


\begin{tabular}{|c|c|c|}
\hline Study & $\begin{array}{l}\text { Goldstein, English, Shafer, \& } \\
\text { Kaczmarek (1997) }\end{array}$ & $\begin{array}{l}\text { McGee, Almeida, \& Sulzer- } \\
\text { Azaroff (1992) }\end{array}$ \\
\hline $\begin{array}{l}\text { Subjects/ } \\
\text { setting }\end{array}$ & $\begin{array}{l}4 \text { typically developing children } \\
\text { and } 4 \text { children with disabilities, } \\
\text { ages ranging from } 42 \text { to } 61 \\
\text { months (Cohort } 1 \text { ) } \\
4 \text { typically developing children } \\
\text { and } 4 \text { children with disabilities, } \\
\text { ages ranging from } 40 \text { to } 61 \\
\text { months } \\
\text { (Cohort } 2 \text { ) } \\
\text { Across activities in an integrated } \\
\text { classroom }\end{array}$ & $\begin{array}{l}3 \text { peer tutors and } 3 \text { children with } \\
\text { autism, ages ranging from } 3 \text { to } 5 \\
\text { years } \\
\text { During free play in an integrated } \\
\text { preschool }\end{array}$ \\
\hline $\begin{array}{l}\text { Dependent } \\
\text { Variable \& }\end{array}$ & Social communicative acts & Reciprocal peer interactions \\
\hline Measurement & $\begin{array}{l}\text { Event recording } \\
\text { MOOSES }\end{array}$ & $\begin{array}{l}\text { Continuous } 10-\text { s interval } \\
\text { recording }\end{array}$ \\
\hline $\begin{array}{l}\text { Independent } \\
\text { Variable }\end{array}$ & Buddy training procedure & Peer incidental teaching \\
\hline $\begin{array}{l}\text { Experimental } \\
\text { Design }\end{array}$ & $\begin{array}{l}\text { A multiple baseline design } \\
\text { across subjects }\end{array}$ & $\begin{array}{l}\text { A multiple baseline design across } \\
\text { subjects }\end{array}$ \\
\hline Results & $\begin{array}{l}\text { Increase in social interactions } \\
\text { between trained peers and target } \\
\text { children }\end{array}$ & $\begin{array}{l}\text { Increase in reciprocal peer } \\
\text { interactions }\end{array}$ \\
\hline Generality & $\begin{array}{l}\text { Yes. Generalized interactions } \\
\text { with other children }\end{array}$ & $\begin{array}{l}\text { Yes. One child increased in the } \\
\text { generality setting }\end{array}$ \\
\hline $\begin{array}{l}\text { Procedural } \\
\text { Integrity }\end{array}$ & Yes & No \\
\hline $\begin{array}{l}\text { Social } \\
\text { Validity }\end{array}$ & Yes. By using questionnaire & Yes. By teacher and peer ratings \\
\hline
\end{tabular}

Continued

Table 2.2 Summary of studies on peer-initiation intervention 
Table 2.2 (continued)

\begin{tabular}{|c|c|c|}
\hline Study & $\begin{array}{l}\text { Odom, Chandler, Ostrosky, } \\
\text { McConnell, \& Reaney (1992) }\end{array}$ & $\begin{array}{l}\text { Odom, Hoyson, Jamieson, \& } \\
\text { Strain (1985) }\end{array}$ \\
\hline \multirow[t]{2}{*}{$\begin{array}{l}\text { Subjects/ } \\
\text { setting }\end{array}$} & $\begin{array}{l}6 \text { preschool children with } \\
\text { disabilities and } 10 \text { typically } \\
\text { developing kindergarten } \\
\text { children }\end{array}$ & $\begin{array}{l}3 \text { preschool children with } \\
\text { disabilities and } 3 \text { typically } \\
\text { developing children }\end{array}$ \\
\hline & $\begin{array}{l}\text { During structured play activities } \\
\text { in two special education } \\
\text { classrooms }\end{array}$ & $\begin{array}{l}\text { Structured play, a table activity, } \\
\text { and learning centers in a } \\
\text { mainstreamed preschool }\end{array}$ \\
\hline $\begin{array}{l}\text { Dependent } \\
\text { Variable and }\end{array}$ & $\begin{array}{l}\text { Initiations, responses, \& social } \\
\text { interactions }\end{array}$ & Initiations \& response \\
\hline Measurement & $\begin{array}{l}\text { Continuous 6-s interval } \\
\text { recording }\end{array}$ & 10 -s interval recording \\
\hline $\begin{array}{l}\text { Independent } \\
\text { Variable }\end{array}$ & $\begin{array}{l}\text { Peer training \& teacher prompts; } \\
\text { teacher prompts \& visual } \\
\text { feedback; fade verbal prompts; } \\
\text { fade visual feedback }\end{array}$ & $\begin{array}{l}\text { Peer initiation intervention } \& \\
\text { teacher prompts }\end{array}$ \\
\hline $\begin{array}{l}\text { Experimental } \\
\text { Design }\end{array}$ & $\begin{array}{l}\text { A combined sequential and } \\
\text { partial withdrawal design }\end{array}$ & $\begin{array}{l}\text { A multiple baseline design across } \\
\text { settings }\end{array}$ \\
\hline Results & $\begin{array}{l}\text { Increase in social interactions, } \\
\text { maintained after removing } \\
\text { intervention }\end{array}$ & $\begin{array}{l}\text { Increase in social interactions } \\
\text { Decrease in social interactions } \\
\text { with reducing teacher prompts }\end{array}$ \\
\hline Generality & No & $\begin{array}{l}\text { Yes. No generalization to other } \\
\text { classroom setting }\end{array}$ \\
\hline $\begin{array}{l}\text { Procedural } \\
\text { Integrity } \\
\text { Social }\end{array}$ & Teacher prompts & No \\
\hline Validity & No & No \\
\hline
\end{tabular}

Continued 
Table 2.2 (Continued)

\begin{tabular}{|c|c|c|}
\hline Study & Odom \& Watts (1991) & $\begin{array}{l}\text { Sainato, Goldstein, \& Strain } \\
\text { (1992) }\end{array}$ \\
\hline \multirow[t]{2}{*}{$\begin{array}{l}\text { Subjects/ } \\
\text { setting }\end{array}$} & $\begin{array}{l}3 \text { preschool children with autism } \\
\text { and } 3 \text { typically developing } \\
\text { preschool children }\end{array}$ & $\begin{array}{l}6 \text { typical children and } 6 \text { children } \\
\text { with autism }\end{array}$ \\
\hline & $\begin{array}{l}\text { Structured play activities in an } \\
\text { integrated special education } \\
\text { classroom }\end{array}$ & $\begin{array}{l}\text { During a free play in an integrated } \\
\text { preschool }\end{array}$ \\
\hline $\begin{array}{l}\text { Dependent } \\
\text { Variable and }\end{array}$ & Initiations \& responses & Initiations \& responses \\
\hline Measurement & $\begin{array}{l}\text { Continuous event recording within } \\
10 \text {-s intervals }\end{array}$ & $\begin{array}{l}\text { Continuous } 10-\mathrm{s} \text { interval } \\
\text { recording }\end{array}$ \\
\hline & Peer sociometric ratings & \\
\hline $\begin{array}{l}\text { Independent } \\
\text { Variable }\end{array}$ & $\begin{array}{l}\text { Peer initiation intervention; } \\
\text { correspondence training with } \\
\text { visual feedback }\end{array}$ & $\begin{array}{l}\text { Peer confederate training } \\
\text { Self-evaluation training }\end{array}$ \\
\hline $\begin{array}{l}\text { Experimental } \\
\text { Design }\end{array}$ & $\begin{array}{l}\text { A multiple baseline with an } \\
\text { embedded multi-element } \\
\text { component }\end{array}$ & $\begin{array}{l}\text { A multiple baseline design across } \\
\text { subjects }\end{array}$ \\
\hline Results & $\begin{array}{l}\text { Increase in initiations with teacher } \\
\text { prompt (peer initiation } \\
\text { intervention) } \\
\text { Increase in initiations with } \\
\text { correspondence training with } \\
\text { visual feedback }\end{array}$ & $\begin{array}{l}\text { Self-evaluation strategy procedure } \\
\text { increased social interactions }\end{array}$ \\
\hline Generality & No & $\begin{array}{l}\text { Yes. Generalized use of self } \\
\text { evaluation strategy in other setting }\end{array}$ \\
\hline $\begin{array}{l}\text { Procedural } \\
\text { Integrity } \\
\text { Social }\end{array}$ & Teacher prompts & Yes \\
\hline Validity & No & No \\
\hline
\end{tabular}


intervention, the teacher verbally prompted the peer confederate to initiate with the target child if the confederate did not initiate after a short period of time (i.e., 15-20 seconds). The token reinforcement system was implemented for peer initiations toward the target children.

Peers' initiations to the target children resulted in increased positive social interactions, but no generalization to other settings was demonstrated. Social interactions did not substantially decrease after withdrawing the confederates' token reinforcement system; however, they did decrease after reducing teachers' prompts. With reintroducing the teacher prompts to the confederates, peers' initiations increased, which resulted in increased positive social interactions between the target children and the confederate peers. Thus, the findings of this study indicate that teacher prompts are an important part of the peer initiations intervention.

In a subsequent study, Odom and Watts (1991) used correspondence training with visual feedback to fade out teacher prompts in a peer-mediated intervention for young children with autism. Two structured play settings were used for intervention. During the first intervention, three typically developing peers were taught initiation strategies and prompted to initiate play with the children with autism in the first setting. In the second setting, peers were not given any prompts from teachers. Social interactions between the children had increased in the first setting but remained at low levels in the second setting. In the next condition, peer initiation intervention in the first setting was continued, and correspondence training with visual feedback was implemented in the second setting. Social interactions in the second setting increased upon the implementation of corresponding training with visual feedback, but levels of social interactions were lower 
than in the peer initiation intervention setting. In the final condition, only correspondence training with visual feedback was implemented in the first setting where peer initiation intervention was implemented. Social interactions with children with autism during this condition maintained the same levels as during the peer intervention condition. The researchers suggested that correspondence training with visual feedback could be used as a less intrusive strategy to reduce teacher prompts.

Sainato and her colleagues (1992) examined the effects of a self-evaluation procedure on preschool children's use of social interaction strategies with their classmates with autism. Three peer confederates were taught the facilitative strategies to initiate with the target children. In addition, each peer confederate was individually taught self-evaluation skills to increase the peer confederates' use of social interaction strategies without extensive teacher prompts. Results indicted that peers increased their use of strategies, and social interactions between the peers and the target children increased only after the self-evaluation intervention was introduced. Self-evaluation skills resulted in an increase of the peers' use of social interaction strategies as well as social interactions between children.

By extending the study by Sainato et al. (1992) and by Odom and Watts (1991), Odom, Chandler, Ostrosky, McConnell, and Reaney (1992) examined the effects of a strategy for fading out teacher prompts in peer initiation interventions. Peers were taught direct social initiations to children with disabilities, and teacher provided verbal prompts only if a social interaction did not occurred within approximately $30-\mathrm{s}$. In the next condition, teacher verbal prompts to peers and visual feedback that had peers monitor their social initiations toward the target children were provided. Next, verbal prompts and 
visual feedback on social interactions to peers were systematically faded out. Peer initiations increased when the peer initiation intervention and teacher prompts were implemented, which resulted in increases in social interactions with the children with disabilities. After systematic fading out of the prompts and visual feedback to the peers, social interactions continued at the levels obtained during intervention and were maintained during a short maintenance period.

In an attempt to increase the maintenance and generalization of the social interactions, McGee, Almeida, Sulzer-Azaroff, and Feldman (1992) examined the effects of peer incidental teaching to increase reciprocal peer interactions in children with autism. Three typical preschoolers were taught to use incidental teaching. The incidental teaching procedure included waiting for the target child to request a toy, asking the target child to label the toy, and providing praise for the correct answer while giving the toy to the target child. As the peers followed the teaching sequence with an experimenter model, the experimenter supervision and assistance were gradually faded out. Peer incidental teaching resulted in more social interactions between the peers and the children with autism. Social interactions between the peers and the target children maintained during the phase of fading out the experimenter's prompts. However, one child among the three children maintained social interactions in the generality setting.

Goldstein, English, Shafer, and Kaczmarek (1997) extended previous peermediated interventions to address the limitations in maintenance and generalization. They examined the effects of a peer-mediated intervention package that taught typical peers to better discriminate nonverbal communicative behaviors (e.g., smiling, watching or making eye contact, handing over a toy) when interacting with children with disabilities. 
Peers were taught social interaction strategies (buddy training) and prompted to use them during classroom activities. The intervention was distributed across a variety of settings throughout the school day. The peer intervention package across the day resulted in improved social-communicative interactions between the target children and their peer confederates. When peers were reassigned to different target children during generalization probes, the interactions were maintained.

\section{Peer Modeling}

As part of the peer-mediated intervention, peer modeling has been suggested as a strategy to increase social interactions (Baily \& Wolery, 1992; Kohler \& Strain, 1999). Kohler and Strain (1999) suggested that peer modeling might produce positive effects on social behaviors as well as on children's generalized imitation, motor and language, and pre-academic skills. Moreover, the peer modeling procedure may reduce the amount of teacher time and teacher prompts and could provide more helpers in the classroom for children with disabilities (Wert, Caldwell, \& Wolery, 1996). This procedure could be easily embedded into classroom routine activities and facilitates more generalized observational learning (Wert et al. 1996). No recent studies using peer modeling to increase social interactions were found. This review includes the studies on using peer modeling to increase imitation of peers' classroom activities. Table 2.3 provides a brief overview of the studies on peer-modeling's effect on imitation.

Carr and Darcy (1990) examined the effects of peer modeling on facilitating peer imitation for young children with autism and whether the effects generalized to different settings. A typically developing peer served as a model for four children with autism 


\begin{tabular}{|c|c|c|}
\hline$\overline{\text { Study }}$ & Carr \& Darcy (1990) & $\begin{array}{l}\text { Venn, Wolery, Werts, Morris, } \\
\text { DeCesare, \& Cuffs (1993) }\end{array}$ \\
\hline \multirow[t]{2}{*}{$\begin{array}{l}\text { Subjects/ } \\
\text { setting }\end{array}$} & $\begin{array}{l}4 \text { preschool children with autism } \\
\text { and a } 5 \text {-year old typically } \\
\text { developing child }\end{array}$ & $\begin{array}{l}3 \text { preschool children with } \\
\text { disabilities }\end{array}$ \\
\hline & $\begin{array}{l}\text { A hallway in a day school } \\
\text { program for children with } \\
\text { developmental disabilities }\end{array}$ & $\begin{array}{l}\text { During an art activity in a } \\
\text { mainstreamed program }\end{array}$ \\
\hline $\begin{array}{l}\text { Dependent } \\
\text { Variable and }\end{array}$ & Imitation of peer modeling & $\begin{array}{l}\text { Full imitation; assisted imitation, } \\
\text { approximation, errors/non }\end{array}$ \\
\hline Measurement & $\begin{array}{l}\text { Frequency of correct imitated } \\
\text { responses of } 10 \text { opportunities }\end{array}$ & responses \\
\hline $\begin{array}{l}\text { Independent } \\
\text { Variable }\end{array}$ & Peer imitation training & $\begin{array}{l}\text { 5-s momentary time sample } \\
\text { Embedded progressive time delay } \\
\text { in the art activity }\end{array}$ \\
\hline $\begin{array}{l}\text { Experimental } \\
\text { Design }\end{array}$ & $\begin{array}{l}\text { A multiple baseline design } \\
\text { across subjects }\end{array}$ & $\begin{array}{l}\text { A multiple probe design across } \\
\text { subjects }\end{array}$ \\
\hline Results & Increase in imitated responses & $\begin{array}{l}\text { Increase in peer imitation in the } \\
\text { art activity }\end{array}$ \\
\hline Generality & $\begin{array}{l}\text { Yes. Generalized imitation in } \\
\text { the nontraining setting }\end{array}$ & $\begin{array}{l}\text { Yes. Generalized imitation in the } \\
\text { nontraining setting }\end{array}$ \\
\hline $\begin{array}{l}\text { Procedural } \\
\text { Integrity }\end{array}$ & No & Yes \\
\hline $\begin{array}{l}\text { Social } \\
\text { Validity }\end{array}$ & No & No \\
\hline
\end{tabular}

Table 2.3 Summary of studies on peer modeling 
using a common preschool activity (Follow-the-Leader). After a peer model was trained to perform the targeted activities, the peer model modeled the activities while telling the target children what to do (e.g., "watch me," "pick up the cup"). The intervention was implemented at 10 different locations in the hallway. As a result of the intervention, all of the target children demonstrated increased imitation of the model's behaviors in the intervention and generality setting. Additionally, they reported anecdotal data that the model often embellished an activity and the observer frequently imitated such behaviors during the intervention.

Venn, Wolery, Morris, and Cuffs (1993) conducted a study to examine the effectiveness of embedding progressive time delay in art activities to teach young children with disabilities to imitate peers. Five requests to imitate peers were embedded into daily art activities for three target children with autism and other disabilities. The teacher asked the target child to watch what the peer performed, and then the target child was requested to do it. Physical assistance was provided to perform the behavior modeled by the peer immediately after the request. For the delayed request, the teacher waited for the child to imitate the peer after giving the request. The length of time that the teacher waited after giving the request and before providing the physical assistance increased gradually (e.g., 0-s, 2-s, 4-s, and 6-s). The target children's peer imitations increased with intervention and generalized into other activities (i.e., fine motor area).

\section{Summary}

Peer initiation interventions have demonstrated the effectiveness on increasing social interactions between children with autism and typically developing children. However, researchers have noted that most of the interventions required teacher intensive 
prompts and showed lack of maintenance and generalization (Brown \& Odom, 1994;

Chandler, Lubeck, \& Fowler, 1992; Fox \& McEvoy, 1993; Hundert \& Houghton, 1992;

McGee et al., 1992; Odom et al., 1992; Sasso et al., 1998). Researchers have developed procedures in an attempt to increase maintenance and generalization of the effects of peer initiation interventions while using corresponding training (Odom \& Watts, 1992), teacher prompt fading out procedures (Odom et al., 1992), self-evaluation strategies (Sainato et al., 1992), peer incidental teaching (McGee et al., 1992) and distributing the intervention across the school day (Goldstein et al., 1997).

The studies have demonstrated that the peer modeling procedure increased the imitation of peer models' behaviors in children with disabilities, and their imitations generalized into the nontraining setting. In addition, the peer modeling procedure may be a less intrusive strategy that can be incorporated into classroom routines without extensive training.

\section{Generality}

Stokes and Baer (1977) defined the generalization of behavior as "the occurrence of relevant behavior under different nontraining conditions (across subjects, setting, behaviors, and/or time) without the scheduling of the same events in those conditions as had been scheduled in the training conditions" (p.350). Effective social interaction interventions should be concerned about how behavior changes can be extended across situations, people, and responses to persist over time (Fox \& McEvoy, 1993). However, the literature on social interaction interventions reports that the generality of newly learned social behaviors has been limited (Brown \& Odom, 1994; Chandler et al., 1992; Fox \& McEvoy, 1993; Hundert \& Houghton, 1992; McConnell, 2002). 
There are a number of strategies used to promote generalized behavior in children with disabilities (Stokes \& Baer, 1977; Stokes \& Osnes, 1986). Some of these strategies include using natural consequences, using multiple exemplars, and programming common stimuli.

\section{Contacting Natural Consequences}

One strategy for increasing generality and maintenance of newly learned social behavior is to teach behaviors that are more likely to contact with naturally reinforcing consequences (Stokes \& Osnes, 1986). Certain behaviors are more likely to be reinforced by the natural environment (Fox \& McEvoy, 1993). Researchers note that specific behaviors are more likely to evoke social responses and positive social interactions such as sharing, play assisting, verbally organizing play, rough and tumble play, and showing affection (Tremblay, Strain, Hendrickson, \& Shores, 1981; Fox \& McEvoy, 1993; Goldstein et al., 1997). Additionally, studies on friendship activities demonstrated that greeting, sharing, complimenting, and sharing affection behaviors have a high probability of receiving positive responses from peers and of facilitating positive interactions (McEvoy et al. 1990; Twardosz et al., 1983).

Teaching children to recruit social behavior from peers would promote generalization to other situations and other children (Stokes \& Osnes, 1986). For instance, teaching children specific play initiations (e.g., "Let's play duck-duck-goose.") and general social initiations (e.g., "Come play with me") would be more likely to recruit natural consequences (Brown \& Odom, 1994). Importantly, both increasing functional social initiations of children with disabilities as well as increasing responding to peer initiations would facilitate contacting with natural consequences (Brown \& Odom, 1994). 


\section{Using Multiple Exemplars}

More generality of social interactions in children with autism has been observed in interventions using multiple trainers, multiple settings, and multiple response exemplars (Stokes \& Osnes, 1989). Multiple exemplar training in social behavior has been applied across multiple peers, other stimuli, or activity settings (Fox \& McEvoy, 1993). Additionally, teaching multiple exemplars of target social skills is important to increase generalization of social behaviors. Only initiation or only responding to other's social behavior may not be effective since many possible social initiations and responses might be appropriate across the various situations (Brown \& Odom, 1994).

\section{Programming Common Stimuli}

Newly acquired social skills would be more likely to generalize into the nontraining setting if the nontraining setting shares common physical and social stimuli with the training setting (Brown \& Odom, 1994). The most frequent common physical stimuli have included the same room or physical setting, the same type of assessment, or the same type of toys (Fox \& McEvoy, 1993). Additionally, the presence of the interventionist or trained peers in the generality setting may facilitate generality because of acquired discriminative properties (Stokes \& Osnes, 1989).

\section{Conclusion}

The importance of children's development and learning in the early years has been strongly emphasized in practice and research (Sandall et al., 2000). To date, a variety of empirically validated strategies in early childhood special education and applied behavior analysis have been developed. The increasing inclusion of young children with disabilities demands broader strategies that accommodate the range of 
children's educational needs and that can be easily incorporated into instructional routines. Among the variety of effective instructional strategies, the high-probability request sequence has been demonstrated as an antecedent and non-aversive procedure, which can be well incorporated into classroom routines (Ardoin et al., 1999; Davis et al. 1992, 1994, 2000; Killu et al., 1998; Santos \& Lingungaris/Kraft, 1999; Sanchez-Fort et al., 1995). Few studies on the use of the high-probability request sequence have addressed the social behaviors of young children with autism with peers in their natural environment (Davis \& Reichle, 1996; Davis et al., 1994).

Building positive social relationships between children with and without disabilities is one of the most important goals of inclusion. Due to the substantial social skill deficits of children with autism, promoting positive social interactions in young children with autism has been a critical issue in educational research. Peer-mediated interventions have demonstrated the strongest empirical support for increasing social interactions between children. However, researchers noted that these strategies often required extensive teacher prompts and showed lack of generalization and maintenance of social interactions (Chandler et al., 1992; Hundert \& Houghton, 1992; Odom et al., 1992; Sainato et al., 1992; Sasso et al., 1998). Few studies have been implemented to teach social behaviors to children with autism as well as to their typically developing peers.

Teaching social behaviors to children with autism as well as to the typically developing children at the same time would be a powerful intervention to increase social interactions (Odom \& Watts, 1991). This study will extend the literature by examining the effects of a combined high-probability request sequence and peer-mediated 
intervention on increasing social interactions of young children with autism in an inclusive setting. In addition, this study will examine the effects of the intervention on generalized social interactions. Social validity measures will be obtained from parents of participants, and professionals in early childhood education. 


\section{CHAPTER 3}

\section{METHOD}

This section describes the research methodology, data collection and analyses used to answer the research questions. A description of the children, setting, materials, dependent variables, measurement, procedural integrity, research design, procedures and social validity measures are included.

\section{Participants}

The participants were selected from an inclusive charter school for children with autism spectrum disorders. This study was conducted in the preschool/kindergarten transition classroom. The classroom consisted of six children with disabilities and seven typically developing peers. The classroom had one lead teacher and two assistants. The participants included three children between the ages of 4 and 6 years old. One target child had an independent diagnosis of autism by the 1994 American Psychiatric Association's Diagnostic and Statistical Manual of Mental Disorders (4 $4^{\text {th }}$ ed.). The two other target children had been independently diagnosed as PDDNOS (Pervasive 
Developmental Disorder, Not Otherwise Specified). Six of the typical peers in the class were also included in this study. Participants with disabilities were selected who had IEP objectives related to social skills.

Direct observations of the students were conducted in the classroom as well as interviews with teachers in order to identify participants who did not interact with peers during free play center time. Several prerequisite skills were required for inclusion into the study. Participants were required to have the ability to imitate simple motor tasks and verbalization. For the children with autism, scores on the Childhood Autism Rating Scale (Schopler, 1988) were obtained from the school record or assessed by the experimenter. The CARS is a 15-item rating scale that differentiates between mild/moderate to severe autism and other developmental disabilities. Each child's cognitive skills and communication skills were assessed by the experimenter using the Battelle Developmental Inventory (Newborg et al., 1984). Results from the tests are summarized in Table 3. 1. Typical peers who followed teacher directions consistently, who demonstrated age appropriate interactions with peers, and who attended school regularly were chosen from the classroom. These trained peers were three females ages 51, 52, and 61-months old, respectively. Another three nontrained generality peers were two males, and one female ages, 66, 51, and 54-months old, respectively. Parent permission was obtained for all participants prior to the beginning of data collection, in addition to permission from The Ohio State University Behaviors and Social Science Institutional Review Board. 


\begin{tabular}{llll}
\hline Characteristics & Eric & Paul & Chris \\
\hline Age & 63 months & 75 months & 77 months \\
Sex & Male & Male & Male \\
Diagnosis & PDDNOS & PDDNOS & Autism \\
& & & \\
CARS $_{\mathrm{a}}$ & 31.5 & 33.5 & 42 \\
Cognition $_{\mathrm{b}, \mathrm{c}}$ & 43 months & 35 months & 30 months \\
Receptive Language $_{\mathrm{b}, \mathrm{c}}$ & 32 months & 23 months & 23 months \\
Expressive Language $_{\mathrm{b}, \mathrm{c}}$ & 30 months & 18 months & 16 months \\
\hline
\end{tabular}

a- Childhood Autism Rating Scale (Schopler, 1988), scores of 30-36 indicating mild to moderate autism and scores over 36 indicating severe autism.

b- Battelle Developmental Inventory (Newborg et al., 1984)

c- Age-equivalency scores reported in months

Table 3.1: Characteristics of target children

Eric

Eric was a 63 month-old male who had an independent diagnosis of PDDNOS (Pervasive Developmental Disorder, Not Otherwise Specified), who attended a centerbased early childhood special education classroom for two years. He received a score of 31.5 on the Childhood Autism Rating Scale (Schopler, 1988) indicating mild to moderate autism. Eric received the following age equivalent scores on the Battelle Developmental Inventory (Newborg et al., 1984): cognition, 43 months; receptive language, 32 months; and expressive language, 30 months. He was able to verbally respond to adults and peers, 
and sometimes expressed spontaneous comments. Eric participated in action songs during circle time, however, he often engaged in stereotypic finger flapping and in the inappropriate play with toys during center time. Eric often did not interact with peers appropriately although he sometimes responded to his peers' initiations. If other children attempted to engage Eric he often ignored them or exhibited negative responses toward them.

Eric's peer, Stacie, was a 53 month-old female. Stacie engaged in play with others and followed the teacher's directions. Stacie would occasionally attempt to talk with her friends, but would easily cease to initiate if they did not respond. Eric's generality peer, Megan, was a 54 month-old female. She engaged in appropriate play with her friends or herself, and most of time was quiet.

Paul

Paul was a 75 month-old male who had an independent diagnosis of PDDNOS, and had attended a center-based early childhood special education classroom for three years. He received a score of 33.5 on the Childhood Autism Rating Scale (Schopler, 1988) indicating mild to moderate autism. Paul received the following age equivalent scores on the Battelle Developmental Inventory (Newborg et al., 1984): cognition, 35 months; receptive language, 23 months; and expressive language, 18 months. Paul participated in action songs during circle time, and followed teachers' simple, and routine requests; however, he exhibited disruptive behaviors (e.g., kicking, crying, hitting himself, throwing away the task materials) when he was asked to do demanding tasks or requests. Paul did not exhibit appropriate play skills and often engaged in stereotypic play with \ 
several specific toys (e.g., horses, dinosaurs, etc.). Paul responded to teacher's initiations, however, he seldom interacted with other children, and was more likely to avoid other children when they initiated to him.

Paul's peer, Jennifer, was a 51 month-old female. Jennifer played and interacted with other children appropriately, however, she was hesitant to initiate to Paul, and would seldom engage with him. Paul's generality peer, Randy, was a 66 month-old male. Randy would play with Jennifer, however, he seldom engaged in play with Paul although he played in close proximity to him.

\section{Chris}

Chris was a 77-month-old male who had an independent diagnosis of autism, who had been the recipient of a discrete trial program for two years, and who had attended a center-based early childhood special education classroom for 3 years. Chris received a score of 42 on the Childhood Autism Rating Scale (Schopler, 1988) indicating severe autism. Chris received the following age equivalent scores on the Battelle Developmental Inventory (Newborg et al., 1984): cognition, 30 months; receptive language 23 months; and expressive language 16 months. Chris liked to write letters, draw, and hold the puppy book while sitting in a bean bag, and sucking his thumb. Chris was able to follow the daily routine; however, he exhibited disruptive behaviors (e.g., screaming, hitting himself or others on the head, pinching, scratching, etc.) during some transition times. He seldom engaged in play and typically stared into space while sucking his thumb. When he was asked to do demanding tasks, he often screamed, hit, pinched, or scratched others. When other children attempted to play with him, he often yelled or hit them. 
Chris's peer, Hilary, was a 61 month-old female. She was very responsible child who took charge of her friends with disabilities. Hilary was not fearful of Chris's behavior and sometimes gave Chris prompts not to do certain inappropriate behaviors. Although Hilary occasionally attempted to play with Chris, if other children were present she would often engage them. If Chris did not respond she would cease to initiate and play by herself. Tyler, Chris's generality peer, was a 51-month-year old male. He was not fearful of Chris's behavior even when Chris attempted to pinch him.

\section{Experimenter}

The experimenter is a doctoral candidate in the Special Education and Applied Behavior Analysis program at The Ohio State University. She was a teacher in a middle school for three years, an early childhood special education teacher for two years, an educational diagnostician, and an administrator in early childhood special education for five years prior to her enrollment in the doctoral program.

\section{Classroom Staff}

The classroom staff consisted of one lead teacher and two teacher assistants. The lead teacher holds Ohio certification in Developmental Handicaps and Early Education of the Handicapped and has taught preschoolers with disabilities for five years. Both of the teacher's assistants are certified as independent care providers in the state of Ohio. The assistants had each had one year of experience in a classroom setting.

\section{Research setting}

This study was conducted in a private charter school licensed by the state of Ohio to deliver educational services for children from preschool through third grade. This study was conducted in the preschool/kindergarten transition classroom. The classroom 
consisted of six children with disabilities and seven typically developing peers between the ages of 4 and 6 years old. The classroom contained one teacher and two assistants. The classroom was separated into defined play areas (See Figure 3. 1).

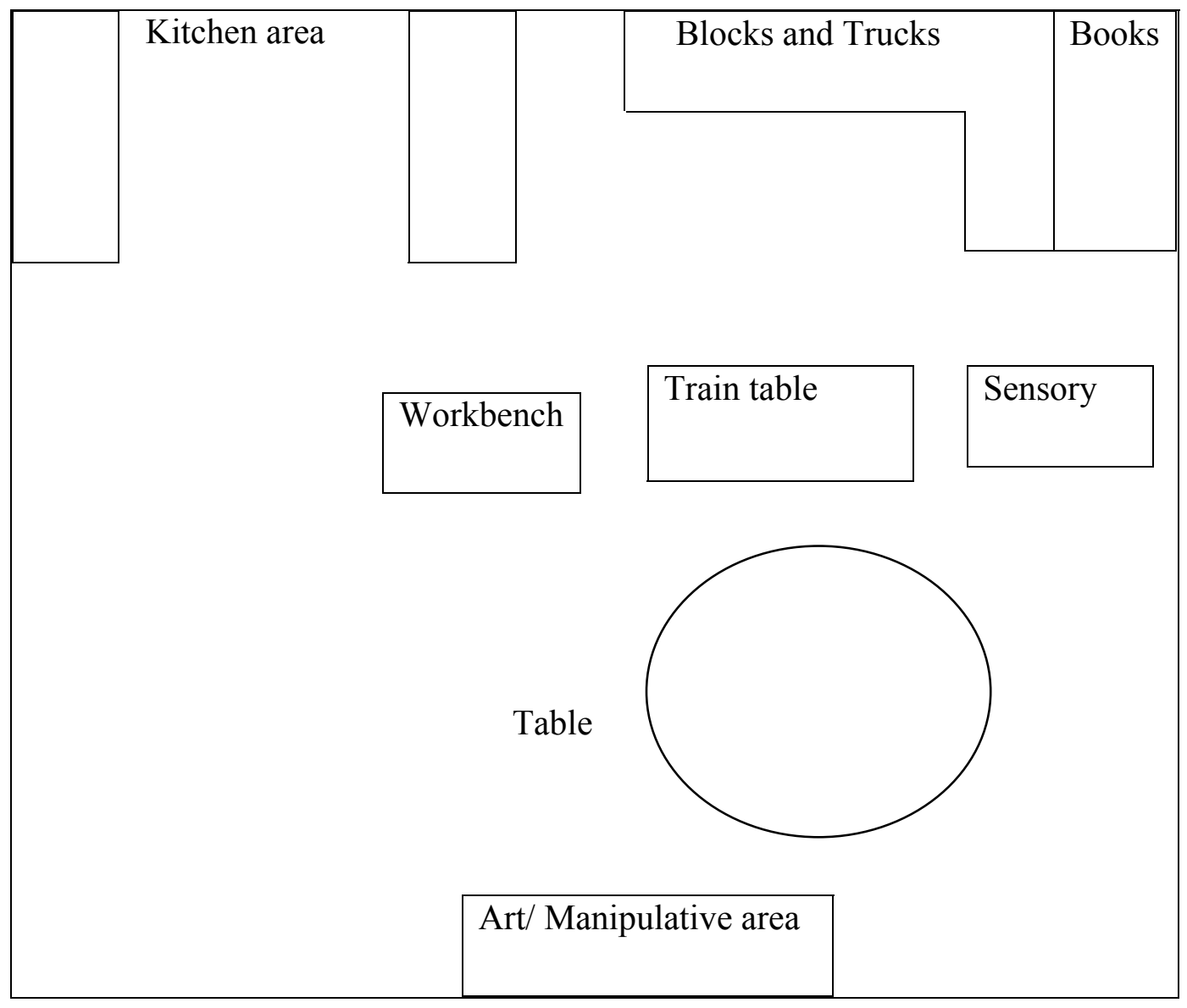

Figure 3.1 Illustration of classroom 
These play areas included a kitchen area, an art/manipulative area, blocks and trucks area, books/language area, train table, workbench, and a sensory area. Three intervention settings were selected for each target child based on the child's preference and the settings that would encourage interactive play between children. The targeted areas for the study were the kitchen area, blocks and trucks area, train table, and drawing area. The sensory area, workbench, and blocks and trucks were selected for generality settings as well. The daily schedule in the classroom included free play, circle time, center time, story time, lunch, recess, art/language/math/ board games, and snack. Research was conducted Monday through Friday 10:00-11:00 a.m. during center time.

Materials and Equipment

A variety of materials and equipment were used to implement this study. These included toys and play materials, index cards, data collection forms, consent forms, video camera, tripod, videotapes, audiotape recorder, interval tape, stop watch, and two placemats.

Toys and Play Materials

Each of the three target areas per child was clearly defined and contained easily accessible age appropriate toys and materials. Toys and play materials were selected based on the following criterion: developmental and age appropriateness, the extent to which items were found in typical preschool settings, child preferences, and the likelihood that the toy would prompt social interactions. 
Kitchen area. The following items were located in the kitchen area: a child size table, two chairs, play stove, sink, baby doll, baby bottles, play food, play pizza set, play dishes, lunch box, cash register, play money, dress-up clothes and hats, and a play doctor kit.

Blocks and Trucks. Two $.9 \mathrm{~m}$ by $1.2 \mathrm{~m}$ bookshelves contained the following materials: cardboard blocks, wooden blocks, construction vehicles, cars, semi-trucks, dump trucks, airplane, farm animals, dinosaurs, a castle and knights, and pop tubes.

Train table. The table was a $1.8 \mathrm{~m}$ by $.8 \mathrm{~m}$ wooden train table. On the table was a large wooden track that circled the perimeter of the table with a bridge and a mountain, cave and train station. There were a variety of trains, trees, houses, road signs, barrels, and loaders.

Art/Manipulative area. The Art/Manipulative area was placed near a big table, and materials were available on a nearly bookcase. This area included paints, markers, glue, play dough, a variety of puzzles. Drawing materials and a notebook were used for intervention.

\section{Index Cards}

White, $13 \mathrm{~cm}$ by $7.5 \mathrm{~cm}$ index cards were used to cue the experimenter on the delivery of requests.

Data Collection Forms

Printed data collection forms were used to record and code during intervention and generality: (a) participant's prompted initiations (i.e., those initiations preceded by a low probability request), (b) unprompted initiations by participants, (c) responses to initiations, (d) delivery of and response to high probability and low probability requests, 
(e) inter-prompt time (i.e., time between the reinforcement of the previous request and the delivery of the next request), (f) negative interactions, and (g) disruptive behavior, (h) experimenter general prompts (see Appendix A). Other forms include the procedural integrity checklist (see Appendix C), parent and teacher questionnaires (see Appendix D), social validity forms (see Appendix E), and high-probability and low-probability request status assessment forms (see Appendix F).

\section{Consent Form}

Signed consent forms were obtained from the parent of each child participating in the study. Consent forms were secured for the purpose of (a) the child's participation in the research study; (b) permission for the child to be videotaped; and (c) permission for release of information (see Appendix G).

Video Recording Equipment

All experimental and generality sessions were recorded on digital video cassette tapes. A Sony Digital Handycam video camera (DCR-TRV340 NTSC) was used to record all sessions. A Sony Electret Condenser Microphone was attached to the video camera to enhance the quality of videotape to measure the children's behavior. The camera was positioned on a tripod mounted on a countertop to enable views of all play areas.

Audio tape recorder and 6-s Interval Tape

A 6-s interval tape was made using a stopwatch and a handheld cassette recorder for coding purposes. The 6-s intervals were played directly into the auditory system of the video camera by placing it within range of the video camera microphone. 


\section{Stop Watch}

A digital stopwatch was used for timing the intervention.

\section{Placemats}

Two placemats were used to help children define the play area in the block area. The placemats were $.4 \mathrm{~m}$ by $.3 \mathrm{~m}$ in size.

\section{Definition and Measurement of Dependent Variables}

This study focused on increasing social interactions between children with autism spectrum disorders and typically developing peers in an inclusive setting. During baseline and intervention, responses to low probability requests (i.e., prompted initiations), unprompted social initiations, and unprompted social responses were measured as dependent variables. Additional data on negative interactions and disruptive behaviors were observed. The dependent variables were defined as follows:

\section{Definition of Dependent Variables}

Response to low-probability request

The response to a low- probability request was defined as the child initiating the requested response within 5-s and the successful completion of a targeted low-probability request as determined (See Appendix H). In this study, the low-probability requests were the requests to initiate to a peer, which the student had a history of being unlikely to respond (i.e., with a criterion of responding to less than $50 \%$ of the opportunities). The assignment of low probability request per target child was determined during assessment (see Appendix E). Examples of low-probability requests are presented in Table 3. 2. 


\begin{tabular}{|c|c|c|}
\hline Participants & $\begin{array}{l}\text { Low-probability request (percent } \\
\text { correct responses to requests } \\
\text { during assessment) }\end{array}$ & $\begin{array}{l}\text { High-probability request (percent } \\
\text { correct responses to requests } \\
\text { during assessment) }\end{array}$ \\
\hline \multirow[t]{4}{*}{ Eric } & $\begin{array}{l}\text { Say to (peer) "how are } \\
\text { you?"(50\%) }\end{array}$ & Hands on your shoulders $(80 \%)$ \\
\hline & $\begin{array}{l}\text { Say to (peer) "fly the plane to } \\
\text { me" }(60 \%)\end{array}$ & Build an airport ( $80 \%)$ \\
\hline & Push the train to (peer) $(40 \%)$ & Connect trains together $(90 \%)$ \\
\hline & $\begin{array}{l}\text { Say to (peer) "I am making a } \\
\text { sandwich for you" }(60 \%)\end{array}$ & $\begin{array}{l}\text { Put the sandwich on the plate } \\
(90 \%)\end{array}$ \\
\hline \multirow[t]{4}{*}{ Paul } & $\begin{array}{l}\text { Shake hands with your friend } \\
(50 \%)\end{array}$ & Move your shoulder $(80 \%)$ \\
\hline & $\begin{array}{l}\text { Say to (peer) "horse please" } \\
(60 \%)\end{array}$ & Put the cow in the farm $(90 \%)$ \\
\hline & Say to (peer) "train please" $(40 \%)$ & Put the barrel in loader $(80 \%)$ \\
\hline & Give (peer) the pizza ( $40 \%)$ & Cut the pizza $(90 \%)$ \\
\hline \multirow[t]{4}{*}{ Chris } & Say to (peer) "hi, (peer)" $(40 \%)$ & Clap your hands $(70 \%)$ \\
\hline & $\begin{array}{l}\text { Say to (peer) "notebook, please" } \\
(40 \%)\end{array}$ & Write the letter "C" $(80 \%)$ \\
\hline & Give (peer) the train $(50 \%)$ & Push the train $(80 \%)$ \\
\hline & $\begin{array}{l}\text { Put the sandwich on (peer)'s plate } \\
(50 \%)\end{array}$ & $\begin{array}{l}\text { Put the cheese on your pizza } \\
(90 \%)\end{array}$ \\
\hline
\end{tabular}

Table 3.2: Examples of low-probability and high-probability requests for target children (Note: Complete low-probability and high-probability requests are located in Appendix H) 


\section{Social Interaction}

Social interaction was categorized into initiations, and responses. Social interactions were defined and measured using adaptations of Odom et al.'s recoding system $(1987 ; 1992)$.

Initiation. An initiation was any verbal or gestural behavior that the target child directed to a peer or the peer directed to a target child that was not preceded by a social behavior from the same peer in the previous 3-seconds.

Response. A response was any verbal or gestural behavior that was directed toward a peer initiation that occurred in the previous 3 -seconds. The following statements describe social interactions:

1. Attention seeking: The child attempts to direct or call the attention of the other child (e.g., making eye contact, verbal greeting or any appropriate physical gesture, tapping a child on the arm, saying "look at this", and showing off).

2. Greeting: The child emits a vocal greeting (e.g., "Hi," "How are you," "Hello," etc.) or any appropriate physical gesture (e.g., hand waving).

3. Requesting: The child orders or directs other children in order to receive an object, information, or begin or terminate some activity.

4. Complimenting: The child makes statement indicating affection, attraction, or praise.

5. Assisting: The child teaches, shows how to play, or helps another child.

6. Play organizing: The child verbally specifies an activity, role, or other play for peers (e.g., "Let’s play house.”). 
7. Sharing or cooperating: The child offers or exchanges an object with another child; both cooperate in the use of one object or toy or both simultaneously use the same materials or engage in turn taking.

\section{Other Behaviors}

Negative social interaction. Negative interaction was defined as any inappropriate verbal or gestural behavior toward another child such as hitting, kicking, pushing, destroying others' construction, or vocalizations such as crying, shouting, or a calling another child name.

Disruptive behavior. Disruptive behavior was defined as any inappropriate verbal or gestural behaviors such as throwing away the toys, hitting himself, or screaming during play, or inappropriate responses by the child that were not necessary for performing a request.

\section{Measurement}

The children were videotaped during one hour center time using a video camera mounted on a tripod. The secondary observer monitored the video camera during all sessions to capture all aspects of the experimental phases. Children's behaviors were recorded using a combination 6-s partial interval and event-recording scheme for 10 minutes. Children's discrete social initiations, responses, and other behaviors such as negative interactions, disruptive behaviors, and self-stimulating behaviors were measured via 6-s partial interval recording. Children's responses to high -probability and lowprobability requests were recorded using event recording. Based on a count of appropriate responses to high-probability and low-probability requests, a percentage of appropriate responding to requests was calculated. Children's responses to requests were 
categorized into responses, nonresponses, and noncompliance. Coding sheets were designed to capture the relevant dimensions of the observations (see Appendix A).

\section{Procedures to Assess Believability of Data}

Accuracy measures were conducted and analyzed to ensure the believability of the coded data. Approximately $20 \%$ of all videotaped sessions were observed by a second observer to determine the accuracy of the observations. A percentage correct was calculated for children's responses to the requests, social initiations and responses, disruptive behaviors, delivery of low-probability request and high-probability request sequences, and the experimenter's general prompts.

\section{Accuracy Measures}

All experimental and generality sessions were videotaped. Accuracy data were collected for children's responses to the requests, social initiations and responses, disruptive behavior, delivery of low-probability and high-probability requests, and the experimenter's general prompts.

Observers. The experimenter served as the primary observer and recorded children's responses to requests, social initiations and responses, other behaviors including negative interactions, disruptive behaviors, self-stimulating behaviors, delivery of low-probability and high-probability requests, and the experimenter's general prompts during experimental and generality sessions from observing the videotapes.

The second observer was an undergraduate student major in special education at The Ohio State University. The observer had experience working with young children with disabilities as a teacher assistant. The second observer conducted accuracy measures for dependent variables, delivery of low-probability and high-probability 
requests, and the experimenter's general prompts. The second observer also collected data to measure procedural integrity checklists, and helped monitor the video camera to capture all aspects of the experiment.

The third observer was a undergraduate special education student at The Ohio State University who had completed at least one course and practicum that involved working with young children with disabilities. The third observer collected data to measure procedural integrity by checklist and helped monitor the video camera to capture all aspects of the experiment.

Training. Prior to the beginning of the study, the experimenter provided the second observer with written and verbal definitions of the dependent variables (see Appendix B). The observers jointly viewed and discussed videotapes of children during center time. The experimenter and second observer identified and coded children's social initiations, responses, and experimenter's general prompts using the 6-second interval tape. The experimenter and second observer identified and coded children's responses to low-probability requests and high-probability requests using the event recording. The experimenter and second observer trained until they reached at least $95 \%$ agreement on at least two sessions.

General procedures for accuracy measures. Following each session the experimenter independently viewed and coded the video tape. Dependent variables and experimenter's behaviors were identified and coded on the data collection sheets. For measurement of accuracy the experimenter and second observer jointly viewed the 
videotape and independently coded and recorded the dependent variables and experimenter behaviors. If coding was not clear for any observer, two observers watched the behavior until the observers reached to the agreement.

Accuracy measure was assessed for approximately $20 \%$ of the sessions for each child during each phase of the experiment. The percentage of agreement was calculated for each child by dividing the number of agreements by the number of agreements plus disagreement and multiplying by 100 (on a point by point basis for occurrence and non occurrence) (Cooper, Heron, \& Heward, 1987). The following formula was used for calculating percentage accuracy:

\# of agreements

\# of agreements + disagreements

$$
\mathrm{X} 100=\text { agreement } \%
$$

Procedural Integrity

Procedural integrity measurements were conducted to ensure that the experimenter accurately and consistently implemented the intervention with each child. Two primary measures of procedural integrity occurred. First, a checklist of the steps used during intervention was developed for each condition. Second, the delivery of lowprobability and high-probability request, and the number of intervals of experimenter prompts provided to the students were recorded and counted. Accuracy was calculated for $20 \%$ of the experimental and generality sessions.

Checklist of the steps used during intervention. A checklist of experimental procedures was developed and provided to the second and third observers. The observers completed the checklists while observing experimenter behaviors across all conditions. The observers marked each procedural step with regard to experimenter behavior as 
either observed (+), not observed (-), or not applicable (NA). If the experimenter did not maintain at least a $90 \%$ correct implementation of the procedural steps, a review of the steps was conducted using written material and practice of the procedural implementation without the presence of the child. Interobserver agreement between the second and the third observers for procedural integrity was conducted for $20 \%$ of all experimental phases and generality sessions.

\section{Delivery of low-probability and high- probability requests. Experimenter's} behaviors necessary for implementing each low-probability and high-probability request sequence were recorded by the experimenter and second observer while viewing videotaped sessions using the event recording scheme. Observers ensured that at least three high-probability requests were delivered prior to the delivery of a low-probability request, and at least three appropriate responses to high-probability requests were obtained prior to the delivery of a low-probability request. Appropriate responding to both high-probability requests was followed by a praise statement, and these were measured as well. Inter-prompt time between the reinforcement of the previous request and the delivery of the next request was measured to ensure that the experimenter delivered each request within 5-s after reinforcement for performing the last request.

Response to high-probability request. The response to a high-probability request was defined as the child initiating the requested response within 5-s and the successful completion of a targeted high-probability request as determined (See Appendix H). These behaviors are responses to requests to which each participant performs consistently or is likely to respond to (i.e., with a criterion of $80 \%$ or greater). Each target child's highprobability requests were assessed. The high-probability requests consisted of the 
requests to perform preferred action songs that the child liked and the play skills appropriate within the given context. Examples of high-probability requests are presented in Table 3.2.

Experimenter's general prompts. The experimenter general prompts were measured by the experimenter and second observer while viewing videotaped sessions using a partial-interval recording scheme. The experimenter's general prompts were defined as prompts to direct the child's inappropriate behaviors. The experimenter provided general prompts to stay in the assigned center, to engage in the play, or to stop disruptive behaviors (e.g., "Get busy," "Stay in your center," "Don't hit your friend," "hands down," etc.).

\section{Experimental Design}

A single subject multiple baseline design across subjects was used to assess the effects of high probability request sequence with embedded peer modeling on increasing social interactions between children with autism and their peers during center time. When using a multiple baseline design across subjects, the effects of the independent variables were predicted, verified and replicated by the repeated opportunities provided by using several subjects. Predictions were based on the response of the participant when exposed to the intervention after stable responding occurred during baseline. Verification occurred when the participant moved into the intervention condition with no change in the baseline responding of the other participants. This pattern was repeated as each participant moved from one condition to the next. Replication occurred when participant's target behaviors responded in the same manner as the other participant's when introduced to the same experimental conditions (Cooper et al., 1987). Experimental control was demonstrated in 
this design by determining the children's level of compliant responding to lowprobability requests, and social interactions between children. The levels of compliant responses to requests during low-probability request alone were compared to the same behavior following the systematic implementation of high-probability request sequences with embedded peer modeling. The levels of social interactions were compared with baseline levels of the same behavior. There was an increase of child behaviors during intervention over the established baseline levels of the same behaviors, while baseline conditions remained the same for the other children.

Data were collected and graphed during the intervention period for percent correct responses to requests, and the number of the intervals of social initiations and responses. Intervention was introduced sequentially when stable responding had occurred. The intervention was implemented for the first participant when a stable rate of responding was present during the baseline condition in both the intervention and generality settings. Intervention was introduced to the second child when the first child demonstrated stable responding to the intervention. The same decision guidelines were used before starting intervention for the third child. This process was replicated when introducing the next phase of experiment.

Data Analysis

Experimental control in a multiple baseline design is observed by visual inspection of the data. Visual inspection was used to evaluate the experimental effects and determine the clinical significant of the intervention (Cooper et al., 1987). Daily data collection provided a basis for the decisions regarding progress and when to make 
condition changes. Within each condition, data were analyzed to determine the number of data points, variability within phases, and changes in level and trends within and between phases.

The percent correct responses to requests and the number of intervals of social initiations and responses were the basis of the experimental analysis and were graphed daily. Additional data were collected on negative interactions, disruptive behaviors and self-stimulating behaviors in the intervention and generality setting. Data were collected across all experimental conditions. The experimenter behaviors including delivery of low-probability and high-probability requests and the experimenter general prompts were also monitored.

\section{Procedures}

The five experimental conditions were as follows: baseline, low-probability requests alone, high-probability request sequence with embedded peer modeling, lowprobability requests alone, and maintenance (prompt removal). Generality probes were conducted in the nontraining setting during center time which followed the experimental sessions across all conditions.

\section{General Procedures}

For the purpose of the study three specific play areas per child were chosen based on the children's play preferences and play materials prompting interactive play. These play settings included kitchen, blocks and truck area, train table, and art/manipulative area. Children's participation in each setting was rotated throughout the study. The preschool's normal routine during center time was to have the children play in two centers that the teacher assigned before the class. Children could move from center to 
center within the assigned two centers. The experimenter assigned one intervention center and generality center, and the teacher assigned another center. The target child, the peer, and the generality peer were assigned the same center. However, no instruction was given to the generality peer except a general prompt when they left the assigned center and when they engaged in inappropriate behaviors. Children were required to play in each area for 10 minutes. The second observer started to play the interval tape right after the experimenter gave the general instruction to the target child and the peer, and cued the experimenter to conclude after 10-min.

\section{Normative Measurement}

Prior to baseline, observations were conducted to obtain normative data on the numbers of intervals with social initiations, and social responses among typically developing peers. Five typical children were randomly selected in the same class. The experimenter collected data on the children's social initiations and responses toward other children in the training setting during a center time. These observations were conducted for 5 days for all five students. The average intervals of social initiations were 7.4 for 10 -min play. The average intervals of social responses were 1.6. The average intervals of total social behaviors (i.e., initiations and responses) were 9 during 10 minutes. These observation data were similar to the previous studies (Davis \& Reichle, 1996; Davis et al. 1994) which observed 8 initiations by young children during the 10minute free play. These data provided a guide to determine how frequently a lowprobability request (i.e., prompt for social initiation) should be issued to approximate natural peer interactions. 


\section{Status Assessment of High-Probability and Low-Probability request}

Children's preferences for center time activities and play materials were observed. Teachers and parents were also surveyed with regard to children's preferences prior to assessment of high-probability and low-probability requests. Three intervention settings and one generality setting per child were selected. The high-probability and lowprobability status of requests in each intervention setting was determined by assessing each child's responding to the pool of requests. In addition to play settings, the requests adapted from action songs and friendship activities were assessed. Friendship activities using songs and games have demonstrated effects on increasing social interactions among children, prompting greetings, complementing, and displaying affection behaviors (Brown, McEvoy, \& Bishop, 1991; Brown, Raglan, \& Bishop, 1989; Brown \& Odom, 1995; Cooper \& McEvoy, 1996; McEvoy, Twardosz, \& Bishop, 1990; Twardosz, Nordquist, Simon, \& Botkin, 1984).

Prior to assessing the status of high-probability and low-probability requests for each child, the experimenter examined the children's IEP, observed the participants in the centers, and surveyed the teacher, the teacher assistants, and the parents about the requests that the children could perform during play (see Appendix D). Early childhood special education teachers were asked to determine whether the play skills were appropriate for young children. Next, the experimenter selected the requests that were relevant to three play settings and adapted from action songs and friendship activities for each child. Specific requests were delivered 10 times to each child, and a percentage of correct responding was calculated during a 3 week assessment period. The lowprobability requests (i.e., requests for social initiations) were determined by children's 
responding to less than $50 \%$ of the opportunities. The high-probability requests were determined with a criterion of children's responding to $80 \%$ or greater of the requests. However, for Child 1, Eric, low-probability requests were those to which he responded $60 \%$ or less of the time. For Child 3, Chris, high-probability requests were those to which he responded $70 \%$ or more of the time. Four low-probability requests in each of three intervention settings and four requests adapted from friendship activities were determined. The total low-probability requests per child were 16 requests. Thirty three highprobability requests for Child 1, Eric, and Child 2, Paul, and 28 high-probability requests for Child 3, Chris were determined (see Appendix H).

\section{Baseline}

The target child, typical peer, and generality peer were assigned to an intervention center. Three intervention settings per group were rotated throughout the sessions. The target child and his peer were instructed, "Stay in your center and play with your friend. Now go and play." Stickers or small toys were offered non-contingently to the target child and peer before starting play. The generality peer played in the same center without any instruction. The experimenter gave general prompts to play only when the child was off-task or engaged in stereotypic behaviors or disruptive behaviors (e.g. "Get busy," "Play, stay in your center," etc.). If the child was engaged in disruptive behavior, the experimenter followed the behavior management procedures regularly used by the classroom teachers. That is, the experimenter brought the child to the chart, and had the child put the sad mark on it while providing corrective feedback (e.g, "Pinching your friend is not a good choice. That's sad. Don't pinch your friend."). The experimenter did 
not give any specific prompts to interact with children. After 10-min play, the children were verbally praised for doing a good job and were told that they may stay or change their center.

Peer training. After stable responding was achieved in baseline, the experimenter trained the peer to recognize the target child' initiations and to respond to them. The experimenter used role-play and discussion for peer training.

The peer was told the play situation specific to the target child's play settings and available toys. The second observer or third observer played the role of the target child. The experimenter delivered the low-probability request to the observer and the observer responded to the experimenter's low-probability requests as if she were the target child. The peer was told to wait until the target child followed the experimenter's instruction when the experimenter told the target child what to do. The experimenter asked the peer what her response might be to the initiation. When the peer did not respond appropriately, the experimenter modeled and discussed how to respond to the initiation. The same procedures continued for all target behaviors in three intervention settings. Peer training sessions continued until the peer reached to the criterion of $90 \%$ correct responses to the experimenter's questions for 3 consecutive sessions. Peer training scripts for three peers are located in Appendix I.

Additionally, when the peers' responses to the target children's prompted initiations or unprompted initiations decreased, the experimenter reviewed the target behaviors with the peers and asked what their responses might be to the given initiation. The review sessions with each peer were conducted before the intervention in each intervention setting during sessions \# 51 through \#55. 


\section{Low-probability requests alone}

The target child, peer, and generality peer were assigned to an intervention center. Three intervention centers chosen for each target child were rotated throughout the sessions. The experimenter delivered eight low-probability requests to each target participant during a 10-min center time. Low-probability requests were verbal requests to initiate social behavior toward the peer (See Appendix H). Eight low-probability requests included four requests adapted from friendship activities (e.g., "Shake hands with your friend," "Say to Hilary, Hi," etc.) and four other requests relevant to the assigned play setting (e.g., "Push the train to Stacie," "Give Jennifer the pizza," etc.). Low-probability requests were written on individual index cards to cue the experimenter on the delivery of requests. Before each session the experimenter shuffled the cards with low-probability requests to vary the order of their delivery. However, the low-probability requests included friendship activities that were delivered at the beginning or end of the session in the appropriate context.

Before starting to play, the target child and the peer were told "Stay in your center and play with your friend. Now, go and play." No instructions were given to the generality peer assigned in the same center in order that she/he would be able to play with either the target, peer, or by herself/himself. After giving the general instructions, the experimenter delivered a low-probability request to the target child. If the target child

performed the request within 5-s, the experimenter provided verbal and gestural praise. If the target child did not perform the request, the experimenter waited approximately 75 -s, an amount of time that was based upon the normative data and previous studies (Davis \& Reichle, 1996; Davis et al., 1994). After the 75-s, the experimenter delivered a 
new low-probability request. No consequence was provided for nonresponse to requests. The experimenter did not issue any specific prompts to interact; general prompts were issued when the child was off-task or engaged in stereotypic behaviors or disruptive behaviors (e.g. "Get busy," "play, stay in your center," etc.). After 10-min of play the children were verbally praised, and toys or stickers were given to the target child and the peer.

\section{High-Probability Request Sequences with Embedded Peer Modeling}

Once stable baseline responding was established the high-probability request sequence using embedded peer modeling was implemented. The target child, peer, and generality peer were assigned to an intervention center. Three intervention centers chosen for each target child were rotated throughout the sessions. The same eight low-probability requests as the previous low-probability request condition were used. High-probability requests consisted of the requests to perform play skills relevant to the play setting (e.g., "Cut the pizza," "Build an airport," etc), and the requests adapted from action songs (e.g., "Hands on your shoulder," "Move your eyebrows," etc.) (see Appendix H). The highprobability request sequences for each child were written on the index cards to cue the experimenter. Each card displayed 6 different high-probability requests written. The cards were shuffled every session so that the order of delivery was varied.

Before starting the intervention, the target child and peer were told, "We are going to play a fun game. You need to listen to me, and listen to your friend to play together. And do what I am asking you.” The high-probability request sequence was first delivered to the peer, and then the same high-probability request sequence was delivered to the target child. In effect, the target child observed how the peer responded to the requests, and how 
she was praised. Furthermore the peer initiated the target child responding to a social behavior. Table 3. 3 presents an example of the high-probability request sequence using embedded peer modeling.

\begin{tabular}{|c|c|c|c|}
\hline \multicolumn{4}{|c|}{ Delivery of high-probability request sequences to peer } \\
\hline Experimenter & Peer & Experimenter & Target \\
\hline $\begin{array}{l}\text { "Cut the } \\
\text { pizza"(High-P) }\end{array}$ & Cut the pizza & Praise & Observe \\
\hline $\begin{array}{l}\text { "Put the pizza on } \\
\text { the plate" (High-P) }\end{array}$ & $\begin{array}{l}\text { Put the pizza on the } \\
\text { plate }\end{array}$ & Praise & Observe \\
\hline $\begin{array}{l}\text { "Pretend to eat } \\
\text { pizza" (High-P) }\end{array}$ & Pretend to eat pizza & Praise & Observe \\
\hline $\begin{array}{l}\text { "Give(peer) the } \\
\text { pizza" }\end{array}$ & $\begin{array}{l}\text { Give the target child } \\
\text { the pizza }\end{array}$ & Praise & Receive the pizza \\
\hline (Low-P) & & & \\
\hline \multicolumn{4}{|c|}{ Delivery of high-probability request sequences to target child } \\
\hline Experimenter & Target child & Experimenter & Peer \\
\hline $\begin{array}{l}\text { "Cut the } \\
\text { pizza"(High-P) }\end{array}$ & Cut the pizza & Praise & Observe \\
\hline $\begin{array}{l}\text { "Put the pizza on } \\
\text { the plate" (High-P) }\end{array}$ & $\begin{array}{l}\text { Put the pizza on the } \\
\text { plate }\end{array}$ & Praise & Observe \\
\hline $\begin{array}{l}\text { "Pretend to eat } \\
\text { pizza" (High-P) }\end{array}$ & Pretend to eat pizza & Praise & Observe \\
\hline $\begin{array}{l}\text { "Give( peer) the } \\
\text { pizza" } \\
\text { (Low-P) }\end{array}$ & $\begin{array}{l}\text { Give the peer } \\
\text { the pizza }\end{array}$ & Praise & Receive the pizza \\
\hline
\end{tabular}

Table 3.3 Example of a high-probability request sequence using embedded peer modeling 
The high-probability request sequence included (a) rapid-paced delivery of three high-probability requests (i.e., within 5-s of each other); (b) delivery of verbal or gestural praise (e.g., tickling, patting, thumbs up, etc.); and (c) delivery of the low- probability request within 5-s reinforcement for performing the previous high-probability request.

After issuing the high-probability request, if the child did not perform the request, a different high-probability request was delivered 5-s after the delivery of the previous request. The experimenter continued to deliver high-probability requests until three consecutive responses were obtained. The low-probability request was delivered immediately (within 5-s) after reinforcement for performing the last high-probability request. If the child did not respond to the low-probability request, the experimenter issued the next high-probability request sequence 5 -s after the delivery of the previous request. If the children did not continue the interactive play after successful performing the high-probability request sequence, the experimenter issued the next high-probability request sequence. After 10-min of play the experimenter provided verbal praise, gave the children a sticker or a small toy and asked them to give it each other while saying "good job."

Low-Probability Requests Alone

During this condition, the high-probability request sequence using embedded peer modeling was withdrawn and remained the same as the previous low-probability request procedure. This condition was provided to monitor whether the child's responding to the low-probability requests would be maintained after removal of the intervention. 


\section{Maintenance}

The setting and context of play remained the same as in the baseline phase. Children were told to play with the toys and their peers without the low-probability requests. This condition was provided to assess the extent to which the increased social interactions were maintained without the prompts.

\section{Generality}

Generality probes were conducted in the nontraining setting during center time. Procedures were identical to baseline procedures, however, no stickers or toys were given to the children. The target child, peer, and generality peer were assigned to the generality setting. The target child and his peer were told, "Stay in your center and play with your friend. Now go and play.” During play, no prompts were provided except for general prompts given when the children were off-task or engaged in stereotypic behaviors or disruptive behaviors. After 10-min of play the children were verbally praised for doing a good job and were told that they could stay or change their center.

\section{Social Validity}

Social validity involves assessing the acceptability or viability of the goals, procedures and outcomes to those who would be the most influenced by the interventions (Fawcett, 1991; Schwartz \& Baer, 1991). According to Schwartz and Baer (1991), it is recommended that social validity be a standard part of any intervention, that those assessments be conducted throughout the intervention, and that all relevant consumers be included. The relevant consumers in this study were the parents of the target children and professionals in early childhood special education including the target children's teachers. 
For this study, these consumers were asked to provide information regarding the social importance of the intervention goals, procedures, and outcomes. Social validity forms and instructions are located in Appendix E.

\section{Intervention Goals}

The social validity of the intervention goals was addressed by gathering information from three parents of the children participating in the study, and three early childhood special education teachers at the school. Parents and teacher were asked to fill out a questionnaire that asked about their goals for their children in the social interaction domain. In addition, the questions involved asking the parents and the teacher about the types of toys the children played with at home. The lead teacher and the assistants in the targeted classroom were included in the planning process of how the procedures would be implemented and which play areas and requests would be chosen for intervention.

Another questionnaire involved asking the parents and the teachers at school about the research goals and research questions. They were asked whether they thought each research question was valid and useful (See Appendix D).

\section{Intervention Procedures}

In order to determine the social acceptability and usability of the intervention procedures the experimenter gathered information from 20 professionals in early childhood special education. The teachers were asked to read a description of highprobability request sequence using embedded peer modeling.

The professionals were asked to view three unidentified 2 minute segments of videotape depicting the target children during baseline, low-probability request intervention, and high-probability request sequence using embedded peer modeling. Next, 
the professionals were asked whether they thought the intervention would be easy to use during the daily class routine, and whether they would use the intervention in their classroom when considered both time and effort necessary for the intervention.

\section{Intervention Outcomes}

The same professionals in early childhood special education above were asked to complete a checklist which included targeted skills by intervention in this research after viewing the videotape. The experimental phases were randomly placed. The teachers were asked to view one videotaped segment and then to complete a checklist. The same procedures were repeated for three experimental phases per child. Next, the teachers were asked to answer follow-up questions regarding whether they thought this intervention would be effective to increase social interactions between children with autism and typically developing peers. 


\section{CHPATER 4}

\section{RESULTS}

The results of this study are presented in this chapter. The chapter begins with a report of the procedures implemented to ensure the believability of the data including measures of procedural integrity for experimental procedures and experimenter prompts. Interobserver agreement was calculated for the procedural integrity checklist. Accuracy measures were conducted for delivery of the low-probability requests and the highprobability request sequences, responses to high-probability requests, and experimenter prompts, as well as for the dependent variables.

Summaries of individual children's data across all conditions are presented for the dependent variables of compliant responding to low-probability requests, social initiations and responses. Results for children's compliant responding to low-probability requests include the percent correct responses to low-probability requests during the initial low-probability requests alone, the high-probability request sequence with embedded peer modeling, and the low-probability request condition. Data on social initiations and responses include the number of intervals of observed social initiations and responses for each child during all experimental conditions and generality probes. 
Additional data on other behaviors such as disruptive behaviors negative interactions, and self-stimulating behaviors were obtained and presented. In addition, social validity results from parents and the professionals in early childhood special education are provided.

\section{Procedural Integrity}

Procedural integrity data were gathered to ensure the fidelity of the implementation of experimental procedures and experimenter prompts. The data were collected using procedural integrity checklists to record observed experimental procedural steps. Data were collected using event recording to examine the procedure of each delivery of the low-probability requests and high-probability request sequence. A partial-interval recording scheme was used for experimenter prompts. Accuracy measures were conducted for procedural integrity checklists, the delivery of the low-probability requests and the high-probability requests checklists, as well as experimenter prompts.

\section{Procedural Integrity Checklists}

To help ensure that experimental procedures were conducted consistently and as described, data were collected using procedural integrity checklists specifically designed to address each experimental and generality condition (see Appendix C). The second and third observer completed procedural integrity checklists as they observed the experimenter during the intervention sessions across all conditions. Accuracy measures for procedural integrity checklists were conducted for approximately $20 \%$ of the experimental sessions and approximately $30 \%$ of the generality sessions. Table 4.1 displays a summary of procedural integrity checklist measures and IOA for procedural integrity checklists was $100 \%$ of all participants during all conditions. The following describes the procedural integrity for each child overall conditions. 


\begin{tabular}{|c|c|c|c|c|c|c|c|c|c|c|}
\hline & \multicolumn{2}{|c|}{ Baseline } & \multicolumn{2}{|c|}{ Low-P } & \multicolumn{2}{|c|}{ High-P } & \multicolumn{2}{|c|}{ Low-P } & \multicolumn{2}{|c|}{ Maintenance } \\
\hline & $\mathrm{I}$ & $\mathrm{G}$ & $\mathrm{I}$ & $\mathrm{G}$ & $\mathrm{I}$ & $\mathrm{G}$ & $\mathrm{I}$ & $\mathrm{G}$ & $\mathrm{I}$ & $\mathrm{G}$ \\
\hline \multicolumn{11}{|l|}{ Eric } \\
\hline \# of sessions & 6 & 2 & 10 & 2 & 13 & 5 & 8 & 4 & 6 & 2 \\
\hline \# of checklist completed & 2 & 1 & 2 & 1 & 3 & 1 & 2 & 1 & 2 & 1 \\
\hline$\%$ of sessions checklist completed & 30 & 50 & 20 & 50 & 23 & 20 & 25 & 25 & 33 & 50 \\
\hline$\%$ of steps completed correctly & 100 & 100 & 94 & 100 & 100 & 100 & 100 & 100 & 100 & 100 \\
\hline \# of checklists for IOA & 2 & 1 & 2 & 1 & 3 & 1 & 2 & 1 & 2 & 1 \\
\hline$\%$ of IOA & 100 & 100 & 100 & 100 & 100 & 100 & 100 & 100 & 100 & 100 \\
\hline \multicolumn{11}{|l|}{ Paul } \\
\hline \# of sessions & 10 & 3 & 11 & 3 & 18 & 6 & 11 & 3 & 4 & 2 \\
\hline \# of checklists completed & 3 & 1 & 3 & 1 & 5 & 2 & 3 & 1 & 1 & 1 \\
\hline$\%$ of sessions checklist completed & 30 & 33 & 27 & 33 & 28 & 33 & 27 & 33 & 25 & 50 \\
\hline \# of steps completed correctly & 100 & 100 & 100 & 100 & 100 & 100 & 100 & 100 & 100 & 100 \\
\hline \# of checklist for IOA & 3 & 1 & 3 & 1 & 5 & 2 & 3 & 1 & 1 & 1 \\
\hline$\%$ of IOA & 100 & 100 & 100 & 100 & 100 & 100 & 100 & 100 & 100 & 100 \\
\hline \multicolumn{11}{|l|}{ Chris } \\
\hline \# of sessions & 6 & 4 & 10 & 3 & 19 & 5 & 7 & 4 & 1 & - \\
\hline \# of checklists completed & 4 & 2 & 3 & 1 & 4 & 1 & 2 & 1 & 1 & - \\
\hline$\%$ of sessions checklist completed & 25 & 50 & 30 & 33 & 21 & 20 & 29 & 25 & 100 & - \\
\hline$\%$ of steps completed correctly & 100 & 100 & 100 & 100 & 100 & 100 & 100 & 100 & 100 & - \\
\hline \# of checklists for IOA & 4 & 2 & 3 & 1 & 4 & 1 & 2 & 1 & 1 & - \\
\hline$\%$ of IOA & 100 & 100 & 100 & 100 & 100 & 100 & 100 & 100 & 100 & - \\
\hline
\end{tabular}

Table 4.1: Summary of procedural integrity checklists completed and interobserver agreement (IOA) calculated for procedural integrity checklists for participants across conditions in the intervention (I) and generality setting $(\mathrm{G})$. 
Eric

Procedural integrity checklists were completed for at least $20 \%$ for all conditions for Eric. The number of steps completed correctly ranged from 94 to $100 \%$ across all conditions. IOA which was measured for the entire procedural integrity checklist for experimental and generality sessions was $100 \%$.

Paul

For Paul, procedural integrity checklists were completed for at least $25 \%$ of all sessions across all conditions. The number of steps completed correctly was $100 \%$ for all conditions. IOA which was measured for the entire procedural integrity checklist for experimental and generality sessions was $100 \%$.

\section{Chris}

The observers completed procedural integrity checklists for at least $20 \%$ of all sessions across all conditions. The number of steps completed correctly was $100 \%$ for all conditions. IOA which was measured for the entire procedural integrity checklist for experimental and generality sessions was $100 \%$.

\section{Delivery of Low-Probability and High-Probability Requests}

The summary of the delivery of the low-probability and the high-probability request sequence is reported for each child during the low-probability requests alone and high-probability request sequences with peer modeling. The data include the number of low-probability and high-probability requests delivered, percentage of praise delivered for the correct responses to requests, inter-prompt time between the high-probability requests and between the high-probability and the low-probability request. Accuracy measures were conducted for delivery of the low-probability and the high-probability 
requests. Table 4.2 provides a summary of the mean number and range of the lowprobability and the high-probability requests delivered, the mean percentage of praise delivered for correct responses to the requests, and the accuracy measures for the delivery of the low-probability and high-probability requests.

\section{Eric and Stacie}

During baseline, no low-probability requests were delivered as the children were observed. During 10 sessions of low-probability requests alone, eight low-probability requests were delivered each session. The percentage of praise delivered for correct responding to the low-probability requests ranged from 0 to $100 \%$ with a mean of $90 \%$. In the first low-probability request session, Eric responded to one low-probability request out of eight low-probability requests, however, the experimenter did not deliver the praise for his correct response. Accuracy measures were conducted for $20 \%$ of the sessions and resulted $100 \%$.

During high-probability requests sequences with peer modeling, 13 sessions were conducted. The number of the high-probability requests delivered for Eric ranged from 22 to 26 with a mean of 24.31. Praise was correctly delivered for correct responding to high-probability requests $100 \%$ of the time. Inter-prompt times (IPT) between the highprobability requests ranged from 1 to 5 -s with a mean of 1.5 -s. The mean of the lowprobability requests delivered for Eric was 7.8 with a range from 7 to 8 . The percentage of praise delivered for the correct responding to the low-probability requests was $100 \%$. Inter-prompt times (IPT) between the last high-probability request and the lowprobability request ranged from 1 to 5 -s with a mean of 1.7-s. Accuracy measures conducted for $20 \%$ of the sessions and the results were $100 \%$. 


\begin{tabular}{|c|c|c|c|c|c|c|}
\hline & Eric & Paul & Chris & Stacie & Jennifer & Hillary \\
\hline \multicolumn{7}{|l|}{ Low-P } \\
\hline \# of sessions & 10 & 11 & 10 & - & - & - \\
\hline \# of low-p delivered & 8 & 8 & 8 & - & - & - \\
\hline$\%$ of praise for correct & 90 & 100 & 100 & & & \\
\hline response to low-p & $(0-100)$ & - & - & - & - & - \\
\hline$\%$ of Accuracy measured & 20 & 27 & 30 & - & - & - \\
\hline$\%$ of Accuracy & 100 & 100 & 100 & - & - & - \\
\hline \multirow{2}{*}{$\begin{array}{l}\text { High-P } \\
\text { \# of sessions } \\
\text { \# of high-p delivered }\end{array}$} & 13 & 18 & 19 & 13 & 18 & 19 \\
\hline & $\begin{array}{c}24.31 \\
(22-26)\end{array}$ & $\begin{array}{c}24.06 \\
(24-25)\end{array}$ & $\begin{array}{c}25.73 \\
(24-31)\end{array}$ & $\begin{array}{c}24.85 \\
(24-30)\end{array}$ & $\begin{array}{c}24 \\
-\end{array}$ & $\begin{array}{l}24 \\
-\end{array}$ \\
\hline \multirow{2}{*}{$\begin{array}{l}\% \text { of praise for correct } \\
\text { response to high-p } \\
\text { IPT }\end{array}$} & 100 & 100 & 100 & 100 & 100 & 100 \\
\hline & $\begin{array}{l}1.48 \\
(1-5)\end{array}$ & $\begin{array}{l}1.38 \\
(1-3)\end{array}$ & $\begin{array}{l}1.30 \\
(1-3)\end{array}$ & $\begin{array}{l}1.52 \\
(1-5)\end{array}$ & $\begin{array}{l}1.33 \\
(1-3)\end{array}$ & $\begin{array}{l}1.17 \\
(1-3)\end{array}$ \\
\hline \# of low-p delivered & $\begin{array}{c}7.8 \\
(7-8)\end{array}$ & $\begin{array}{l}8 \\
-\end{array}$ & $\begin{array}{c}7.9 \\
(7-8)\end{array}$ & $\begin{array}{c}7.8 \\
(7-8)\end{array}$ & $\begin{array}{l}8 \\
-\end{array}$ & $\begin{array}{l}8 \\
-\end{array}$ \\
\hline \multirow{2}{*}{$\begin{array}{l}\% \text { of praise for correct } \\
\text { response to low-p } \\
\text { IPT }\end{array}$} & 100 & 100 & 100 & 100 & 100 & 100 \\
\hline & $\begin{array}{l}1.73 \\
(1-5)\end{array}$ & $\begin{array}{l}1.46 \\
(1-3)\end{array}$ & $\begin{array}{l}1.36 \\
(1-3)\end{array}$ & $\begin{array}{l}1.83 \\
(1-5)\end{array}$ & $\begin{array}{l}1.46 \\
(1-3)\end{array}$ & $\begin{array}{l}1.31 \\
(1-3)\end{array}$ \\
\hline \multirow{2}{*}{$\begin{array}{l}\% \text { of Accuracy measured } \\
\% \text { of Accuracy }\end{array}$} & 23 & 28 & 21 & 23 & 28 & 21 \\
\hline & 100 & 100 & 100 & 100 & 100 & 100 \\
\hline \multirow{5}{*}{$\begin{array}{l}\text { Low-P } \\
\text { \# of sessions } \\
\text { \# of low-p delivered } \\
\% \text { of praises for correct } \\
\text { responses to low-p } \\
\% \text { of Accuracy measured } \\
\% \text { of Accuracy }\end{array}$} & 8 & 11 & 7 & - & - & - \\
\hline & 8 & 8 & 8 & - & - & - \\
\hline & 100 & 100 & 100 & - & - & - \\
\hline & 25 & 27 & 29 & - & - & - \\
\hline & 100 & 100 & 100 & - & - & - \\
\hline
\end{tabular}

Table 4.2: The mean percentage and range of delivery of the low-p and the high-p requests and accuracy measures for delivery of the low-p and high-p requests. (IPT = Inter-prompt time) 
For Eric's peer, Stacie, the mean number of the high-probability requests delivered was 24.85 with a range from 24 to 30 . The praise provided for correct responses to the high-probability requests was $100 \%$. IPT between the high-probability requests ranged from 1 to 5 -s with a mean of 1.5 -s. The mean number of the lowprobability requests delivered for Stacie was 7.8 with a range from 7 to 8 . Praise was correctly delivered for correct responding to low-probability requests $100 \%$ of the time. IPT between the last high-probability request and the low-probability request ranged from 1 to 5 -s with a mean of 1.8-s. Accuracy measures for the delivery of highprobability and low-probability requests were conducted for $23 \%$ of the sessions during this condition. Accuracy resulted in $100 \%$.

Over eight sessions of the low-probability requests alone condition, eight lowprobability requests were delivered each session and the praise was correctly delivered for the correct responses to the requests $100 \%$ of the time. Accuracy measures for the low-probability requests conducted for $23 \%$ of the sessions and resulted in $100 \%$.

\section{Paul and Jennifer}

During the baseline condition, no low-probability requests were delivered as the children were observed. During 11 sessions of low-probability requests alone, eight lowprobability requests were delivered during each session, and correct delivery of praise statements occurred over $100 \%$ of correct responses to low-probability requests. Twenty seven percent of the sessions were measured for accuracy checks. Accuracy resulted in $100 \%$.

Over 18 sessions of high-probability requests sequences with peer modeling, the high-probability requests for Paul were delivered with a mean of 24.06 and a range from 
24 to 25 . The experimenter delivered praise for the correct responses to the highprobability requests $100 \%$ of available opportunities. Inter-prompt times (IPT) between the high-probability requests ranged from 1 to 3 -s with a mean of 1.4-s. The mean number of the low-probability requests delivered for Paul was 8 . The percentage of praise statements delivered for correct responding to low-probability requests was $100 \%$. Interprompt times (IPT) between the last high-probability request and the low-probability request ranged from 1 to 3 -s with a mean of 1.5-s. Accuracy measures were conducted for $28 \%$ of the sessions and resulted in $100 \%$.

For Jennifer, Paul's peer, the mean number of the high-probability requests delivered was 24 and the praise provided for correct responding to each high-probability request was $100 \%$. IPT between the high-probability requests ranged from 1 to 3 -s with a mean of 1.3-s. The mean number of low-probability requests delivered for Jennifer was 8. Correct delivery of praise statements occurred during $100 \%$ of correct responding to low-probability requests. IPT between the last high-probability request and the lowprobability request ranged from 1 to 3 -s with a mean of 1.5-s. Accuracy measures for the delivery of the high-probability and low-probability requests were conducted for $28 \%$ of the sessions during this condition. Accuracy measures resulted in $100 \%$.

During 11 sessions of low-probability requests alone, the number of lowprobability requests delivered during each session was eight. Praise was correctly delivered for correct responding to low-probability requests $100 \%$ of the time.

\section{Chris and Hilary}

During the baseline condition, no low-probability requests were delivered as the children were observed. Over 10 sessions of the low-probability requests alone condition, 
the number of low-probability requests delivered during each session was eight. Praise statements, delivered by the experimenter for correct responses was $100 \%$. Accuracy measures were conducted for $30 \%$ of the sessions, and accuracy on delivery of lowprobability resulted in $100 \%$.

During 19 sessions in high-probability request sequences with embedded peer modeling, the number of the high-probability requests delivered for Chris ranged from 24 to 31 with a mean of 25.73 . The experimenter's praise delivered for the correct responses to the high-probability requests was $100 \%$. IPT between the high-probability requests ranged from 1 to 3 -s with a mean of 1.3-s. The mean number of the low-probability requests delivered for Chris was 7.9 with a range from 7 to 8 . The percentage of praises delivered for the correct responding to the low-probability requests was $100 \%$. IPT between the last high-probability request and the low-probability request ranged from 1 to 3 -s with a mean of 1.3 -s. Accuracy measures were conducted for $21 \%$ of the sessions and were $100 \%$.

For Hilary, Chris's peer, the mean number of the high-probability requests delivered was 24 . The praise provided for the correct responses to the high-probability requests was $100 \%$. IPT between the high-probability requests ranged from 1 to 3 -s with a mean of 1.2-s. The mean number of low-probability requests delivered for Hilary was 8 . Praise for correct responses to the low-probability requests was delivered at $100 \%$. IPT between the last high-probability request and the low-probability request ranged from 1 to 3-s with a mean of 1.3-s. Accuracy measures for the delivery of the high-probability and the low-probability requests were conducted for $21 \%$ of the sessions during this condition. Accuracy measures resulted in $100 \%$ observed compliance to the procedure. 
During low-probability requests alone, seven sessions were conducted. Eight lowprobability requests were delivered during each session, and praise for correct responses to low-probability requests was delivered at $100 \%$. Accuracy measures were conducted for $29 \%$ of the sessions, and accuracy measures on delivery of low-probability requests resulted in $100 \%$.

\section{Experimenter General Prompts}

The summary of the mean number of intervals and range of experimenter prompts, as well as the percentage of accuracy measures for experimenter prompts follows. General prompts were delivered for all conditions by the experimenter to the target children, peers, and generality peers. The experimenter prompts consisted of general prompts to the children to direct the children's inappropriate behaviors. Examples of experimenter general prompts were "Get busy," "Stay in your center," "Don't hit your friend," and "Hands down." Low levels of experimenter prompts were delivered during both intervention and generality for all conditions except when the children engaged in disruptive behaviors. The following information summarizes the mean number of intervals and range of experimenter prompts for each child during both intervention and generality across all conditions. Table 4.3 provides a summary of the mean number of intervals and range of experimenter prompts data during all conditions. 


\begin{tabular}{|c|c|c|c|c|c|c|c|c|c|c|}
\hline \multirow[t]{3}{*}{ Target } & \multirow{2}{*}{\multicolumn{2}{|c|}{ BL }} & \multirow{2}{*}{\multicolumn{2}{|c|}{ Low-P }} & \multirow{2}{*}{\multicolumn{2}{|c|}{ High-P }} & \multirow{2}{*}{\multicolumn{2}{|c|}{ Low-P }} & \multirow{2}{*}{\multicolumn{2}{|c|}{ Maint. }} \\
\hline & & & & & & & & & & \\
\hline & I & $\mathrm{G}$ & I & $\mathrm{G}$ & I & $\mathrm{G}$ & I & $\mathrm{G}$ & I & $\mathrm{G}$ \\
\hline \multicolumn{11}{|l|}{ Eric } \\
\hline \# of sessions & 6 & 2 & 10 & 2 & 13 & 5 & 8 & 4 & 6 & 2 \\
\hline Mean & 4.33 & 4.50 & 4.40 & 3.00 & 1.54 & 1.80 & 1.13 & 1.75 & 1.33 & 1.50 \\
\hline \multirow[t]{3}{*}{ Range } & $2-7$ & $4-5$ & $0-7$ & $2-4$ & $0-5$ & $0-3$ & $0-2$ & $1-2$ & $0-3$ & $1-2$ \\
\hline & \multicolumn{2}{|c|}{$\mathrm{BL}$} & \multicolumn{2}{|c|}{ Low-P } & \multicolumn{2}{|c|}{ High-P } & \multicolumn{2}{|c|}{ Low-P } & \multicolumn{2}{|c|}{ Maint. } \\
\hline & I & $\mathrm{G}$ & I & $\mathrm{G}$ & I & $\mathrm{G}$ & I & $\mathrm{G}$ & I & $\mathrm{G}$ \\
\hline \multicolumn{11}{|l|}{ Paul } \\
\hline Mean & 5.10 & 6.67 & 3.45 & 4.00 & 1.61 & 2.83 & 2.18 & 2.67 & 3.50 & 2.50 \\
\hline \multirow[t]{3}{*}{ Range } & $2-15$ & $2-4$ & $1-7$ & $2-6$ & $0-3$ & $2-4$ & $0-5$ & $2-4$ & $2-5$ & $2-3$ \\
\hline & \multicolumn{2}{|c|}{$\mathrm{BL}$} & \multicolumn{2}{|c|}{ Low-P } & \multicolumn{2}{|c|}{ High-P } & \multicolumn{2}{|c|}{ Low-P } & \multicolumn{2}{|c|}{ Maint } \\
\hline & I & G & I & G & I & G & I & $\mathrm{G}$ & I & G \\
\hline \multicolumn{11}{|l|}{ Chris } \\
\hline \# of ses & 16 & 4 & 10 & 3 & 19 & 5 & 7 & 4 & 1 & - \\
\hline Mean & 5.00 & 2.50 & 5.80 & 4.33 & 2.16 & 1.80 & 2.57 & 2.00 & 3.00 & - \\
\hline Range & $2-13$ & $1-4$ & $2-11$ & $3-5$ & $0-4$ & $1-3$ & $0-5$ & $0-4$ & 3 & - \\
\hline \multicolumn{11}{|l|}{ Peers } \\
\hline & \multicolumn{2}{|c|}{ BL } & \multicolumn{2}{|c|}{ Low-P } & \multicolumn{2}{|c|}{ High-P } & \multicolumn{2}{|c|}{ Low-P } & \multicolumn{2}{|c|}{ Maint. } \\
\hline & I & $\bar{G}$ & I & $\bar{G}$ & I & G & I & G & I & $\mathrm{G}$ \\
\hline \multicolumn{5}{|l|}{ Stacie } & 13 & 5 & 8 & 4 & 6 & 2 \\
\hline Mean & 1.00 & 1.50 & 0.40 & 0.50 & 0.38 & 0.00 & 0.38 & 0.75 & 0.67 & 1.00 \\
\hline \multirow[t]{3}{*}{ Range } & $0-4$ & $1-2$ & $0-1$ & $0-1$ & $0-2$ & - & $0-1$ & $0-2$ & $0-2$ & - \\
\hline & & & & $\mathrm{N}-\mathrm{P}$ & & h-P & & $v-P$ & & \\
\hline & $\mathrm{I}$ & G & $\mathrm{I}$ & G & $\mathrm{I}$ & G & $\mathrm{I}$ & G & $\mathrm{I}$ & $\mathrm{G}$ \\
\hline $\begin{array}{l}\text { Jennifer } \\
\text { \# of sess }\end{array}$ & 10 & 3 & 11 & 3 & 18 & 6 & 11 & 3 & 4 & 2 \\
\hline Mean & 2.30 & 1.33 & 1.82 & 3.00 & 0.89 & 0.67 & 0.45 & 0.00 & 0.25 & 0.00 \\
\hline Range & $0-7$ & $1-2$ & $0-6$ & $1-6$ & $0-2$ & $0-2$ & $0-2$ & - & $0-1$ & - \\
\hline
\end{tabular}

Continued

Table 4.3: The mean number of intervals and range of general prompts for participants during the intervention (I) and generality setting $(\mathrm{G})$. 
Table 4.3 (continued)

\section{Hillary}

\begin{tabular}{ccccccccccc}
\multicolumn{2}{c}{ BL } & \multicolumn{2}{c}{ Low-P } & \multicolumn{2}{c}{ High-P } & \multicolumn{2}{c}{ Low-P } & \multicolumn{2}{c}{ Maint } \\
\hline I & G & I & G & I & G & I & G & I & G \\
\hline
\end{tabular}

\# of sessions

Mean

$\begin{array}{lll}16 & 4 & 10\end{array}$

Range

$\begin{array}{llll}0.81 & 0.75 & 0.40 & 0.00\end{array}$

$19 \quad 5$

$0.58 \quad 0.60$

7

$0-2 \quad 0-1 \quad 0-2 \quad-$

$0-3 \quad 0-1$

\section{Generality Peers}

\begin{tabular}{cccccccccc}
\multicolumn{2}{c}{ BL } & \multicolumn{2}{c}{ Low-P } & \multicolumn{2}{c}{ High-P } & \multicolumn{2}{c}{ Low-P } & \multicolumn{2}{c}{ Maint. } \\
\hline I & G & I & G & I & G & I & G & I & G \\
\hline
\end{tabular}

Megan

$\begin{array}{lcccccccccc}\text { \# of sessions } & 3 & 2 & 6 & 2 & 13 & 4 & 3 & 3 & 5 & 2 \\ \text { Mean } & 0.00 & 0.50 & 0.00 & 1.50 & 0.00 & 0.25 & 0.00 & 0.00 & 0.00 & 0.00\end{array}$

Range

$\begin{array}{cccccccccc}- & 0-1 & - & 1-2 & - & 0-1 & - & - & - & -\end{array}$

Randy

\begin{tabular}{llllllllll}
\hline \multicolumn{2}{c}{ BL } & & \multicolumn{2}{c}{ Low-P } & \multicolumn{2}{c}{ High-P } & \multicolumn{2}{c}{ Low-P } & \multicolumn{2}{c}{ Maint. } \\
\hline I & G & I & G & I & G & I & G & I & G \\
\hline
\end{tabular}

\# of sessions

Mean

$\begin{array}{cccccccccc}9 & 3 & 11 & 3 & 18 & 5 & 11 & 3 & 3 & 2 \\ 0.11 & 0.33 & 0.18 & 0.00 & 0.06 & 0.00 & 0.09 & 0.00 & 0.33 & 0.00\end{array}$

Range

$0-1 \quad 0-1 \quad 0-2 \quad-\quad 0-1 \quad-\quad 0-1 \quad-\quad 0-1 \quad$ -

\begin{tabular}{cccccccccc}
\hline \multicolumn{2}{c}{ BL } & & \multicolumn{2}{c}{ Low-P } & \multicolumn{2}{c}{ High-P } & \multicolumn{2}{c}{ Low-P } & \multicolumn{2}{c}{ Maint } \\
\hline I & G & I & G & I & G & I & G & I & G \\
\hline
\end{tabular}

Tyler

\begin{tabular}{lcccccccccc} 
\# of sessions & 16 & 4 & 10 & 3 & 17 & 5 & 7 & 4 & - & - \\
Mean & 0.81 & 1.25 & 0.40 & 0.00 & 0.18 & 0.40 & 0.29 & 0.50 & - & - \\
Range & $0-5$ & $0-2$ & $0-1$ & - & $0-2$ & $0-1$ & $0-1$ & $0-1$ & - & - \\
\hline
\end{tabular}




\section{Eric, Stacie, and Megan}

Baseline. During baseline for intervention and generality, the range of intervals of general prompts for Eric was 2 to 7 with a mean of 4.33, and 4 to 5 with a mean of 4.5, respectively. The mean number of intervals of the general prompts for Eric's peer, Stacie, in the intervention and generality setting, was 1 with a range from 0 to 4 , and 1.5 with a range from 1 to 2 . The mean number of intervals of the prompts for Eric's generality peer, Megan in the intervention and generality setting was 0 , and 0.5 with a range from 0 to 1 , respectively.

Low-probability requests alone. The number of intervals of general prompts for Eric in intervention and generality setting ranged from 0 to 7 with a mean number of 4.4, and ranged from 2 to 4 with a mean of 3.0, respectively. The mean number of intervals of general prompts for Stacie for intervention and generality was 0.4 (range from 0 to 1 ) and 0.5 (range from 0 to 1 ), respectively. The mean number of intervals of general prompts for Megan in intervention and generality setting was 0 , and 1.5 with a range from 1 to 2 , respectively. The general prompts for Eric, Stacie, and Megan remained at the same levels as during baseline.

High-probability request sequences with embedded peer modeling. The mean number of intervals of general prompts for Eric in the intervention setting and generality setting decreased to 1.54 with a range from 0 to 5 , and 1.80 with a range from 0 to 3 , respectively. The number of intervals of general prompts for Stacie in intervention ranged from 0 to 2 with a mean of 0.38 , and no prompts were provided in the generality setting. No general prompts were given to Megan in the intervention setting. The mean number 
of intervals of general prompts in the generality setting for Megan was 0.25 with a range from 0 to 1 . The general prompts for Stacie and Megan maintained at the same levels as during the low-probability request condition.

Low-probability requests alone. The number of intervals of general prompts in intervention setting for Eric ranged from 1 to 2 with a mean of 1.13, and in the generality setting ranged from 1 to 2 with a mean of 1.75 . For Stacie, the mean number of intervals of general prompts for the intervention and generality setting was 0.38 with a range from 0 to 1 , and 0.75 with a range from 0 to 2 , respectively. No general prompts were given to Megan in the intervention and generality setting. The general prompts for Eric, Stacie, and Megan remained at the same levels as the high-probability request sequences using embedded peer modeling.

Maintenance. The mean number of intervals of general prompts in the intervention setting for Eric was 1.33 with a range from 0 to 3; the mean of this same measure in the generality setting was 1.5 with a range from 1 to 2 . The number of intervals of general prompts for Stacie in the intervention setting ranged from 0 to 2 with a mean of 0.67 . The mean number of general prompts for Stacie was 1. No general prompts were delivered to Megan. The general prompts for Eric, Stacie, and Megan maintained the same levels as the previous low-probability request condition. Paul, Jennifer, and Randy

Baseline. The mean number of intervals of general prompts for Paul in the intervention and generality setting was 5.1 with a range from 2 to 15 , and 6.67 with a range from 2 to 4 , respectively. The number of intervals of general prompts for Jennifer, Paul's peer, in the intervention setting ranged from 0 to 7 with a mean of 2.3, and the 
general prompts in the generality setting ranged from 1 to 2 with mean of 1.33 . For Paul's generality peer, Randy, the mean number of intervals of general prompts in the intervention and generality setting were 0.11 with a range from 0 to 1 , and 0.33 with a range from 0 to 1 .

Low-probability requests alone. For Paul, the mean number of intervals of general prompts during intervention was 3.45 with a range from 1 to 7 ; the mean number of intervals of general prompts in the generality setting was 4 with a range from 2 to 6 . Levels of general prompts for Paul in the intervention and generality setting during this condition decreased somewhat. For Jennifer, the intervals of general prompts in the intervention setting ranged from 0 to 6 with a mean of 1.82 . The mean number of intervals of general prompts in the generality setting was 3 with a range from 1 to 6 . The general prompts for her in the intervention setting maintained the same levels, but the general prompts in the generality setting increased slightly to 3 . For Randy, the mean of general prompts in the intervention setting was 0.18 with a range from 0 to 2 , however, no general prompts were provided in the generality setting. The general prompts to Randy remained the same as during the baseline condition.

High-probability request sequences with embedded peer modeling. The mean number of intervals of general prompts for Paul in the intervention and generality setting decreased to 1.61 with a range from 0 to 3 , to 2.83 with a range from 2 to 4 , respectively. The number of intervals of general prompts for Jennifer in the intervention setting ranged from 0 to 2 , with a mean of 0.89 ; the mean number of intervals of general prompts in the generality setting was 0.67 with a range from 0 to 2 . The mean number of intervals of 
general prompts for Randy in the intervention setting was 0.06 with a range from 0 to 1 ; no general prompts in the generality setting were provided to Randy. Levels of general prompts for Jennifer and Randy remained low.

Low-probability requests alone. The number of intervals of general prompts in the intervention setting for Paul ranged from 0 to 5 with a mean of 2.18 , and in the generality setting ranged from 2 to 4 with a mean of 2.67 . The general prompts in the intervention setting increased slightly, but maintained low levels overall. For Jennifer, general prompts in the intervention setting remained with a low mean of 0.45 and a range from 0 to 2 . No general prompts were provided in the generality setting. For Randy, general prompts in the intervention setting remained low with a mean of 0.09 and a range from 0 to 1 . No general prompts were given to Randy in the generality setting.

Maintenance. For Paul, the mean number of intervals of general prompts in the intervention and generality setting was 3.5 with range from 2 to 5 , and 2.5 with a range from 2 to 3, respectively. The general prompts for Paul increased somewhat during the maintenance condition. For Jennifer, the number of intervals of general prompts in the intervention setting remained low with a mean of 0.25 and a range from 0 to 1 . No general prompts were provided in the generality setting. The number of intervals of general prompts for Randy in the intervention setting maintained the low levels with a mean of 0.33 and a range from 0 to 1 . No general prompts were provided in the generality setting.

Chris, Hilary, and Tyler

Baseline. For Chris, the mean number of intervals of general prompts in the intervention setting ranged from 2 to 13 with a mean of 5 . The number of intervals of 
general prompts in the generality setting ranged from 1 to 4 with a mean of 2.5. For Hilary, the mean number of intervals of the general prompts in the intervention and generality setting was 0.81 with a range from 0 to 2 , and 0.75 with a range from 0 to 1 . For Tyler, Chris's generality peer, the number of intervals of the general prompts in the intervention setting ranged from 0 to 5 with a mean of 0.81 ; the number of intervals of the general prompts in the generality setting ranged from 0 to 2 with a mean of 1.25 .

Low-probability requests alone. The mean number of intervals of general prompts for Chris in the intervention and generality setting were 5.8 with a range from 2 to 11 , and 4.33 with a range from 3 to 5 . The general prompts for Chris in the intervention setting remained the same, however, the general prompts slightly increased in the generality setting. For Hilary, levels of the general prompts in the intervention setting maintained the same as baseline, with a mean of 0.4 and a range from 0 to 2 . No general prompts were provided in the generality setting. The number of intervals of general prompts for Tyler remained low with a mean of 0.4 and range from 0 to 1 .

High-probability request sequences with embedded peer modeling. The mean number of intervals of general prompts for Chris in the intervention setting and generality setting decreased to 2.16 with a range from 0 to 4 , and 1.80 with a range from 1 to 3 , respectively. The number of intervals of general prompts for Hilary in the intervention and generality setting ranged from 0 to 3 with a mean of 0.58 , and ranged from 0 to 1 with a mean of 0.6. For Tyler, the mean number of intervals of general prompts was 0.18 with a range from 0 to 2 , and 0.4 with a range from 0 to 1 , respectively. The general prompts for Hilary and Tyler maintained the same levels as the low-probability requests condition. 
Low-probability requests alone. The intervals of general prompts in the intervention setting for Chris ranged from 0 to 5 with a mean of 2.57, and in the generality setting ranged from 0 to 4 with a mean of 2 . No general prompts were provided to Hilary. For Tyler, the mean number of intervals of general prompts in the intervention and the generality setting was 0.29 with a range from 0 to $1,0.5$ with a range from 0 to 1 . The general prompts for Chris, Hilary, and Tyler remained at the same levels as the previous condition.

\section{Accuracy Measures for Experimenter General Prompts}

Accuracy measures were conducted for at least $20 \%$ of all sessions across all conditions and settings for experimenter general prompts. The following is a summary of the percentage of accuracy for experimenter prompts delivered to participants for all conditions. Table 4.4 describes the mean percentage and range of accuracy for experimenter general prompts across all conditions.

Eric. The percentage of accuracy for experimenter general prompts both in the intervention and generality setting during baseline was $100 \%$. During low-probability requests, the mean percentage of accuracy in the intervention and generality setting was $99 \%, 100 \%$, respectively. For the high-probability request sequences with embedded peer modeling, the mean percentage of accuracy on experimenter general prompts in the intervention and generality setting was $99 \%, 98 \%$, respectively. During the lowprobability request condition, accuracy for experimenter general prompts both in the intervention and generality setting was calculated to be $100 \%$. Accuracy for the maintenance condition both in the intervention and generality setting was $100 \%$. 


\begin{tabular}{|c|c|c|c|c|c|c|c|c|c|c|}
\hline & \multicolumn{2}{|c|}{$\mathrm{BL}$} & \multicolumn{2}{|c|}{ Low-P } & \multicolumn{2}{|c|}{ High-P } & \multicolumn{2}{|c|}{ Low-P } & \multicolumn{2}{|c|}{ Maintenance } \\
\hline & I & G & I & $\mathrm{G}$ & I & G & I & G & I & G \\
\hline \multicolumn{11}{|l|}{ Eric } \\
\hline$\%$ of sessions & 30 & 50 & 20 & 50 & 23 & 20 & 25 & 25 & 33 & 50 \\
\hline Mean & 100 & 100 & 99 & 100 & 99 & 98 & 100 & 100 & 100 & 100 \\
\hline Range & - & - & - & - & - & - & - & - & - & - \\
\hline \multicolumn{11}{|l|}{ Paul } \\
\hline$\%$ of sessions & 30 & 33 & 27 & 33 & 28 & 33 & 27 & 33 & 25 & 50 \\
\hline Mean & 99 & 98 & 99.7 & 99 & 99.8 & 99.5 & 100 & 100 & 99 & 100 \\
\hline Range & $98-100$ & - & $99-100$ & - & $99-100$ & $99-100$ & - & - & - & - \\
\hline \multicolumn{11}{|l|}{ Chris } \\
\hline$\%$ of sessions & 25 & 50 & 30 & 30 & 21 & 20 & 29 & 25 & 100 & - \\
\hline Mean & 99.5 & 99.5 & 98.7 & 97 & 100 & 98 & 100 & 100 & 99 & - \\
\hline Range & $98-100$ & $99-100$ & $98-100$ & - & - & - & - & - & - & - \\
\hline
\end{tabular}

Table 4.4: Accuracy measures for experimenter general prompts for participants in the intervention (I) and generality setting (G). 
Paul. Accuracy measures for Paul in the intervention setting during baseline ranged from $98 \%$ to $100 \%$ with a mean of $99 \%$. The mean percentage of accuracy in the generality setting was $98 \%$. For the low-probability requests condition, the mean of accuracy in the intervention setting was $99.7 \%$ with a range from $99 \%$ to $100 \%$; the mean percentage of accuracy in the generality setting was $99 \%$. During the high-probability request sequences with embedded peer modeling, accuracy in the intervention setting ranged from $99 \%$ to $100 \%$ with a mean of $99.8 \%$; the accuracy in the generality setting ranged from $99 \%$ to $100 \%$ with a mean of $99.5 \%$. For low-probability requests alone, accuracy for experimenter general prompts both in the intervention and the generality setting was $100 \%$. During the maintenance condition, the mean of accuracy in the intervention setting was $99 \%$ while the mean of accuracy in the generality setting was $100 \%$.

Chris. During baseline, accuracy on experimenter general prompts for Chris in the intervention setting ranged from $98 \%$ to $100 \%$ with a mean of $99.5 \%$; in the generality setting, the mean percentage of accuracy was $99.5 \%$ with a range from $99 \%$ to $100 \%$. During low-probability requests the mean percentage of accuracy in the intervention setting was $98.7 \%$ with a range from $98 \%$ to $100 \%$. For the generality sessions, the mean percentage of accuracy had a mean of $97 \%$. During the high-probability request sequences with embedded peer modeling, accuracy in the intervention setting was $100 \%$ while in the generality setting accuracy was $98 \%$. For the low-probability requests condition, accuracy both in the intervention and generality setting was $100 \%$. For one session of maintenance, accuracy was $99 \%$. 
Responses to high-probability requests during high-probability request sequences with embedded peer modeling

The summary of the mean percentage and range of children's correct responses, nonresponses, and noncompliance to high-probability requests (see Table 4.9), as well as the mean percentage of accuracy measures for responses to high-probability follows.

Table 4.5 provides the mean percentage and range of accuracy for responses, nonresponses, and noncompliance to high-probability requests.

Eric and Stacie

During 13 sessions of the high-probability request sequence with embedded peer modeling, for high-probability requests, Eric responded to a mean percentage of $98.15 \%$ with a range from $92 \%$ to $100 \%$. The mean percentage of nonresponses to highprobability requests was 0.62 with a range from 0 to 4 . Eric did not exhibit any noncompliance to high-probability requests. Twenty three percent of the sessions were measured for accuracy. Accuracy for responses, nonresponses, and noncompliance to high-probability requests was $100 \%$.

Eric's peer, Stacie's mean percentage of responses to high-probability requests was $98 \%$ with a range from $87 \%$ to $100 \%$. The mean percentage of nonresponses to highprobability requests was 0.8 with a range from $0 \%$ to $10 \%$. Stacie's mean percentage of noncompliance to high-probability requests was $0.5 \%$ with a range from $0 \%$ to $4 \%$. Accuracy for responses, nonresponses, and noncompliance to the high-probability requests was $100 \%$. 


\begin{tabular}{|c|c|c|c|c|c|c|c|c|c|c|c|c|c|c|c|}
\hline & & \multirow{2}{*}{\multicolumn{3}{|c|}{$\begin{array}{l}\text { Low-P } \\
\text { Low-P }\end{array}$}} & & \multicolumn{6}{|c|}{ High-P } & & \multirow{2}{*}{\multicolumn{3}{|c|}{$\begin{array}{l}\text { Low-P } \\
\text { Low-P }\end{array}$}} \\
\hline & & & & & & \multicolumn{3}{|c|}{ Low-P } & \multicolumn{3}{|c|}{ High-P } & & & & \\
\hline & & $\mathrm{R}$ & NR & $\mathrm{NC}$ & & $\mathrm{R}$ & NR & $\mathrm{NC}$ & $\mathrm{R}$ & NR & $\mathrm{NC}$ & & $\mathrm{R}$ & NR & $\mathrm{NC}$ \\
\hline \multicolumn{16}{|l|}{ Eric } \\
\hline$\%$ of sessions & $20 \%$ & & & & $23 \%$ & & & & & & & $25 \%$ & & & \\
\hline $\begin{array}{l}\text { Mean } \\
\text { Ranoe }\end{array}$ & & 100 & 100 & 100 & & 100 & 100 & 100 & 100 & 100 & 100 & & 100 & 100 & 100 \\
\hline \multicolumn{16}{|l|}{ Paul } \\
\hline \%of sessions & $27 \%$ & & & & $28 \%$ & & & & & & & $27 \%$ & & & \\
\hline Mean & & 100 & 96 & 96 & & 100 & 100 & 100 & 100 & 100 & 100 & & 100 & 100 & 100 \\
\hline Range & & & $88-100$ & $88-100$ & & - & - & - & - & - & - & & - & - & - \\
\hline \multicolumn{16}{|l|}{ Chris } \\
\hline$\%$ of sessions & $30 \%$ & & & & $21 \%$ & & & & & & & $29 \%$ & & & \\
\hline Mean & & 100 & 96 & 96 & & 100 & 100 & 100 & 100 & 100 & 100 & & 100 & 100 & 100 \\
\hline Range & & & $88-100$ & $88-100$ & & - & - & - & - & - & - & & - & - & - \\
\hline \multicolumn{16}{|l|}{ Stacie } \\
\hline$\%$ of sessions & & & & & $23 \%$ & & & & & & & & & & \\
\hline Mean & & - & - & - & & 100 & 100 & 100 & 100 & 100 & 100 & & - & - & - \\
\hline Range & & - & - & - & & - & - & - & - & - & - & & - & - & - \\
\hline \multicolumn{16}{|l|}{ Jennifer } \\
\hline \%of sessions & & & & & $28 \%$ & & & & & & & & & & \\
\hline Mean & & - & - & - & & 100 & 100 & 100 & 100 & 100 & 100 & & - & - & - \\
\hline Range & & - & - & - & & - & - & - & - & - & - & & - & - & - \\
\hline \multicolumn{16}{|l|}{ Hillary } \\
\hline$\%$ of sessions & & & & & $21 \%$ & & & & & & & & & & \\
\hline Mean & & - & - & - & & 100 & 100 & 100 & 100 & 100 & 100 & & - & - & - \\
\hline Range & & - & - & - & & - & - & - & - & - & - & & - & - & - \\
\hline
\end{tabular}

Table 4.5: Accuracy measures for the target children's and the peers' responses (R), nonresponse (NR), and noncompliance (NC) to low-probability and high-probability requests. 


\section{Paul and Jennifer}

During 18 sessions of high-probability request sequences with embedded peer modeling, Paul's mean percentage of responses to high-probability requests was $99.56 \%$ with a range from $96 \%$ to $100 \%$. The mean percentage of nonresponses to highprobability requests was $0.22 \%$ with a range from $0 \%$ to $4 \%$. Paul did not exhibit any noncompliance to high-probability requests. Accuracy measures were conducted for $28 \%$ of the sessions. Accuracy for responses, nonresponses, and noncompliance to the high-probability requests was $100 \%$.

Jennifer, Paul's peer responded to a mean percentage of $99 \%$ with a range from $96 \%$ to $100 \%$ for high-probability requests. The mean percentage of nonresponses to high-probability requests was $0.3 \%$ with a range from $0 \%$ to $4 \%$. Jennifer did not display any noncompliance to high-probability requests. Accuracy measures were conducted for $28 \%$ of the sessions and resulted in $100 \%$.

\section{Chris and Hilary}

During 19 sessions of the high-probability request sequence with peer modeling, the mean percent of responses to high-probability requests was $95.74 \%$ with a range from $92 \%$ to $100 \%$. The mean percent of nonresponses to high-probability requests was $3.84 \%$ with a range form $0 \%$ to $10 \%$. Chris did not exhibit any noncompliance to highprobability requests. Accuracy measures were conducted for $21 \%$ of the sessions and resulted in $100 \%$. 
Chris's peer, Hilary's responses to high-probability requests was $100 \%$. She did not display any nonresponses and noncompliance to the high-probability requests.

Accuracy measures were conducted for $21 \%$ and theses results were $100 \%$ accuracy for responses, nonresponses, and noncompliance to the high-probability requests.

\section{Peer Training}

The peers were trained to recognize the target children's initiations and to respond to them until they reached the criterion of $90 \%$ correct responses to the experimenter's questions regarding target behaviors for 3 consecutive sessions.

Stacie, Eric's peer

The mean percentage of correct responses to 16 target behaviors was $96 \%$ with a range from $94 \%$ to $100 \%$ for session 7,8 , and 9 . Procedural integrity checklists were completed for $33 \%$ of the peer training sessions, and the number of steps completed correctly was $100 \%$. During peer review sessions \# 51, 52, and 55, Stacie exhibited 100\% of correct responses to the target behaviors in each setting.

Jennifer, Paul's peer

The mean percentage of correct responses to the 16 target behaviors was $96 \%$ with a range from $94 \%$ to $100 \%$ for sessions 16,18 , and 19 . Procedural integrity checklists were completed for $33 \%$ of the peer training sessions, and the number of steps completed correctly was $100 \%$. During peer review of the sessions \# 52, 53, and 54, she exhibited $100 \%$ of correct responses to the target behaviors in each setting.

Hilary, Chris's peer

The mean percentage of correct responses to the 16 target behaviors was $100 \%$. Procedural integrity checklists were completed for 33\% of the peer training sessions, and 
the number of steps completed correctly was $100 \%$. During the peer review of sessions \# 51, and 52, Hilary exhibited $100 \%$ of correct responses to the target behaviors in each setting.

Procedures to Ensure the Believability of Dependent Variables

Accuracy measures were conducted for children's compliant responding to lowprobability requests and social initiations and responses for all conditions. A percentage of agreement was calculated for accuracy of coding each variable by dividing the total number of agreements for each behavior by the number of agreement plus disagreements for that behavior and multiplying by one hundred. The mean percentage and range of accuracy for each child and variable across all conditions and settings are reported below.

Accuracy Measures for Compliant Responding to Low-Probability Requests

Accuracy measures were conducted for children's compliant responding to lowprobability requests across approximately $20 \%$ of experimental sessions during lowprobability requests alone, high-probability request sequence using embedded peer modeling, and low-probability requests alone (see Table 4.5).

Eric

During low-probability requests alone, accuracy measures were conducted for $20 \%$ of the sessions. Accuracy was $100 \%$ for all three variables: responses, nonresponses, and noncompliance to the low-probability requests. During the high-probability request sequences with embedded peer modeling, $23 \%$ of the sessions were measured for accuracy. Accuracy for all three variables was $100 \%$. For $25 \%$ of the low-probability requests alone, accuracy for the three variables was $100 \%$. For Stacie, Eric's peer, the accuracy during the high-probability requests condition, on the three variables was $100 \%$. 
Paul

Twenty seven percentages of sessions of low-probability requests were measured for accuracy. Accuracy for responses to low-probability requests was $100 \%$. The mean percentage of accuracy for both nonresponses and noncompliance to low-probability requests was $96 \%$ with a range from $88 \%$ to $100 \%$. During the high-probability request sequences with embedded peer modeling, $28 \%$ of sessions were measured for accuracy. Accuracy on all three variables was $100 \%$. For Paul's peer, Jennifer, accuracy on responses, nonresponses, and noncompliance was calculated for $28 \%$ of the highprobability requests sequence using peer modeling. These results were $100 \%$ accurate for responses, nonresponses, and noncompliance to low-probability requests.

\section{Chris}

Thirty percent of the low-probability requests sessions were measured for accuracy checks. For Chris, accuracy for responses to low-probability requests during the low-probability requests condition alone was $100 \%$. The mean percentage of accuracy for both nonresponses and noncompliance to low-probability requests was $96 \%$ with a range from $88 \%$ to $100 \%$. During $21 \%$ of high-probability request sequences using embedded peer modeling accuracy was measured; accuracy for the three variables was $100 \%$.

During $29 \%$ of the low-probability requests sessions, accuracy was measured; accuracy for responses, nonresponses, and noncompliance to low-probability requests was $100 \%$. For Chris's peer, Hilary, accuracy measures were conducted for $21 \%$ of the highprobability request sequences using embedded peer modeling. Accuracy for responses, nonresponses, and noncompliance to low-probability requests was $100 \%$. 


\section{Accuracy Measures for Social Initiations and Responses}

Accuracy measures were conducted for at least $20 \%$ of all sessions across all conditions and settings for social initiations and responses. The following is a summary of the percentage of accuracy for social interactions. Table 4.6 describes the mean percentage and range of accuracy for social initiations and responses in the intervention setting. Table 4.7 describes the mean percentage and range of accuracy for social initiations and responses in the generality setting.

Eric

During $30 \%$ of the baseline sessions, the mean percentage of accuracy for social initiations and responses was $99 \%, 99.5 \%$ with a mean of $99 \%$ to $100 \%$, respectively. In the generality setting, $50 \%$ of the baseline sessions were measured. The mean percentage of accuracy for social initiations and responses was 99.5 with a range from $99 \%$ to $100 \%$, and $100 \%$, respectively.

For low-probability requests alone, accuracy measures in the intervention setting were conducted for $20 \%$ of the sessions. Accuracy for social initiations ranged from $96 \%$ to $97 \%$ with a mean of $96.5 \%$; the range of accuracy for social responses was $97 \%$ to $98 \%$ with a mean of $97.5 \%$. In the generality setting accuracy measures were conducted for $20 \%$ of the sessions. Accuracy measures on social initiations and responses were $97 \%$, and $99 \%$, respectively.

During the high-probability requests sequences with peer modeling, accuracy measures in the intervention settings were conducted for $23 \%$ of the sessions. Accuracy for social initiations ranged from $98 \%$ to $99 \%$ with a mean of $98.3 \%$. The mean percentage of accuracy for social responses was $98.6 \%$ with range from $98 \%$ to $99 \%$. 


\begin{tabular}{|c|c|c|c|c|c|c|}
\hline & \multicolumn{2}{|c|}{ Eric } & \multicolumn{2}{|c|}{ Paul } & \multicolumn{2}{|c|}{ Chris } \\
\hline & I & $\mathrm{R}$ & I & $\mathrm{R}$ & I & $\mathrm{R}$ \\
\hline \multicolumn{7}{|l|}{$\mathrm{BL}$} \\
\hline$\%$ sessions & 30 & 30 & 30 & 30 & 25 & 25 \\
\hline Mean & 99 & 99.5 & 100 & 100 & 100 & 100 \\
\hline Range & - & $99-100$ & - & - & - & - \\
\hline \multicolumn{7}{|l|}{ Low-P } \\
\hline$\%$ sessions & 20 & 20 & 27 & 27 & 30 & 30 \\
\hline Mean & 96.5 & 97.5 & 98.5 & 99.7 & 99.3 & 99 \\
\hline Range & $96-97$ & $97-98$ & $97-100$ & $99-100$ & 94-100 & $98-100$ \\
\hline \multicolumn{7}{|l|}{ High-P } \\
\hline$\%$ sessions & 23 & 23 & 28 & 28 & 21 & 21 \\
\hline Mean & 98.3 & 98.6 & 99.4 & 99.3 & 99.3 & 99.3 \\
\hline Range & $98-99$ & $98-99$ & $97-100$ & $98-100$ & $99-100$ & $98-100$ \\
\hline \multicolumn{7}{|l|}{ Low-P } \\
\hline$\%$ sessions & 25 & 25 & 27 & 27 & 29 & 29 \\
\hline Mean & 96.5 & 97 & 97.3 & 99 & 96 & 95.3 \\
\hline Range & $96-97$ & $96-98$ & $95-100$ & $97-100$ & $95-97$ & $94-97$ \\
\hline \multicolumn{7}{|l|}{ Maintenance } \\
\hline$\%$ sessions & 33 & 33 & 25 & 25 & 100 & 100 \\
\hline Mean & 99.5 & 98 & 100 & 100 & 98 & 98 \\
\hline Range & $99-100$ & $97-99$ & - & - & - & - \\
\hline
\end{tabular}

Table 4.6: Accuracy measures for social initiations (I) and responses (R) in the intervention setting. 


\begin{tabular}{|c|c|c|c|c|c|c|}
\hline & \multicolumn{2}{|c|}{ Eric } & \multicolumn{2}{|c|}{ Paul } & \multicolumn{2}{|c|}{ Chris } \\
\hline & I & $\mathrm{R}$ & I & $\mathrm{R}$ & I & $\mathrm{R}$ \\
\hline \multicolumn{7}{|l|}{$\mathrm{BL}$} \\
\hline \%sessions & 50 & 50 & 33 & 33 & 50 & 50 \\
\hline Mean & 99.5 & 100 & 99 & 99 & 99 & 98.5 \\
\hline Range & $99-100$ & 100 & - & - & $98-100$ & $97-100$ \\
\hline \multicolumn{7}{|l|}{ Low-P } \\
\hline \%sessions & 20 & 20 & 33 & 33 & 33 & 33 \\
\hline Mean & 97 & 99 & 99 & 100 & 99 & 100 \\
\hline Range & - & - & - & - & - & - \\
\hline \multicolumn{7}{|l|}{ High-P } \\
\hline$\%$ sessions & 20 & 20 & 33 & 33 & 20 & 20 \\
\hline Mean & 95 & 95 & 98.5 & 99.5 & 100 & 100 \\
\hline Range & - & - & $97-100$ & $99-100$ & - & - \\
\hline \multicolumn{7}{|l|}{ Low-P } \\
\hline \%sessions & 25 & 25 & 33 & 33 & 25 & 25 \\
\hline Mean & 96 & 95 & 98 & 97 & 97 & 96 \\
\hline Range & - & - & - & - & - & - \\
\hline \multicolumn{7}{|l|}{ Maintenance } \\
\hline \%sessions & 50 & 50 & 50 & 50 & - & - \\
\hline Mean & 99 & 96 & 99 & 98 & - & - \\
\hline Range & - & - & - & - & - & - \\
\hline
\end{tabular}

Table 4.7: Accuracy measures for social initiations (I) and responses (R) in the generality setting. 
Twenty percent of the sessions in the generality setting were measured for accuracy checks. The mean percentage of accuracy for both social initiations and responses was $95 \%$.

During the low-probability requests alone condition, $25 \%$ of the sessions in the intervention setting were measured for accuracy checks. The range of accuracy for social initiations was $96 \%$ to $97 \%$ with a mean of $96.5 \%$. Accuracy for social responses was $97 \%$ with a range from $96 \%$ to $98 \%$. For $25 \%$ of the sessions in the generality setting, accuracy on social initiations and responses was $96 \%, 95 \%$, respectively.

For the maintenance condition, accuracy measures in the intervention setting were conducted for $33 \%$ of the sessions. Accuracy for social initiations yielded a mean of $99.5 \%$ with a range from $99 \%$ to $100 \%$. The range of accuracy for social responses was $97 \%$ to $99 \%$ with a mean of $98 \%$. Fifty percent of the sessions in the generality setting were measured for accuracy. Accuracy measures for both social initiations and responses were $99 \%$, and $96 \%$, respectively.

Paul

Accuracy measures in the intervention setting were conducted for $30 \%$ of the baseline sessions for Paul. The mean percentage of accuracy measures for both social initiations and responses was $100 \%$. In the generality setting, $33 \%$ of the baseline sessions were measured. The mean of accuracy for both social initiations and responses was $99 \%$.

During the low-probability requests alone conditions, accuracy measures in the intervention setting were conducted for $27 \%$ of the sessions. Accuracy measures for social initiations ranged from $97 \%$ to $100 \%$ with a mean of $98.5 \%$. The percentage of the 
range of accuracy for social responses was $99 \%$ to $100 \%$ with a mean of $99.7 \%$. In the generality setting, accuracy measures were conducted for $33 \%$ of the sessions. The mean percentage of accuracy for social initiations and responses was $99 \%$ and $100 \%$, respectively.

During the high-probability request sequences with embedded peer modeling, accuracy measures in the intervention settings were conducted for $28 \%$ of the intervention sessions. Accuracy on social initiations ranged from $97 \%$ to $100 \%$ with a mean of $99.4 \%$. The mean percentage of accuracy for social responses was $99.3 \%$ with range from $98 \%$ to $99 \%$. In the generality setting, $33 \%$ of the sessions were measured for accuracy checks. Accuracy for social initiations ranged from $97 \%$ to $100 \%$ with a mean of $98.5 \%$. The range of accuracy for social responses was $99 \%$ to $100 \%$ with a mean of $99.5 \%$.

During the low-probability request alone condition, $27 \%$ of the sessions in the intervention setting were measured for accuracy checks. The range of accuracy for social initiations was $95 \%$ to $100 \%$ with a mean of $97.3 \%$. Accuracy for social responses was $99 \%$ with a range from $97 \%$ to $100 \%$. Accuracy checks in the generality setting were taken for $33 \%$ of the sessions; the percentage of accuracy for social initiations and responses was $98 \%$, and $97 \%$, respectively.

For the maintenance condition, accuracy measures in the intervention setting were conducted for $25 \%$ of the sessions. The mean percentage of accuracy for both social initiations and responses was $100 \%$. During the generality probes, $50 \%$ of the sessions were measured for accuracy. Accuracy measures for social initiations and social responses were $99 \%$, and $98 \%$, respectively. 


\section{Chris}

During baseline, accuracy measures were conducted for $25 \%$ of the sessions. The mean percentage of accuracy for both social initiations and responses was $100 \%$. In the generality setting, $50 \%$ of the sessions were measured for accuracy checks. The mean percentage of accuracy on social initiations and responses in the generality setting was $99 \%$ with a range from $98 \%$ to $100 \%$, and $98.5 \%$ with a range from $97 \%$ to $100 \%$, respectively.

For the low-probability requests alone, $30 \%$ of the sessions were measured for accuracy. Accuracy for social initiations in the intervention setting was $99.3 \%$ with a range from $94 \%$ to $100 \%$. The mean percentage of accuracy for social responses in the intervention setting was $99 \%$ with a range from $98 \%$ to $100 \%$. In the generality setting, accuracy measures were conducted for $33 \%$ of the sessions. Accuracy for social initiations and responses was 99\%, and 100\%, respectively.

During high-probability request sequences with peer modeling, accuracy measures in the intervention setting were conducted for $21 \%$ of the sessions. The mean percentage of accuracy for social initiations and responses in the intervention setting was $99.3 \%$ with a range from $99 \%$ to $100 \%$, and $99.3 \%$ with a range from $98 \%$ to $100 \%$. The mean percentage of accuracy for both social initiations and responses in the generality setting was $100 \%$.

For low-probability requests, accuracy measures in the intervention setting were conducted for $29 \%$ of the sessions. The mean percentage of accuracy was $96 \%$ with a range from $95 \%$ to $97 \%$, and $95.3 \%$ with a range from $94 \%$ to $97 \%$, respectively. In the 
generality setting, $25 \%$ of the sessions were measured for accuracy. The mean percentage of accuracy for social initiations and responses in the generality setting was $97 \%$, and $96 \%$, respectively.

\section{Accuracy Measures for Disruptive Behaviors}

Disruptive behavior was recorded using interval recording. Accuracy measures were conducted for disruptive behavior for at least for $20 \%$ of all conditions. Table 4.8 describes the mean percentage and range of accuracy for disruptive behaviors in the intervention and generality setting.

Eric

During baseline, $30 \%$ of the sessions in the intervention setting and $50 \%$ of the sessions in the generality setting were measured for accuracy checks. Accuracy for disruptive behaviors in both the intervention and generality setting was $100 \%$. During low-probability requests alone, accuracy measures were conducted for $20 \%$ of the sessions in the intervention and the generality setting. The accuracy in both settings was $100 \%$. During the high-probability requests sequence with embedded peer modeling, $23 \%$ of the intervention sessions and $20 \%$ of the generality sessions were measured for accuracy. Accuracy for disruptive behaviors in both intervention and the generality setting was $100 \%$. During low-probability requests, $25 \%$ of the sessions in the intervention and generality sessions were measured for accuracy. Accuracy for disruptive behaviors in both intervention and in the generality setting was $100 \%$. During the maintenance condition, accuracy measures were conducted for $33 \%$ of the sessions in the intervention setting, and for $50 \%$ of the sessions in the generality setting. Accuracy in both settings was $100 \%$. 


\begin{tabular}{|c|c|c|c|c|c|c|}
\hline & \multicolumn{2}{|c|}{ Eric } & \multicolumn{2}{|c|}{ Paul } & \multicolumn{2}{|c|}{ Chris } \\
\hline & I & $\mathrm{G}$ & I & $\mathrm{G}$ & I & $\mathrm{G}$ \\
\hline \multicolumn{7}{|l|}{$\overline{B L}$} \\
\hline \%sessions & 30 & 50 & 30 & 33 & 25 & 50 \\
\hline Mean & 100 & 100 & 100 & 100 & 100 & 100 \\
\hline Range & - & - & - & - & - & - \\
\hline \multicolumn{7}{|l|}{ Low-P } \\
\hline \%sessions & 20 & 20 & 27 & 33 & 30 & 33 \\
\hline Mean & 100 & 100 & 100 & 100 & 97.7 & 98 \\
\hline Range & - & - & - & - & $96-98$ & - \\
\hline \multicolumn{7}{|l|}{ High-P } \\
\hline \%sessions & 23 & 20 & 28 & 33 & 21 & 20 \\
\hline Mean & 100 & 100 & 100 & 100 & 99.8 & 100 \\
\hline Range & - & - & - & - & $99-100$ & - \\
\hline \multicolumn{7}{|l|}{ Low-P } \\
\hline \%sessions & 25 & 25 & 27 & 33 & 29 & 25 \\
\hline Mean & 100 & 100 & 100 & 100 & 100 & 100 \\
\hline Range & - & - & - & - & - & - \\
\hline \multicolumn{7}{|l|}{ Maintenance } \\
\hline$\%$ sessions & 33 & 50 & 25 & 50 & 100 & - \\
\hline Mean & 100 & 100 & 100 & 100 & 100 & - \\
\hline Range & - & - & - & - & - & - \\
\hline
\end{tabular}

Table 4.8: Accuracy measures for disruptive behaviors in the intervention (I) and generality settings $(\mathrm{G})$. 
Paul

During the baseline condition, accuracy measures were conducted for $30 \%$ of the sessions in the intervention setting, and for $33 \%$ of the sessions in the generality setting. Accuracy for disruptive behaviors in both settings was 100\%. During low-probability requests alone, accuracy measures were conducted for $27 \%$ of the sessions in the intervention setting, and for $33 \%$ of the sessions in the generality setting. Accuracy in both settings was $100 \%$. For Paul, during the high-probability requests with embedded peer modeling, accuracy measures were conducted for $28 \%$ of the sessions in the intervention setting and $33 \%$ of the sessions in the generality setting. Accuracy for disruptive behavior in both settings was 100\%. During the low-probability requests alone, $27 \%$ of the interventions sessions and $33 \%$ of the generality sessions were measured for accuracy checks. Accuracy for both settings was 100\%. During the maintenance condition, accuracy measures were conducted for $25 \%$ of the sessions in the intervention setting, and $50 \%$ of the sessions in the generality setting. Accuracy for both settings was $100 \%$. During maintenance, $25 \%$ of the intervention sessions, and $50 \%$ of the generality sessions were measured for accuracy checks. Accuracy for both settings was $100 \%$.

\section{Chris}

During the baseline condition, accuracy measures were conducted for $23 \%$ of the interventions sessions and $50 \%$ of the generality sessions. Accuracy in both settings was $100 \%$. During low-probability requests, $30 \%$ of the intervention sessions and $33 \%$ of the generality sessions were measured for accuracy checks. The mean percentage of accuracy in the intervention and in the generality settings was $97.7 \%$ with a range from $96 \%$ to $98 \%$, and $98 \%$, respectively. During the high-probability request sequences with 
embedded peer modeling, accuracy measures were conducted for $21 \%$ of the intervention sessions and for $20 \%$ of the generality sessions. The mean percentage of accuracy for disruptive behaviors in the intervention and the generality settings was $99.8 \%$ with a range from $99 \%$ to $100 \%$, and $100 \%$, respectively. During the low-probability requests alone condition, $29 \%$ of the interventions sessions and $25 \%$ of the generality sessions were measured for accuracy checks. Accuracy in both settings was $100 \%$. During maintenance, one session in the intervention setting was measured for accuracy. Accuracy for disruptive behavior was $100 \%$.

\section{Dependent Variables}

The dependent variables measured in this study were children's compliant responding to low-probability requests to initiate social behaviors toward peers, social initiations and responses. Dependent variables were observed and measured during free play in center time.

\section{Compliant Responding to Low-Probability Requests}

The following section will address the research question, "What are the effects of the use of high-probability request sequences with embedded peer modeling on compliant responding to low-probability requests to initiate social behaviors for young children with autism?"

The results of each child's percent correct responses to low-probability requests to initiate social behaviors toward peers are represented for low-probability requests, the high-probability request sequences with embedded peer modeling, and a second lowprobability request condition. Figure 4.1 visually displays the percent correct responses to low-probability requests during the initial low-probability requests alone condition, the 
high-probability request sequences with peer modeling, and the second low-probability request condition. Table 4.9 presents the mean percentage and range of participants' compliant responses, nonresponses, and noncompliance to the low-probability requests to initiate social behaviors.

Eric

Baseline. No low-probability requests were delivered as the children were observed during six sessions of baseline.

Low-probability requests alone. During 10 sessions of low-probability requests alone, Eric responded to a mean of $34.14 \%$ with a range from $13 \%$ to $50 \%$. Baseline data demonstrated some variability and gradual stability. The mean percentage of nonresponses to the low-probability requests was $66 \%$ with a range from $50 \%$ to $88 \%$. Eric did not exhibit any noncompliance to the low-probability requests.

High-probability request sequences with embedded peer modeling. Eric's compliant responding to low-probability requests to initiate social behaviors to peers during the high-probability request sequence using embedded peer modeling ranged from $75 \%$ to $100 \%$ with a mean of $92.38 \%$ over 13 sessions. For sessions 28 and 29 , observations did not occur due to the target child's absences. For session 31, and sessions 34-40, observations did not occur due to the peer's absences. Eric's compliant responding to low-probability requests sharply increased with the implementation of the intervention. 


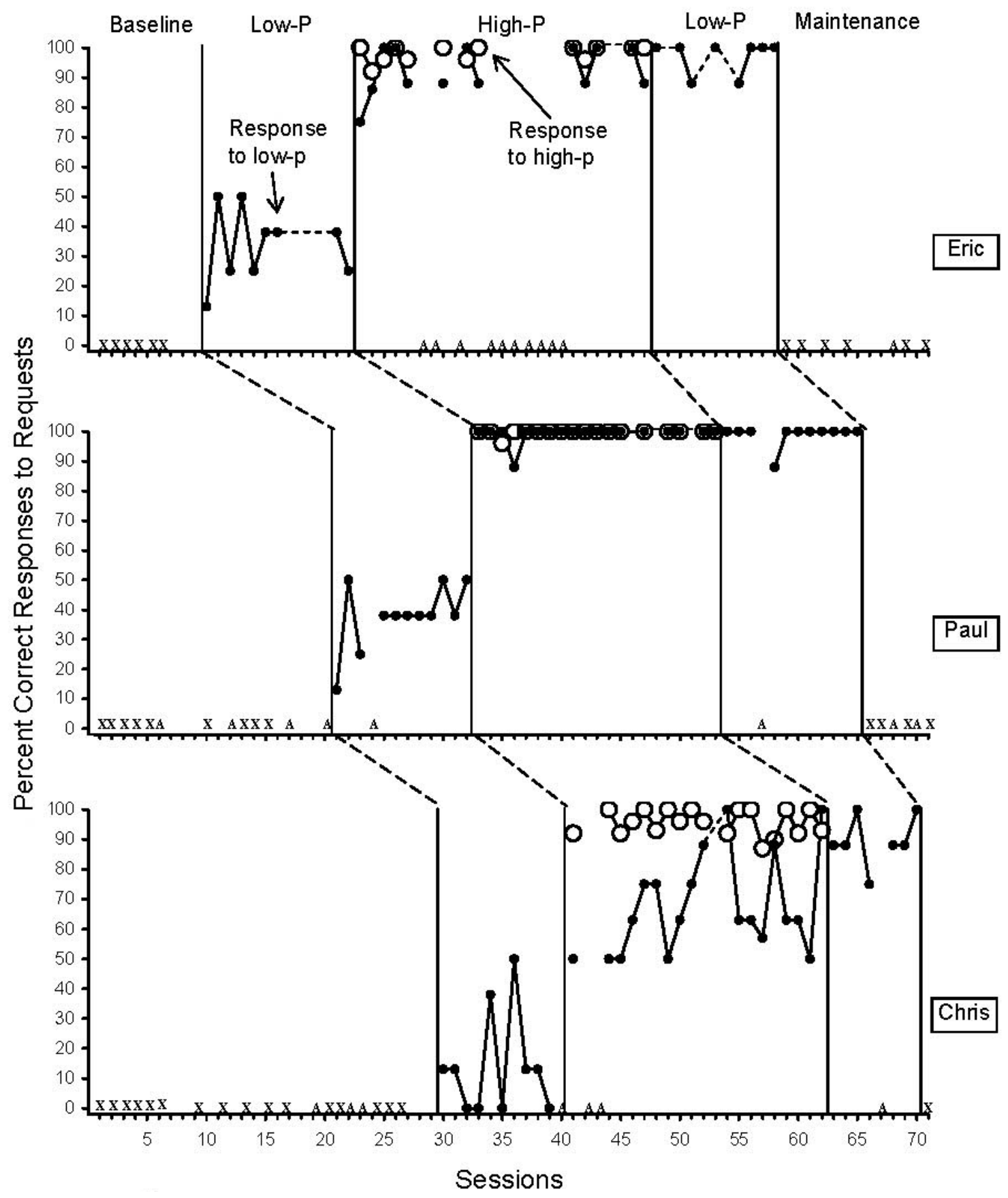

Figure 4.1: Percent correct responses to requests. Filled circles $(\rightarrow-)$ represent percent correct responses to Low-P requests, and open circles (-O-) represent percent correct responses to High-P requests; "A" represents absence; "X" depicts the sessions that data were taken without Low-P requests in baseline and maintenance. 


\begin{tabular}{|c|c|c|c|c|c|c|c|c|c|c|c|c|c|c|c|}
\hline & & \multirow{2}{*}{\multicolumn{3}{|c|}{$\begin{array}{l}\text { Low-P } \\
\text { Low-P }\end{array}$}} & & \multicolumn{6}{|c|}{ High-P } & & \multirow{2}{*}{\multicolumn{3}{|c|}{$\begin{array}{l}\text { Low-P } \\
\text { Low-P }\end{array}$}} \\
\hline & & & & & & \multicolumn{3}{|c|}{ Low-P } & \multicolumn{3}{|c|}{ High-P } & & & & \\
\hline & & $\mathrm{R}$ & NR & $\mathrm{NC}$ & & $\mathrm{R}$ & NR & $\mathrm{NC}$ & $\mathrm{R}$ & NR & $\mathrm{NC}$ & & $\mathrm{R}$ & NR & $\mathrm{NC}$ \\
\hline Eric & $10_{\mathrm{a}}$ & & & & $13_{\mathrm{b}}$ & & & & & & & 8 & & & \\
\hline Mean & & 34.14 & 66.00 & 0.00 & & 92.38 & 6.00 & 2.00 & 98.15 & 0.62 & 0.00 & & 97.00 & 3.25 & 0.00 \\
\hline Range & & $13-50$ & $50-88$ & - & & $75-100$ & $0-25$ & $0-13$ & $92-100$ & $0-4$ & - & & $88-100$ & $0-13$ & - \\
\hline Paul & $11_{\mathrm{a}}$ & & & & $18_{\mathrm{b}}$ & & & & & & & $11_{\mathrm{c}}$ & & & \\
\hline Mean & & 37.81 & 38.81 & 23.90 & & 99.33 & 0.72 & 0.00 & 99.56 & 0.22 & 0.00 & & 98.90 & 0.00 & 0.85 \\
\hline Range & & $13-50$ & $0-87$ & $0-62$ & & $88-100$ & $0-13$ & - & $96-100$ & $0-4$ & - & & $88-100$ & - & $0-13$ \\
\hline Chris & $10_{\mathrm{a}}$ & & & & $19_{\mathrm{b}}$ & & & & & & & $7 \mathrm{c}$ & & & \\
\hline Mean & & 14.00 & 50.10 & 36.60 & & 67.68 & 24.42 & 8.21 & 95.74 & 3.84 & 0.00 & & 89.57 & 3.43 & 3.57 \\
\hline Range & & $0-50$ & $13-100$ & $0-88$ & & $50-100$ & $0-50$ & $0-29$ & $92-100$ & $0-10$ & - & & $75-100$ & $0-12$ & $0-25$ \\
\hline Stacie & - & & & & $13_{\mathrm{b}}$ & & & & & & & - & & & \\
\hline Mean & & - & - & - & & 100.00 & 0.00 & 0.00 & 98.00 & 0.80 & 0.50 & & - & - & - \\
\hline Range & & - & - & - & & - & - & - & $87-100$ & $0-10$ & $0-4$ & & - & - & - \\
\hline Jennifer & - & & & & $18_{\mathrm{b}}$ & & & & & & & - & & & \\
\hline Mean & & - & - & - & & - & - & - & 99.00 & 0.30 & 0.00 & & - & - & - \\
\hline Range & & - & - & - & & - & - & - & $96-100$ & $0-4$ & - & & - & - & - \\
\hline Hillary & - & & & & $19_{b}$ & & & & & & & - & & & \\
\hline Mean & & - & - & - & & 100.00 & 0.00 & 0.00 & 100.00 & 0.00 & 0.00 & & - & - & - \\
\hline Range & & - & - & - & & - & - & - & - & - & - & & - & - & - \\
\hline
\end{tabular}

$\mathrm{a}-$ Number of sessions during the Low-P condition

$b$ - Number of sessions during the High-P condition

$c$ - Number of sessions during the second Low-P condition

Table 4.9: The mean percentage and range of the target children's and peers' responses (R), nonresponses (NR), noncompliance (NC) to low-probability and high-probability requests. 
The mean percentage of Eric's nonresponses to the low-probability requests was $6 \%$ with a range from 0 to $25 \%$. The mean percentage of noncompliance to the low-probability requests was $2 \%$ with a range from 0 to $13 \%$. Additionally, Eric's peer, Stacie was asked to perform the low-probability requests as a peer model. The mean percentage of the compliant responding to low- probability requests was $100 \%$.

Low-probability requests alone. Eric maintained a mean level of responding to low-probability requests of $97 \%$ with a range of $88 \%$ to $100 \%$ over 8 sessions. His responses to low-probability requests slightly increased than during the high-probability request sequences with peer molding. Eric maintained steady responding to lowprobability requests during this condition, and demonstrated an increase from his responding during the first low-probability request condition. The mean percentage of the nonresponses to low-probability requests was $3.25 \%$ with a range from $0 \%$ to $13 \%$. Eric did not engage in any nocompliance to low-probability requests during this condition. Paul

Baseline. No low-probability requests were delivered as the children were observed during 10 sessions of the baseline condition.

Low-probability requests alone. During 11 sessions of low-probability requests, Paul responded to a mean of $37.81 \%$ of low-probability requests, with a range of $13 \%$ to $50 \%$. Paul's compliant responding to low-probability requests showed stability with a little variability at the beginning of the condition. The nonresponses to the lowprobability requests ranged from $0 \%$ to $87 \%$ with a mean of $38.81 \%$ and the noncompliance to the low-probability requests ranged from $0 \%$ to $62 \%$ with a mean of $23.90 \%$. 
High-probability request sequences with embedded peer modeling. Paul's compliant responding to low-probability requests to initiate social behaviors during the high-probability request sequence using embedded peer modeling ranged from $88 \%$ to $100 \%$ with a mean of $99.33 \%$ over 18 sessions. The mean percentage of the nonresponses to the low-probability requests was $0.72 \%$ with a range from 0 to $13 \%$. Paul's compliant responding to low-probability requests sharply increased with the implementation of the intervention. He demonstrated stable responding during this condition while exhibiting $100 \%$ of responding to requests during all but one session. Paul's peer, Jennifer responded $100 \%$ to the low-probability requests to initiate social behaviors with Paul.

Low-probability requests alone. Eleven sessions of low-probability requests were conducted with Paul. Paul's compliant responding to low-probability requests ranged from $88 \%$ to $100 \%$, with a mean of $98.90 \%$. The mean percentage of noncompliance to the low-probability requests was $0.85 \%$ with a range from 0 to $13 \%$. His responses to low-probability requests during all but one session was $100 \%$. Paul maintained steady responding during this condition. Compared to the first the low-probability request condition Paul exhibited robust change in his responsiveness to low-probability requests during the second low-probability request alone condition.

\section{Chris}

Baseline. No low-probability requests were delivered as the children were observed during 16 sessions of the baseline condition.

Low-probability requests. During 10 sessions of low-probability requests, Chris complied to a mean of $14 \%$ of the requests, with a range from $0 \%$ to $50 \%$. The mean percentage of nonresponses to the low-probability requests was $50.10 \%$ with a range 
from $13 \%$ to $100 \%$. The mean percentage of noncompliance to the low-probability requests was $36.60 \%$ with a range from $0 \%$ to $88 \%$. Chris' responding to the lowprobability requests to initiate social behaviors to peers was low with some variability.

High-probability request sequences with embedded peer modeling. Chris's compliant responding to the low-probability requests to initiate social behaviors to peers during the high-probability request sequence using embedded peer modeling ranged from $50 \%$ to $100 \%$ with a mean of $67.68 \%$, over 19 sessions. The nonresponses to the lowprobability requests ranged from $0 \%$ to $50 \%$ with a mean of $24.42 \%$, and the noncompliance to the low-probability requests ranged from $0 \%$ to $29 \%$ with a mean of $8.21 \%$. There was an increase in level with some variability over the low-probability requests condition. His peer, Hilary, demonstrated $100 \%$ correct responding to the lowprobability requests during this condition.

Low-probability requests alone. During the 7 sessions of low-probability requests, Chris maintained the mean of 89.57 , with a range of $75 \%$ to $100 \%$ of responding to lowprobability requests. Nonresponses to the low-probability requests ranged from $0 \%$ to $12 \%$ with mean of $3.43 \%$. The mean percentage of noncompliance to the low-probability requests was $3.57 \%$ with a range from $0 \%$ to $25 \%$. His responding to low-probability requests during this condition showed a continuing increase. Following this same trend, the responding remained more stable than the responding during the high-probability request sequence. 


\section{Social Interactions in the Intervention Setting}

This following section will address the research question, "What are the effects of the use of high-probability request sequences with embedded peer modeling on social interactions of young children with autism toward their typically developing peers?"

The results of each child's total social initiations and responses, total unprompted initiations and responses to the peer and generality peer are represented for all experimental conditions in the intervention setting. Additionally, the social behaviors of the trained peers toward the target children are reported. Figure 4.2 visually displays the numbers of intervals of the target children's social initiations and responses for all conditions. Table 4.10 and Table 4.11 present the mean number of intervals and range of the target children's social initiations and responses to the trained peers and generality peers, and the mean number of intervals and range of the trained peers' social initiations and responses to the target children and generality peer during the experimental conditions.

\section{Eric and Stacie}

Baseline. Six data points were obtained for Eric's baseline. During baseline, the number of intervals of his initiations and responses to the peer and generality peer were low. The mean number of intervals of total unprompted social initiations and responses to the peer and to the generality peer were 0.67 with a range of 0 to 3 . The mean number of intervals of initiations to the peer and generality peer was both 0.17 with a range from 0 to 1 . The number of intervals of responses to the peer ranged from 0 to 2 with a mean of 0.33. Eric exhibited no response behaviors to the generality peer. 


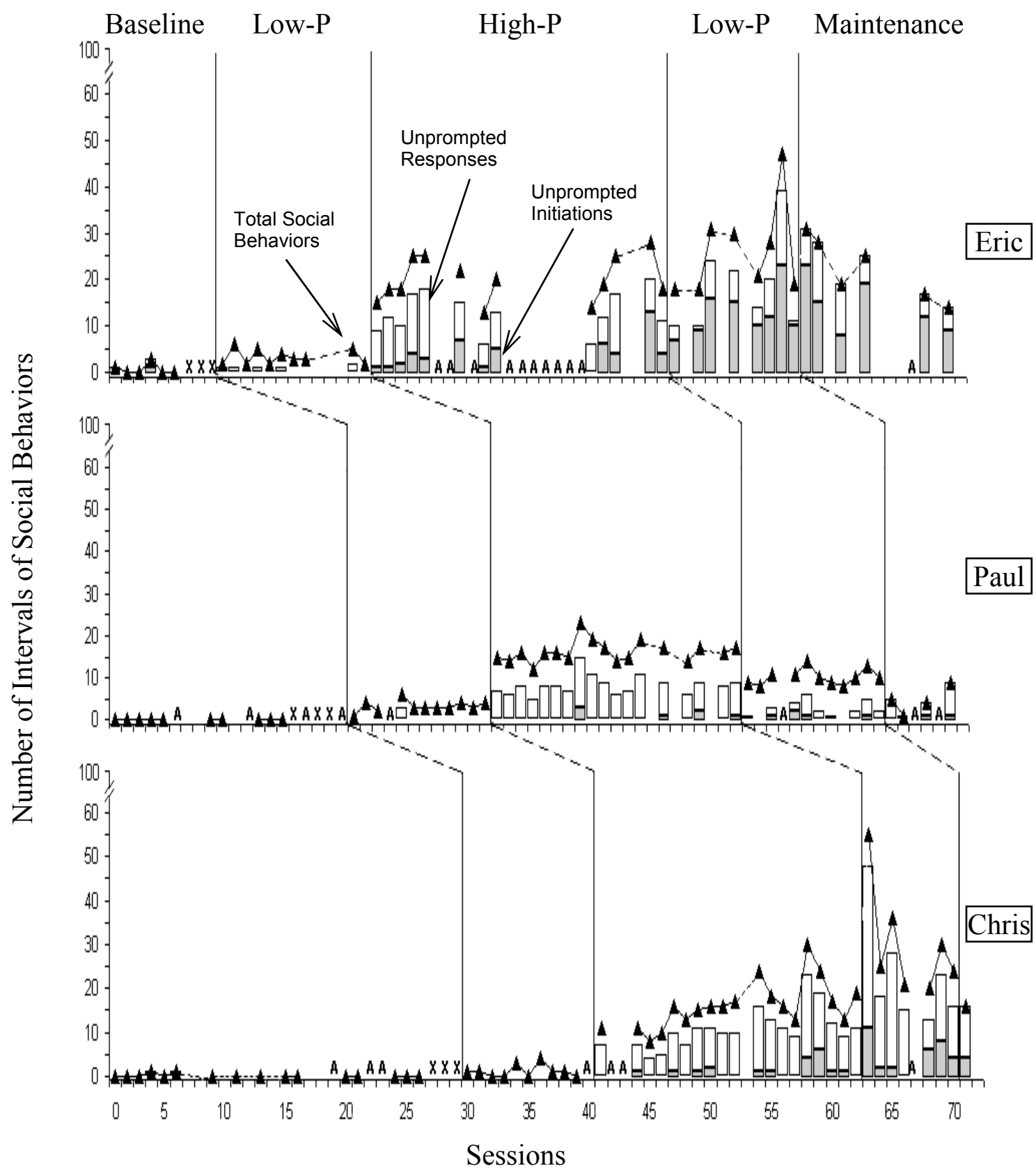

Figure 4.2: Number of intervals of social behaviors in the intervention setting. Bar graphs depict number of intervals of unprompted social initiations and responses to all peers. Data points $(\boldsymbol{t})$ represent total number of intervals in which social interactions of both prompted and unprompted initiations and responses occurred in the intervention setting; "A" represents absences; " $\mathrm{X}$ " represents peer trainings. 


\begin{tabular}{|c|c|c|c|c|c|c|c|c|}
\hline \multirow{3}{*}{ Eric } & \multicolumn{4}{|c|}{$\mathrm{I}$} & \multicolumn{2}{|c|}{$\mathrm{R}$} & \multirow{3}{*}{$\begin{array}{c}\text { Total } \\
\mathrm{UI}_{\mathrm{b}} \& \mathrm{UR}_{\mathrm{c}} \\
\mathrm{P} \& \mathrm{G}\end{array}$} & \multirow{3}{*}{$\begin{array}{c}\text { Total } \\
\text { I \& R } \\
\text { P\& G }\end{array}$} \\
\hline & \multicolumn{2}{|c|}{ Prompted } & \multicolumn{2}{|c|}{ Unprompted } & \multicolumn{2}{|c|}{ Unprompted } & & \\
\hline & $\mathrm{P}$ & $\mathrm{G}$ & $\mathrm{P}$ & $\mathrm{G}$ & $\mathrm{P}$ & $\mathrm{G}$ & & \\
\hline \multicolumn{9}{|l|}{$\mathrm{BL}\left(6_{\mathrm{a}}\right)$} \\
\hline Mean & 0.00 & - & 0.17 & 0.17 & 0.33 & 0.00 & 0.67 & 0.67 \\
\hline Range & - & - & $0-1$ & $0-1$ & $0-2$ & - & $0-3$ & $0-3$ \\
\hline \multicolumn{9}{|l|}{ Low-P $\left(10_{a}\right)$} \\
\hline Mean & 2.8 & - & 0.00 & 0.00 & 0.6 & 0.00 & 0.6 & 3.4 \\
\hline Range & $1-5$ & - & - & - & $0-2$ & - & $0-2$ & $2-6$ \\
\hline \multicolumn{9}{|l|}{$\operatorname{High}-\mathrm{P}\left(13_{\mathrm{a}}\right)$} \\
\hline Mean & 7.23 & - & 3.00 & 0.92 & 6.85 & 0.15 & 10.92 & 18.15 \\
\hline Range & $6-8$ & - & $0-7$ & $0-10$ & $0-15$ & $0-1$ & $0-18$ & $8-25$ \\
\hline \multicolumn{9}{|l|}{ Low-P $\left(8_{a}\right)$} \\
\hline & 7.75 & - & 12.50 & 0.25 & 5.88 & 0.13 & 18.75 & 26.50 \\
\hline & $7-8$ & - & $7-23$ & $0-2$ & $1-16$ & $0-1$ & $13-39$ & $18-47$ \\
\hline \multicolumn{9}{|c|}{ Maintenance $\left(6_{a}\right)$} \\
\hline Mean & - & - & 11.67 & 2.67 & 7.50 & 1.17 & 23.00 & 23.00 \\
\hline Range & - & - & $5-23$ & $0-10$ & $5-11$ & $0-3$ & $14-31$ & $14-31$ \\
\hline \multirow{3}{*}{ Paul } & \multicolumn{4}{|c|}{ I } & \multicolumn{2}{|c|}{$\mathrm{R}$} & Total & Total \\
\hline & \multicolumn{2}{|c|}{ Prompted } & \multicolumn{2}{|c|}{ Unprompted } & \multicolumn{2}{|c|}{ Unprompted } & $\mathrm{UI}_{\mathrm{b}} \& \mathrm{UR}_{\mathrm{c}}$ & $I \& R$ \\
\hline & $\mathrm{P}$ & $\mathrm{G}$ & $\mathrm{P}$ & $\mathrm{G}$ & $\mathrm{P}$ & $\mathrm{G}$ & $P \& G$ & $P \& G$ \\
\hline \multicolumn{9}{|l|}{$\operatorname{BL}\left(10_{a}\right)$} \\
\hline Mean & 0.00 & - & 0.00 & 0.00 & 0.00 & 0.00 & 0.00 & 0.00 \\
\hline Range & - & - & - & - & - & - & - & - \\
\hline \multicolumn{9}{|l|}{ Low-P $\left(11_{\mathrm{a}}\right)$} \\
\hline Mean & 3.00 & - & 0.00 & 0 & 0.27 & 0.00 & 0.27 & 3.27 \\
\hline Range & $1-4$ & - & - & - & $0-3$ & - & $0-3$ & $1-6$ \\
\hline \multicolumn{9}{|l|}{ High-P(18 $)$} \\
\hline Mean & 7.94 & - & 0.39 & 0 & 7.89 & 0.00 & 8.28 & 16.22 \\
\hline Range & $7-8$ & - & $0-3$ & - & $6-12$ & - & $5-15$ & $12-23$ \\
\hline \multicolumn{9}{|l|}{ Low-P(11 $\mathrm{a})$} \\
\hline Mean & 7.91 & - & 0.45 & 0 & 1.55 & 0.27 & 2.27 & 10.18 \\
\hline Range & $7-8$ & - & $0-2$ & - & $0-5$ & $0-3$ & $0-6$ & $8-14$ \\
\hline \multicolumn{9}{|c|}{ Maintenance $\left(4_{a}\right)$} \\
\hline Mean & - & - & 0.50 & 0 & 2.50 & 1.75 & 4.75 & 4.75 \\
\hline Range & - & - & $0-1$ & - & $1-4$ & $0-4$ & $1-9$ & $1-9$ \\
\hline
\end{tabular}

a- Number of sessions

$\mathrm{b}$-Unprompted initiation

c-Unprompted response

Continued

Table 4.10: The mean number of intervals and range of the target children's social initiations (I) and responses (R) to the peer $(P)$ and generality peer $(G)$ in the intervention settings. 
Table 4.10 (continued)

\begin{tabular}{|c|c|c|c|c|c|c|c|c|}
\hline \multirow{3}{*}{ Chris } & \multicolumn{4}{|c|}{ I } & \multicolumn{2}{|c|}{$\mathrm{R}$} & \multirow{3}{*}{$\begin{array}{c}\text { Total } \\
\frac{\mathrm{UI}_{\mathrm{b}} \& \mathrm{UR}_{\mathrm{c}}}{\mathrm{P} \& \mathrm{G}}\end{array}$} & \multirow{2}{*}{$\begin{array}{l}\text { Total } \\
\text { I \& R }\end{array}$} \\
\hline & \multicolumn{2}{|c|}{ Prompted } & \multicolumn{2}{|c|}{ Unprompted } & \multicolumn{2}{|c|}{ Unprompted } & & \\
\hline & $\mathrm{P}$ & $\mathrm{G}$ & $\mathrm{P}$ & $\mathrm{G}$ & $\mathrm{P}$ & $\mathrm{G}$ & & $P \& G$ \\
\hline \multicolumn{9}{|l|}{$\mathrm{BL}\left(16_{\mathrm{a}}\right)$} \\
\hline Mean & 0.00 & - & 0.00 & 0.00 & 0.00 & 0.13 & 0.13 & 0.13 \\
\hline Range & - & - & - & - & - & $0-1$ & $0-1$ & $0-1$ \\
\hline \multicolumn{9}{|l|}{ Low-P(10a $)$} \\
\hline Mean & 1.10 & - & 0.00 & 0.00 & 0.00 & 0.00 & 0.00 & 1.10 \\
\hline Range & $0-4$ & - & - & - & - & - & - & $0-4$ \\
\hline \multicolumn{9}{|l|}{ High-P(19a) } \\
\hline Mean & 5.37 & - & 0.95 & 0.05 & 9.68 & 0.11 & 10.79 & 16.16 \\
\hline Range & $4-8$ & - & $0-6$ & $0-1$ & $4-19$ & $0-2$ & $4-23$ & $8-30$ \\
\hline \multicolumn{9}{|l|}{ Low-P(7a) } \\
\hline Mean & 7.14 & - & 4.29 & 0.43 & 15.00 & 3.29 & 23.00 & 30.14 \\
\hline Range & $6-8$ & - & $0-11$ & $0-2$ & $5-30$ & $0-7$ & $15-48$ & $21-55$ \\
\hline \multicolumn{9}{|c|}{ Maintenance $\left(1_{\mathrm{a}}\right)$} \\
\hline Mean & 0 & - & 4 & 0 & 12 & 0 & 16 & 16 \\
\hline Range & - & - & - & - & - & - & - & - \\
\hline
\end{tabular}




\begin{tabular}{|c|c|c|c|c|c|c|c|c|c|c|c|c|}
\hline \multirow[t]{3}{*}{ Stacie } & \multicolumn{4}{|c|}{$\bar{I}$} & \multirow{2}{*}{\multicolumn{2}{|c|}{$\begin{array}{c}\mathbf{R} \\
\text { Unprompted }\end{array}$}} & \multirow{2}{*}{\multicolumn{3}{|c|}{$\begin{array}{c}\text { I \& } \mathbf{R} \\
\text { Unprompted }\end{array}$}} & \multirow{2}{*}{\multicolumn{3}{|c|}{$\begin{array}{c}\text { Total I \& } \mathbf{R} \\
\text { Prompted \& Unprompted }\end{array}$}} \\
\hline & \multicolumn{2}{|c|}{ Prompted } & \multicolumn{2}{|c|}{ Unprompted } & & & & & & & & \\
\hline & $\mathrm{T}$ & $\mathrm{G}$ & $\mathrm{T}$ & $\mathrm{G}$ & $\mathrm{T}$ & $\mathrm{G}$ & $\mathrm{T}$ & $\mathrm{G}$ & Total & $\mathrm{T}$ & G & Total \\
\hline \multicolumn{13}{|l|}{$\operatorname{BL}\left(6_{a}\right)$} \\
\hline Mean & - & - & 0.67 & 3.17 & 0.00 & 1.67 & 0.67 & 4.83 & 5.50 & 0.67 & 4.83 & 5.50 \\
\hline Range & - & - & $0-4$ & $0-17$ & - & $0-7$ & $0-4$ & $0-20$ & $0-20$ & $0-4$ & $0-20$ & $0-20$ \\
\hline \multicolumn{13}{|c|}{ Low-P $\left(10_{a}\right)$} \\
\hline Mean & - & - & 2.1 & 3.4 & 1.7 & 0.8 & 3.8 & 4.2 & 8 & 3.8 & 4.2 & 8 \\
\hline Range & - & - & $0-7$ & $0-15$ & $0-3$ & $0-5$ & $0-8$ & $0-20$ & $2-20$ & $0-8$ & $0-20$ & $0-20$ \\
\hline \multicolumn{13}{|c|}{ High-P (13a) } \\
\hline Mean & 7.92 & - & 2.77 & 0.08 & 6.92 & 0.00 & 9.69 & 0.08 & 9.77 & 17.62 & 0.08 & 17.62 \\
\hline Range & $7-8$ & - & $0-8$ & $0-1$ & $4-11$ & - & $5-15$ & $0-1$ & $5-15$ & $13-23$ & $0-1$ & $13-23$ \\
\hline \multicolumn{13}{|l|}{ Low-P $\left(8_{\mathrm{a}}\right)$} \\
\hline Mean & - & - & 7.75 & 0.00 & 11.88 & 0.00 & 19.63 & 0.00 & 19.63 & 19.63 & 0.00 & 19.63 \\
\hline Range & - & - & $1-18$ & - & $6-24$ & - & $7-42$ & - & $7-42$ & $7-42$ & - & $7-42$ \\
\hline \multicolumn{13}{|c|}{ Maintenance $\left(6_{a}\right)$} \\
\hline Mean & - & - & 8.83 & 2.00 & 9.00 & 1.17 & 17.83 & 3.17 & 21.00 & 17.83 & 3.17 & 21.00 \\
\hline Range & - & - & $5-13$ & $0-5$ & $3-17$ & $0-5$ & $12-29$ & $0-10$ & $12-29$ & $12-29$ & $0-10$ & $12-29$ \\
\hline
\end{tabular}

$\mathrm{a}-$ Number of sessions

Continued

Table 4.11: The mean number of intervals and range of the peers' social initiations (I) and responses (R) to the target (T) and the generality peer $(\mathrm{G})$ in the intervention setting. 
Table 4.11 (continued)

\begin{tabular}{|c|c|c|c|c|c|c|c|c|c|c|c|c|}
\hline \multirow[t]{3}{*}{ Jennifer } & \multicolumn{4}{|c|}{ I } & \multirow{2}{*}{\multicolumn{2}{|c|}{$\begin{array}{c}\mathbf{R} \\
\text { Unprompted }\end{array}$}} & \multirow{2}{*}{\multicolumn{3}{|c|}{$\frac{\text { I \& R }}{\text { Unprompted }}$}} & \multirow{2}{*}{\multicolumn{3}{|c|}{$\begin{array}{c}\text { Total I \& } \mathbf{R} \\
\text { Prompted \& Unprompted }\end{array}$}} \\
\hline & \multicolumn{2}{|c|}{ Prompted } & \multicolumn{2}{|c|}{ Unprompted } & & & & & & & & \\
\hline & $\mathrm{T}$ & $\bar{G}$ & $\mathrm{~T}$ & $\mathrm{G}$ & $\mathrm{P}$ & $\mathrm{G}$ & $\mathrm{T}$ & $\mathrm{G}$ & Total & $\mathrm{T}$ & $\mathrm{G}$ & Total \\
\hline BL (10a) & & & & & & & & & & & & \\
\hline Mean & - & - & 0.00 & 2.80 & 0.00 & 2.10 & 0.00 & 4.90 & 4.90 & 0.00 & 4.90 & 4.90 \\
\hline Range & - & - & - & $0-9$ & - & $0-11$ & - & $0-18$ & $0-18$ & - & $0-18$ & $0-18$ \\
\hline Low-P (11a) & & & & & & & & & & & & \\
\hline Mean & - & - & 0.36 & 3.09 & 1.64 & 0.73 & 2.00 & 3.82 & 5.82 & 2.00 & 3.82 & 5.82 \\
\hline Range & - & - & $0-4$ & $0-7$ & $0-3$ & $0-2$ & $0-7$ & $0-9$ & $1-10$ & $0-7$ & $0-9$ & $1-10$ \\
\hline High-P (18a) & & & & & & & & & & & & \\
\hline Mean & 8.00 & - & 1.28 & 0.50 & 6.61 & 0.11 & 7.89 & 0.61 & 8.50 & 15.89 & 0.61 & 16.50 \\
\hline Range & - & - & $0-5$ & $0-4$ & $4-10$ & $0-1$ & $4-11$ & $0-4$ & $5-15$ & $12-23$ & $0-4$ & $12-23$ \\
\hline Low-P (11a) & & & & & & & & & & & & \\
\hline Mean & - & - & 1.73 & 1.82 & 7.09 & 0.91 & 8.82 & 2.73 & 11.55 & 8.82 & 2.73 & 11.55 \\
\hline Range & - & - & $0-6$ & $0-6$ & $6-8$ & $0-4$ & $7-13$ & $0-10$ & 8-19 & $7-13$ & $0-10$ & $8-19$ \\
\hline Maintenance & & & & & & & & & & & & \\
\hline Mean & - & - & 2.75 & 9.00 & 0.25 & 2.50 & 3.00 & 11.50 & 14.50 & 3.00 & 11.50 & 14.50 \\
\hline Range & - & - & $1-4$ & 2.19 & $0-1$ & $1-7$ & $1-4$ & $3-26$ & $4-30$ & $1-4$ & $3-26$ & $4-30$ \\
\hline
\end{tabular}


Table 4.11 (continued)

\begin{tabular}{|c|c|c|c|c|c|c|c|c|c|c|c|c|}
\hline \multirow[t]{3}{*}{ Hillary } & \multicolumn{4}{|c|}{ I } & \multirow{2}{*}{\multicolumn{2}{|c|}{$\frac{\mathbf{R}}{\text { Unprompted }}$}} & \multirow{2}{*}{\multicolumn{3}{|c|}{\begin{tabular}{|c|} 
I \& R \\
Unprompted
\end{tabular}}} & \multirow{2}{*}{\multicolumn{3}{|c|}{$\begin{array}{c}\text { Total I \& R } \\
\text { Prompted \& Unprompted }\end{array}$}} \\
\hline & \multicolumn{2}{|c|}{ Prompted } & \multicolumn{2}{|c|}{ Unprompted } & & & & & & & & \\
\hline & $\mathrm{T}$ & $G$ & $\mathrm{~T}$ & G & $\mathrm{T}$ & G & $\mathrm{T}$ & $\mathrm{G}$ & Total & $\mathrm{T}$ & G & Total \\
\hline BL (16a) & & & & & & & & & & & & \\
\hline Mean & - & - & 0.19 & 1.06 & 0.00 & 1.00 & 0.19 & 2.06 & 2.25 & 0.19 & 2.06 & 2.25 \\
\hline Range & - & - & $0-2$ & $0-7$ & - & $0-7$ & $0-2$ & $0-12$ & $0-12$ & $0-2$ & $0-12$ & $0-12$ \\
\hline Low-P (10a) & & & & & & & & & & & & \\
\hline Mean & - & - & 0.90 & 2.60 & 0.70 & 1.60 & 1.60 & 4.20 & 5.80 & 1.60 & 4.20 & 5.80 \\
\hline Range & - & - & $0-5$ & $0-7$ & $0-3$ & $0-7$ & $0-5$ & $0-14$ & $1-14$ & $0-5$ & $0-14$ & $1-14$ \\
\hline High-P (19a) & & & & & & & & & & & & \\
\hline Mean & 8.00 & - & 5.05 & 0.26 & 4.68 & 0.42 & 9.74 & 0.68 & 10.42 & 17.74 & 0.68 & 18.42 \\
\hline Range & - & - & $0-11$ & $0-2$ & $0-9$ & $0-4$ & $1-20$ & $0-6$ & $1-20$ & $9-28$ & $0-6$ & $9-28$ \\
\hline Low-P (7a) & & & & & & & & & & & & \\
\hline Mean & - & - & 16.00 & 1.29 & 8.43 & 1.00 & 24.43 & 2.29 & 26.71 & 24.43 & 2.29 & 26.71 \\
\hline Range & - & - & $6-31$ & $0-5$ & $2-16$ & $0-4$ & $10-47$ & $0-9$ & $16-47$ & $10-47$ & $0-9$ & $16-47$ \\
\hline Maintenance & & & & & & & & & & & & \\
\hline Mean & - & - & 16 & 0 & 4 & 0 & 20 & 0 & 20 & 20 & 0 & 20 \\
\hline Range & - & - & 16 & - & 4 & - & 20 & - & 20 & 20 & - & 20 \\
\hline
\end{tabular}


Stacie, Eric's peer, demonstrated few interactions with Eric. The mean number of intervals of total unprompted social initiations and responses was 5.50 with a range of 0 to 20 . The mean number of intervals of total unprompted social initiations and responses to Eric, and the generality peer were 0.67 with a range of 0 to 4 , and 4.83 with a range of 0 to 20 , respectively. The number of intervals of unprompted initiations to Eric ranged from 0 to 4 with a mean of 0.67 , and the number of intervals of unprompted initiations to the generality peer ranged from 0 to 17 with a mean of 3.17 . The mean number of intervals of unprompted responses to Eric and to the generality peer was 0 , and 1.67 with a range of 0 to 7 , respectively.

Low-probability requests alone. During 10 sessions, the mean number of intervals of the total social initiations and responses to the peer and the generality peer was 3.4 with a range from 2 to 6 . The mean number of intervals of prompted initiations (i.e., responses to the low-probability requests) was 2.8 with a range of 1 to 5 . The mean number of intervals of unprompted responses to the peer was 0.6 with a range of 0 to 2 . Eric did not spontaneously initiate to the peer and generality peer without low-probability prompts. During this condition, Eric's unprompted social behaviors toward the peer and generality peer remained low.

Stacie engaged in more play with Eric during this condition than during baseline. However, the levels of her interactions with Eric were low. The mean number of intervals of total unprompted social initiations and responses to the target child and the generality peer was 8 with a range of 0 to 20.The mean number of intervals of unprompted social initiations and responses to Eric, and to the generality peer was 3.8 with a range of 0 to 8 , and 4.2 with a range of 0 to 20 . The mean number of intervals of unprompted initiations 
to Eric and to the generality peer was respectively, 2.1 with a range of 0 to $7,3.4$ with a range of 0 to 15. The mean number of intervals of unprompted responses to Eric and the generality peer was 1.7 with a range of 0 to $3,0.8$ with a range of 0 to 5 , respectively.

High-probability request sequences with embedded peer modeling. Eric's mean number of intervals of the total social initiations and responses to the peer and to the generality peer was 18.15 with a range of 8 to 25 during 13 sessions. The mean number of his prompted initiations increased from 2.8 to 7.23 . The mean number of intervals of total unprompted social initiations and responses to the peer and to generality peer was 10.92 with a range of 0 to 18 . The number of intervals of unprompted initiations to the peer ranged from 0 to 7 with a mean of 3 , and the number of intervals of unprompted initiations to generality peer ranged from 0 to 10 with a mean of 0.92 . The mean number of intervals of unprompted responses to the peer and the generality peer was 6.85 with a range of 0 to 15 , and 0.15 with a range of 0 to 1 , respectively. The data demonstrated the immediate increase in the level of his interactions with the peer and the generality peer in this condition.

Stacie's total initiations and responses to Eric and the generality peer ranged from 13 to 23 with a mean number of 17.62 . The mean number of intervals of the prompted initiations (i.e., responses to the low-probability requests) that were performed as a model was 7.92 with a range from 7 to 8 . The mean number of intervals of total unprompted initiations and responses to the target child and the generality peer was 9.77 with a range of 5 to 15 . The mean number of intervals of unprompted social initiations and responses to Eric, and the generality peer was 9.69 with a range of 5 to $15,0.08$ with a range of 0 to 1, respectively. The mean number of intervals of unprompted initiations to Eric and the 
generality peer was 2.77 with a range of 0 to 8 , and 0.08 with a range of 0 to 1 , respectively. The mean number of intervals of unprompted responses to Eric was 6.92 with a range of 4 to 11 , however, she engaged in no responses to the generality peer. She engaged in more social interactions with Eric than the generality peer during this condition. Her unprompted initiations to Eric remained at the same level as the previous condition, however, her unprompted responses to Eric increased more than during the low-probability request condition.

Low-probability requests alone. The condition occurred for eight sessions. Eric's total social initiations and responses had a mean number of 26.50 with a range of 18 to 47 . The prompted initiations maintained at a mean number of intervals of 7.75 after removing the high-probability request sequence. The number of intervals of the total unprompted social initiations and responses to the peer and to the generality peer ranged from 13 to 39 with a mean of 18.75 . The mean number of intervals of the unprompted social initiations to the peer and the generality peer were 12.50 with a range of 7 to 23 , and 0.25 with a range of 0 to 2 , respectively. The mean number of intervals of unprompted social responses to the peer and the generality peer were 5.88 with a range of 1 to 16 , and 0.13 with a range of 0 to 1 , respectively. The unprompted social initiations and responses continued the increasing trend.

Stacie's mean number of intervals of the total unprompted social initiations and responses to Eric was 19.63 with a range of 7 to 42 . Stacie's mean number of intervals of unprompted social initiations and responses to Eric, and the generality peer was 19.63 with a range of 7 to 42 , and 0 respectively. Stacie engaged in no interactions with the generality peer during this condition. The intervals of unprompted initiations to Eric 
ranged from 1 to 18 with a mean number of 7.75 . The mean number of intervals of the unprompted responses to Eric was 11.88 with a range of 6 to 24 . Stacie's interactions with Eric increased more than in the previous high-probability request sequence condition.

Maintenance. Over 6 sessions Eric's total unprompted initiations and responses had a mean of 23.33 with a range from 14 to 31 . The mean number of intervals of the unprompted initiations to the peer and the generality peer was 11.67 with a range from 5 to 23 , and 2.67 with a range from 0 to 10 , respectively. The mean number of intervals of unprompted responses to the peer and generality peer was 7.50 with a range of 5 to 11 , and 1.17 with a range of 0 to 3 , respectively. Eric maintained an increased level of social initiations and responses to the peer without any prompts.

Stacie's total unprompted social initiations and responses to Eric and the generality peer ranged from 12 to 29 with a mean number of 21 . Stacie's mean number of intervals of total unprompted social initiations and responses to Eric, and the generality peer was 17.83 with a range from 12 to 29 , and 3.17 with a range from 0 to 10 , respectively. The mean number of unprompted initiations to Eric and the generality peer was 8.83 with a range from 5 to 13 , and 2 with a range from 0 to 5 , respectively. The mean number of intervals of unprompted responses to Eric and the generality peer was 9 with a range of 3 to 17 , and 1.17 with a range of 0 to 5 , respectively. Stacie's interactions with Eric remained at the same level as the previous low-probability requests condition. 


\section{Paul and Jennifer}

Baselines. Paul exhibited no social interactions to the peer, Jennifer, or the generality peer during 10 sessions. Paul's peer, Jennifer's unprompted initiations and responses to the generality peer had a mean of 4.90 with a range from 0 to 18 . Jennifer engaged in no interactions with Paul during this condition.

Low-probability requests alone. Over 11 sessions, the mean number of intervals of the total social initiations and responses to the peer and generality peer was 3.27 with a range from 1 to 6 . Paul's mean number of intervals of prompted initiations (i.e., response to the low-probability requests) was 3.0 with a range of 1 to 4 . His unprompted social behavior was the responses to the peer with a mean number of intervals of 0.27 , and with a range of 0 to 3 . The levels of social interactions were low.

The mean number of Jennifer's number of intervals of the total unprompted initiations and responses was 5.82 with a range of 1 to 10 . Her mean number of intervals of total unprompted initiations and responses to Paul and the generality peer was 2 with a range from 0 to 7 , and 3.82 with a range from 0 to 9 , respectively. The mean number of intervals of the unprompted initiations to Paul and the generality peer was 0.36 with a range from 0 to 4 , and 3.09 with a range from 0 to 7 , respectively. The mean number of intervals of the unprompted responses to Paul and the generality peer was 1.64 with a range from 0 to 3 , and 0.73 with a range from 0 to 2 , respectively. While Jennifer's social interactions with Paul increased slightly they remained very low.

High-probability request sequences with embedded peer modeling. The mean number of intervals of Paul's total social initiations and responses was 16.22 with a range from 12 to 23. The mean number of intervals of prompted initiations increased from 3 to 
7.94 during this condition. The mean number of intervals of the total unprompted social initiations and responses ranged from 5 to 15 with a mean of 8.28. Paul engaged in no interactions with the generality peer. The unprompted social initiations increased slightly from the previous condition with a mean number of intervals of 0.39 , and a range of 0 to 3. The mean number of intervals of the unprompted responses to the peer was 7.89 with a range from 6 to 12. Paul's overall social initiations and responses including unprompted social behaviors increased from the previous condition with the implementation of the high-probability request sequence using embedded peer modeling.

The mean number of intervals of Jennifer's total social initiations and responses to Paul and the generality peer was 16.50 with a range of 12 to 23 . The mean number of intervals of the prompted initiations to Paul was 8 . The mean number of intervals of the total unprompted initiations and responses to Paul and to the generality peer was 8.50 with a range from 5 to 15 . The mean number of intervals of unprompted initiations and responses to Paul and the generality peer was 7.89 with a range from 4 to 11 , and 0.61 with a range from 0 to 4, respectively. She engaged in the unprompted initiations to Paul with a mean number of 1.28 and with a range from 0 to 5 , and unprompted initiations to the generality peer ranged from 0 to 4 with a mean number of 0.50 . The mean number of intervals of the unprompted responses to Paul and to the generality peer was 6.61 with a range of 4 to 10 , and 0.11 with a range of 0 to 1 , respectively. Jennifer engaged in more interactions with Paul in this condition.

Low-probability requests alone. There were 11 data points during this condition. The mean number of intervals of Paul's total social initiations and responses was 10.18 with a range from 8 to 14 . The prompted initiations maintained at a mean number of 
intervals of 7.91 during the second low-probability request condition. The intervals of the total unprompted social initiations and responses ranged from 0 to 6 with a mean of 2.27. The mean number of intervals of the unprompted social initiations to the peer was 0.45 with a range from 0 to 2 . The mean number of intervals of the unprompted social responses to the peer and the generality peer was 1.55 with a range of 0 to 5 , and 0.27 with a range from 0 to 3 , respectively. Although his prompted initiations and unprompted initiations maintained at the same level as in the previous condition, his unprompted social responses decreased from the previous condition.

During this condition, the levels of Jennifer's unprompted social interactions with Paul remained the same as the previous condition although her total social initiations and response to Paul decreased slightly. The unprompted initiations and response to Paul and the generality peer ranged from 8 to 19 with a mean number of 11.55 . Her mean number of intervals of total unprompted initiations and responses to Paul and the generality peer was 8.82 with a range from 7 to 10 , and 2.73 with a range from 0 to 10 , respectively. The mean number of intervals of unprompted initiations to Paul and to the generality peer was 1.73 with a range from 0 to 6 , and 1.82 with a range from 0 to 6 , respectively. The mean number of intervals of unprompted responses to Paul and to the generality peer was 7.09 with a range from 6 to 8 , and 0.91 with a range from 0 to 4 , respectively.

Maintenance. During four sessions, the mean number of intervals of Paul's total unprompted initiations and responses ranged from 1 to 9 with a mean of 4.75 . The mean number of intervals of the unprompted initiations to the peer was 0.50 with a range from 0 to 1 . He engaged in no initiations with the generality peer. The mean number of 
intervals of the unprompted responses to the peer and the generality peer was 2.50 with a range of 1 to 4 , and 1.75 with a range of 0 to 4 , respectively. The unprompted initiations and responses increased slightly from the previous low-probability request condition, and he engaged in responses to the generality peer during this condition although his total social initiations and responses decreased slightly.

The mean number of intervals of Jennifer's total unprompted initiations and responses to Paul and the generality peer was 14.50 with a range of 4 to 30 . The mean number of intervals of Jennifer's unprompted initiations and responses to Paul and the generality peer was 3 with a range from 1 to 4 , and 11.50 with a range from 3 to 26 , respectively. The mean number of intervals of the unprompted initiations to Paul and to the generality peer was 2.75 with a range from 1 to 4 , and 9 with a range from 2 to 19 , respectively. The mean number of intervals of the unprompted responses to Paul and to the generality peer was 0.25 with a range from 0 to 1 , and 2.50 with a range from 1 to 7 , respectively. The unprompted initiations to Paul slightly increased than during the previous condition, however, her unprompted responses to Paul decreased during this condition. Jennifer engaged in more social interactions with the generality peer than with Paul.

\section{Chris and Hilary}

Baseline. Across a total of 16 sessions, the mean number of intervals of Chris's total unprompted social initiations and responses ranged from 0 to 1 with mean number of intervals of 0.13 . His social behavior engaged during baseline was the responses to the generality peer with a mean number of intervals of 0.13 with a range from 0 to 1 . The levels of the social interactions were very low. 
Hilary, Chris's peer demonstrated low levels of interactions with Chris during baseline. The mean number of intervals of the total unprompted initiations and responses to Chris and the generality peer was 2.25 with a range of 0 to 12 . The mean number of intervals of unprompted initiations and responses to Chris and to the generality peer was 0.19 with a range from 0 to 2 , and 2.06 with a range from 0 to 12 , respectively. The mean number of intervals of the unprompted initiations to Chris and to the generality peer was 0.19 , with a range from 0 to 2 , and 1.06 with a range from 0 to 7 , respectively. Hilary exhibited no responses with Chris; the mean number of intervals of the unprompted responses to the generality peer was 1 with a range from 0 to 7 .

Low-probability requests. The mean number of intervals of Chris's total social initiations and responses was 0.10 with a range of 0 to 4 over 10 sessions. The mean number of intervals of prompted initiations (i.e., responses to low-probability requests) was 1.10 with a range from 0 to 4 . Chris engaged in no initiations and responses with the peer and the generality peer but in only responses to the low-probability requests (i.e., prompted initiations).

The mean number of Hilary's total unprompted initiations and responses to Chris and to the generality peer was 5.80 with a range of 1 to 14 . Her mean number of intervals of unprompted initiations and responses to Chris and to the generality peer were 1.60 with a range from 0 to 5 , and 4.20 with a range from 0 to 14 . The mean number of intervals of unprompted initiations to Chris and to the generality peer was 0.90 with a range from 0 to 5 , and 2.60 with a range from 0 to 7 , respectively. The mean number of 
intervals of unprompted responses to Chris and to the generality peer was 0.70 with a range from 0 to 3 , and 1.60 with a range from 0 to 7 . Hilary's interactions with Chris remained at low levels during this condition.

High-probability request sequences with embedded peer modeling. The mean number of intervals of Chris's total social initiations and responses ranged from 8 to 30 with a mean of 16.16 over 19 sessions. The prompted initiations increased from the mean of intervals of 1.10 to 5.37 . The mean number of intervals of the total unprompted social initiations and responses to the peer and to the generality peer was 10.79 with a range from 4 to 23 . The mean number of intervals of unprompted initiations to the peer and the generality peer was 0.95 with a range from 0 to $6,0.05$ with a range of 0 to 1 , respectively. The number of intervals of unprompted responses to the peer ranged from 4 to 19 with a mean of 9.68 and the number of intervals of the unprompted responses to the generality ranged from 0 to 2 with a mean of 0.11 . Chris's social behaviors toward the peer and the generality peer sharply increased as compared to the previous baseline and the low-probability requests condition.

The mean number of Hilary's total initiations and responses to Chris and the generality peer was 18.42 with a range of 9 to 28 . The mean number of intervals of prompted initiations was 8 . The total mean number of intervals of unprompted initiations and responses to Chris and to the generality peer was 10.42 with a range of 1 to 20 . Her mean number of intervals of unprompted initiations and responses to Chris and to the generality peer was 9.74 with a range from 1 to 20 , and 0.68 with a range from 0 to 9 . The mean number of intervals of unprompted initiations to Chris and to the generality 
peer was 5.05 with a range from 0 to 11 , and 0.26 with a range from 0 to 2 , respectively. The intervals of unprompted responses to Chris ranged from 0 to 9 with a mean number of 4.68 , and the intervals of the unprompted responses to the generality peer ranged from 0 to 4 with a mean number of 0.42 . Hilary engaged in more social interactions with Chris during this condition than during the previous low-probability requests condition.

Low-probability requests alone. The mean number of intervals of Chris's total social initiations and responses to the peer and to the generality peer ranged from 21 to 55 with a mean of 30.14 over 7 sessions. His prompted initiations (i.e., responses to the lowprobability requests) increased from the mean of intervals of 5.38 to 7.14 with a range from 6 to 8 . The mean number of intervals of the total unprompted social initiations and responses ranged from 15 to 48 with a mean of 23.00 . The mean number of intervals of the unprompted social initiations to the peer and the generality peer was 4.29 with a range from 0 to 11, and 0.43 with a range from 0 to 2 , respectively. The mean number of intervals of the unprompted social responses to the peer and the generality peer was 15 with a range from 5 to 30 , and 3.29 with a range from 0 to 7 respectively. Chris's unprompted initiations and responses continued the increasing trend and he engaged in more social interactions with the generality peer than in the high-probability request sequences using peer modeling.

The mean number of Hilary's total unprompted initiations and responses to Chris and the generality peer was 26.71 with a range of 16 to 47 . The mean number of intervals of unprompted initiations and responses to Chris and to the generality peer was 24.43 with a range from 10 to 47 , and 2.29 with a range from 0 to 9 , respectively. The mean 
number of intervals of unprompted initiations to Chris and to the generality peer was 16 with a range from 6 to 31 , and 1.29 with a range from 0 to 5 . The mean number of unprompted responses to Chris and the generality peer was 8.43 with a range from 2 to 16, and 1 with a range from 0 to 4 . Hilary's interactions toward Chris demonstrated continuous increase.

Maintenance. One data point was obtained for Chris with withdrawing the lowprobability prompts. Chris's unprompted social initiations and responses to the peer were 16. In this session he engaged in 4 intervals of initiations to the peer, and 12 intervals of responses to the peer in this session. He engaged in social interactions only with the peer due to the absence of the generality peer. Chris maintained his increased unprompted initiations and responses after removing the low-probability prompts.

The mean number of intervals of Hilary's unprompted initiations and responses to Chris was 20. The mean number of intervals of unprompted initiations to Chris was 16 , and of unprompted responses to Chris was 4. Her interactions toward Chris maintained at the same level as the previous low-probability request condition during maintenance.

\section{Social Interactions in the Generality Setting}

This following section will address the research question, "What are the effects of the use of high-probability request sequences with embedded peer modeling on the social interactions of young children with autism toward their typically developing peers during the generality sessions?" The results of each child's total number of intervals of unprompted initiations to peer and generality peer, and responses to peer and generality peer are represented for all experimental conditions during the generality sessions. Additionally, the social behaviors of the trained peers toward each target child are 
reported. Figure 4.3 presents the number of intervals of social initiations and response to the peer and generality peer. Table 4.12 presents the mean number of intervals and range of target children's social initiations and responses to trained peers and generality peers in the generality setting, and Table 4.13 presents the mean number of intervals and range of the peers' social initiations and responses to the target children and generality peers in the generality setting.

Eric and Stacie

During the generality sessions for Eric, the mean number of intervals of total unprompted initiations and responses ranged from 0 to 1 with a mean of 0.50 . He displayed only one initiation to the generality peer during two sessions. Eric's peer, Stacie, did interact with the generality peer in this condition. During two conditions, Stacie had one initiation to the generality peer.

During the low-probability requests condition for Eric, his interactions slightly increased, however, his interactions remained at low levels. The mean number of intervals of total unprompted social initiations and responses to the peer and the generality peer ranged from 1 to 3 with a mean of 2 . The mean number of intervals of unprompted initiations to the peer was 1 . The number of intervals of unprompted response to the peer ranged from 0 to 2 with a mean of 1 . He engaged no social interactions with the generality peer. Eric's peer, Stacie, showed slight increases in initiations to Eric during this condition. The mean number of total unprompted social initiations and responses to the peer and generality peer was 15 with a range from 12 to 18. Stacie had a mean number of 2 unprompted initiations to the target child during two sessions of the low-probability request condition. The mean number of intervals of 


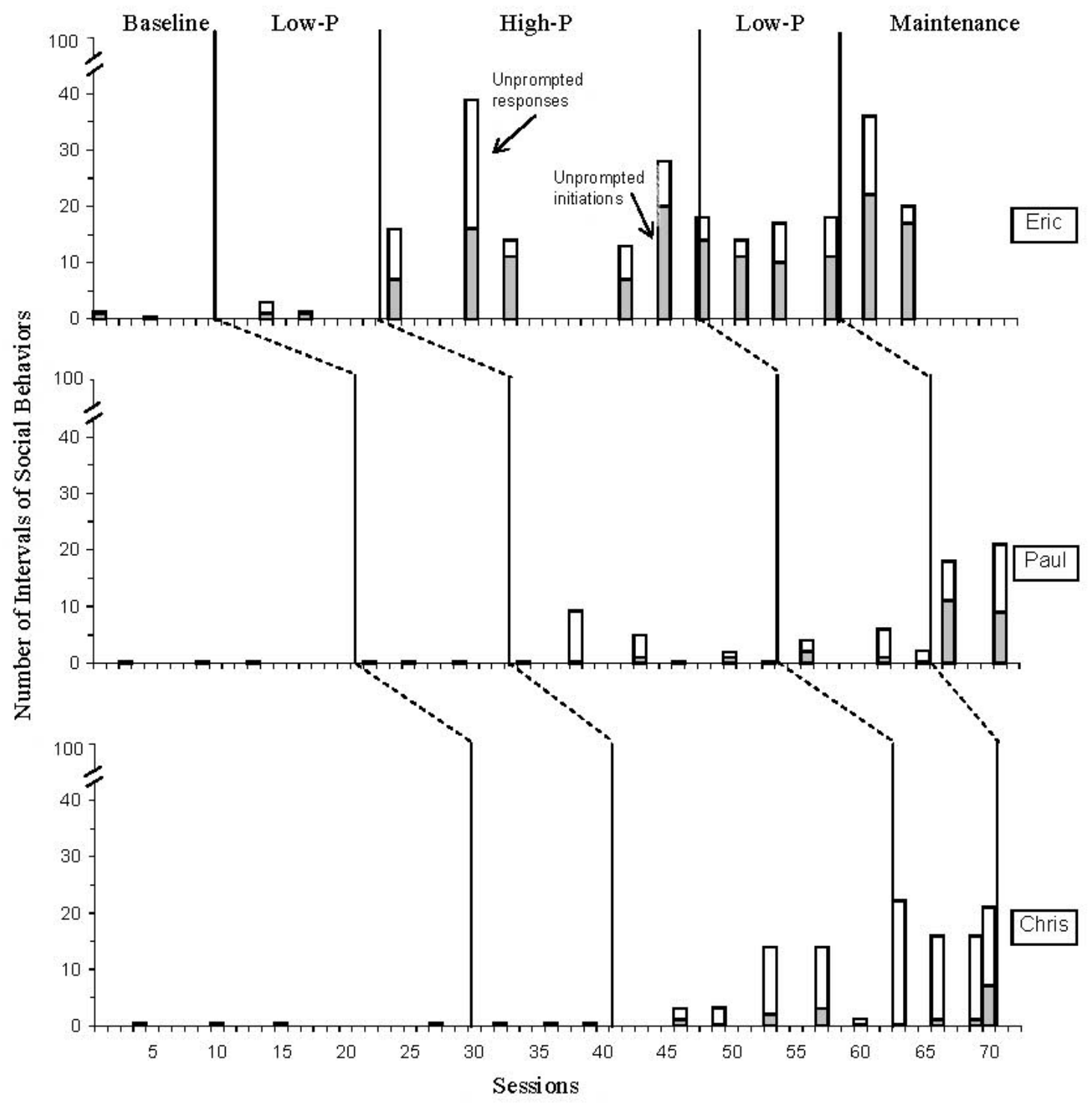

Figure 4.3: Number of intervals of social behaviors in the generality setting. 


\begin{tabular}{|c|c|c|c|c|c|c|c|}
\hline \multirow[t]{2}{*}{ Eric } & \multicolumn{3}{|c|}{$\overline{U_{\mathrm{b}}}$} & \multicolumn{3}{|c|}{$\mathrm{UR}_{\mathrm{c}}$} & \multirow{2}{*}{$\frac{\text { Total UI \& UR }}{\text { P \& G }}$} \\
\hline & $\mathrm{P}$ & $G$ & Total & $\mathrm{P}$ & $\mathrm{G}$ & Total & \\
\hline \multicolumn{8}{|l|}{$\operatorname{BL}\left(2_{a}\right)$} \\
\hline Mean & 0.00 & 0.50 & 0.50 & 0.00 & 0.00 & 0.00 & 0.50 \\
\hline Range & - & $0-1$ & $0-1$ & - & - & - & $0-1$ \\
\hline \multicolumn{8}{|c|}{ Low-P $\left(2_{\mathrm{a}}\right)$} \\
\hline Mean & 1 & 0 & 1 & 1 & 0 & 1 & 2 \\
\hline Range & - & - & - & $0-2$ & - & $0-2$ & $1-3$ \\
\hline \multicolumn{8}{|c|}{ High-P (5a) } \\
\hline Mean & 4.60 & 7.60 & 12.20 & 3.40 & 6.40 & 9.80 & 22.00 \\
\hline Range & $1-10$ & $6-13$ & $7-20$ & $0-13$ & $1-10$ & $3-23$ & $13-39$ \\
\hline \multicolumn{8}{|c|}{ Low-P (4a) } \\
\hline Mean & 5.75 & 7.67 & 11.67 & 4.00 & 1.67 & 5.25 & 16.75 \\
\hline Range & $3-11$ & $0-8$ & $10-14$ & $2-7$ & $0-3$ & $3-7$ & $7-18$ \\
\hline \multicolumn{8}{|c|}{ Maintenance $\left(2_{\mathrm{a}}\right)$} \\
\hline Mean & 3.00 & 16.50 & 19.50 & 0.50 & 8.00 & 8.50 & 28.00 \\
\hline Range & $0-6$ & $11-22$ & $17-22$ & $0-1$ & $2-14$ & $3-14$ & $20-36$ \\
\hline \multirow[t]{2}{*}{ Paul } & & $\mathrm{UI}_{\mathrm{b}}$ & & & $\mathrm{UR}_{\mathrm{c}}$ & & Total UI \& UR \\
\hline & $\mathrm{P}$ & G & Total & $\mathrm{P}$ & $\mathrm{G}$ & Total & $P \& G$ \\
\hline \multicolumn{8}{|l|}{ BL (3 a) } \\
\hline Mean & 0.00 & 0.00 & 0.00 & 0.00 & 0.00 & 0.00 & 0.00 \\
\hline Range & - & - & - & - & - & - & - \\
\hline \multicolumn{8}{|c|}{ Low-P (3 a) } \\
\hline Mean & 0.00 & 0.00 & 0.00 & 0.00 & 0.00 & 0.00 & 0.00 \\
\hline Range & - & - & - & - & - & - & - \\
\hline \multicolumn{8}{|c|}{ High-P $\left(6_{a}\right)$} \\
\hline Mean & 0.33 & 0.00 & 0.33 & 1.00 & 1.33 & 2.33 & 2.67 \\
\hline Range & $0-1$ & - & $0-1$ & $0-4$ & $0-5$ & $0-9$ & $0-9$ \\
\hline \multicolumn{8}{|c|}{ Low-P (3 a) } \\
\hline Mean & 0.67 & 0.33 & 1.00 & 0.67 & 2.33 & 3.00 & 4.00 \\
\hline Range & $0-2$ & $0-1$ & $0-2$ & $0-2$ & $0-5$ & $2-5$ & $2-6$ \\
\hline \multicolumn{8}{|c|}{ Maintenance $(2$ a) } \\
\hline Mean & 6.50 & 3.50 & 10.00 & 4.50 & 5.00 & 9.50 & 19.50 \\
\hline Range & $2-11$ & $0-7$ & $9-11$ & $2-7$ & $0-10$ & $7-12$ & $18-21$ \\
\hline
\end{tabular}

Table 4.12: The mean number of intervals and range of the target children's social initiations (I) and responses (R) to the peer $(\mathrm{P})$ and generality peer $(\mathrm{G})$ in the generality setting. 
Table 4.12 (continued)

\begin{tabular}{|c|c|c|c|c|c|c|c|}
\hline \multirow[t]{2}{*}{ Chris } & \multicolumn{3}{|c|}{$\mathrm{UI}_{\mathrm{b}}$} & \multicolumn{3}{|c|}{$\mathrm{UR}_{\mathrm{c}}$} & \multirow{2}{*}{$\begin{array}{c}\text { Total UI\&UR } \\
\text { P \& G }\end{array}$} \\
\hline & $\mathrm{P}$ & G & Total & $\mathrm{P}$ & G & Total & \\
\hline \multicolumn{8}{|l|}{$\mathrm{BL}\left(4_{\mathrm{a}}\right)$} \\
\hline Mean & 0.00 & 0.00 & 0.00 & 0.00 & 0.00 & 0.00 & 0.00 \\
\hline Range & - & - & - & - & - & - & - \\
\hline \multicolumn{8}{|c|}{ Low-P (3 a) } \\
\hline Mean & 0.00 & 0.00 & 0.00 & 0.00 & 0.00 & 0.00 & 0.00 \\
\hline Range & - & - & - & - & - & - & - \\
\hline \multicolumn{8}{|c|}{ High-P $\left(5_{\mathrm{a}}\right)$} \\
\hline Mean & 0.80 & 0.40 & 1.20 & 2.00 & 3.80 & 5.80 & 7.00 \\
\hline Range & $0-2$ & $0-1$ & $0-3$ & $0-4$ & $0-10$ & $1-11$ & $1-14$ \\
\hline \multicolumn{8}{|c|}{ Low-P (4 a) } \\
\hline Mean & 2.25 & 0.00 & 2.25 & 11.75 & 4.75 & 16.50 & 18.75 \\
\hline Range & $0-7$ & - & $0-7$ & $6-15$ & $0-16$ & $14-22$ & $16-22$ \\
\hline \multicolumn{8}{|c|}{ Maintenance } \\
\hline Mean & - & - & - & - & - & - & - \\
\hline Range & - & - & - & - & - & - & - \\
\hline
\end{tabular}




\begin{tabular}{|c|c|c|c|c|c|c|c|c|c|}
\hline \multirow[t]{2}{*}{ Stacie } & \multicolumn{3}{|c|}{$\mathrm{UI}_{\mathrm{b}}$} & \multicolumn{3}{|c|}{$\mathrm{UR}_{\mathrm{c}}$} & \multicolumn{3}{|c|}{ Total UI \& UR } \\
\hline & $\mathrm{T}$ & $\mathrm{G}$ & Total & $\mathrm{T}$ & $\mathrm{G}$ & Total & $\mathrm{T}$ & $\mathrm{G}$ & Total \\
\hline \multicolumn{10}{|l|}{$\operatorname{BL}\left(2_{a}\right)$} \\
\hline Mean & 0.00 & 0.50 & 0.50 & 0.00 & 0.00 & 0.00 & 0.00 & 0.50 & 0.50 \\
\hline Range & - & $0-1$ & $0-1$ & - & - & - & - & $0-1$ & $0-1$ \\
\hline \multicolumn{10}{|c|}{ Low-P $\left(2_{a}\right)$} \\
\hline Mean & 2.00 & 11.50 & 13.50 & 0.00 & 1.50 & 1.50 & 2.00 & 13.00 & 15.00 \\
\hline Range & - & $9-14$ & $11-16$ & - & $1-2$ & $1-2$ & - & $10-16$ & 12.00 \\
\hline \multicolumn{10}{|c|}{ High-P $\left(5_{a}\right)$} \\
\hline Mean & 4.20 & 3.60 & 7.80 & 3.40 & 1.40 & 4.80 & 7.60 & 5.00 & 12.60 \\
\hline Range & $0-14$ & $1-8$ & $1-18$ & $0-9$ & $0-5$ & $1-14$ & $0-23$ & $2-9$ & $2-32$ \\
\hline \multicolumn{10}{|c|}{ Low-P $\left(4_{a}\right)$} \\
\hline Mean & 4.75 & 2.50 & 7.25 & 4.50 & 0.50 & 5.00 & 9.25 & 3.00 & 12.25 \\
\hline Range & $2-10$ & $0-7$ & $3-10$ & $2-10$ & $0-1$ & $2-10$ & $4-20$ & $0-8$ & $5-20$ \\
\hline \multicolumn{10}{|c|}{ Maint. $\left(2_{\mathrm{a}}\right)$} \\
\hline Mean & 1.67 & 12.67 & 14.33 & 2.33 & 4.67 & 7.00 & 4.00 & 17.33 & 21.33 \\
\hline Range & $1-3$ & $2-20$ & $3-21$ & $0-5$ & $3-8$ & $3-13$ & $1-6$ & $5-28$ & $6-34$ \\
\hline
\end{tabular}

a- Number of sessions

$\mathrm{b}$-Unprompted initiation

c-Unprompted response

Continued

Table 4.13: The mean number of intervals and range of peers' social initiations (I) and responses to the target children (T) and the generality peer $(\mathrm{G})$ in the generality setting. 
Table 4.13 (continued)

\begin{tabular}{|c|c|c|c|c|c|c|c|c|c|}
\hline \multirow[t]{2}{*}{ Jennifer } & \multicolumn{3}{|c|}{$\mathrm{UI}_{\mathrm{b}}$} & \multicolumn{3}{|c|}{$\overline{U^{2}}$} & \multicolumn{3}{|c|}{ Total UI \& UR } \\
\hline & $\mathrm{T}$ & $\mathrm{G}$ & Total & $\mathrm{T}$ & $\mathrm{G}$ & Total & $\mathrm{T}$ & $\mathrm{G}$ & $\mathrm{T} \& \mathrm{G}$ \\
\hline \multicolumn{10}{|l|}{$\mathrm{BL}\left(3_{\mathrm{a}}\right)$} \\
\hline Mean & 0.00 & 6.00 & 6.00 & 0.00 & 5.33 & 5.33 & 0.00 & 11.33 & 11.33 \\
\hline Range & - & $1-15$ & $1-15$ & - & $0-12$ & $0-12$ & - & $1-27$ & $1-27$ \\
\hline \multicolumn{10}{|l|}{ Low-P $\left(3_{\mathrm{a}}\right)$} \\
\hline Mean & 0.00 & 1.33 & 1.33 & 0.00 & 2.33 & 2.33 & 0.00 & 3.67 & 3.67 \\
\hline Range & - & $0-2$ & $0-2$ & - & $2-3$ & $2-3$ & - & $3-4$ & $3-4$ \\
\hline \multicolumn{10}{|l|}{ High-P $\left(6_{a}\right)$} \\
\hline Mean & 1.00 & 2.67 & 3.67 & 0.00 & 2.67 & 2.67 & 1.00 & 5.33 & 6.33 \\
\hline Range & $0-4$ & $2-4$ & $0-4$ & - & $0-10$ & $0-10$ & $0-4$ & $1-12$ & $4-13$ \\
\hline \multicolumn{10}{|l|}{ Low-P (3a) } \\
\hline Mean & 0.67 & 2.33 & 3.00 & 0.33 & 1.33 & 1.67 & 1.00 & 3.67 & 4.67 \\
\hline Range & $0-2$ & $0-5$ & $0-7$ & $0-1$ & $0-2$ & $0-3$ & $0-3$ & $0-7$ & $0-10$ \\
\hline \multicolumn{10}{|l|}{ Maint. $(2 \mathrm{a})$} \\
\hline Mean & 4.50 & 0.00 & 4.50 & 5.00 & 0.00 & 5.00 & 9.50 & 0.00 & 9.50 \\
\hline Range & $2-7$ & - & $2-7$ & $0-10$ & - & $0-10$ & $2-17$ & - & $2-17$ \\
\hline
\end{tabular}


Table 4.13 (continued)

\begin{tabular}{|c|c|c|c|c|c|c|c|c|c|}
\hline \multirow[t]{2}{*}{ Hillary } & \multicolumn{3}{|c|}{$\mathrm{UI}_{\mathrm{b}}$} & \multicolumn{3}{|c|}{$\mathrm{UR}_{\mathrm{c}}$} & \multicolumn{3}{|c|}{ Total UI \& UR } \\
\hline & $\mathrm{T}$ & $\mathrm{G}$ & Total & $\mathrm{T}$ & $\mathrm{G}$ & Total & $\mathrm{T}$ & $\mathrm{G}$ & $\mathrm{T} \& \mathrm{G}$ \\
\hline \multicolumn{10}{|l|}{$\operatorname{BL}\left(4_{a}\right)$} \\
\hline Mean & 0.00 & 5.25 & 5.25 & 0.00 & 2.25 & 2.25 & 0.00 & 7.50 & 7.50 \\
\hline Range & - & $0-14$ & $0-14$ & - & $0-8$ & $0-8$ & - & $0-22$ & $0-22$ \\
\hline \multicolumn{10}{|l|}{ Low-P $\left(3_{a}\right)$} \\
\hline Mean & 0.67 & 2.67 & 3.33 & 0.00 & 4.33 & 4.33 & 0.67 & 7.00 & 7.67 \\
\hline Range & $0-1$ & $0-4$ & $1-5$ & - & $0-12$ & $0-12$ & $0-1$ & $1-16$ & $2-16$ \\
\hline \multicolumn{10}{|l|}{ High-P (5a) } \\
\hline Mean & 2.00 & 5.20 & 7.20 & 0.40 & 6.20 & 6.60 & 2.40 & 11.40 & 13.80 \\
\hline Range & $0-4$ & $0-14$ & $2-15$ & $0-2$ & $1-13$ & $0-13$ & $0-6$ & $1-19$ & $3-28$ \\
\hline \multicolumn{10}{|l|}{ Low-P (4a) } \\
\hline Mean & 12.75 & 5.75 & 18.50 & 1.50 & 2.75 & 4.25 & 14.25 & 8.50 & 22.75 \\
\hline Range & $9-16$ & $1-18$ & $12-34$ & $0-6$ & $0-9$ & $0-9$ & $9-19$ & $2-27$ & $12-43$ \\
\hline \multicolumn{10}{|l|}{ Maint. } \\
\hline Mean & - & - & - & - & - & - & - & - & - \\
\hline Range & - & - & - & - & - & - & - & - & - \\
\hline
\end{tabular}


unprompted initiations to the generality peer was 11.5 and ranged from 9 to 14 . The mean number of unprompted responses to the target child and the peer were 0 , and 1.5 with a range from 1 to 2, respectively. Stacie's initiations to Eric slightly increased; however, she continued to exhibit low levels of social interactions with Eric.

For five sessions during the high-probability request sequences with peer modeling the mean number of intervals of the Eric's total unprompted social initiations and responses was 22 with a range of 13 to 39 . The mean number of intervals of unprompted initiations to the peer and the generality peer was 4.60 with a range of 1 to 10 , and 7.60 with a range from 6 to 13 , respectively. The mean number of intervals of the unprompted responses to the peer and the generality peer was 3.40 with a range from 1 to 13 , and 6.40 with a range from 1 to 10 , respectively. The levels of his interactions with the generality peer as well as the peer sharply and immediately increased upon the intervention.

Stacie's interactions with Eric sharply increased during this condition. The number of intervals of the total unprompted initiations and responses to the target child and generality peer ranged from 2 to 32 with a mean of 12.60 . The mean number of intervals of total unprompted social initiations and responses to the target child ranged from 0 to 23 with a mean of 7.60 . The mean number of intervals of total unprompted social initiations and responses to the generality peer was 5 with a range from 2 to 9 . The mean number of intervals of unprompted initiations to the target child and generality peer was 4.20 with a range from 0 to $14,3.60$ with a range from 1 to 8 , respectively. The mean number of intervals of unprompted responses to the target child and generality peer was 3.40 with a range from 0 to 9 , and 1.40 with a range from 0 to 5 , respectively. 
Four generality sessions during the low-probability request condition were conducted. The mean number of intervals of total unprompted initiations and responses to the peer and the generality peer was 16.75 with a range of 7 to 18 . His unprompted initiations to the peer and generality peer ranged from 3 to 11 with a mean of 5.75, and ranged from 0 to 8 with a mean of 7.67, respectively. The mean number of intervals of unprompted responses to the peer and generality peer was 4 with a range from 2 to 7 , and 1.67 with a range from 0 to 3 , respectively. The levels of his interactions were lower than during the previous condition. However, his interactions with the peer remained at the high levels.

Stacie's increased levels of social interactions with Eric maintained during the low-probability request condition. The mean number of the unprompted initiations and responses to the peer and generality peer was 12.25 with a range from 5 to 20 . The mean number of unprompted social initiations and responses to the target child was 9.25 with a range from 4 to 20; the mean number of unprompted social initiations and responses to the generality peer was 3 with a range from 0 to 8 . The intervals of unprompted initiations to the target child and the generality peer ranged from 2 to 10 with a mean number of 4.75 , and ranged from 0 to 7 with a mean number of 2.50 . The mean number of intervals of unprompted responses to the target and the generality peer was 4.50 with a range from 2 to $10,0.50$ with a range from 0 to 1 , respectively.

During Eric's maintenance phase, the mean number of total unprompted initiations and responses was 28 with a range of 20 to 36 . The unprompted initiations to the peer and to the generality peer ranged from 0 to 3 with a mean number of 3 , and ranged from 11 to 22 with a mean number of 16.50 , respectively. The mean number of 
the unprompted responses to the peer and the generality peer was 0.50 with range from 0 to 1 , and 8 with a range from 2 to 14 , respectively. During the maintenance condition, the level of his interactions increased. Stacie's interactions with Eric during this condition decreased although her total initiations and responses increased. For Stacie, the mean number of total unprompted initiations and responses to the peer and generality peer was 21.33 with a range from 6 to 34. Stacie's unprompted initiations and responses to the target child and the generality peer ranged from 1 to 6 with a mean number of 4 , and ranged from 5 to 28 with a mean of 17.33 , respectively. The mean number of intervals of unprompted initiations to Eric was 1.67 with a range from 1 to 3 . The mean number of intervals of unprompted initiations to the generality peer was 12.67 with a range from 2 to 20. The mean number of the intervals of unprompted responses to the target child and generality peer was 2.33 with a range from 0 to 5 , and 4.67 with a range from 3 to 8 , respectively.

Paul and Jennifer

Paul engaged in no social interactions with the peer or the generality peer over 3 sessions of baseline condition. Paul's peer, Jennifer engaged in play with the generality peer only. The mean number of intervals of Jennifer's unprompted initiations and responses to the generality peer were 6 with a range from 1 to 15 , and 5.33 with a range from 0 to 12 , respectively.

Three generality sessions were conducted during the low-probability request condition. Paul did not interact with his peer and the generality peer during this condition. 
His peer, Jennifer interacted with the generality peer. The mean number of intervals of unprompted initiations and responses to the generality peer were 1.33 with rage from 0 to 2 , and 2.33 with a range from 2 to 3 , respectively.

During the high-probability request sequences with embedded peer modeling, the levels of Paul's interactions slightly increased. Additionally, he engaged in interactions with the generality peer. The mean number of the total unprompted initiations and responses to the peer and to the generality peer was 2.67 with a range from 0 to 9 . The number of intervals of unprompted initiations to the peer and the generality peer ranged from 0 to 1 with a mean of 0.33 , and 0 , respectively. The mean number of intervals of unprompted responses to the peer and generality peer was 1 with a range from 0 to 4 , and 1.33 with a range from 0 to 5, respectively. Paul's peer, Jennifer's mean number of total unprompted initiations and responses to the target child and generality peer was 6.33 with a range from 4 to 13. Jennifer's unprompted initiations and responses to Paul ranged form 0 to 4 with a mean of 1 . Her unprompted initiations and responses to the generality peer ranged from 1 to 12 with a mean of 5.33. For Jennifer the mean number of unprompted initiations to Chris and to the generality peer was 1 with a range from 0 to 4 , and 2.67 with a range from 2 to 4 , respectively. The number of intervals of unprompted responses to the generality peer ranged from 0 to 10 with a mean of 2.67. Jennifer engaged in no responses to Paul.

Three generality sessions were conducted during the low-probability request condition. Paul's total number of intervals of unprompted initiations and responses to the peer and generality peer ranged from 2 to 6 with a mean of 4 . The mean number of unprompted initiations to the peer and generality peer was 0.67 with a range from 0 to 2 , 
and 0.33 with a range from 0 to 1 , respectively. The mean number of unprompted responses to the peer and generality peer was 0.67 with a range from 0 to 2 , and 2.33 with a range from 0 to 5 , respectively. Paul's social behaviors toward the peer and generality peer continued the increasing trend during this condition. Jennifer's social initiations and responses to Paul maintained the same levels as the previous condition. Jennifer's total unprompted initiations and responses to the target child and generality peer ranged from 0 to 10 with a mean number of 4.67 . The mean number of intervals of unprompted social initiations and responses to Paul was 1 with a range from 0 to 3 . The mean number of intervals of unprompted social initiations and responses to the generality peer was 3.67 with a range from 0 to 7 . The mean number of unprompted initiations to the target child and generality peer was 0.67 with a range from 0 to 2 , and 2.33 with a range from 0 to 5 , respectively. Jennifer's mean number of unprompted responses to the target child and generality peer was 0.33 with a range from 0 to $1,1.33$ with a range from 0 to 2 , respectively.

During maintenance, the level of Paul's interactions with the peer and the generality peer sharply increased. The mean number of total unprompted initiations and responses to the peer and the generality peer was 19.50 with a range from 18 to 21 . The mean of the unprompted initiations to the peer and to the generality peer was 6.50 with a range from 2 to 11 , and 3.50 with a range from 0 to 7 , respectively. The number of intervals of unprompted responses to the peer ranged from 2 to 7 , with a mean of 4.50 . The mean number of unprompted responses to the generality peer was 5 with a range from 0 to 10 . 
Jennifer's interactions with Paul sharply increased during this condition. The number of intervals of total unprompted initiations and responses to Paul and the generality peer ranged from 2 to 17 with a mean of 9.50. Jennifer engaged in no social interactions with the generality peer. The number of intervals of unprompted initiations to Paul was 4.5 with a range from 2 to 7 , and the mean number of intervals of the unprompted responses to Paul was 5, with a range from 0 to 10 .

\section{Chris}

During the baseline condition, Chris engaged in no social interactions with the peer or generality peer. His peer, Hillary did not interact with Chris, however, she engaged in the play with the generality peer during this condition. The mean number of unprompted initiations and responses to the generality peer was 5.25 with a range from 0 to 14 , and 2.25 with a range from 0 to 8 , respectively.

During the low-probability request condition Chris did not interact with the peer or the generality peer. Chris's peer, Hilary initiated to Chris with a mean of 0.67 with a range from 0 to 1 , however, she did not engage in the response to Chris. For Hilary, the mean number of unprompted initiations and responses to the generality peer was 2.67 with a range from 0 to 4 , and 4.33 with a range from 0 to 12, respectively.

Levels of initiations and responses increased during the high-probability request sequences with embedded peer modeling. The mean number of total unprompted initiations and responses to the peer and to the generality peer was 7.00 with a range from 1 to 14 . The number of intervals of unprompted initiations to the peer ranged from 0 to 2 with a mean of 0.8 and unprompted initiations to the generality peer ranged from 0 to 1 with a mean of 0.4 . The mean number of unprompted responses to the peer and generality 
peer was 2 with a range from 0 to 4 , and 3.80 with a range from 0 to 10 , respectively. Chris engaged in interactions with the generality peer as well as the peer during this condition.

During this condition, for Hilary, the level of initiations and responses to Chris increased. The mean number of Hilary's total unprompted initiations and responses to the target child and the generality peer was 13.80 and ranged from 3 to 28 . The mean number of intervals of unprompted initiations and responses to the target child was 2.4 with a range from 0 to 6 while the mean number of intervals of unprompted initiations and responses to the generality peer was 11.40 with a range from 1 to 19 . The number of intervals of unprompted initiations to the target child ranged from 0 to 4 with a mean of 2 , and the number of intervals of unprompted initiations to the generality peer ranged from 0 to 14 with a mean of 5.20. The mean number of the intervals of unprompted responses to the target and the generality peer was 0.4 with a range from 0 to $2,6.2$ with a range from 1 to 13 .

During the low-probability request condition, the number of intervals of the total unprompted initiations and responses to the peer and generality peer ranged from 16 to 22 with a mean of 18.75 . The mean number of unprompted initiations to the peer and generality peer were 2.25 with a range from 0 to 7 , and 0 , respectively. The mean number of unprompted responses to the peer and generality peer was 11.75 with a range from 6 to 15 , and 4.75 with a range from 0 to 16 , respectively. The increasing trend in social interactions with the peer and generality peer continued over seven sessions.

During this condition, Hilary's level of social interactions with Chris increased. The number of interval of unprompted initiations and responses to the peer and generality 
peer ranged from 12 to 43 with a mean of 22.75 . The number of intervals of unprompted initiations and responses to the target child and generality peers was 14.25 with a range from 9 to $19,8.50$ with a range from 2 to 27 , respectively. The mean number of unprompted initiations to the target child and generality peer was 12.75 with a range from 9 to 16 , and 5.75 with a range from 1 to 18 , respectively. The mean number of unprompted responses to the target child and generality peer was 1.50 with a range from 0 to 6 , and 2.75 with a range from 0 to 9 , respectively. No sessions were conducted during the maintenance condition due to the end of the school year.

\section{Additional data on other behaviors}

\section{Disruptive Behaviors}

In addition to the dependent variable, additional data for disruptive behaviors were recorded. Table 4.14 represents the mean number of intervals and range of disruptive behaviors across all experimental conditions in the intervention and generality setting.

Eric. During baseline condition in intervention setting, Eric rarely engaged in disruptive behavior with a mean number of 0.2 and a range from 0 to 1 . During the lowprobability request condition in the intervention setting, the mean number of intervals of disruptive behaviors was 0.4 with a range from 0 to 3 . Eric displayed no disruptive behavior during the high-probability request sequences with embedded peer modeling. During the following low-probability request and maintenance sessions, he did not engage in any disruptive behavior. In the generality setting, Eric displayed no disruptive behavior across all experimental conditions. 


\begin{tabular}{|c|c|c|c|c|c|c|c|c|c|c|c|c|c|c|c|c|c|c|c|c|}
\hline & \multicolumn{4}{|c|}{ BL } & \multicolumn{4}{|c|}{ Low-P } & \multicolumn{4}{|c|}{ High-P } & \multicolumn{4}{|c|}{ Low-P } & \multicolumn{4}{|c|}{ Maintenance } \\
\hline & \multicolumn{2}{|r|}{ I } & \multicolumn{2}{|c|}{$\bar{G}$} & \multicolumn{2}{|c|}{ I } & \multicolumn{2}{|c|}{$\bar{G}$} & \multicolumn{2}{|c|}{ I } & \multicolumn{2}{|c|}{$\overline{\mathrm{G}}$} & \multicolumn{2}{|c|}{ I } & \multicolumn{2}{|c|}{$\bar{G}$} & \multicolumn{2}{|c|}{ I } & \multicolumn{2}{|r|}{$\bar{G}$} \\
\hline & $\mathrm{D}$ & $\mathrm{S}$ & $\mathrm{D}$ & $\mathrm{S}$ & $\mathrm{D}$ & $\mathrm{S}$ & $\mathrm{D}$ & $\mathrm{S}$ & $\mathrm{D}$ & $\mathrm{S}$ & $\mathrm{D}$ & $\mathrm{S}$ & $\mathrm{D}$ & $\mathrm{S}$ & $\mathrm{D}$ & $\mathrm{S}$ & $\mathrm{D}$ & $\mathrm{S}$ & $\mathrm{D}$ & $\mathrm{S}$ \\
\hline \multicolumn{21}{|l|}{ Eric } \\
\hline $\begin{array}{l}\text { \# of } \\
\text { sessions }\end{array}$ & \multicolumn{2}{|r|}{6} & \multicolumn{2}{|c|}{2} & \multicolumn{2}{|c|}{10} & \multicolumn{2}{|c|}{2} & \multicolumn{2}{|c|}{13} & \multicolumn{2}{|c|}{5} & \multicolumn{2}{|c|}{8} & \multicolumn{2}{|c|}{4} & \multicolumn{2}{|c|}{6} & \multicolumn{2}{|r|}{2} \\
\hline Mean & 0.20 & 2.60 & 0.00 & 0.50 & 0.40 & 15.60 & 0.50 & 3.00 & 0.00 & 3.75 & 0.00 & 0.67 & 0.00 & 3.50 & 0.00 & 9.75 & 0.00 & 8.50 & 0.00 & 8.50 \\
\hline Range & $0-1$ & $0-5$ & - & $0-1$ & $0-3$ & $0-56$ & $0-1$ & $2-4$ & - & $0-20$ & - & $0-2$ & - & $0-11$ & - & $3-18$ & - & $2-20$ & - & $4-13$ \\
\hline \multicolumn{21}{|l|}{ Paul } \\
\hline $\begin{array}{l}\text { \# of } \\
\text { sessions }\end{array}$ & \multicolumn{2}{|c|}{10} & \multicolumn{2}{|c|}{3} & \multicolumn{2}{|c|}{11} & \multicolumn{2}{|c|}{3} & & 8 & & 5 & & 1 & 3 & 3 & & 4 & & 2 \\
\hline Mean & 1.60 & 15.78 & 0.33 & 12.00 & 2.09 & 5.18 & 0.67 & 6.67 & 0.06 & 5.88 & 0.67 & 12.00 & 0.58 & 9.90 & 0.67 & 7.33 & 0.00 & 13.00 & 0.00 & 10.00 \\
\hline Range & $0-10$ & $0-41$ & $0-1$ & $5-17$ & $0-5$ & $0-12$ & $0-2$ & $2-9$ & $0-1$ & $0-20$ & $0-4$ & $9-17$ & $0-1$ & $2-29$ & $0-1$ & $6-10$ & - & $1-22$ & - & - \\
\hline Chris & & & & & & & & & & & & & & & & & & & & \\
\hline $\begin{array}{l}\text { \# of } \\
\text { sessions }\end{array}$ & & 16 & & & 1 & & & & & & & 5 & & 7 & 2 & 4 & & 1 & & - \\
\hline Mean & 1.13 & 25.56 & 0.75 & 9.25 & 6.00 & 10.70 & 3.33 & 4.67 & 0.79 & 7.79 & 1.20 & 8.40 & 1.43 & 1.57 & 0.00 & 3.75 & 1.00 & 0.00 & - & - \\
\hline Range & $0-7$ & $5-49$ & $0-2$ & $2-28$ & $0-14$ & $1-21$ & $2-6$ & $1-10$ & $0-2$ & $0-21$ & $0-3$ & $0-33$ & $0-9$ & $0-9$ & - & $0-12$ & - & - & - & - \\
\hline
\end{tabular}

Table 4.14: The mean number of intervals and range of the target children's disruptive behaviors(D) and self-stimulating behaviors $(\mathrm{S})$ in the intervention(I) and generality setting $(\mathrm{G})$. 
Paul. In the intervention setting, Paul's number of intervals of disruptive behaviors during baseline ranged from 0 to 10 with a mean of 1.6. During the lowprobability request condition, Paul's disruptive behavior increased. The mean number of intervals of disruptive behavior was 2.09 with a range from 0 to 5 . His disruptive behavior decreased to a mean of 0.06 with a range from 0 to 1 during the high-probability request sequences with embedded peer modeling. During the low-probability request condition, the levels of his disruptive behavior remained low. Paul engaged in no disruptive behavior during the maintenance condition.

In the generality setting, the mean number of intervals of disruptive behavior was 0.33 with a rang from 0 to 1 during baseline, 0.67 with a range from 0 to 2 during the low-probability request condition, 0.67 with a range from 0 to 4 during the highprobability request intervention. Paul engaged no disruptive behavior in the generality setting during maintenance.

Chris. Chris engaged in disruptive behavior with a mean number of 1.13 and with a range from 0 to 7 in the intervention setting during baseline. During the lowprobability request condition, the mean number of intervals of disruptive behavior was 6 which ranged from 1 to 14 . Chris's disruptive behavior decreased during the highprobability request intervention. The number of intervals of disruptive behavior ranged from 0 to 2 with a mean of 0.79 . During the low-probability request condition, the mean number of intervals of disruptive behavior was 1.43 with a range from 0 to 9 . During one session of the maintenance, Chris exhibited one disruptive behavior. 
In the generality setting the mean number of intervals of disruptive behavior was 0.75 with a range from 0 to 2 during baseline. During the low-probability request condition, the mean of intervals of disruptive behavior was 3.33 with a range from 2 to 6 . Chris engaged in disruptive behavior with a mean number of 1.2 and a range from 0 to 3 during the high-probability request sequences with embedded peer modeling. During the low-probability requests, Chris engaged in no disruptive behaviors.

\section{Self-Stimulating Behaviors}

Each target child's self-stimulating behaviors were recorded. Table 4.14 represents the mean number of intervals and the range of self-stimulating behaviors across all experimental conditions in the intervention and generality setting.

Eric. During the baseline condition in the intervention setting, Eric engaged in self-stimulating behaviors with a mean number of intervals of 2.60 and a range from 0 to 5. During the low-probability request condition in the intervention setting, the mean number of intervals of self-stimulating behaviors was 15.60 with a range from 0 to 56 . Eric displayed self-stimulating behaviors with a mean number of intervals of 3.75 and a range from 0 to 20 during the high-probability request sequences with embedded peer modeling. During the following low-probability request, the mean number of intervals of self-stimulating behaviors was 3.50 with a range from 0 to 11 . Eric's self-stimulating behaviors ranged from 2 to 20 with a mean of 8.50 during the maintenance condition. Eric's self stimulating behaviors in the intervention setting decreased after implementing the high-probability request sequence intervention, remained at the same levels during the second low-probability requests, and increased during the maintenance condition. 
In the generality setting, Eric's mean number of intervals of self-stimulating behaviors was 0.50 with a range from 0 to 1 . During the low-probability request condition in the generality setting, the mean number of intervals of self-stimulating behaviors was 3 with a range from 2 to 4 . Eric's self-stimulating behaviors during the high-probability request sequence using embedded peer modeling ranged from 0 to 2 with a mean of 0.67 . During the second low-probability request condition, Eric engaged in self-stimulating behaviors with a mean number of intervals of 9.75 with a range from 3 to 18 . The mean number of intervals of self-stimulating behaviors during maintenance was 8.50 with a range from 4 to 13 . Eric's self-stimulating behaviors in the generality setting decreased during the high-probability request sequence intervention and increased again during the next low-probability request and maintenance condition.

Paul. In the intervention setting, Paul's number of intervals of self-stimulating behaviors during baseline ranged from 0 to 41 with a mean of 15.78. During the lowprobability request condition, Paul's self-stimulating behavior decreased. The mean number of intervals of self-stimulating behaviors was 5.18 with a range from 0 to 12 . During the high-probability request sequences with embedded peer modeling, his selfstimulating behaviors remained at the same levels as during the previous condition. The mean number of intervals of self-stimulating behaviors was 5.88 with a range from 0 to 20. During the low-probability request condition, the levels of his self-stimulating behaviors increased to a mean number of intervals of 9.9 with a range from 2 to 29 . His self-stimulating behaviors during the maintenance condition ranged from 1 to 22 with a mean number of intervals of 13 . 
In the generality setting, the mean number of intervals of self-stimulating behaviors was 12 with a range from 5 to 17 during baseline, 6.67 with a range from 2 to 9 during the low-probability request condition, and 12 with a range from 9 to 17 during the high-probability request intervention. Paul's self-stimulating behaviors ranged from 6 to 10 with a mean number of intervals of 7.33 during the low-probability request condition. During maintenance, he engaged in self-stimulating behaviors with a mean number of intervals of 10 .

Chris. Chris engaged in self-stimulating behaviors with a mean number of 25.56 and with a range from 5 to 49 in the intervention setting during baseline. During the lowprobability request condition, the mean number of intervals of self-stimulating behaviors was 10.70 with a range from 1 to 21 . Chris's self-stimulating behaviors decreased during the high-probability request sequences with embedded peer modeling. The number of intervals of self-stimulating behaviors ranged from 0 to 21 with a mean of 7.79. During the low-probability request condition, the mean number of intervals of self-stimulating behaviors was 1.57 with a range from 0 to 9 . During one session of the maintenance, Chris exhibited no self-stimulating behaviors. Chris's self-stimulating behaviors in the intervention setting decreased as the sessions continued.

In the generality setting, the mean number of intervals of self-stimulating behaviors was 9.25 with a range from 2 to 28 during baseline. During the low-probability request condition, the mean of intervals of disruptive behavior was 4.67 with a range from 1 to 10 . Chris engaged in self-stimulating behaviors with a mean number of 8.40 and a range from 0 to 33 during the high-probability request sequence. During the low- 
probability requests, the mean number of intervals of self-stimulating behaviors was 3.75 with a range from 0 to 12 . Chris's self-stimulating behaviors in the generality setting decreased toward the end of the sessions.

\section{Negative interactions}

Negative interactions were recoded using partial interval recording across all conditions. Few negative interactions were observed for the target children.

Eric. Eric engaged in few negative interactions with a mean of 0.16 intervals and a range from 0 to 1 during baseline in the intervention setting. No negative interactions were recorded in the generality setting. During the low-probability requests alone, Eric exhibited a mean of intervals of 0.2 negative interactions in the intervention setting. No negative interactions were observed during the other conditions.

Paul. Paul engaged in no negative interactions across all conditions in the intervention and generality settings.

Chris. During the baseline condition, Chris engaged in no negative interactions in the intervention and generality settings. During the low-probability requests alone condition, the mean of intervals of negative interactions in the intervention setting was 0.3 with a range from 0 to 2 . Chris exhibited no negative interactions in the generality setting. During the high-probability request sequences with embedded peer modeling, Chris engaged in negative interactions with mean of 0.3 and a range from 0 to 2 in the intervention setting. In the generality setting the mean of intervals of negative interactions was 1 with a range from 0 to 2 . During the low-probability requests alone, the mean of intervals of negative interactions in the intervention setting was 0.29 with a 
range from 0 to 2 . Chris engaged in no negative interactions in the generality setting. During one session of the maintenance condition, Chris displayed no negative interactions in the intervention setting.

\section{Social Validity}

Information was collected from relevant consumers and evaluated to determine the social validity of the intervention goals, procedures, and outcomes. The following is a summary of the results of the social validity information gathered from parents of the children participating in the study and the professionals in early childhood special education including the classroom teachers with whom the study was conducted.

In this section the following research question will be addressed: To what extent do the parents and early childhood special education teachers find the intervention goals, procedures, and outcomes to be relevant, useful, and effective for children with autism?

\section{Intervention Goals}

The social validity of the intervention goals was addressed by gathering information from three parents of the children participating in the study, and three early childhood special education teachers at the school. Parents and teachers were requested to fill out a questionnaire that asked about the intervention goals before conducting the study. Parents and early childhood special education teachers were asked whether they considered the research questions to be valid and useful for their children. Results are summarized as follows (see Table 4.15). 


\begin{tabular}{|c|c|c|c|c|c|c|c|}
\hline & & $\begin{array}{l}\text { Eric's } \\
\text { parent }\end{array}$ & $\begin{array}{l}\text { Paul's } \\
\text { parent }\end{array}$ & $\begin{array}{l}\text { Chris's } \\
\text { parent }\end{array}$ & $\begin{array}{l}\text { Classroom } \\
\text { teacher }\end{array}$ & $\begin{array}{l}\text { Teacher } \\
1\end{array}$ & $\begin{array}{l}\text { Teacher } \\
2\end{array}$ \\
\hline 1 & $\begin{array}{l}\text { Do you think this research question is valid/useful for your child's } \\
\text { education? } \\
\text { What are the effects of the use of high-probability requests sequence } \\
\text { on social interactions of young children with autism and typically } \\
\text { developing children in an inclusive setting? }\end{array}$ & Unsure & Yes & Yes & Yes & Yes & Yes \\
\hline 2 & $\begin{array}{l}\text { Do you think this research question is valid/useful for your child's } \\
\text { education? } \\
\text { To what extent does the child generalize social interactions to a } \\
\text { nontraining condition? }\end{array}$ & Yes & Yes & Yes & Yes & Yes & Yes \\
\hline 3 & $\begin{array}{l}\text { Do you think this research question is valid/useful for your child's } \\
\text { education? } \\
\text { To what extend does the child maintain social interactions in an } \\
\text { inclusive setting following the removal of the high-probability } \\
\text { request intervention? }\end{array}$ & Yes & Yes & Yes & Yes & Yes & Yes \\
\hline 4 & $\begin{array}{l}\text { Do you think this research question is valid/useful for your child's } \\
\text { education? } \\
\text { To what extent does the child maintain the social interactions in an } \\
\text { inclusive setting following the removal of the low-probability request } \\
\text { prompts? }\end{array}$ & Yes & Yes & Yes & Yes & Yes & Yes \\
\hline 5 & $\begin{array}{l}\text { Do you think this research question is valid/useful for your child's } \\
\text { education? } \\
\text { To what extent does the parent find the intervention goals, } \\
\text { procedures, and outcomes to be relevant, valuable, and effective with } \\
\text { their children during center time in an inclusive setting? }\end{array}$ & Yes & Yes & Yes & Yes & Yes & Yes \\
\hline 6 & $\begin{array}{l}\text { Do you think this research question is valid/useful for your child's } \\
\text { education? } \\
\text { To what extent do early childhood special education teachers find the } \\
\text { intervention goals, procedures, and outcomes to be relevant, useful, } \\
\text { and effective with children with autism in an inclusive setting? }\end{array}$ & Yes & Yes & Yes & Yes & Yes & Yes \\
\hline
\end{tabular}

Table 4.15: Summary of parent and teacher questionnaire. 


\section{Parents}

Eric. Eric's mother answered that the five research questions were valid and useful for her child. However, for the first question she marked that she was unsure of the usefulness of the question regarding the effects of the use of high-probability request sequences on social interactions of young children with autism and typically developing children in an inclusive setting. Additionally she wrote her goal on increasing social interactions was using appropriate greetings (e.g., "Good bye," "How are you?”).

Paul. Paul's parent answered that she thought all research questions were useful and valid for her child. Her goal, regarding social interactions, was teaching turn-taking.

Chris. Chris's mother answered that she thought all research questions were useful and valid for her child. In the domain of social interactions, she wanted her child to talk and play with other children.

\section{Teachers}

Three teachers including the classroom teacher who conducted the study were asked to fill out a questionnaire. All of the teachers answered that all of the research questions were useful and valid for the children with autism.

\section{Intervention Procedures}

The experimenter gathered information from 20 professionals in early childhood special education to determine the social acceptability and usability of the intervention procedures. They included 10 early childhood special education teachers, two speech therapists, two occupational therapists, one regular education teacher, three graduate students (student teachers), and two assistants in the classroom where the study was conducted. Their experiences of working with young children with disabilities ranged 
from one to six years. Teachers were asked to view three unidentified 2-min segments of videotape depicting the target children during baseline, low-probability requests alone, and the high-probability request sequence using embedded peer modeling. Video segments that were representative of each child's performance in each condition were chosen. Teachers were asked whether they thought the intervention would be easy to use during the daily routine, and whether they would use the intervention in their classroom when considering both time and effort necessary for the intervention.

Sixty percent of the professionals responded that the high-probability intervention using peer modeling would be easy to use during the student's regular routine. They reported that this intervention was simple enough to be adapted to fit in with the children's natural routine setting with readily available materials, the activities the children would enjoy, as well as during free-choice center time. Additionally, children with such low levels of social interactions would benefit from such an intense intervention. On the other hand, $40 \%$ of the professionals responded that the intervention would be time consuming with the demands made by the rest of the students in the classroom. In the classroom, one on one adult interaction was not always available. Preassessment for high-probability and low-probability requests would be time consuming in a classroom served by one teacher.

After observing the amount of time and effort needed to implement the procedures described in the high-probability request sequence using peer modeling, $85 \%$ of the professionals responded that they would use the intervention in their classroom. They reported that this intervention enabled the child to engage in play and social interactions, demonstrated a difference in behaviors as shown in video clips, was 
effective, and was possible to incorporate into some activities. Additionally, the intervention could be modified and adapted to be less demanding using more naturally occurring activities. One teacher responded that due to the labor intensive preparation, this would be considered as a viable intervention when other less intensive interventions had failed. On the other hand, some professionals responded that the intervention seemed hard, or time consuming to implement if the classroom were too busy and include too many children.

Eighty five percent of the professionals responded that the high-probability request intervention was useful to improve social interactions between children. They reported that the intervention promotes communication and language, and motivates and promotes appropriate social interactions between children because of the low level of stress placed on the performance. Additionally, they noted that this intervention would be effective in terms of the use of the peer model and providing an opportunity for the target child to experience child to child appropriate interactions. However, several professionals reported that the intervention did not seem to natural in terms of prompting children.

\section{Intervention Outcomes}

Information was gathered from the same 20 professionals in early childhood special education above and evaluated to determine the social validity of the intervention outcomes. After viewing video clips, the professionals were asked to complete a checklist which included skills targeted by intervention in this study. Results are summarized as follows (see Table 4.16). 


\begin{tabular}{|c|c|c|c|c|c|c|c|c|c|c|}
\hline & \multirow[t]{3}{*}{ Skills } & \multicolumn{9}{|c|}{$\%$ of the professionals observed skills } \\
\hline & & \multicolumn{3}{|c|}{ Eric } & \multicolumn{3}{|c|}{ Paul } & \multicolumn{3}{|c|}{ Chris } \\
\hline & & $\mathrm{BL}$ & Low-p & High-p & $\mathrm{BL}$ & Low-p & High-p & BL & Low-p & High-p \\
\hline 1 & Complies with the requests & 15 & 25 & 95 & 10 & 70 & 95 & 5 & 25 & 95 \\
\hline 2 & Focuses on a task/play & 35 & 0 & 100 & 15 & 15 & 100 & 5 & 25 & 95 \\
\hline 3 & Shares materials/toys with peers & 0 & 5 & 100 & 0 & 10 & 90 & 0 & 5 & 100 \\
\hline 4 & Responds when spoken to & 40 & 25 & 100 & 20 & 75 & 100 & 60 & 90 & 100 \\
\hline
\end{tabular}

$\varpi$

Table 4.16: Summary of observed skills for the target children during intervention videotaped segments by the professionals in early childhood special education. 
Eric

During baseline for Eric, $15 \%$ of the professionals observed the first skill in the checklist "complies with requests." Thirty five percent of the professionals identified the second skill in the checklist "focuses on a task/play." For the third skill "shares

materials/toys with peers," none of the professionals identified the skill. Forty percent of the professionals observed the fourth skill "responds when spoken to." During the first low- probability requests condition, $25 \%, 0 \%, 5 \%$, and $25 \%$ of the professionals identified having observed the first, second, third, and the fourth skill on the checklist, respectively. For the high-probability request sequences with embedded peer modeling condition, $95 \%-100 \%$ of the professionals identified having observed the target child performing the skills listed on the checklist.

Paul

During baseline for Paul, 10\% of the professionals observed the first skill in the checklist "complies with requests." Fifteen percent of the professionals identified the second skill in the checklist "focuses on a task/play." None of the professionals identified having observed the third skill "shares materials/toys with peers." Twenty percent of the professionals observed the fourth skill "responds when spoken to." For the first lowprobability requests condition, $70 \%$ of the professionals observed the first skill, $15 \%$ of the professionals identified having observed the second skill, $10 \%$ of the professionals reported having observed the third skill, and $75 \%$ of the professionals had observed the fourth skill in the checklist. During the high-probability request sequences with peer modeling, $95 \%, 100 \%, 90 \%$, and $100 \%$ of the professionals identified having observed the above skills, respectively. 


\section{Chris}

During baseline for Chris, $5 \%$ of the professionals observed the first skill in the checklist "complies with requests." Five percent of the professionals identified the second skill in the checklist "focuses on a task/play." None of the professionals identified having observed the third skill "shares materials/toys with peers." Sixty percent of the professionals observed the fourth skill "responds when spoken to." For the first lowprobability requests condition, $25 \%$ of the professionals observed the first skill, $25 \%$ of the professionals identified having observed the second skill, $5 \%$ of the professionals reported having observed the third skill, and $90 \%$ of the professionals had observed the fourth skill in the checklist. During the high-probability request sequences with embedded peer modeling, $95 \%, 95 \%, 100 \%$, and $100 \%$ of the professionals identified having observed the above skills, respectively. 


\section{CHAPTER 5}

\section{DISCUSSION}

This chapter discusses the results of the study investigating the effects of the highprobability request sequence using peer modeling on compliant responding to requests, as well as for increasing the social interactions of young children with autism in an inclusive classroom. Limitations of the study, results relative to the research questions, implications for practice, and directions for future research will be discussed.

\section{Limitations of the Study}

This study was limited by the length of the study and the nature of the participants.

\section{Length of Study}

This study was conducted over a course of 16 weeks. The school year ended before follow-up data could be collected. Social interaction interventions require implementation over an extended period of time while providing multiple and repeated opportunities to practice emerging skills (Kohler \& Strain, 1999). More sessions to practice targeted social behaviors would have likely led to an increase in unprompted social behaviors. 
One session during maintenance was observed for Chris. No follow-up data were obtained for the target children. It would have been beneficial to observe the children's social behaviors for additional maintenance and follow-up sessions.

\section{Participants}

The role of peers, as well as the target children's social behaviors, is important for increasing social interactions. The second peer of this study was found to have limited skills. She could verbally respond to the experimenter's questions about what she might do when her paired target child, Paul, initiated a social interaction with her. However, she was often hesitant to initiate and respond to the target child during play (although she engaged in interactive play with the generality peer in the same setting) and she often left her assigned center. However, when the generality peer, Randy, initiated play with Paul, she was more likely to engage him in play. Thus, a different match between the peer and this target child may have an increase in more social interactions that could be observed between the children.

The first target child's peer, Stacie, missed seven consecutive sessions since she and her family were on vacation during that period. Due to her absences, intervention with Eric was not implemented for those days.

\section{Research Questions}

The following is a discussion of the results of the study as they pertain to the research questions provided in Chapter 1.

What are the effects of the use of high-probability request sequences with embedded peer modeling on complaint responding to low-probability requests to initiate social behaviors for young children with autism? 
Data were collected in each session on the children's compliant responding to requests to initiate social behaviors during the initial low-probability request alone condition, the high-probability request sequences with embedded peer modeling, and the second low-probability request condition. No low-probability requests were delivered when the children were observed during the baseline. During the initial low-probability request condition, Eric displayed few responses to the low-probability requests, and he often ignored his peer's play initiations. Paul exhibited disruptive behaviors both when the experimenter invited him to the assigned center and gave him the instructions before observation and upon delivery of some low-probability requests during the session. Paul's compliant responding to the low-probability requests was low. Chris also had low levels of compliant responding and often displayed no response or noncompliance to the low-probability requests.

The high-probability request sequence intervention was combined with peer modeling to increase complaint responding to requests as well as social interactions. During the high-probability request sequences with embedded peer modeling, all of the participants' compliant responding to low-probability requests increased immediately upon implementation of the intervention. The experimenter's general prompts for the three target children decreased during this condition. Eric exhibited high levels of compliant responding to low-probability requests while displaying low levels of selfstimulating behaviors. He often smiled and laughed while performing the highprobability requests. Paul's compliant responding to the low-probability requests increased after introducing the intervention. His disruptive behaviors decreased and his self-stimulating behavior maintained the same levels as the low-probability request 
condition. He eagerly participated in the intervention activities while waiting for the next high-probability request sequence. Chris exhibited an increase in complaint responding to low-probability requests with some variability. His disruptive and self-stimulating behaviors decreased, and he displayed more engagement in appropriate play during the intervention. He often laughed during the delivery of requests and praise statements.

The low-probability request alone condition was reintroduced to assess whether compliant responding to requests was maintained after withdrawal of the high-probability request sequence. Upon return to the low-probability request condition, the target children's compliant responding to low-probability requests maintained at the previous high levels. The experimenter's general prompts remained at the same levels as during the previous condition. Eric's levels of compliant responding to the low-probability requests increased to higher levels than those observed during the high-probability request sequence using peer modeling. Eric's engagement in self-stimulating behaviors remained at the same levels as during the previous condition. Paul maintained high levels of compliant responding to the low-probability requests. He engaged in low levels of disruptive behaviors, but his self-stimulating behaviors increased more than levels observed during the high-probability request sequence using peer modeling. It is worth noting that he was in the process of losing a tooth and the increase in self-stimulating behavior might have been related to this event. For Chris, the levels of compliant responding to the low-probability requests increased more during this condition than during the high-probability request sequence using peer modeling. His disruptive behaviors increased slightly but remained at the low levels. He also engaged in less selfstimulating behavior during this condition. 
Research on the use of the high-probability request sequence has found that compliant responding to low-probability requests increases with implementation of the intervention (Davis \& Reichle, 1996; Davis et al., 1992, 1994, 2000; Durchame \& Worling, 1994; Mace et al., 1988; Killu et al., 1998; Sanchez-Fort et al., 1995; Santos \& Lignugaris/Kraft, 1999). The results of this study support the existing literature on the effectiveness of the high-probability request sequence intervention on compliant responding to requests.

Regarding the maintenance of compliant responding to low-probability requests, some studies have shown that compliant responding to low-probability requests decreased to the baseline levels after withdrawal of the high-probability request intervention (Belfiore et al., 1997; Mace et al., 1988; Mace \& Belfiore, 1990; Kennedy et al., 1995; Singer et al., 1987; Wehby \& Hollahan, 2000). Other studies demonstrated that with the systematic fading procedure of the high-probability request sequence, the target children's compliance maintained the same levels as during the high-probability request sequence (Ducharme \& Worling, 1994; Ardoin et al., 1999). In this study, the increased compliant responding of the target children maintained the high levels, and two of the children's compliant responding to the low-probability requests continued increasing trends after removal of the high-probability request sequence. The results of this study are consistent with the findings of Davis et al. (1992; 1994), and Killu et al. (1998). In this study, the natural community of reinforcement from social interactions between children may have helped to maintain and increase compliant responding to the low-probability requests after removal of the intervention. 
The present study supports and extends findings in the literature regarding the high-probability request sequence intervention. Further, the intervention was implemented involving peers as peer models as well as play partners.

What are the effects of the use of high-probability request sequences with embedded peer modeling on the social interactions of young children with autism toward their typically developing peers?

Children's social initiations and responses were observed across all experimental conditions. During baseline, all participants were given instructions to stay in the center and play with a friend. The three target children seldom engaged in social interactions with peers.

During the initial low-probability request condition, prompted social initiations increased slightly with the implementation of low-probability requests while remaining at the low levels. However, unprompted initiations and responses maintained the same levels as during the baseline condition. Eric often ignored his peer's initiations and engaged in more self-stimulating behavior. Paul's unprompted social interactions remained at the low levels, and he often engaged in stereotypic behaviors (e.g., repeatedly pounding the floor with his toys). Chris engaged in no unprompted social interactions during this condition. Peers attempted several unprompted initiations to the target children at the beginning of the low-probability request condition after peer training and before moving to the low-probability request condition. Their initiations did not continue as the sessions went on largely because the target children were not responding to the peers. 
Upon introduction of the high-probability request sequences with embedded peer modeling, both the target children and the peers were prompted to initiate social behaviors toward each other. All the children's unprompted social initiations and responses as well as prompted initiations increased. Eric exhibited an immediate increase in social initiations and responses. He engaged in interactive play with his peer, Stacie, while using the target behaviors (e.g., "Hey, fly the plane to me," "Let's build an airport," "How are you?" "I like to play with you," etc.). Additionally, he often initiated play using the same high-probability requests delivered by the experimenter (e.g., "Take off the run way," "Fold down the stairs," etc.). When his peer did not respond to his initiations, he initiated Stacie again ("I am talking to you," "I flied the plane to you," etc.). Eric exhibited a slight increase in interactions with the untrained, generality peer during this condition while he engaged in no interactions with her during the low-probability request condition. Eric's peer, Stacie, showed the same level of unprompted initiations as during the previous condition while responding to Eric's play initiations most of the time. Additionally, her interactions focused upon Eric rather than upon the generality peer, although she did engage in more interactions with the generality peer during the lowprobability request alone condition. The second target child, Paul, showed increased levels of social initiations and responses toward his peer during the intervention. He responded to all of his peer's initiations; however, his unprompted initiations remained at relatively low levels while exhibiting a slight increase. One week after implementation of the intervention, he displayed unprompted initiations to his peer using the targeted lowprobability requests (e.g., "Come to me, Jennifer," tickling his peer, etc.); however, his peer, Jennifer, did not respond to his unprompted initiations. Jennifer displayed a slight 
increase in unprompted initiations to Paul, but they nevertheless remained at low levels. Jennifer sometimes did not respond to Paul's initiations and did not want to share toys with him. Chris's social initiations and responses showed higher levels than during the low-probability request condition. He engaged in responses most of time when his peer, Hilary, initiated toward him. His unprompted initiations increased but still remained at low levels. As the sessions continued, he engaged in more unprompted initiations. $\mathrm{He}$ engaged in interactions with the generality peer during this condition. Hilary increased her unprompted social initiations and responses to Chris, and she engaged in more interactions with Chris than with the generality peer.

After reintroducing the low-probability request alone condition, Eric's initiations and responses to his peer increased more than during the high-probability request sequence intervention. His peer, Stacie, exhibited more interactions with him than during the high-probability request sequence using peer modeling. She displayed no interactions with the generality peer during this condition. For Paul, his initiations and responses to his peer decreased slightly during this condition. Paul's peer, Jennifer, had levels of social initiations that were slightly decreased although she maintained the same levels of unprompted initiations and responses as in the previous condition. The third target child, Chris, continued to show increasing social initiations and responses to his peer, and his generality peer. His peer, Hilary, demonstrated continuous increasing interactions toward Chris. During this condition, Hilary often prompted Chris to play while using the same high-probability requests that the experimenter had delivered (e.g., "Push the train," "Put the barrel in loader," "Cut the pizza," etc.). She modeled and provided physical assistance when Chris did not respond to her. 
The low-probability request prompts were removed to assess whether social interactions between the children were maintained during the maintenance condition. Eric maintained the same levels of unprompted initiations and responses to his peer, Stacie, and his social behaviors toward the generality peer increased during this condition. Stacie exhibited more initiations and responses to him than during the low-probability request sequence. Paul's unprompted initiations and responses increased slightly, and he engaged in more interactions with his generality peer than during the previous condition. Paul's peer, Jennifer, showed a slight increase in unprompted social initiations to him. She engaged in more interactions with the generality peer. Chris's unprompted initiations remained at the same levels as during the previous condition, but his responses to his peer, Hilary, maintained relatively high levels while showing a slight decrease.

Results of this study can be compared with two fields of research, including the high-probability request sequence intervention and peer-mediated social interaction studies. Davis et al. (1994) found that using the high-probability request intervention increased social interactions between children with disabilities and typically developing children and that the target children's social behaviors generalized to the generality peer in the intervention and generality setting. Additionally, after removing the prompts, children's social interactions maintained and even increased more than during the highprobability request sequence intervention in their study. With the exception of Paul and Jennifer, whose social behaviors slightly decreased the results of this study support Davis et al. (1994). Regarding the continued increase in social interactions after removing 
intervention, Davis et al. (1994) proposed that the prompted interactions during the intervention may have prevented an increase in the unprompted interactions due to the time children engaged in prompted interactions.

In addition, in this study the targeted requests included behaviors that are more likely to facilitate other children's responses, such as greetings, complimenting, and demonstrating affectionate behaviors (Fox \& McEvoy, 1993; Tremblay et al., 1981). Additionally, prompting both the target children and the peers to initiate may have facilitated ongoing interactions and would have provided them with natural communities of reinforcement for engagement in social interactions.

In the studies on peer-mediated social interaction interventions, peer initiations decreased after removing teacher prompts (Odom et al., 1985). Researchers noted that peer confederates in peer-mediated interventions may become weary from their roles as the initiating playmate for the child with disabilities and, thus, their levels of social initiations might become fewer as the intervention progresses (Odom et al., 1987; Odom $\&$ Watts, 1991). Thus, subsequent studies have focused on maintaining peer initiations using teacher prompts fading procedures, corresponding training, incidental teaching, and self-evaluation strategies (McGee et al., 1992; Odom \& Watts, 1991; Odom et al., 1992; Sainato et al., 1992). In this study, the peers were trained once stable responding was demonstrated by the target children during baseline before moving to the low-probability request sequence. During the high-probability request sequence, the peers were provided with the high-probability request sequence to initiate the target children while modeling for the target children. After the high-probability request sequences with embedded peer modeling phase, the peers were not given any prompts to interact with the target children. 
Although Jennifer did not maintain the same levels of social behaviors as during the highprobability sequence intervention, results indicated that the peers' unprompted initiations to the target children showed a continued increasing trend toward the end of the study. Odom and Watts (1991) suggested that the peers and the children with disabilities might be taught social interaction skills at the same time in order to encourage more reciprocal social interactions rather than the one-sided interactions that occur when one child is always initiated by the peer or the target child. In this study, prompting the target children as well as the peers using the high-probability request sequence during the intervention may account for maintaining the peers' interactions toward the target children.

Another component of this study was peer modeling. Peer modeling was proposed to increase the social behaviors of children with disabilities (Bailey \& Wolery, 1992; Kohler \& Strain, 1999). No recent studies using peer modeling focused on social interactions had been reported prior to this study. Thus, comparison of the combined high-probability request sequence using embedded peer modeling with current research is difficult. In the studies on using peer modeling to increase imitation of peer's behaviors, Carr and Darcy (1990) and Venn et al. (1993) found that peer modeling increased the target children's imitation of classroom activities in a natural environment.

Although this study did not measure the separate effects of peer modeling on social interactions, peer modeling may partially account for the target children's increased social behaviors. The target children understood the sequence of the intervention and waited their turn after delivery of the high-probability request sequence. During the previous condition, the target children often ignored their peers' initiations or sometimes exhibited negative interactions with their peers; however, the target children 
were more likely to respond to their peers' initiations after the intervention was introduced. Additionally, it was observed that the target children imitated their peers' extended play (i.e., building a tall and long airport building, pretending to eat toy food, peek-a-boo play, pouring tea into a cup, etc.). Bailey and Wolery (1992) suggest that future research would need to address whether peer modeling procedures result in the learning of complex social play skills. In this study, the high-probability request sequence consisted of a sequence of the related play skills within the given context (e.g., "Pick up the pizza," "Cut the pizza," "Put the cheese on the pizza," "Give Hilary the pizza," etc.). Moreover, the third peer used this sequence independently for Chris and provided physical assistance when Chris did not responded to her prompts. In this study, it was proposed that a sequence of play skills that consisted of response chains may facilitate social play with peer modeling.

Peer modeling is an important way of learning for children (Car \& Dary, 1990). This procedure is easily embedded into daily activities without extensive teacher time and prompting and facilitates more generalized observational learning (Wert et al., 1996). A more structured peer modeling procedure for increasing social interactions would be beneficial to build effective strategies.

Regarding the types of social interactions, the three children demonstrated different results. The first target child, Eric, showed a sharp increase in unprompted social initiations as well as responses, and he engaged in more initiations than responses during the play. The second child, Paul, had initially low levels of social initiations although his social initiations slightly increased with the implementation of the intervention. His social behaviors were focused on responses to his peer or his generality 
peer. Paul showed significant deficits in language skills and rarely talked with others but used some request words if necessary. The third child, Chris, demonstrated robust changes in social responses to his peer or his generality peer; however, his unprompted initiations showed delayed increase after intervention was introduced. Chris seldom talked with others, and he often repeated the sentences that were said.

Social skills are complex, requiring multiple skills from other developmental domains such as communication, play, and cognitive skills (Bailey \& Wolerly, 1992). In particular, communication skills are very important for ongoing extended social interactions. The first target child, Eric, was able to comment using simple sentences related to the play situation. Eric's communication skills may have contributed to his increased social behaviors, especially initiations. The other two children had limited language skills, which may have influenced their social behaviors. Chris demonstrated that his social initiations were increasing toward the end of the study. Paul showed a sharp increase in social initiations during the generality setting at the end of the study. Both target children and their peers engaged in more play toward the end of the study and found more fun play that was not included in the intervention. Paul, his peer, and his generality peer engaged in playing with a toy tool box with sounds, and they were taking turns clicking the sound button. Additionally, Paul enjoyed simple games (i.e., "Up high, down low, too slow.") that other children in the class liked to do during the transition time or free play. For Chris, his peer, Hilary, played "Boo" to get his attention. They enjoyed playing "peek-a-boo" together. After finding the common game to play, Paul's and Chris's social initiations toward the other children increased much more than before. 
This result suggests that adapting a game that the target children and peers commonly like would facilitate the social interactions of children with limited communication skills and their typically developing peers.

What are the effects of the use of high-probability request sequences with embedded peer modeling on the social interactions of young children with autism toward their typically developing peers during generality sessions?

For each session, data were collected to determine the number of intervals of unprompted social initiations and responses in the generality setting. The general procedure remained the same as during baseline; however, the children were not given any stickers or toys during the generality sessions. The experimenter's general prompts for the children remained at low levels across the conditions. During the baseline condition, all children exhibited no interactions except that Eric engaged one initiation in the generality setting. His peer engaged in interactive play, mostly with the generality peer.

For the generality sessions for the initial low-probability request alone condition, all children's social interactions were very low. Social interactions between Eric and Stacie increased slightly, however, remained at the low levels. Paul and Chris continued to display no interactions. During this condition, their peers, Jennifer and Hilary engaged in social interactions with the generality peers.

During the generality sessions for the high-probability request sequences with embedded peer modeling, the social interactions of all three children increased. Eric exhibited more unprompted initiations and responses toward his generality peer as well as his trained peer. Stacie, Eric's peer, engaged in interactive play with Eric as well as with 
the generality peer. All three children played often and talked together as a group. Eric often used the target behaviors during play (e.g., "I like to play with you guys."). Paul exhibited a slight increase in initiations and responses, but his overall initiations remained at the low levels. His peer, Jennifer, slightly increased her interactions with Paul. She also engaged in more interactions with the generality peer. Chris's initiations and responses increased with the generality peer as well as with his trained peer, Hilary. Like Paul's peer, Hilary exhibited increased interactions with him while also playing more with the generality peer.

For the generality sessions of the second low-probability request condition, all three target children's social interactions increased more than during the high-probability request sequences with embedded peer modeling. Eric maintained high levels of social initiations and responses with both his trained peer and his generality peer. Stacie engaged in more interactions with Eric during this condition. Paul exhibited a slight increase in initiations and responses toward his generality peer as well as toward his trained peer although his initiations and responses remain low overall. Jennifer maintained the same levels of social interactions with Paul. Chris's social initiations and responses to his peer, Hilary, increased more than during the previous condition. Hilary engaged in interactive play with him more than with the generality peer.

During the maintenance condition in the generality setting, Eric and Paul exhibited increases in unprompted initiations and responses. Eric continued interactive play with Stacie and his generality peer. Stacie engaged in interactions more with the generality peer; however, they continued to play as a group. Paul's initiations and responses with his generality peer and his trained peer sharply increased. They played 
together while engaging in turn taking. Jennifer engaged in interactions with Paul rather than with the generality peer during this condition. No generality data were taken during the maintenance phase for Chris.

The results of this study regarding generality support Davis et al. (1994). Davis et al. demonstrated that children's unprompted social interactions generalized to the trained peers in the nontraining setting and the generality peers in both the intervention and generality setting. In their study, the low-probability requests were prompted in the nontraining settings; however, this study did not provide any prompts for the children to interact in the generality setting as occurred in the baseline condition. In relation to the results of unprompted social interactions, this study is consistent with Davis et al. (1994).

Goldstein et al. (1997) demonstrated that interactions were maintained when the peers were reassigned to different target children during the generality probes. They distributed the intervention to facilitate generalization across a variety of settings throughout the school day. This study rotated three intervention settings, and the highprobability and low-probability requests included multiple exemplars even though the intervention was provided during one hour center time in the morning. Additionally, several generality strategies were included in the high-probability request sequence using peer modeling. Odom and Brown (1994) suggested that teaching children to recruit social behaviors from peers would promote generalization to other situations and other children. In this intervention, the targeted behaviors included specific play initiations (e.g., "fly the plane to me," "Pizza, please," etc.) and general social initiations (e.g., "I like to play with you," "How are you?" "Hi," etc.) to recruit social behaviors from peers. Additionally, the targeted behaviors included some affectionate behaviors that were more likely to 
facilitate positive social interactions (Fox \& McEvoy, 1993; McEvoy et al., 1990; Twardosz et al., 1983). These strategies may have facilitated the generalized social interactions with the generality peers in the intervention setting and with the trained peer and generality peer in the nontraining settings.

To what extent do parents and early childhood special education teachers find the intervention goals, procedures, and outcomes to be relevant, useful, and effective for children with autism?

Parents and professionals in early childhood special education assessed the social validity of the intervention goals, procedures, and outcomes. Three parents of target children and three early childhood special education teachers were asked whether they considered the research questions to be valid and useful for their children. All of the parents and the teachers answered that all of the research questions were useful and valid for the children with autism except one parent answered "unsure" for one of the research questions. Additionally, parents were asked to identify goals in the social interaction domain, which included the targeted behaviors.

To obtain data regarding the intervention procedures, 20 professionals in early childhood special education watched three unidentified 2-minute segments of videotape depicting the target children and answered open-ended questions regarding the following conditions: baseline, the initial low-probability request alone condition, and the highprobability request sequence using peer modeling. Most of the professionals responded that this intervention would be easy to use during the students' regular routine, and they would use this intervention in their classroom. Additionally, most of professionals thought that the high-probability request intervention using peer modeling would be 
useful to improve social interactions between the children. Some of the respondents indicated that the intervention seemed time-consuming if the classroom was too busy and included too many children.

To assess the intervention outcomes, the same 20 professionals completed the checklists that consisted of the skills targeted by the intervention. Over $95 \%$ of the professionals responded that they had observed all targeted skills during the highprobability request sequences with embedded peer modeling. In addition to compliant behaviors to requests and social interactions, at least $95 \%$ of the professionals observed that the children focused on the task/play. Several professionals reported that the intervention did not seem to be natural in terms of prompting the children.

In addition to the professionals' assessment of intervention outcomes, the target children's social interactions can be compared to normative data on typically developing children. Normative data samples on social interactions were collected in the same classroom in which the study was conducted. Overall, all target children's social initiations and responses in the intervention and generality setting met or exceeded the levels of social interactions observed by typically developing children in the same classroom.

Few previous studies on using the high-probability request sequence reported on social validity (Davis et al., 2000; Durcharme \& Wolering, 1994; Horner et al., 1991; Killu et al., 1998). Durcharme and Wolering (1992) found that parents reported high levels of satisfaction with the high-probability request sequence. Other studies reported that the intervention was effective and practical to implement (Davis et al., 2000; Horner 
et al., 1991; Killu et al., 1998). The results of social validity assessment in this study supported the previous studies on the use of the high-probability request sequence.

Some professionals indicated that this intervention seemed to be time-consuming as part of a daily routine, and they perceived the high-probability request sequence to be unnatural. However, other professionals reported that the high-probability request sequence intervention would be easy to modify and adapt by using more naturally occurring activities based on the classroom environment and the specific target behaviors.

\section{Implications for Practice}

The results of this study suggest that the combined methods of the highprobability request sequence and peer modeling were successful for increasing compliant responding to requests to initiate social behaviors and social initiations and responses between children with autism spectrum disorders and typically developing children. Prompting the target children and peers to interact at the same time by combining the high-probability request sequences and the peer-mediated social interaction intervention was an effective procedure to encourage interactions between the children. These two interventions are recommended by the Division of Early Childhood Recommended Practice Guidelines (DEC) (Wolery, 2000). The high-probability request sequence was suggested as one of several strategies to increase the complexity and duration of the children's play, engagement, appropriate behavior, and learning (Wolery, 2000). Additionally, the DEC recommended that peer-mediated strategies be used to promote social and communicative behavior (Wolery, 2000).

This intervention was conducted during center time using typical play materials in the classroom. The targeted low-probability requests were chosen based on the children's 
IEP goals, the parents' social skill goals for their children and individual assessments that were embedded into the children's interactive play within the context of their routine activities. Additionally, the intervention consisted of using the high-probability requests that the children liked to perform while using their favorite play materials and action songs. Embedding instruction into existing classroom activities and routines was considered to be an effective strategy in the inclusive setting (Horn, Lieber, Sandall, \& Schwartz, 2000). Pretti-Frontczak and Bricker (2001) described that the embedding strategy promised intervention that: a) provides multiple opportunities for children to practice and learn targeted skills within the daily activities and events in the children's natural environment; b) is compatible with an inclusive program; c) focuses on a child's interests and motivation; d) can be implemented by professionals, parents, or peers; and e) can be incorporated into a wide range of curricula models. The high-probability request sequence could be incorporated into classroom routines while addressing the individual child's educational needs.

The potential for observational learning and facilitating positive social relationships between children are major rationales for the inclusion of children with disabilities (Werts et al.,1996). Additionally, Erwin and Robin (1999) described typical peers as a viable source of support who can provide positive interactions in ways that adults cannot. Young typically developing children may be able to make accommodations appropriate to the individual needs of children with disabilities while playing or communicating (Erwin, 1996; Guralnick, 1999). This study included the peers as models as well as play partners. Peers were trained how to respond to each targeted social initiation of the target children and were prompted to initiate to the target children 
by delivering the high-probability request sequence as a model. They maintained social interactions with the target children while extending the play. A peer modeling procedure would be usable to increase other important skills as well as social interactions without extensive training. Additionally, the classroom teacher responded that the intervention would be effective in terms of using the peer model and providing an opportunity for the target child to experience appropriate child to child interactions.

The results of the study demonstrated that social interactions generalized to nontrained peers in the intervention and the generality setting. Generality and the maintenance of social interactions between children has been a critical issue in studies on increasing the social interactions of children with autism. Selecting targeted social behaviors is an important factor for generalized social interactions. Recruiting social behaviors from peers, including specific play initiations and general social initiations, would increase generalized social interactions (Brown \& Odom, 1994). Additionally, some behaviors such as sharing, assisting with play, verbally organizing play, engaging in rough and tumble play, complimenting, and displaying affectionate behaviors would be more likely to facilitate other children's interactions (Tremblay et al., 1981; Fox \& McEovy, 1993). Providing various examples of social behaviors and fun experiences for children would facilitate generalized social interactions with other children and in the nontraining setting.

\section{Directions for Future Research}

Literature on the high-probability request sequence procedure has demonstrated its effectiveness in increasing compliance with requests and has extended into teaching specific skills in natural environments along with methodological extensions. More 
research is needed to maximize the effectiveness of the high-probability request in teaching young children with disabilities and to increase the feasibility of the procedure in early childhood special education settings.

This research extended the literature on the high-probability request sequence and peer-mediated social interaction interventions by combining the instructions. Future research could investigate the effects of this combined intervention on increasing social interactions by using adapted specific fun games (e.g., board games, "Simon says," etc.) that are popular among typically developing children. Peers' participation in the intervention as models as well as play partners may be an important factor to maintain the children's social interactions. Thus, providing pleasant experiences for the children is necessary so that the peers would not be weary of their role as play partner to children with autism who have limited language skills.

Future research might investigate the use of the high-probability request sequence for teaching pre-academic skills to young children with disabilities. Some studies have demonstrated the effectiveness of the intervention on academic tasks with older children with disabilities (Belfiore et al., 1997; Wehby \& Hollahan, 2000). Additionally, Mace and Belfiore (1990) demonstrated that increasing compliance to task-related demands may have the collateral effect of reducing problem behaviors that are maintained by escape from demand. Some children with disabilities have difficulty learning preacademic skills while engaging in escape and avoidance behaviors. By combining the high-probability request sequence with other existing effective procedures such as task 
analysis, prompting strategies, or time delay, the effects of the high-probability request sequence intervention on teaching pre-academic skills for young children with autism could be further investigated.

The literature on the high-probability request sequence intervention has implications for use with a wide range of children with disabilities and for improving a variety of skills. As researchers have been prompted to extend the procedure to all areas of individual learning and development (Davis \& Reichle, 1996; Davis et al., 1992, 1994; 2000; Killu et al., 1998; Sanchez-Fort et al., 1995; Santos \& Lignugaris/Kraft, 1999), future research might examine the effectiveness of the use of the high-probability request sequence for improving a broader range of skills (e.g., nonverbal tasks) with children with severe disabilities such as those with motor skills and self-help skills.

Future research might examine the effectiveness of the high-probability request sequence to improve group responding. Children in preschools spend the majority of their time in large group activities such as circle time and activity time (Bailey \& Wolery, 1992; Pretti-Frontczak \& Bricker, 2001). During large group activities, children are more likely to have more dead time waiting for other children to complete activities (Baily \& Wolery, 1992). Moreover, in large groups, children with disabilities may not be skilled at responding to group instructions and may be more likely to engage in challenging behaviors. One study demonstrated that the high-probability request procedure can be interspersed across class activities during group transitions of elementary students (Ardoin et al., 1999). Future research could apply the procedure to increase group responding for young children during large group activities such as circle time. 
Finally, research might examine the effectiveness of this strategy's use in the home by parents and siblings. Several studies have demonstrated that the interventions implemented by parents were successful in increasing compliant responding (Ducharme \& Worlring, 1994; McComas et al., 1998). In addition to parents, the effects of the procedure when used by siblings might be investigated to increase other specific skills such as appropriate play skills.

\section{Summary}

The increasing inclusion of young children with disabilities in classrooms with typically developing children demands the use of various instructional strategies to provide effective interventions for children with a wide range of educational needs in early childhood settings. Additionally, these instructional strategies need to be incorporated into the instructional routines of the child's natural classroom environment. Among the variety of effective instructional strategies, the high-probability request sequence has been demonstrated as an antecedent and non-aversive procedure, which is well-incorporated into classroom routines (Davis \& Brady, 1993). The high-probability request sequence procedure has been demonstrated to be an effective strategy to increase compliance and recently has been applied to teach specific skills. Few studies on the use of the high-probability request sequence have addressed the social behaviors of young children with autism with peers in their natural environment (Davis et al., 1994).

Building meaningful social relationships between children with and without disabilities is an important goal in inclusion. Due to the substantial social skill deficits of children with autism, facilitating social interactions has been a critical issue in educational research. Peer-mediated interventions have shown the strongest empirical 
support for social behaviors (Rogers, 2000; Sasso et al., 1998; Zanolli, et al., 1996). However, it is noted that these strategies have been limited in generalization and maintenance after removal of the intervention.

The present study investigated the effects of the high-probability request intervention and peer modeling on compliant responding to low-probability requests to initiate social behaviors and social interactions of young children with autism spectrum disorders. This study was implemented in an inclusive classroom using the children's favorite toys and play materials during their center time. The high-probability request intervention was first delivered to peer models and then to the target children. Daily observations were completed during an hour of center time, and all sessions were videotaped.

Results of the study indicate that compliant responding of target children to lowprobability requests increased and was maintained after withdrawal of the highprobability request sequence using peer modeling. The intervention resulted in increased social interactions between children with autism spectrum disorders and typically developing children. Social interactions were maintained for two groups of children after withdrawal of the intervention, and the children's social interactions generalized to the nontrained generality peers and into the nontraining setting.

The results of the social validity assessment indicate that parents and early childhood special education teachers perceived that the research questions in this study were valid and useful. Professionals in early childhood special education reported that the intervention was feasible for use in a typical classroom routine. Additionally, regarding 
intervention outcomes, most of them observed the targeted skills during the intervention and reported that the intervention was effective in increasing social interactions.

The combined strategy of the high-probability request sequence and peer modeling was shown to be effective for increasing compliant responding to requests and social interactions in young children with autism spectrum disorders. The intervention can be embedded in classroom activities using typical toys and play materials, it facilitates observational learning for children with autism spectrum disorders using peer modeling, and it facilitates generalized social interactions by providing multiple exemplars and experiences.

This research extended the literature on the high-probability request sequence and peer-mediated social interaction interventions by combining the two strategies. Future research may investigate the effects of the high-probability request sequence with peer modeling using adapted games in social interactions. Directions for future research include investigating the effectiveness of this strategy with pre-academic skills, with other skills for a wide range of children with disabilities, with group responding, and with parents and siblings in the home setting. 


\section{LIST OF REFERENCES}

American Psychiatric Association (1994). Diagnostic and Statistical Manual of Mental Disorders ( $4^{\text {th }}$ ed.). Washington, DC: Author.

Ardoin, S. P., Martens, B. K., \& Wolfe, L. A. (1999). Using high-probability instruction sequences with fading to increase student compliance during transitions. Journal of Applied Behavior Analysis, 32, 339-351.

Bailey, D. B., \& Wolery, M. (1992). Teaching infants and preschoolers with disabilities. Englewood Cliffs, NJ: Prentice-Hall, Inc.

Belfiore, P. J., Lee, D. V., Vargas, A. U., \& Skinner, C. (1997). Effects of high preferences single-digit mathematics problem performance. Journal of Applied Behavior_Analysis, 30, 327-330.

Brown, W., McEvoy, M. A., \& Bishop, N. (1991). Incidental teaching of social behavior: A naturalistic approach for promoting young children's peer interactions. Teaching Exceptional Children, 24(1), 35-38.

Brown, W. H., \& Odom, S. L. (1995). Naturalistic peer interventions for promoting preschool children's social interactions. Preventing School Failure, 39, 38-43.

Brown, W. H., Ragland, E., \& Bishop, N. (1989). A naturalistic teaching strategy to promote young children's peer interactions. Teaching Exceptional Children, 21(4), 8-10.

Carr, E. G., \& Darcy, M. (1990). Setting generality of peer modeling in children with autism. Journal of Autism and Developmental Disorders, 20, 45-59.

Carr, E. G., Newsom, C. D., \& Binkoff, J. A. (1976). Stimulus control of self-destructive behavior in a psychotic child. Journal of Abnormal Child Psychology, 4, 139153. 
Chandler, L. K., Lubeck, R. C., \& Fowler, S. A. (1992). Generalization and maintenance of preschool children's social skills: A critical review and analysis. Journal of Applied Behavior Analysis, 25, 415- 428.

Cooper, C., \& McEvoy, M. A. (1996). Group friendship activities: An easy way to develop the social skills of young children. Teaching Exceptional Children, 28(3), 67-69.

Davis, C. A. (1995). Peer as behavior change agents for preschoolers with behavioral disorders. Preventing School Failure, 39, 4-9.

Davis, C. A., \& Brady, M. P. (1993). Expanding the utility of behavioral momentum with young children: where we've been, where we need to go. Journal of Early Intervention, 17, 211-223.

Davis, C. A., Brady, M. P., Hamilton, R., McEvoy, M. A., \& Williams, R. E. (1994). Effects of high-probability requests of young children with severe disabilities. Journal of Applied Behavior Analysis, 27, 619-637.

Davis, C. A., Brady, M. P., Williams, R. E., \& Hamilton, R. (1992). Effects of highprobability requests on the acquisition and generalization of responses to requests in young children with behavior disorders. Journal of Applied Behavior Analysis, 25, 905-916.

Davis, C. A., \& Reichle, J. (1996). Variant and invariant high-probability requests: Increasing appropriate behaviors in children with emotional-behavioral disorders. Journal of Applied Behavior Analysis, 29, 471-482.

Davis, C. A., Reichle, J., \& Southard, K. L. (2000). High-probability requests and a preferred item as distracter: Increasing successful transitions in children with behavior problems. Education and Treatment of Children, 23, 423-440.

Ducharme, J. M., \& Worling, D. E. (1994). Behavioral momentum and stimulus fading in the acquisition and maintenance of child compliance in the home. Journal of Applied Behavior Analysis, 27, 639-647.

Englemann, S., \& Colvin, G. T. (1983). Generalized compliance training: A direct instruction program for managing severe behavior problems. Austin, TX: ProED.

Erwin, E. J., \& Schreiber, R. (1999). Creating supports for young children with disabilities in natural environments. Early Childhood Special Education, 26, 167171. 
Fawcett, S. B. (1991). Social validity: A note on methodology. Journal of Applied Behavior Analysis, 24, 235-239.

Frea, W., Craig-Unkefer, L., Odom, S. L., \& Johnson, D. (1999). Differential effects of structured social integration and group friendship activities for promoting social interaction with peers. Journal of Early Intervention, 22, 230-242.

Goldstein, H., English, K., Shafer, K., \& Kaczmarek, L. (1997). Interaction among preschoolers with and without disabilities: Effects of across the day peer intervention. Journal of Speech, Language, and Hearing Research, 40, 33-48.

Goldstein, H., Kaczmarek, L., Pennington, R., \& Shafer, K. (1992). Peer-mediated intervention: Attending to, commenting on, and acknowledging the behavior of preschoolers with autism, Journal of Applied Behavior Analysis, 25, 289-305.

Guralnick, M. (1990). Social competence and early intervention. Journal of Early Intervention, 14, 3-14.

Guralnick, M. (1999). The nature and meaning of social integration for young children with mild developmental delays in inclusive settings. Journal of Early Intervention, 22, 70-88.

Harchick, A. E., \& Putzier, V. (1990). The use of high-probability requests to increase compliance with instructions to take medication. Journal of the Association for Persons with Severe Handicaps, 15, 40-43.

Houlihan, D., \& Brandon, P. K. (1996). Compliant in a momentum: A commentary of Nevin. Journal of Applied Behavior Analysis, 29, 549-555.

Houlihan, D., Jacobson, L., \& Brandon, P. K. (1994). Replication of a high-probability request sequence with varied interprompt times in a preschool setting. Journal of Applied Behavior Analysis, 27, 737-738.

Horner, R., Day, M., Sprague, J., O’ Brien, M., \& Healthfield, L. (1991). Interspersed requests: A nonaversive procedure for reducing aggression and self-injury during instruction. Journal of Applied Behavior Analysis, 24, 265-278.

Hundert, J., \& Houghton, A. (1992). Promoting social interaction of children with disabilities in integrated preschools: A failure to generalize. Exceptional Children, 54, 311-320.

Ivory, J., \& McCollum, J. A. (1999). Effects of social and isolate toys on social play in an inclusive setting. The Journal of Special Education, 32, 238-243. 
Kennedy, C. H., Itkonen, T., \& Lindquist, K. (1995). Comparing interspersed requests and social comments as antecedents for increasing student compliance. Journal of Applied Behavior Analysis, 28, 97-98.

Killu, K. (1999). High-probability request research: Moving beyond compliance. Education and Treatment of Children, 22, 471-491.

Killu, K., Sainato, D. M., Davis, C. A., Ospelt, H., \& Paul, J. N. (1998). Effects of highprobability request sequences on preschoolers' compliance and disruptive behavior. Journal of Behavioral Education, 8, 347-368.

Koegel, L. K., Koegel, R. L., Frea, W. D., \& Fredeen, R. M. (2001). Identifying early intervention targets for children with autism in inclusive school settings. Behavior Modification, 25, 745-761.

Kohler, F., Anthony, L., Steighner, S., \& Hoyson, M. (2001). Teaching social interaction skills in the integrated preschool: An examination of naturalistic tactics. Topics in Early Childhood Special Education, 21, 93-103, 113.

Kohler, F. W., \& Strain, P. S. (1990). Peer-assisted interventions: Early promises, notable achievements, and future aspirations. Clinical Psychology Review, 10, $441-452$.

Kohler, F. W., \& Strain, P. S. (1999). Maximizing peer-mediated resources in integrated preschool classrooms. Topics in Early Childhood Special Education, 19, 92-102.

Mace, F. C. (1996). In pursuit of general behavioral relations. Journal of Applied Behavior Analysis, 29, 557-563.

Mace, F. C., \& Belfiore, P. (1990). Behavioral momentum in the treatment of escapemotivated stereotypy. Journal of Applied Behavior Analysis, 23, 507-514.

Mace, F. C., Hock, M. L., Lalli, J. S., West, B. J., Belfiore, P., Pinter, E., \& Brown, D. K. (1988). Behavioral momentum in the treatment of noncompliance. Journal of Applied Behavior Analysis, 21, 123-141.

Mace, F. C., Lalli, J. S., Shea, M. C., Lalli, E. P., West, B. J., Robert, M., \& Nevin, J. A. (1990). Journal of the Experimental Analysis of Behavior, 54, 163-172.

Mace, F. C., Mauro, E. C., Boyajian, A. E., \& Eckert, T. L. (1997). Effects of reinforcer quality on behavioral momentum: Cooperated applied and basic research. Journal of Applied Behavior Analysis, 30, 1-20. 
McComas, J. M., Wacker, D. P., \& Cooper, L. J. (1998). Increasing compliance with medical procedures: Application of the high-probability request procedure to a toddler. Journal of Applied Behavior Analysis, 31, 289-290.

McComas, J. M., Wacker, D. P., Cooper, L .J., Peck, S., Golonka, Z., Millard, T., \& Richman, D. (2000). Effects of the high-probability request procedure: Patterns of responding to low-probability requests. Journal of Developmental and Physical Disabilities, 12, 157-171.

McConnell, S. R., Sisson, L. A., Cort, C., \& Strain, P. S. (1991). Effects of social skills training and contingency management of reciprocal interaction of preschool children with behavioral handicaps. Journal of Special Education, 24, 473-495.

McEvoy, M. A., Nordquist, V. M., Twardosz, S., Heckaman, K., Wehby, J. H., \& Denny, R. K. (1988). Promoting autistic children's peer interaction in an in integrated early childhood setting using affection activities. Journal of Applied Behavior Analysis, 21, 193-200.

McEvoy, M. A., Twardosz, S., \& Bishop, N. (1990). Affection activities: Procedures for encouraging young children with handicaps to interact with their peers. Education and Treatment of Children, 13, 160-167.

McGee, G. G., Almeida, C., Sulzer-Azaroff, B., \& Feldman, R. S. (1992). Promoting reciprocal interactions via peer incidental teaching, 25, 117-126. Journal of Applied Behavior Analysis, 25, 117-126.

McGee, G. G., Morrier, M. J., \& Daly, T. (1999). Incidental teaching approach to toddlers with autism. Journal of the Association for Persons with Severe Handicaps, 24, 133-146.

Nevin, J. A. (1974). Response strength in multiple schedules. Journal of the Experimental Analysis of Behavior, 21, 389-408.

Nevin, J. A. (1984). Pavlovian determiners of behavioral momentum. Animal Learning \& Behavior, 12, 363-370.

Nevin, J. A. (1996). The momentum of compliance. Journal of Applied Behavior Analysis. Journal of Applied Behavior Analysis, 29, 535-547.

Nevin, J., Mandell, C., \& Atak, J. (1983). The analysis of behavioral momentum. Journal of the Experimental Analysis of Behavior, 39, 49-59.

Nevin, A., Mandell, C., \& Yarensky, P. (1981). Response rate and resistance to change in chained schedules. Journal of Experimental Psychology: Animal Behavior Processes, 7, 278-294. 
Newborg, J., Stock, J. R., Wnek, L., Guidubaldi, J., \& Svinicki, J. (1984). Battelle Developmental Inventory. Allen, TX: DLM.

Odom, S. L., \& Brown, W. H. (1993). Social interaction skills interventions for young children with disabilities in integrated settings. In C.A Peck, S. L. Odom, \& D.D. Bricker (Eds.), Integrating young children with disabilities into community programs: Ecological perspectives on research and implementation (pp. 39-64). Baltimore, MD: Paul H. Brookes Publishing Co.

Odom, S. L., Hoyson, M., Jamieson, B., Strain, P. (1985). Increasing handicapped Preschoolers' peer social interactions: Cross-setting and component analysis. Journal of Applied Behavior Analysis, 18, 3-16.

Odom, S. L., McConnell, S. R., McEvoy, M. A., Peterson, C., Ostrosky, M., Chandler, L. K., Spcicuzza, R. J., Skellenger, A., Creighton, M., \& Favazza, P.C. (1999). Relative effects of interventions supporting the social competence of young children with disabilities. Topics in Early Childhood Special Education, 19, 7591.

Odom, S. O., Peterson, C., McConnell, S., \& Ostrosky, M. (1990). Ecobehavioral analysis of early education/specialized classroom settings and peer social interaction. Education and Treatment of Children, 13, 316-330.

Odom, S. L., \& Strain, P. S. (1986). A comparison of peer-initiation and teacherantecedent interventions for promoting reciprocal social interaction of autistic preschoolers. Journal of Applied Behavior Analysis, 19, 59-71.

Odom, S. L., \& Watts, E. (1991). Reducing teacher prompts in peer-mediated interventions for young children with autism. Journal of Special Education, $25,26-43$.

Plaud, J., \& Gaither, G. A. (1996). Behavioral momentum: Implications and development from reinforcement theories. Behavior Modification, 20, 183-210.

Pretti-Frontczak, K., \& Bricker, D. (2001). Use of the embedding strategy during daily activities by early childhood education and early childhood special education teachers. Infant-Toddler Intervention, 11, 111-128.

Rortvedt, A. K., \& Miltenberger, R. G. (1994). Analysis of a high-probability instructional sequence and time-out in the treatment of child noncompliance. Journal of Applied Behavior Analysis, 27, 327-330. 
Sainato, D. M., \& Carta, J. J. (1992). Classroom influences on the development of social competence in young children with disabilities. In S. Odom, S. McConnell, \& M. McEvoy (Eds.), Social competence of young children with disabilities: Issues and strategies for intervention(pp. 92-109). Baltimore: Paul H. Brookes Publishing Co.

Sanchez-Fort, M. R., Brady, M. P., \& Davis, C. A. (1995). Using high-probability requests to increase low-probability communication behavior in young children with severe disabilities. Education and Training in Mental Retardation and Developmental Disabilities, 6, 151-165.

Sandall, S., McLean, M. E., Santos, R. M., \& Smith, B. J. (2000). DEC's new recommended practices: The context for change. In S. Sandall, M. E. McLean, \& B. J. Smith (Eds.), DEC recommended practices in early intervention/early childhood special education (pp. 5-13). Longmont, CO: Sopris West.

Santos, R. M. (2001). Using what children know to teach them something new: Applying high-probability procedures in the classroom and at home. In M. Ostrosky, \& S. Sandall (Eds.), Teaching strategies: What to do to support young Children's development (pp.71-80). Longmont, CO: Sopris West.

Santos, R. M., \& Lignugaris/Kraft, B. (1999). The effects of direct questions on preschool children's responses to indirect requests. Journal of Behavioral Education, 9, 193-210.

Schwartz, I. S. (2000). Standing on the shoulders of giants: Looking ahead to facilitating membership and relationships for children with disabilities, Topics in Early Childhood Special Education, 20, 123-128.

Schwartz, I. S., \& Bear, D. M. (1991). Social validity assessments: Is current practice state of the art? Journal of Applied Behavior Analysis, 24, 189-204.

Schopler, E., Recichler, R. J., \& Renner, B. R. (1988). The Childhood Autism Rating Scale (CARS). Los Angeles: Western Psychological Services.

Singer, G. H. S., Singer, J., \& Horner, R. H. (1987). Using pretask requests to increase the probability of compliance for students with severe disabilities. Journal of the Association for Persons with Severe Handicaps, 12, 287-291.

Stokes, T. F., \& Baer, D. M. (1977). An implicit technology of generalization. Journal of Applied Behavior Analysis, 10, 349-367.

Stokes, T. F., \& Osnes, P. G. (1989). An operant pursuit of generalization. Behavior Therapy, 20, 337-355. 
Stokes, T. F., \& Osnes, P. G. (1986). Programming generalization of children's social behavior. In P. S. Strain, M. J., \& H. M., Walker (Eds.), Children's social behavior: Development, assessment, and modification (pp. 407-443). Orland, FL: Academic Press.

Twardosz, S., Nordquist, V. M., Simon, R., \& Botkin, D. (1983). The effect of group affection activities on the interaction of socially isolate children. Analysis and Intervention in Developmental Disabilities, 13, 311-338.

Venn, M. L., Werts, M. G., Morris, A., \& DeCesare, L. D. (1993). Embedding instruction in art activities to teach preschoolers with disabilities to imitate their peers. Early Childhood Research Quarterly, 8, 277-294.

Wehby, J. H., \& Hollahan, M. S. (2000). Effects of high-probability requests on the latency to initiate academic task. Journal of Applied Behavior Analysis, 33, 259-262.

Werts, M., G., Caldwell, N. K., \& Wolery, M. (1996). Peer modeling of response chains: observational learning by students with disabilities. Journal of Applied Behavior Analysis, 29, 53-66.

Wolery, M. (2000). Recommended practices in child-focused interventions. In S. Sandall, M. E. McLean, \& B. J. Smith (Eds.), DEC recommended practices in early intervention/early childhood special education (pp.29-37). Longmont, CO: Sopris West.

Wolery, M., \& Gast, D. L. (2000).Classroom research for young children with disabilities: Assumptions that guided the conduct of research. Topics in Early Childhood Special Education, 20, 49-55.

Zanolli, K., Daggett, J., \& Adams, T. (1996). Teaching preschool age autistic children to make spontaneous initiations to peers using priming. Journal of Autism and Developmental Disorders, 26, 407-422.

Zarcone, J. R., Iwata, B. A., Hughes, C. E., \& Vollmer, T. R. (1993). Momentum versus extinction effects in the treatment of self-injurious escape behavior. Journal of Applied Behavior Analysis, 26, 135-136.

Zarcone, J. R., Iwata, B. A., Mazaleski, J. L., \& Smith, R.G. (1994). Momentum and extinction effects on self-injurious escape behavior and noncompliance. Journal of Applied Behavior Analysis, 27, 649-658. 
APPENDIX A

DATA COLLECTION FORMS 
Data Collection Sheet

Date:

Child: Session \#: Observer:

IOA Observer:

Experimental Condition: Setting/Activity:

Code: HP=Delivery of high-probability requests, LP=Delivery of low-probability request, R: Response to request, NR: Nonrespons to request, NC: Noncompliance to request, Pr: Teacher praise, T: Target child, P: The paired peer, Op: Other peer, A: Adult, Pt: Prompted, N: Negative interaction, D: Disruptive behaviors

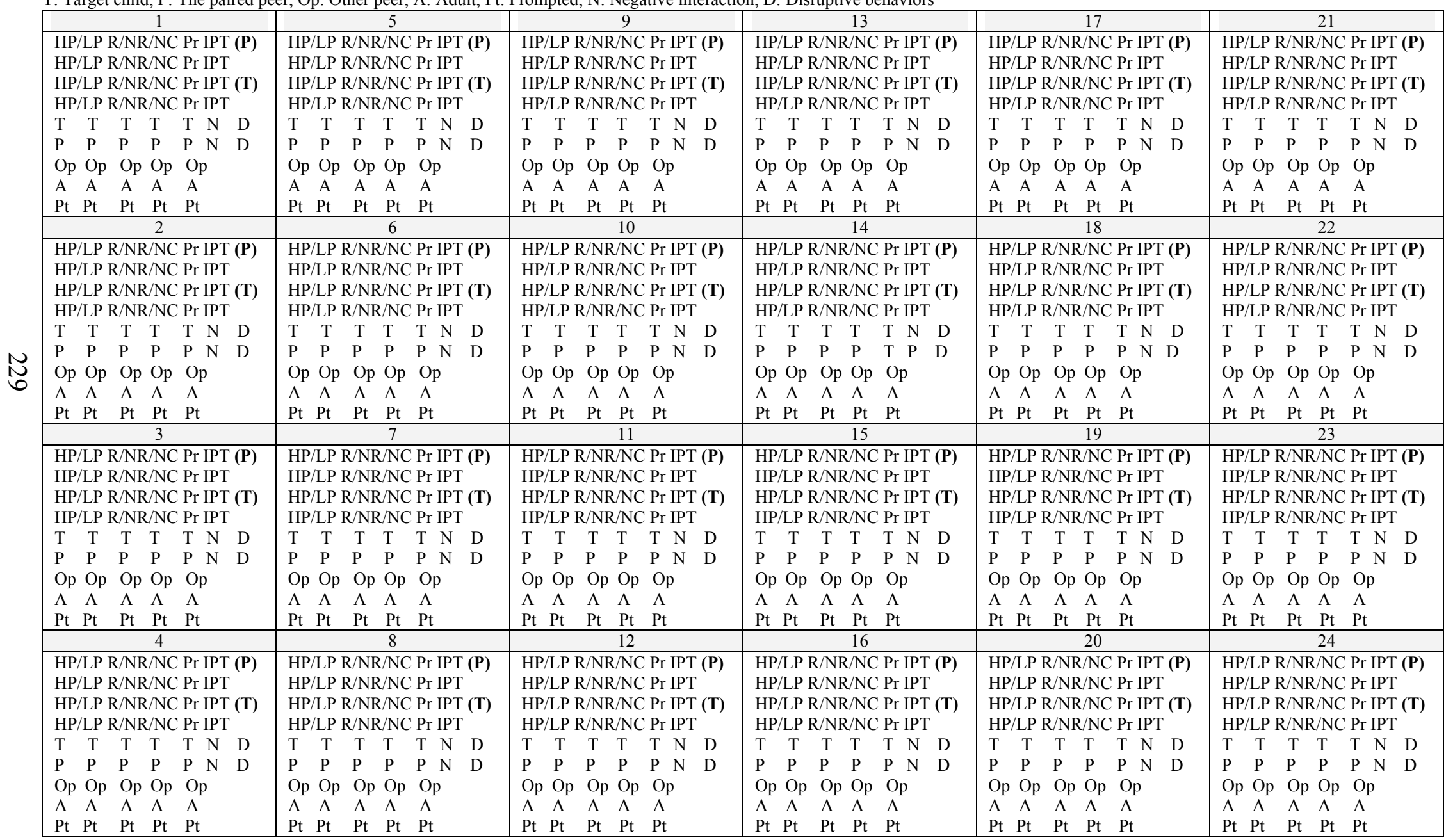




\section{Data Collection Sheet}

Date:

Child:

Session \#:

Observer:

IOA Observer:

Experimental Condition Setting/Activity:

of low-probability request, R: Response to request, NR: Nonrespons to request, NC: Noncompliance to request, Pr: Teacher praise, T: Target child, P: The paired peer, Op: Other peer, A: Adult, Pt: Prompted, N: Negative interaction, D: Disruptive behaviors

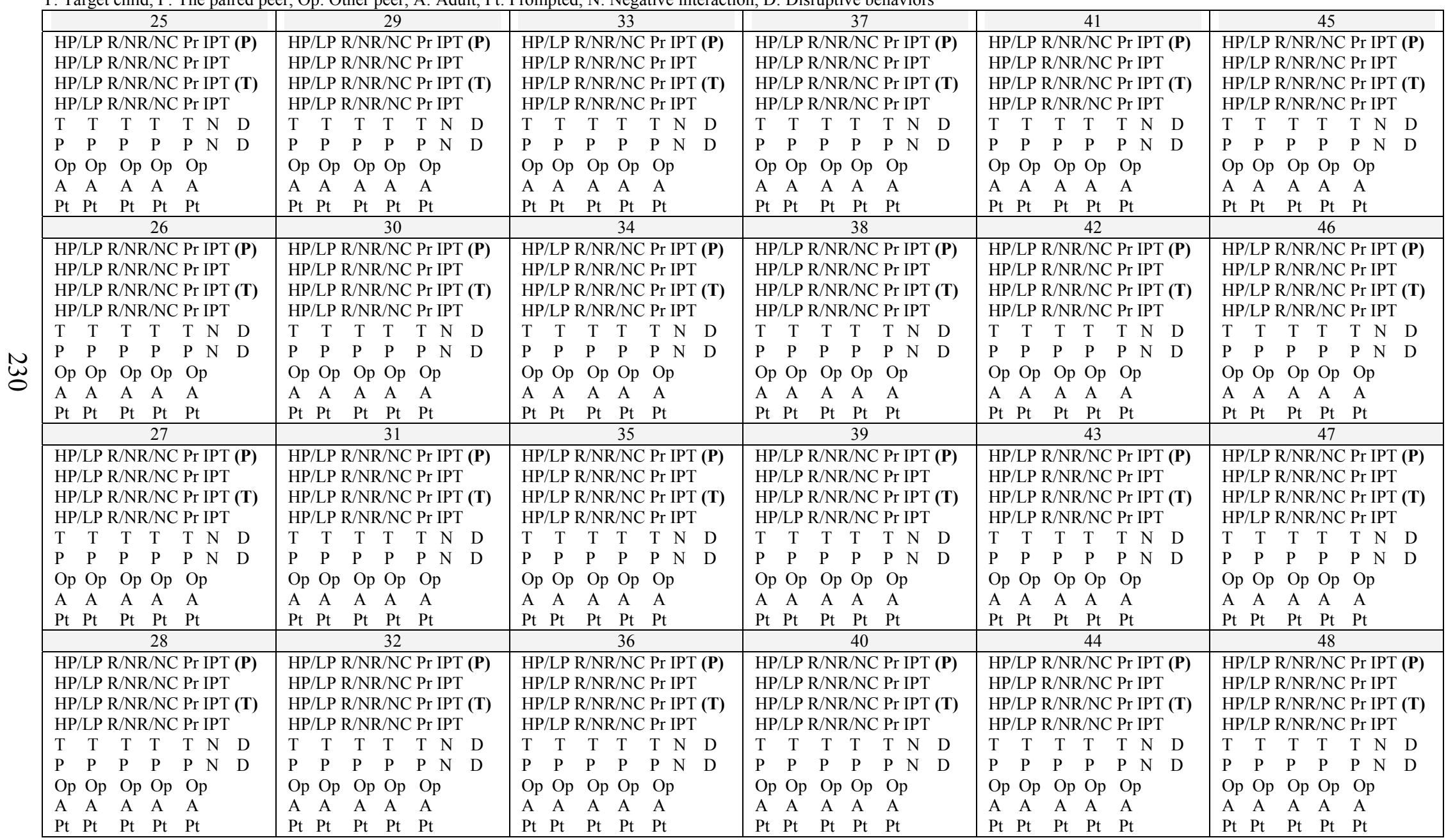


Data Collection Sheet

Date:

Child: Session \#: Observer:

IOA Observer:

Experimental Condition: Setting/Activity:

Code: HP=Delivery of high-probability requests, LP=Delivery of low-probability request, R: Response to request, NR: Nonrespons to request, NC: Noncompliance to request, Pr: Teacher praise, T: Target child, P: The paired peer, Op: Other peer, A: Adult, Pt: Prompted, N: Negative interaction, D: Disruptive behaviors

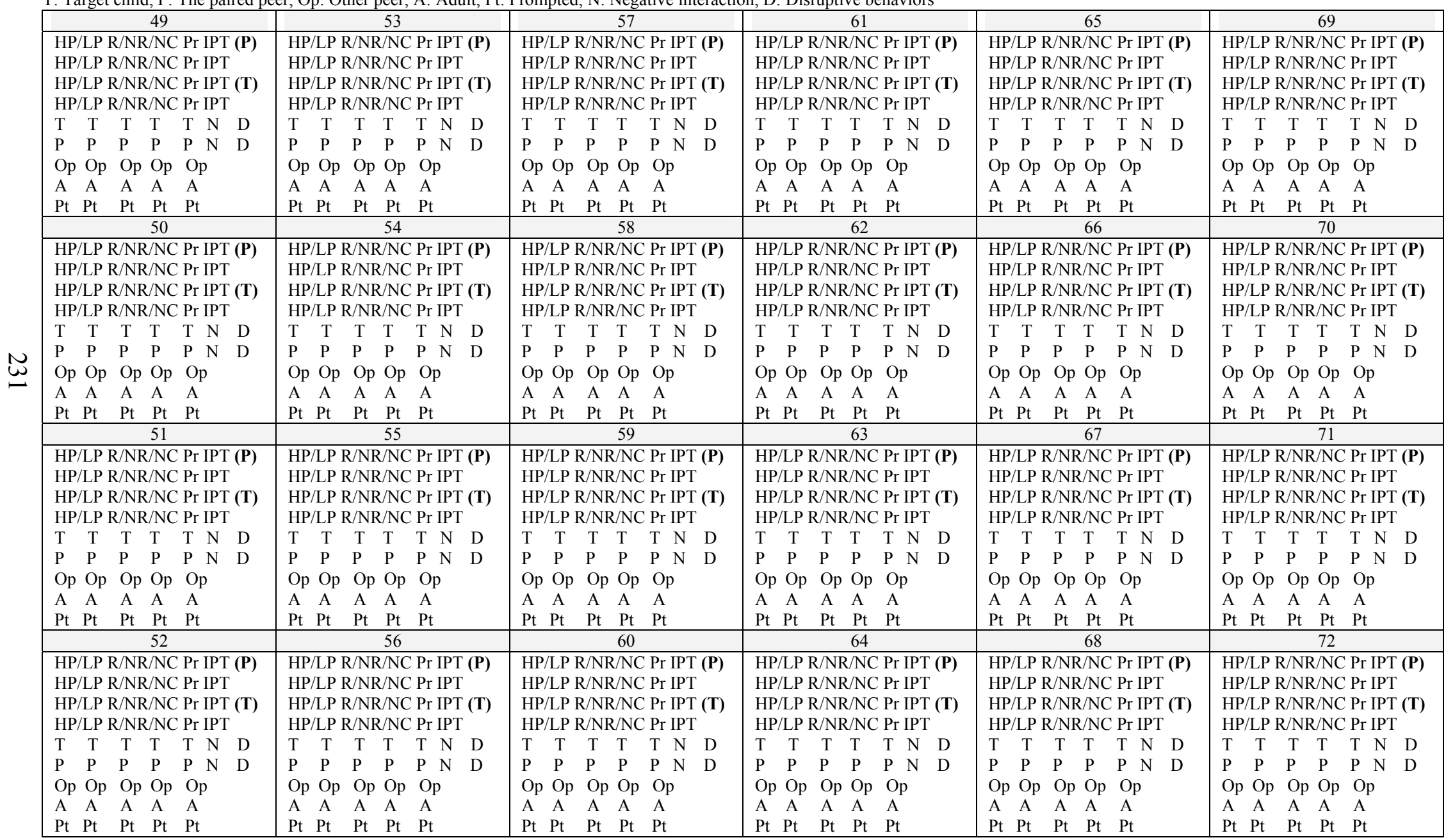


Data Collection Sheet

Date:

Child: Session \#: Observer:

IOA Observer:

Experimental Condition: Setting/Activity:

Code: HP=Delivery of high-probability requests, LP=Delivery of low-probability request, R: Response to request, NR: Nonrespons to request, NC: Noncompliance to request, Pr: Teacher praise, T: Target child, P: The paired peer, Op: Other peer, A: Adult, Pt: Prompted, N: Negative interaction, D: Disruptive behaviors

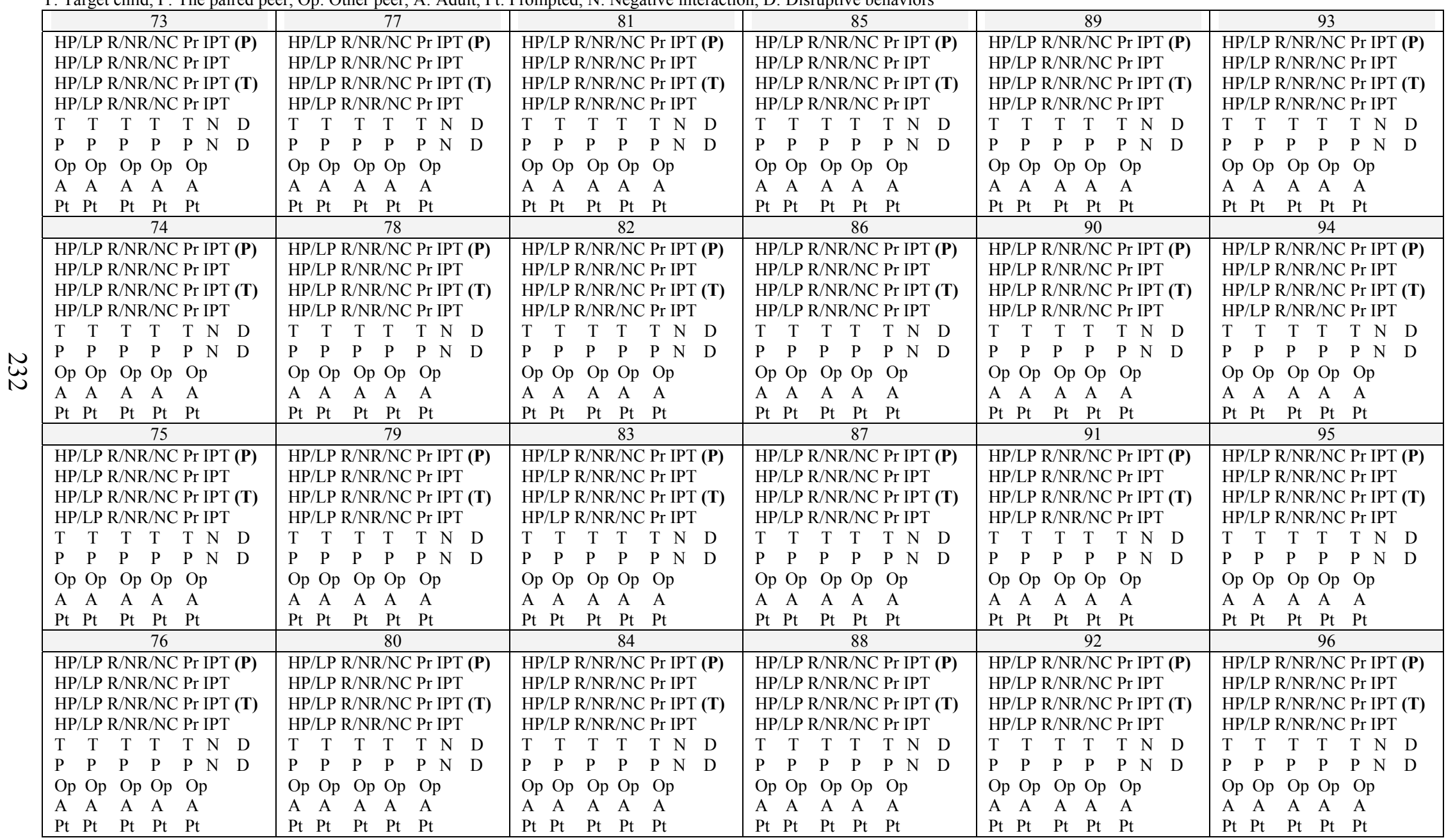


Data Collection Sheet

Date:

Child: Session \#: Observer:

IOA Observer:

Experimental Condition: Setting/Activity:

Code: HP=Delivery of high-probability requests, LP=Delivery of low-probability request, R: Response to request, NR: Nonrespons to request, NC: Noncompliance to request, Pr: Teacher praise, T: Target child, P: The paired peer, Op: Other peer, A: Adult, Pt: Prompted, N: Negative interaction, D: Disruptive behaviors

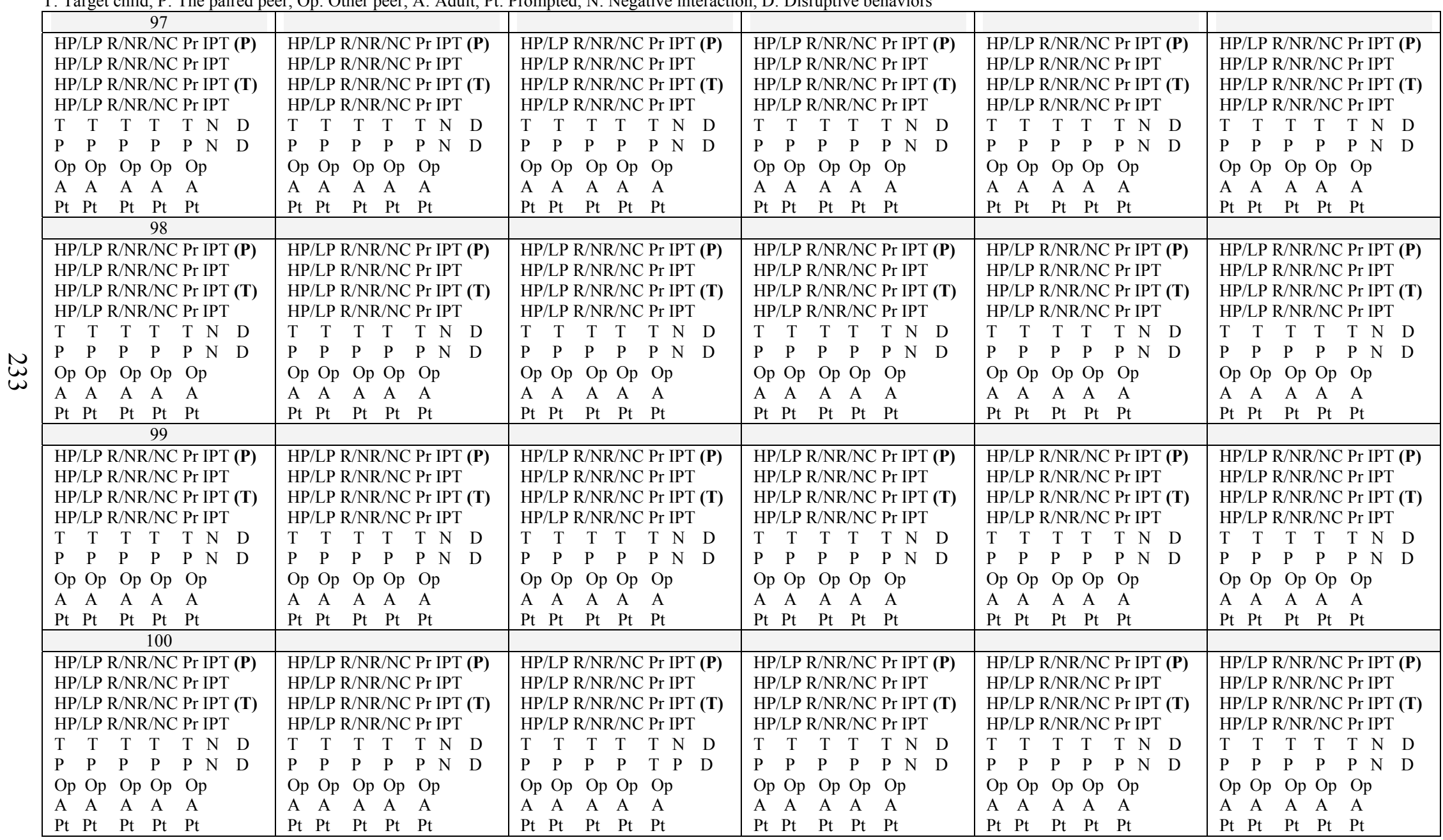


APPEPNDIX B

CODING MANUAL 


\section{Coding Manual}

This coding system is based on interactions between the children and responses to the high-probability request sequences. Partical time sampling procedure using a 6-s interval will be used to observe social interactions. Event recording will be used to observe responses to the high-probability request sequences.

Responses to the high-probability request sequence

Recording procedure: event recording is a tally or count of behaviors as they occur (Cooper, Heron, \& Heward, 1987). The high-probability requests procedure is performed as follows (Davis, 1995): (a) deliver a sequence of three high-probability requests with rapid pace, (b) deliver praise for performance of these high-p requests, (c) deliver the low-p requests, and (d) deliver praise for the performance of the low-probability request.

\section{Experimenter behavior}

- Delivery of the high-probability request (HP) is coded by circling HP when the experimenter delivers a high-probability request.

- Delivery of the low-probability request (LP) is coded by circling LP when the experimenter delivers a low-probability request.

- Delivery of praise is coded by circling P if the experimenter praises a highprobability or a low-probability response.

- Inter-prompt time (IPT) is time between the reinforcement of the previous request and delivery of the next request (i.e., within $5 \mathrm{~s}$ ).

\section{Child Behavior}

- Response to the high-probability or the low-probability (R) will be coded by circling $(\mathrm{R})$ next to HP/LP in a same line. The response to the high-probability or the low-probability requests defined as the initiation of the task within 5-s of a request by the experimenter.

- Nonresponse to request (NR) is circled if the child fails to emit any response.

- Noncompliance to request (NC) is circled if the child (a) responds inappropriately, (b) fails to initiate a requested response or (c) fails complete the requested response.

- Disruptive behavior is defined as any inappropriate verbal or gestural behaviors such as hitting, pinching, and screaming during play, or inappropriate responses by the child which are not necessary for performing a request.

\section{Social Interaction Code}

Recording procedure for 6-s partial interval recording Interval recording is used to measure the presence or absence of behavior within specific time intervals (Cooper, Heron, \& Heward, 1987). In partial interval recording the 
observer records simply whether the behavior was present or absent at any time during the interval. Partial interval recording is not concerned with how many times the behavior occurrs during the interval or how long the behavior is present.

Social interactions between:

T-The target child. The child with autism spectrum disorder

P-The peer. The typically developing child who is paired with the target child.

OP-The typically developing peer who has not participated and is not paired with the target child during intervention.

Social interactions are categorized as initiations and responses.

\section{Initiations}

An initiation was any verbal or gestural behavior that the target child directed to a peer or the peer directed to a target child that was not preceded by a social behavior from the same peer in the previous 3-seconds (e.g., grettings, sharing, assisting, touching, comments, calling the peer's name, giving directions and other positive directed behaviors)

The 3-second rule: Initiations are defined by their occurrence following a three second period without interactions. For example, if child B doesn't hear child A or chooses to ignore him/her then child A might say Child B's name 3 times in a row. This would be only recorded as one initiation. When Child A waits and initiates again 3-s after, it would be recorded as 2 initiations.

Initiations are coded by drawing a line from the person that initiated interaction to the person the interactions was directed to. If the child's initiation is spontaneous without any prompt, the initiation is coded without marking "Pt" (Prompt). If the child's initiation is prompted by the low-probability request, it is coded by circling "Pt."

Types and examples of initiations:

- Attention seeking: The child attempts to direct or call the attention of an other child (e.g., making an eye contact, verbal greeting or any appropriate physical gesture, tapping a child on the arm, saying "look at this," or showing off).

- Complimenting: The child makes statement indicating affection, attraction, liking or praise.

- Affection: patting, hugging or holding hands with another child.

- Assisting: The child teaches, shows how to play, or helps another child.

- Play organizing: The child verbally specifies an activity, role, or other play for peers to engage (e.g., "Let's play house.").

- Sharing or cooperating: The child verbally or nonverbally offers or exchanges an object with another child; both cooperate in the use of one object or toy or simultaneously use the same materials or in turn taking. 


\section{Response}

A response is any verbal or gestural behavior that is directed toward a peer initiation that occurred in the previous 3-seconds. These behaviors include looking or answering when his name is called, following directions.

The 3-second rule: Response must fall within three-seconds of the previous initiation. For example, if child A says, "Hi," and child B doesn't answer then all of a sudden about 5 seconds later child B says, "Hi". That is not recorded as a response. It would be recorded as an initiation.

Responses are coded by drawing a line from the person who responds to the person to whom the response is directed to. If the child's response is spontaneous without any prompt, the initiation is coded without marking "Pt: (Prompt). If the child's response is prompted, it is coded by circling "Pt."

Types and examples of responses:

- Responding to another child's utterance

- Repeating, expanding unpon a previous untterance, and requesting clarification

- Descriptive talking such as giving a play idea, complimenting, offering to share

- Sharing, turn taking, or exchanging toys

- Pointing, motioning, or nodding toward their buddy or materials they are working with

- An acknowledgement of the other child's utterance

$\underline{\text { Negative interactions }}$

Negative interactions include undesirable interactions such as hitting, kicking, pushing, destroying others' construction, or vocalization such as crying, shouting, or calling another child namea.

Negative interaction will be coded by marking in $\mathrm{N}$.

\section{Adult's behavior}

General Verbal and Physical Prompts (Pt).

The following statements describe adult prompts defined and coded as " $\mathrm{Pt}$ ".

- Verbal statements or physical guidance, instruction, or feedback to cue the child to stay in his/her center.

- Verbal statements or physical guidance, instruction, or feedback to cue the child to redirect child behavior.

- Verbal statements or physical guidance, instruction, or feedback to cue the child to prompt engagement with materials.

- Prompts will be recorded as they occur.

- See "the high-probability request sequences" for other adult's behavior. 
Coding rules for the high-probability request sequences and social interactions

The experimenter delivered the high-probability request, the target child responded to the request within 5-s, the experimenter delivered praise to the target child, and delivered the next request in 3-s. This is recorded based on each trial regardless of interval (i.e. event recording):

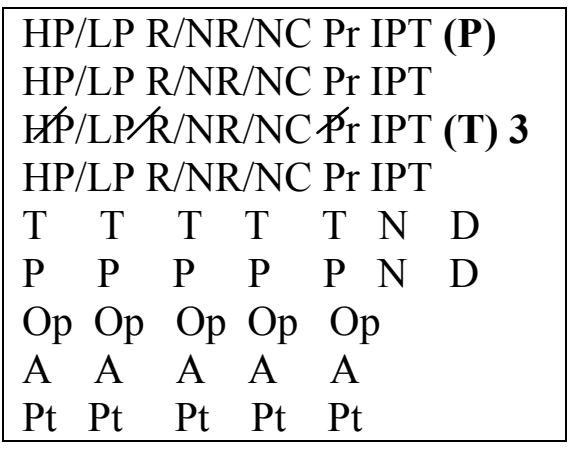

One initiation from the target to the paired peer is considered one initiation. An example might be the target child saying the paired peer's name "Hi Cindi." If the initiation is prompted by the experimenter (i.e. response to the high-probability or low-probability request), it is connected with LP. If the initiation is not prompted and spontaneous, it is coded by drawing a line from $\mathrm{T}$ to $\mathrm{P}$ :

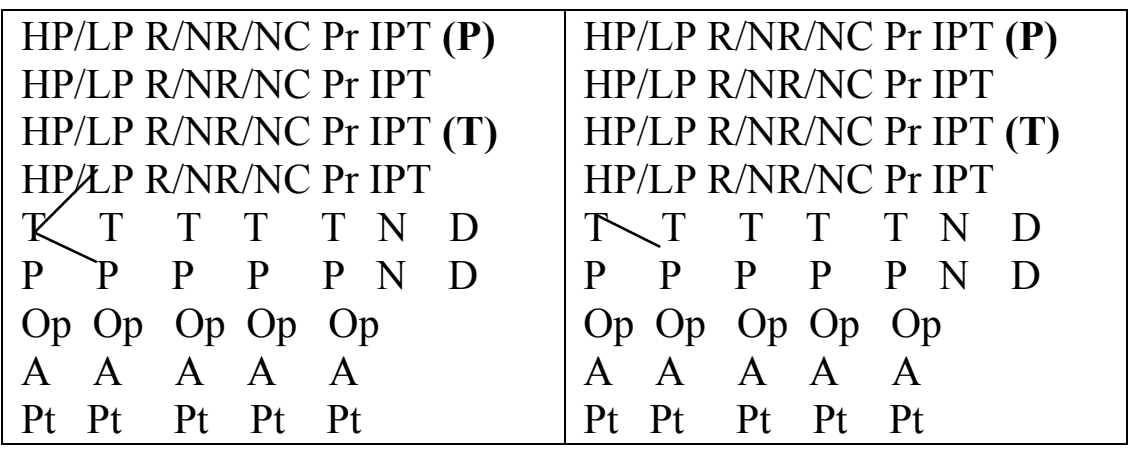

Two spontaneous initiations, one from the target to the paired peer, and another from the target to the other peer without a response:

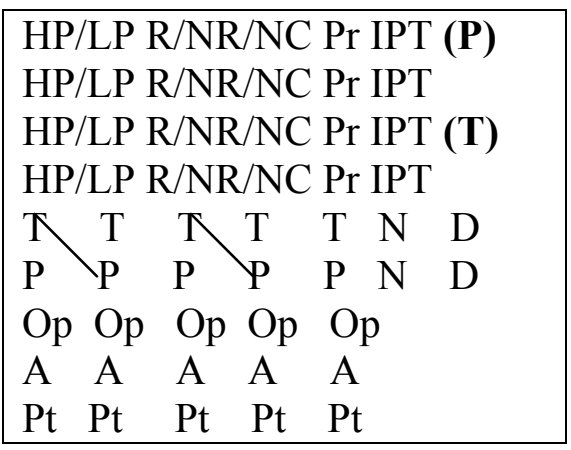


One initation and one response from the target to the peer and then the peer responded back:

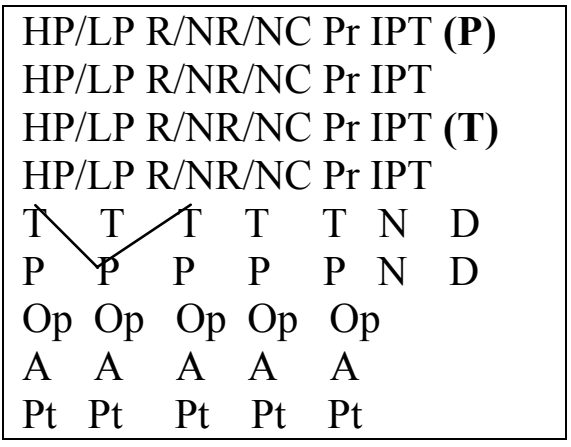

Two initiations, one initiation from the target to the peer after the 3 -second rule the peer says something to the target:

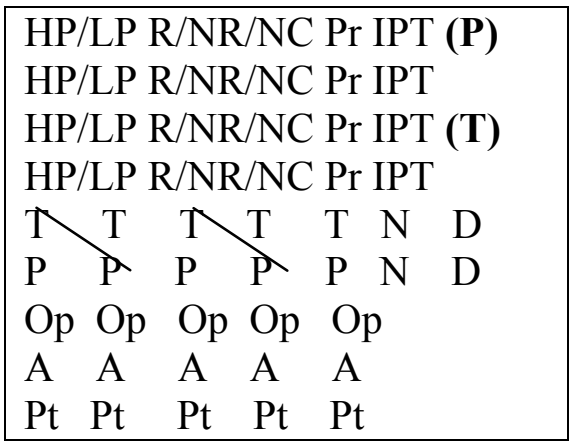

The target and the peer talking back and forth. Two initiation and responses:

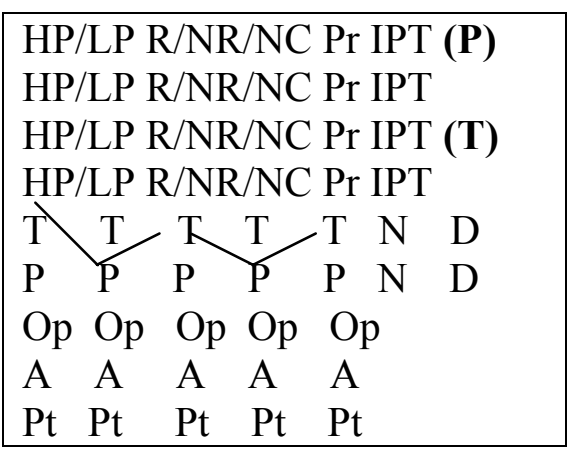


If the target child uses the bathroom or is called out of the room by the teacher, an $\mathrm{X}$ is placed over the entire interval to show that the target child can not be observed.

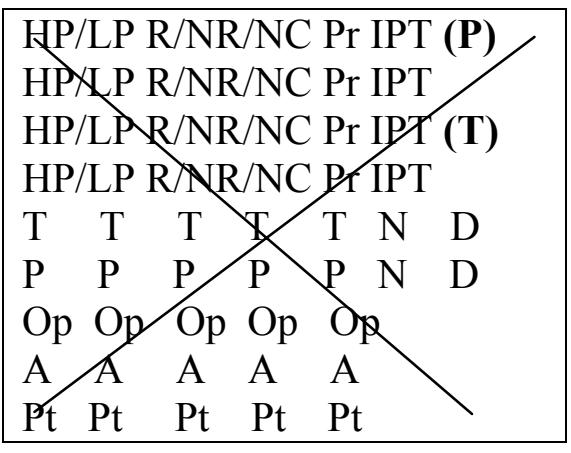


APPENDIX C

PROCEDURAL INTEGRITY CHECKLIST 
Procedural Integrity: Baseline

Date:

Child:

Session \#:

Observer:

IOA Observer:

Setting/Activity:

\begin{tabular}{|c|c|c|}
\hline & Procedure & Observation \\
\hline 1 & All necessary materials are available. & \\
\hline 2 & $\begin{array}{l}\text { Experimenter invites the target child and the peer to } \\
\text { the assigned center. }\end{array}$ & \\
\hline 3 & $\begin{array}{l}\text { Experimenter provides the general instruction to play (e.g., stay in } \\
\text { your center, and play with your friend). }\end{array}$ & \\
\hline 4 & Experimenter gives the children stickers before the session. & \\
\hline 5 & $\begin{array}{l}\text { Experimenter gives prompts to play only when the child leaves his } \\
\text { center, engaged in self-stimulatory behavior, or in disruptive } \\
\text { behavior (e.g., go play, stay in your center, get busy, don't hit your } \\
\text { friend) }\end{array}$ & \\
\hline
\end{tabular}

\section{$+\quad$ Observed \\ - Not observed \\ NA Not applicable}




\section{Procedural Integrity: Peer Training}

Date:

Child:

Session \#:

Observer:

IOA Observer:

Setting/Activity:

\begin{tabular}{|c|c|c|}
\hline & Procedure & Observation \\
\hline 1 & $\begin{array}{l}\text { Experimenter invites the peer and gives her the instruction (e.g., } \\
\text { we will learn how to play with your friend). }\end{array}$ & \\
\hline 2 & All materials are available. & \\
\hline 3 & $\begin{array}{l}\text { Experimenter delivers the low-probability requests to the second } \\
\text { observer. }\end{array}$ & \\
\hline 4 & $\begin{array}{l}\text { The second observer responds to the low-probability requests like } \\
\text { the target child. }\end{array}$ & \\
\hline 5 & $\begin{array}{l}\text { Experimenter provides prompts to wait until the target child } \\
\text { initiates. }\end{array}$ & \\
\hline 6 & $\begin{array}{l}\text { Experimenter asks the peer how to respond when the target child } \\
\text { initiates to her (e.g., what would you do when your friend gives } \\
\text { you the train?). }\end{array}$ & \\
\hline 7 & Experimenter repeats the same steps for each target behavior. & \\
\hline 8 & Experimenter gives the peer sticker after session. & \\
\hline 9 & $\begin{array}{l}\text { Experimenter repeats the same procedure until the peer reaches to } \\
90 \% \text { of correct responses. }\end{array}$ & \\
\hline
\end{tabular}

\section{$+\quad$ Observed \\ - Not observed \\ NA Not applicable}




\section{Procedural Integrity: Low-probability requests alone}

Date:

Child:

Session \#:

Observer:

IOA Observer:

Setting/Activity:

\begin{tabular}{|c|c|c|}
\hline & Procedure & Observation \\
\hline 1 & All necessary materials are available. & \\
\hline 2 & $\begin{array}{l}\text { Experimenter invites the target child and the peer to } \\
\text { the assigned center. }\end{array}$ & \\
\hline 3 & $\begin{array}{l}\text { Experimenter provides the general instruction to play (e.g., stay in } \\
\text { your center, and play with your friend). }\end{array}$ & \\
\hline 4 & $\begin{array}{l}\text { Experimenter delivers low-probability requests without high- } \\
\text { probability requests. }\end{array}$ & \\
\hline 5 & $\begin{array}{l}\text { Experimenter delivers praise statement after each appropriate } \\
\text { response to low-probability request. }\end{array}$ & \\
\hline 6 & $\begin{array}{l}\text { Experimenter uses child's name prior to request while establishing } \\
\text { eye contact prior to the request at eye level of child. }\end{array}$ & \\
\hline 7 & $\begin{array}{l}\text { Experimenter gives prompts to play only when the child leaves his } \\
\text { center, engaged in self-stimulatory behavior, or in disruptive } \\
\text { behavior (e.g., go play, stay in your center, get busy, don't hit your } \\
\text { friend) }\end{array}$ & \\
\hline 7 & $\begin{array}{l}\text { Experimenter gives the children stickers after 10-minute session } \\
\text { with verbal praise. }\end{array}$ & \\
\hline
\end{tabular}

\section{$+\quad$ Observed \\ - Not observed \\ NA Not applicable}




\section{Procedural Integrity: High-probability requests embedded in peer modeling}

Date:

Child: Session \#:

Observer:

IOA Observer:

Setting/Activity:

\begin{tabular}{|c|c|c|}
\hline & Procedure & Observation \\
\hline 1 & All necessary materials are available. & \\
\hline 2 & $\begin{array}{l}\text { Experimenter invites the target child and the peer to } \\
\text { the assigned center. }\end{array}$ & \\
\hline 3 & $\begin{array}{l}\text { Experimenter provides the general instruction to play (e.g., stay in } \\
\text { your center, and play with your friend). }\end{array}$ & \\
\hline 4 & $\begin{array}{l}\text { Experimenter delivers at least } 3 \text { high-probability requests prior to } \\
\text { low-probability request. }\end{array}$ & \\
\hline 5 & $\begin{array}{l}\text { Experimenter delivers praise statement delivers after each } \\
\text { appropriate response to high-probability request. }\end{array}$ & \\
\hline 6 & $\begin{array}{l}\text { Experimenter delivers praise statement after each appropriate } \\
\text { response to low-probability request. }\end{array}$ & \\
\hline 7 & $\begin{array}{l}\text { Experimenter uses child's name prior to request while establishing } \\
\text { eye contact prior to the request at eye level of child. }\end{array}$ & \\
\hline 8 & $\begin{array}{l}\text { Experimenter gives prompts to play only when the child leaves his } \\
\text { center, engaged in self-stimulatory behavior, or in disruptive } \\
\text { behavior (e.g., go play, stay in your center, get busy, don't hit your } \\
\text { friend) }\end{array}$ & \\
\hline 9 & $\begin{array}{l}\text { Experimenter gives the children stickers to exchange each other } \\
\text { after 10-minute session with verbal praise. }\end{array}$ & \\
\hline
\end{tabular}

\section{$+\quad$ Observed \\ - Not observed \\ NA Not applicable}




\section{Procedural Integrity: Generality}

Date:

Child:

Session \#:

Observer:

IOA Observer:

Setting/Activity:

\begin{tabular}{|l|l|l|}
\hline & \multicolumn{1}{|c|}{ Procedure } & Observation \\
\hline 1 & All necessary materials are available. & \\
\hline 2 & $\begin{array}{l}\text { Experimenter invites the target child and the peer to } \\
\text { the assigned center. }\end{array}$ & $\begin{array}{l}\text { Experimenter provides the general instruction to play (e.g., stay in } \\
\text { your center, and play with your friend). }\end{array}$ \\
\hline 4 & $\begin{array}{l}\text { Experimenter gives prompts to play only when the child leaves his } \\
\text { center, engaged in self-stimulatory behavior, or in disruptive } \\
\text { behavior (e.g., go play, stay in your center, get busy, don't hit your } \\
\text { friend). }\end{array}$ & \\
\hline
\end{tabular}

$+\quad$ Observed

- Not observed

NA Not applicable 
APPENDIX D

PARENT AND TEACHER QUESTIONNAIRE 
Child's name:

Dear Parent/ Teacher:

I want to thank you for the opportunity to work with your child. As I explained, this study focuses on teaching the social interaction skills between children. The idea of this study is to teach children to respond to the requests of social initiations (less likely to be performed) with and after their favorite and highly possible requests. In addition, I would like to use the child's favorite toys and play items, activities for intervention. The intervention would include your child's favorite requests delivered immediately prior to a request that the child does not perform well (i.e., social initiation in this study). Thus, I would like to ask you your child's favorite toys, play items, stickers, activities, and the requests that are less likely to be performed and more likely to be performed.

\section{Child's favorite activities, toys, plays materials, and stickers}

Activities, toys, play materials (including the specific manufacture's name)

\section{Stickers}

\section{Directions for completing the survey}

1. Please put circle (Yes) for the requests that your child does $80 \%$ of the time.

2. Please put circle (Not Usually) for the requests that your child does less than $50 \%$ of the time.

\section{Example}

Says " Hi " (Yes) or (Not usually)

Tickle your friend (Yes) or (Not usually)

Give me five (Yes) or (Not usually)

Hug your friend (Yes) or (Not usually)

Hold your friend's hands (Yes) or (Not usually)

Shake hands (Yes) or (Not usually)

Point to (the toy) (Yes) or (Not usually)

Clap your hands (Yes) or (Not usually)

Wave Hi (Yes) or (Not usually)

Say "show me your toy" (Yes) or (Not usually) 
Look at me (Yes) or (Not usually)

Say "look at me" (Yes) or (Not usually)

Say your friend's name (Yes) or (Not usually)

Push (the truck) to your friend (Yes) or (Not usually)

Throw the ball to your friend (Yes) or (Not usually)

Ask your friend to play (Yes) or (Not usually)

Look at the (toys) (Yes) or (Not usually)

Jump (Yes) or (Not usually)

Raise your hand (Yes) or (Not usually)

Tell your friend "good job" (Yes) or (Not usually)

Tell your friend "let's play together" (Yes) or (Not usually)

Touch (your nose or other body part) (Yes) or (Not usually)

Stamp your feet (Yes) or (Not usually)

Tell your friend "thank you" (Yes) or (Not usually)

Tap your friend (Yes) or (Not usually)

Look at your friend (Yes) or (Not usually)

Tell your friend "look at this" (Yes) or (Not usually)

Tell your friend "I am making a ( )" ( Yes ) or ( Not usually )

Roll (the ball) to your friend (Yes) or (Not usually)

Pick up ( ) (Yes) or (Not usually)

Sit down (Yes) or (Not usually)

Give (the toy) to your friend (Yes) or (Not usually)

Share (the toy) with your friend (Yes) or (Not usually)

Stack the block (Yes) or (Not usually)

Please write down if there are any other requests that your child consistently performs and is likely to respond.

Please write down if there are any other requests related to social initiations that you would like to teach.

Thank you for your time.

Sunhwa Jung 


\section{Dear Parent/Teacher:}

I would like to ask if you think that the research goals of my study will help lead to satisfactory outcomes in your child's education. The purpose of this study is to further investigate a strategy to increase social interactions of children with autism in an inclusive setting. This study will employ high-probability request intervention embedded in peer modeling to increase the social interactions of children with autism.

The high-probability request interventions include your child's favorite requests (i.e., the high-probability requests) delivered immediately prior to a request that the child does not perform well (i.e., the low-probability requests which are requests for social behaviors in this study). High-probability and low-probability requests will consist of the play skills relevant to the play settings and low-probability requests will include a social initiation to a peer, which will consist of social behaviors that are likely to be responded. Please put circle "Yes, No, or Unsure" for each question whether you think it is valid/useful for you child's education.

1. Do you think this research question is valid/ useful for your child's education?
Yes
No
Unsure

What are the effects of the use of high-probability request sequence on social interactions of young children with autism and typically developing children in an inclusive setting? The high-probability request sequence includes delivery of three to five high-probability requests (e.g., pick a block, stack the block, pick a block), delivery of praise for each performance of the high-probability request, delivery of the low-probability request (e.g., give the block to your friend), and delivery of praise for the performance of the lowprobability request.

2. Do you think this research question is valid/ useful for your child's education?
Yes
No
Unsure

To what extent does the child generalize social interactions to a nontraining condition? Your child's behavior will be observed whether their learned social behaviors are generalized across the settings without delivery of the high-probability request interventions.

3. Do you think this research question is valid/useful for your child's education?

Yes No Unsure

To what extent does the child maintain social interactions in the inclusive setting following the removal of the high-provability request intervention? Once the child demonstrates high stable responding to the high probability request intervention, the low- 
probability requests (i.e., requests for social initiations) will be delivered to assess if the learned social behaviors are maintained by only prompting the target behaviors without the high-probability request interventions.

4. Do you think this research question is valid/useful for your child's education?

Yes $\quad$ No Unsure

To what extent does the child maintain the social interactions in the inclusive setting following the removal of the prompts? The children will be asked to play and interact with toys and peers without the implementation of any low-probability or highprobability requests on the part of the experimenter. This will demonstrate if high probability sequence intervention increases the spontaneous interactions or unprompted initiation to peers.

5. Do you think this research question is valid/useful for your child's education?
Yes
No
Unsure

To what extent do the parents find the intervention goals, procedures, and outcomes to be relevant, valuable, and effective with their children during center time in an inclusive setting?

6. Do you think this research question is valid/useful for your child's education?
Yes
No
Unsure

To what extent do early childhood special education teachers find the intervention goals, procedures, and outcomes to be relevant, useful, and effective with children with autism in inclusive settings?

Thank you for your time.

Sunhwa Jung 
APPENDIX E

SOCIAL VALIDITY FORM 


\section{Instructions}

You will watch a videotape which includes three 2-minute video clips for each group. These video clips are representative of each phase. The phase consists of 3 phases: baseline, low-probability request alone, and high-probability request intervention. And these conditions are randomly assigned. After watching each video clip, please assess the target child's behaviors based on the checklist. Finally please answer the follow-up questions. Thank you for your time.

Instructions:

1. Read the sheet entitled "intervention procedures"

2. Read the checklist

3. Watch the first video clip for the first group, and complete the first checklist. Then watch the second video clip and complete the second checklist. Continue this for the third video clip.

- Observed: When you observe the target child' behaviors most of the time

- Not observed: When you don't observe the behaviors most of the time

- Include both of the prompted and unprompted behaviors

4. Follow the same steps for the second and third group.

5. Answer the follow-up questions. 


\section{Intervention Procedures}

The high-probability request intervention includes a sequence of easy and favorite requests (i.e., high-probability requests) delivered immediately prior to a request that is not typically performed (i.e., low-probability request) (Davis \& Brady, 1993; Davis, 1995).

The high-probability requests are requests that a child consistently performs (Davis, 1995; Santos, 2001). The low-probability requests are requests that the child does not typically perform, thus, the probability of the child performing them is low (Davis, 1995; Santos, 2001).

\section{Low-probability requests alone}

The experimenter delivered the low-probability requests to each target participant for 10 minutes in the play settings during center time using the toys that each target participant prefers. The experimenter gives verbal requests to initiate interaction with a peer. For example, the experimenter asks the target child "Andrew, give Katie the pizza". If the target child performs the request within 5 seconds, the experimenter provides verbal praise.

\section{High-Probability Request Sequences usin Embedded Peer Modeling}

High-probability and low-probability requests consisted of the play skills relevant to the play settings (e.g., "connect trains together" "cut the pizza", etc), and the low-probability requests consisted of social initiations to a peer.

The high-probability request sequences are first delivered to the peer and then the target child. The high-probability request sequences are as follows:

(a) three high probability requests are delivered rapidly (i.e., within $2 \mathrm{~s}$ to $5 \mathrm{~s}$ );

(b) verbal or gestural praise for each request performed, and

(c) the low probability request is delivered within 5 seconds after reinforcement for performing the last high probability request. 


\section{Child 1}

\section{Video Clip 1}

\begin{tabular}{|l|l|l|}
\hline Behaviors & Not Observed & Observed \\
\hline 1. Complies with requests & & \\
\hline 2. Focuses on a task/play & & \\
\hline 3. Shares materials/toys with peers & & \\
\hline 4. Responds when spoken to & & \\
\hline
\end{tabular}

\section{Video Clip 2}

\begin{tabular}{|l|l|l|}
\hline Behaviors & Not Observed & Observed \\
\hline 1. Complies with requests & & \\
\hline 2. Focuses on a task/play & & \\
\hline 3. Shares materials/toys with peers & & \\
\hline 4. Responds when spoken to & & \\
\hline
\end{tabular}

\section{Video Clip 3}

\begin{tabular}{|l|l|l|}
\hline Behaviors & Not Observed & Observed \\
\hline 1. Complies with requests & & \\
\hline 2. Focuses on a task/play & & \\
\hline 3. Shares materials/toys with peers & & \\
\hline 4. Responds when spoken to & & \\
\hline
\end{tabular}




\section{Child 2}

\section{Video Clip 1}

\begin{tabular}{|l|l|l|}
\hline Behaviors & Not Observed & Observed \\
\hline 1. Complies with requests & & \\
\hline 2. Focuses on a task/play & & \\
\hline 3. Shares materials/toys with peers & & \\
\hline 4. Responds when spoken to & & \\
\hline
\end{tabular}

\section{Video Clip 2}

\begin{tabular}{|l|l|l|}
\hline Behaviors & Not Observed & Observed \\
\hline 1. Complies with requests & & \\
\hline 2. Focuses on a task/play & & \\
\hline 3. Shares materials/toys with peers & & \\
\hline 4. Responds when spoken to & & \\
\hline
\end{tabular}

\section{Video Clip 3}

\begin{tabular}{|l|l|l|}
\hline Behaviors & Not Observed & Observed \\
\hline 1. Complies with requests & & \\
\hline 2. Focuses on a task/play & & \\
\hline 3. Shares materials/toys with peers & & \\
\hline 4. Responds when spoken to & & \\
\hline
\end{tabular}




\section{Child 3}

Video Clip 1

\begin{tabular}{|l|l|l|}
\hline Behaviors & Not Observed & Observed \\
\hline 1. Complies with requests & & \\
\hline 2. Focuses on a task/play & & \\
\hline 3. Shares materials/toys with peers & & \\
\hline 4. Responds when spoken to & & \\
\hline
\end{tabular}

\section{Video Clip 2}

\begin{tabular}{|l|l|l|}
\hline Behaviors & Not Observed & Observed \\
\hline 1. Complies with requests & & \\
\hline 2. Focuses on a task/play & & \\
\hline 3. Shares materials/toys with peers & & \\
\hline 4. Responds when spoken to & & \\
\hline
\end{tabular}

\section{Video Clip 3}

\begin{tabular}{|l|l|l|}
\hline Behaviors & Not Observed & Observed \\
\hline 1. Complies with requests & & \\
\hline 2. Focuses on a task/play & & \\
\hline 3. Shares materials/toys with peers & & \\
\hline 4. Responds when spoken to & & \\
\hline
\end{tabular}




\section{Follow-up Questions}

1. Would it be easy to use the high-probability request intervention during the student's regular routine?
Yes
No
Please explain

2. Balancing the time and effort it would take to implement the procedures described in the high-probability request intervention you observed in the child's play with peer would you use the intervention in your classroom?
Yes
No
Please explain

3. Do you think the high-probability request intervention is useful to improve social interactions between children?
Yes
No
Please explain 
APPENDIX F

HIGH-PROBABILITY REQUEST ASSESSMENT FORM 
High-Probability and Low-Probability Assessment Form

Child:

Setting:

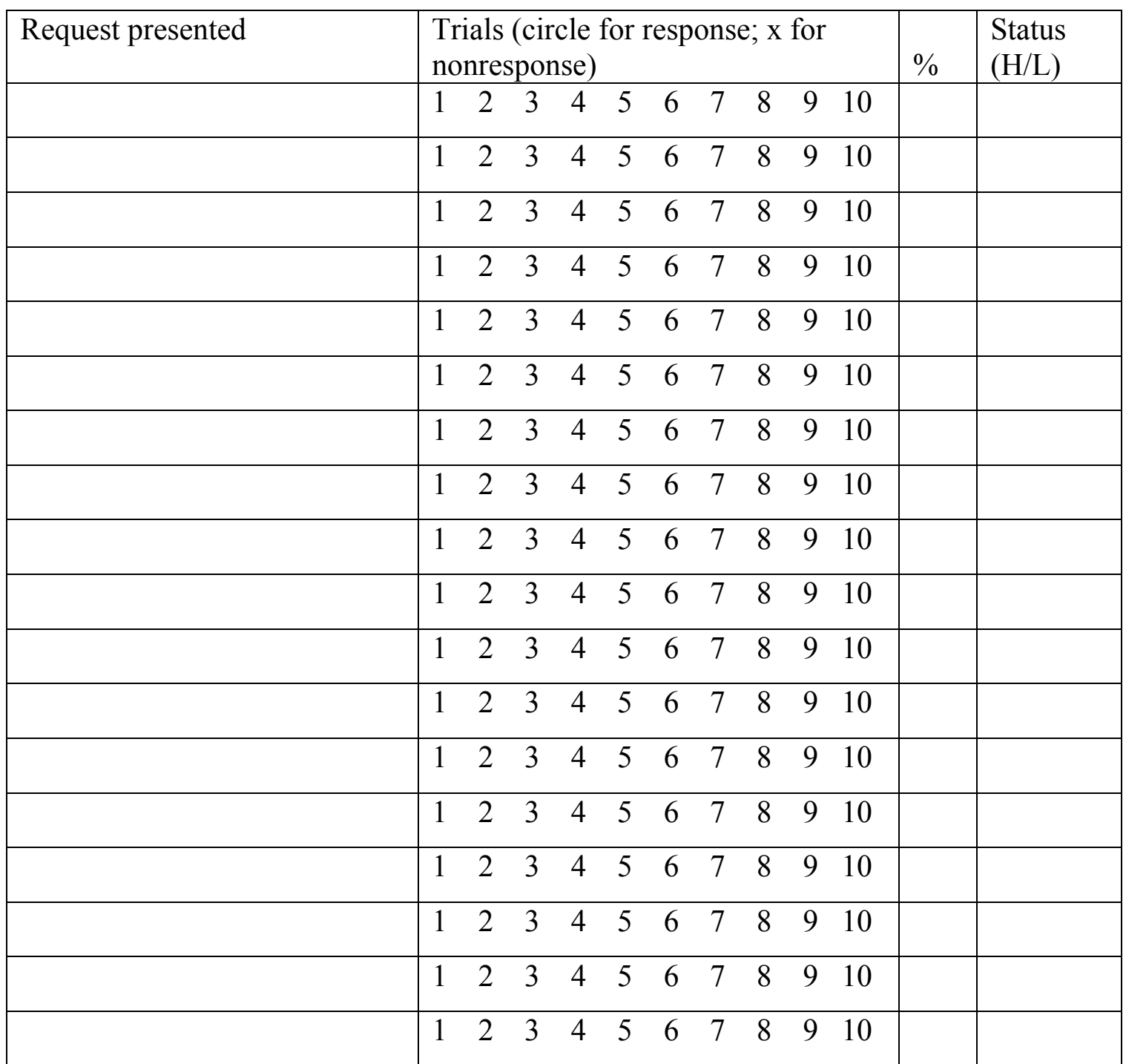


APPENDIX G

CONSENT FORM 


\section{Dear Parents,}

My name is Sunhwa Jung and I am a doctoral candidate in Early Childhood Special Education at the Ohio State University. I am planning to conduct my dissertation, which I will be conducting in your child's classroom. I will be conducting this research under the supervision of my advisor Dr. Sainato, an associate professor at the School of Physical Activity and Educational Services at The Ohio State University. I am writing to you explain my research and ask your permission to include your child in my study. The title of my study is Effects of HighProbability Request Sequences to Increase Social Interactions in Young Children with Autism.

The goal of my study would be to help children learn the social interaction skills, and have positive relationships with their peers in the classroom after the implementation of the highprobability request intervention. This study will involve your child during center time for about $10-15$ minutes per day. The idea is to teach children to respond to the requests of social initiations with and after their favorite and highly possible requests. The high-probability request interventions include your child's favorite requests delivered immediately prior to a request that the child does not perform well, but should be learned (social interaction in this study). This intervention is looking at the child's responses to the requests, and social interactions between children with autism and typical peers.

I would like to request that your child be included in this research study. I am further requesting permission to videotape and audiotape your child during the sessions and permission to access your child's records. The videotapes and audiotapes will be used by the researchers to record data. In order to prepare for this study, your child's educational records, including social skills assessments and individual plans will be reviewed to identify target specific goals for each child. If I have your permission, please sign the enclosed form and return it to me by December 20. All information as well as data collected will be kept confidential. Your child's name will not appear in any publication record or documentation of the study. Data obtained will not be made part of any permanent record that can be identified with your child. I will be happy to share any results with you if you are interested.

You are not obligated to grant permission for your child to participate in this research. If your child participates, you have the right to withdraw him/her from the research at any time to discontinue participation in the study without prejudice to your child.

If you have any questions pertaining to this research or your rights related to participation in this research, please feel free to contact myself at 263-3703 or Dr. Sainato at 292-8709. Thank you for the opportunity to work with your child.

Sincerely,

Sunhwa Jung

Doctoral Candidate

Dr. Diane Sainato

The Ohio State University 
Dear Parents,

My name is Sunhwa Jung and I am a doctoral candidate in Early Childhood Special Education at the Ohio State University. I am planning to conduct my dissertation, which I will be conducting in your child's classroom. I will be conducting this research under the supervision of my advisor Dr. Sainato, an associate professor at the School of Physical Activity and Educational Services at The Ohio State University. I am writing to you explain my research and ask your permission to include your child in my study. The title of my study is Effects of High-Probability Request Sequences to Increase Social Interactions in Young Children with Autism.

This study will be conducted in your child's classroom during free play and center time per day. The participants' plays during the sessions will be videotaped and audiotaped in order to record data. Although we are not requesting permission for your child to participate in the study, we are requesting permission to video and audio tape the entire class during play time to determine the impact of the study during playtime in the classroom. All videotapes will be kept confidential.

If I have your permission, please sign the enclosed form and return it to me by December 20, 2002.

If you have any questions pertaining to this research, please feel free to contact myself at 263-3703 or Dr. Sainato at 292-8709. Thank you for the opportunity to work with your child.

Sincerely,

Sunhwa Jung

Doctoral Candidate

Dr. Diane Sainato

The Ohio State University 


\section{CONSENT FOR PARTICIPATION IN \\ SOCIAL AND BEHAVIORAL RESEARCH}

I consent to my child's participation in the research in research entitled: Effects of HighProbability Request Sequences to Increase Social Interactions in Young Children with Autism.

Dr. Diane Sainato or her authorized representative, Sunhwa Jung, has explained the purpose of the study, the procedures to be followed and the expected duration of my child's participation. I understand the possible benefits of my child's participation.

I acknowledge that I have had the opportunity to obtain additional information regarding the study and that my questions I have raised have been answered to my full satisfaction. Further, I understand that I am free to withdraw consent at any time without prejudice to my child or me.

Finally, I acknowledge that I have read and fully understand the consent form. I sign it freely and voluntarily. A copy has been given to me.

I have read the information above and give permission for my child to participate in the research study.

Signature of Parent/ Guardian

$\overline{\text { Signature of Principal Investigator }}$

Signature of Student Investigator

\section{Date}

Date

Date 


\section{PARENT PERMISSION FOR VIDEOTAPING AND AUDIOTAPING}

I give Sunhwa Jung permission to videotape and audiotape my child during free play and center time at the Children's Center for Developmental Enrichment. I understand that the videotapes and audiotapes will be used in and for the research purpose only. They will be kept confidential, and be kept in a locked file in the principle investigator's office until the results of the study have been published and the 5 years past the publications of the paper, and then the tapes will be erased.

Parent/Guardian

Witness

Principal Investigator

Student Investigator
Date

Date

Date

Date 


\section{RELEASE OF INFORMATION CONSENT FORM}

I hereby authorize to release the following information to Dr. Sainato and Sunhwa Jung, School of Activity and Educational Services, College of Education at The Ohio State University, for the purpose of providing descriptive information for educational research.

Educational evaluations

IEP Goals

(Individualized Education Program)

This consent form has been explained to me and I understand the contents to be released and the need for information and that there are statues and regulations protecting the confidentiality of authorized information. I hereby acknowledge that this consent is truly voluntary. I further understand that I may revoke my consent at any time by giving written notice to Dr. Diane Sainato or Sunhwa Jung.

Child's Name

Parent/Guardian Signature

Date

Principal Investigator

Date

Investigator

Date 
APPENDIX H

HIGH-PROBABILITY AND LOW-PROBABILITY REQEUSTS 
Eric's Low-Probability and High- Probability Requests

\begin{tabular}{|c|c|c|}
\hline Setting & $\begin{array}{l}\text { Low-Probability requests (percent } \\
\text { correct responses to reqeuts during } \\
\text { asessment) }\end{array}$ & $\begin{array}{l}\text { High-Probability Requests } \\
\text { (percent correct responses to } \\
\text { reqeuts during asessment) }\end{array}$ \\
\hline $\begin{array}{l}\text { Friendship } \\
\text { activities }\end{array}$ & $\begin{array}{l}\text { Say to (peer) "how are you?" }(50 \%) \\
\text { Say to (peer) "I like to play with } \\
\text { you" }(40 \%) \\
\text { Say to ( peer ) "Look at me" } \\
\text { Hug your friend }(60 \%)\end{array}$ & $\begin{array}{l}\text { Touch your nose }(100 \%) \\
\text { Clap your hands }(90 \%) \\
\text { Hands on your shoulders }(80 \%) \\
\text { Hands on your knees }(90 \%) \\
\text { Hands up high }(80 \%) \\
\text { Move your eyebrows }(90 \%) \\
\text { Move your shoulders }(80 \%) \\
\text { Look at me }(100 \%)\end{array}$ \\
\hline $\begin{array}{l}\text { Blocks } \\
\text { and } \\
\text { Trucks }\end{array}$ & $\begin{array}{l}\text { Give (peer) the plane }(50 \%) \\
\text { Say to (peer) "I am coming" }(50 \%) \\
\text { Give (peer) the block }(50 \%) \\
\text { Say to (peer) "fly the plane to me" } \\
(60 \%)\end{array}$ & $\begin{array}{l}\text { Take off the roof }(80 \%) \\
\text { Fold down the stairs }(80 \%) \\
\text { Build an airport }(80 \%) \\
\text { Touch the wing }(80 \%) \\
\text { Put the block next to the airplane } \\
(90 \%) \\
\text { Take off the run away }(90 \%) \\
\text { Pick up the airplane }(90 \%) \\
\text { Fly the airplane }(90 \%)\end{array}$ \\
\hline Train & $\begin{array}{l}\text { Give (peer) the train }(40 \%) \\
\text { Push the train to (peer) }(40 \%) \\
\text { Say to (peer) "push the button, } \\
\text { please" ( } 50 \%) \\
\text { Connect trains with your friend } \\
(40 \%)\end{array}$ & $\begin{array}{l}\text { Put the barrel in loader }(90 \%) \\
\text { Push the button }(90 \%) \\
\text { Put the tree on the grass }(90 \%) \\
\text { Connect trains together }(90 \%) \\
\text { Push the train around the track } \\
(80 \%) \\
\text { Put the house on the ground }(80 \%) \\
\text { Pick up the train }(80 \%)\end{array}$ \\
\hline Kitchen & $\begin{array}{l}\text { Give (peer) the pizza }(50 \%) \\
\text { Give (peer) the cheese }(40 \%) \\
\text { Say to (peer) " more pizza, please" } \\
(50 \%) \\
\text { Say to (peer) "I am making a } \\
\text { sandwich for you" }(50 \%)\end{array}$ & $\begin{array}{l}\text { Cut the pizza }(100 \%) \\
\text { Put the pizza on the plate }(90 \%) \\
\text { Put the cup on the table }(80 \%) \\
\text { Put the fork on the table }(80 \%) \\
\text { Put the cheese on your pizza } \\
(80 \%) \\
\text { Put the cheese on your pizza } \\
(80 \%) \\
\text { Make a sandwich }(80 \%) \\
\text { Put the sandwich on the plate } \\
(100 \%) \\
\text { Pick up the sandwich }(90 \%)\end{array}$ \\
\hline
\end{tabular}


Paul's Low-Probability and High- Probability Requests

\begin{tabular}{|c|c|c|}
\hline Setting & $\begin{array}{l}\text { Low-Probability requests (percent } \\
\text { correct responses to requests during } \\
\text { assessment) }\end{array}$ & $\begin{array}{l}\text { High-Probability Requests } \\
\text { (percent correct responses to } \\
\text { requests during assessment) }\end{array}$ \\
\hline $\begin{array}{l}\text { Friendship } \\
\text { activities }\end{array}$ & $\begin{array}{l}\text { Say to (peer) "look at me" }(30 \%) \\
\text { Shake hand with your friend }(50 \%) \\
\text { Hug your friend }(40 \%) \\
\text { Tickle your friend }(50 \%)\end{array}$ & $\begin{array}{l}\text { Give me five }(100 \%) \\
\text { Touch your nose }(100 \%) \\
\text { Clap with your hands }(100 \%) \\
\text { Hands on your shoulder }(100 \%) \\
\text { Hands on your knees }(90 \%) \\
\text { Touch your shoulder }(100 \%) \\
\text { Hands up high }(90 \%) \\
\text { Move your eyebrows }(80 \%) \\
\text { Move your shoulder }(80 \%) \\
\text { Look at me }(80 \%)\end{array}$ \\
\hline $\begin{array}{l}\text { Blocks and } \\
\text { Trucks }\end{array}$ & $\begin{array}{l}\text { Say to (peer) "make a farm" }(40 \%) \\
\text { Say to (peer) "horse please" }(60 \%) \\
\text { Give (peer) the cow }(50 \%) \\
\text { Push the tractor to (peer) }(40 \%)\end{array}$ & $\begin{array}{l}\text { Pick up the cow }(90 \%) \\
\text { Put the cow in the farm }(90 \%) \\
\text { Pick up the horse }(80 \%) \\
\text { Put the horse in the farm }(80 \%) \\
\text { Put the tractor in the farm }(80 \%) \\
\text { Put the cow in the truck }(80 \%) \\
\text { Put the block next to the farm } \\
(80 \%) \\
\text { Push the tractor to the farm } \\
(80 \%) \\
\text { Stack the block }(80 \%)\end{array}$ \\
\hline Train & $\begin{array}{l}\text { Push the train to (peer) }(50 \%) \\
\text { Connect trains with your friend } \\
(50 \%) \\
\text { Say to (peer) "come to me" }(40 \%) \\
\text { Say to (peer) "train please" }(40 \%)\end{array}$ & $\begin{array}{l}\text { Pick up a train }(80 \%) \\
\text { Put the tree on the grass }(80 \%) \\
\text { Push the button }(80 \%) \\
\text { Open the box }(80 \%) \\
\text { Put the barrel in loader }(80 \%) \\
\text { Connect trains together }(80 \%) \\
\text { Put the house on the ground } \\
(90 \%)\end{array}$ \\
\hline Kitchen & $\begin{array}{l}\text { Give (peer) the pizza }(40 \%) \\
\text { Put the pizza on (peer)'s plate } \\
(50 \%) \\
\text { Say to (peer) "pizza please" }(50 \%) \\
\text { Give (peer) the sandwich }(60 \%)\end{array}$ & $\begin{array}{l}\text { Pick up the pizza }(80 \%) \\
\text { Cut the pizza }(90 \%) \\
\text { Put the pizza on your plate }(90 \%) \\
\text { Pretend to eat pizza }(80 \%) \\
\text { Put the fork on the table }(80 \%) \\
\text { Put the cup on the table }(80 \%) \\
\text { Put the sandwich on the plate } \\
(100 \%)\end{array}$ \\
\hline
\end{tabular}


Chris's Low-Probability and High- Probability Requests

\begin{tabular}{|c|c|c|}
\hline Setting & $\begin{array}{l}\text { Low-Probability requests } \\
\text { (percent correct responses to } \\
\text { requests during assessment) }\end{array}$ & $\begin{array}{l}\text { High-Probability Requests } \\
\text { (percent correct responses to } \\
\text { requests during assessment) }\end{array}$ \\
\hline Friendship & Look at your friend $(50 \%)$ & Give me five $(100 \%)$ \\
\hline \multirow[t]{6}{*}{ Activities } & Say to (peer) "hi, (peer)" $(40 \%)$ & Stomp your feet $(70 \%)$ \\
\hline & Tap your friend $(40 \%)$ & Clap your hands $(70 \%)$ \\
\hline & Say to (peer) "good job" $(40 \%)$ & Hands on your knees $(70 \%)$ \\
\hline & & Move your eyebrows ( $70 \%)$ \\
\hline & & Hands up high $(80 \%)$ \\
\hline & & Move your shoulder $(80 \%)$ \\
\hline & Give the slippery soap to (peer) & Stamp Slippery Soap (90\%) \\
\hline \multirow{8}{*}{$\begin{array}{l}\text { Art/Manipulative } \\
\text { (Drawing) }\end{array}$} & $(40 \%)$ & Stamp Mrs. Pepper (90\%) \\
\hline & Say to (peer) "Blues' clues, & Stamp Mr. Sault (100\%) \\
\hline & please" $(50 \%)$ & Stamp Mr. Blues Clues $(100 \%)$ \\
\hline & Say to (peer) "notebook, please" & Stamp your fingers $(90 \%)$ \\
\hline & $(40 \%)$ & Write the letter "C" $(80 \%)$ \\
\hline & Give (peer) the notebook $(30 \%)$ & Write the number "3" (80\%) \\
\hline & & Write the number "7" (80\%) \\
\hline & & Draw a circle $80(80 \%)$ \\
\hline \multirow[t]{6}{*}{ Train } & Give (peer) the train $(50 \%)$ & Pick up the train $(80 \%)$ \\
\hline & Push the train to (peer) $(40 \%)$ & Put the tree on the grass $(80 \%)$ \\
\hline & Give (peer) the barrel $(50 \%)$ & Connect trains together $(70 \%)$ \\
\hline & Say to (peer) "tree please" $(30 \%)$ & Put the barrel in loader $(80 \%)$ \\
\hline & & Push the button $(80 \%)$ \\
\hline & & Push the train $(80 \%)$ \\
\hline \multirow[t]{8}{*}{ Kitchen } & Give (peer) the sandwich (40\%) & Cut the pizza $(80 \%)$ \\
\hline & $\begin{array}{l}\text { Put the sandwich on (peer)'s } \\
\text { plate }(50 \%)\end{array}$ & $\begin{array}{l}\text { Put the cheese on your pizza } \\
(90 \%)\end{array}$ \\
\hline & Give (peer) the pizza ( $40 \%)$ & Put the pizza on the plate \\
\hline & Say to (peer) "Pizza please" & $(90 \%)$ \\
\hline & $(40 \%)$ & $\begin{array}{l}\text { Put the sandwich on the plate } \\
(80 \%)\end{array}$ \\
\hline & & Pretend to eat pizza $(80 \%)$ \\
\hline & & Put the cup on the table $(70 \%)$ \\
\hline & & Pretend to drink water $(70 \%)$ \\
\hline
\end{tabular}


APPENDIX I

PEER TRAINING SCRIPTS 


\section{Peer Training}

The experimenter delivers the low-probability request to the second observer who pretends to be the target child, and the second observer responds to the experimenter's low-probability requests. The peer is told to wait until the target child follows the experimenter's instruction and the experimenter says, "You wait until your friend is doing what I ask him to do"

The experimenter uses role-plays and discusses how to respond to the target child's initiations. The experimenter delivers each low-probability request to the second observer, and asks the peer how she would respond to that. Peer training sessions provide until the peer reaches the criterion of $90 \%$ correct responses to the experimenter's questions for 3 consecutive sessions.

Training for Eric's peer, Stacie

"(Stacie), we are going to learn how to play with your friend, Eric. Ms. ( ) is pretending to be Eric, now. Then you will explain to me how to play with Eric when Eric gives you toys or talks to you."

Friendship activities

1. The experimenter delivers the low-p request to the second observer "Eric, say to Stacie how are you?" After responding to the request, the experimenter asks Stacie "What would you say/do to your friend?" If the peer responds appropriately, verbal praise is provided. If the peer does not respond appropriately, the experimenter models saying, "I am fine. How are you, Eric?"

2. The experimenter delivers the low-p request to the second observer "Eric, say to Stacie, I like to play with you" After responding to the request, the experimenter asks Stacie "What would you say/do to your friend?" If the peer responds appropriately, verbal praise is provided. If the peer does not respond appropriately, the experimenter says, "Great! I like to play with you, too. Let's play."

3. The experimenter delivers the low-p request to the second observer "Eric, say to Stacie, Look at me" After responding to the request, the experimenter asks Stacie "What would you say/do to your friend?" If the peer responds appropriately, verbal praise is provided. If the peer does not respond appropriately, the experimenter models looking at the second observerand saying "Hi Eric" 
4. The experimenter delivers the low-p request to the second observer "Eric, "hug your friend" After responding to the request, the experimenter asks Stacie "What would you say/do to your friend?" If the peer responds appropriately, verbal praise is provided. If the peer does not respond appropriately, the experimenter models hugging the second observer and saying "Hi, Eric"

\section{Blocks and Trucks}

5. The experimenter delivers the low-p request to the second observer "Eric, give Stacie the plane "After responding to the request, the experimenter asks Stacie "What would you say/do to your friend?" If the peer responds appropriately, verbal praise is provided. If the peer does not respond appropriately, the experimenter models receiving the plane and saying "thank you, Eric, this is a big plane."

6. The experimenter delivers the low-p request to the second observer "Eric, give Stacie the block." After responding to the request, the experimenter asks Stacie "What would you say/do to your friend?" If the peer responds appropriately, verbal praise is provided. If the peer does not respond appropriately, the experimenter models while receiving the block, and saying "Thank you, let's build an airport"

7. The experimenter delivers the low-p request to the second observer "Eric, aske to Stacie fly the plane to me." After responding to the request, the experimenter asks to Stacie "What would you say/do to your friend?" If the peer responds appropriately, verbal praise is provided. If the peer does not respond appropriately, the experimenter models saying "All right, here we go."

8. The experimenter delivers the low-p request to the second observer "Eric, Say to Stacie I am coming". After responding to the request, the experimenter asks to Stacie "What would you say to your friend?" If the peer responds appropriately, verbal praise is provided. If the peer does not respond appropriately, the experimenter models receiving the train, and saying "O.K. I am here."

Trains

9. The experimenter delivers the low-p request to the second observer "Eric, Give Stacie the train". After responding to the request, the experimenter asks to Stacie "What would you say/do to your friend?" If the peer responds appropriately, verbal praise is provided. If the peer does not respond appropriately, the experimenter models receiving the train, and saying "Thank you, (Eric), I like the train."

10. The experimenter delivers the low-p request to the second observer "Eric, push the train to Stacie". After responding to the request, the experimenter asks Stacie, 
"What would you say/do to your friend?" If the peer responds appropriately, verbal praise is provided. If the peer does not respond appropriately, the experimenter models receiving the train and saying

"Thank you, Eric. this goes to you again."

11. The experimenter delivers the low-p request to the second observer "Eric, Say Stacie, push the button, Stacie". After responding to the request, the experimenter asks to Stacie "What would you say/do to your friend?" If the peer responds appropriately, verbal praise is provided. If the peer does not respond appropriately, the experimenter models saying "O.K., Eric, here we go."

12. The experimenter delivers the low-p request to the second observer "Eric, connect trains with Stacie." After responding to the request, the experimenter asks Stacie "What would you say/do to your friend?" If the peer responds appropriately, verbal praise is provided. If the peer does not respond appropriately, the experimenter models saying "Good, let's make a long train."

Kitchen

13. The experimenter delivers the low-p request to the second observer "Eric, give Stacie the pizza". After responding to the request, the experimenter asks Stacie "What would you say/ do to your friend?" If the peer responds appropriately, verbal praise is provided. If the peer does not respond appropriately, the experimenter models receiving the pizza and saying "Thank you, Eric, this is a good pizza".

14. The experimenter delivers the low-p request to the second observer "Eric, give Stacie the cheese." After responding to the request, the experimenter asks Stacie "What would you say/ do to your friend?" If the peer responds appropriately, verbal praise is provided. If the peer does not respond appropriately, the experimenter models receiving the cheese and saying "Thank you, Eric."

15. The experimenter delivers the low-p request to the second observer "Eric, say to Stacie more pizza please." After responding to the request, the experimenter asks Stacie "What would you say/do to your friend?" If the peer responds appropriately, verbal praise is provided. If the peer does not respond appropriately, the experimenter models giving pizza and saying "Here it is, I like pizza, too."

16. The experimenter delivers the low-p request to the second observer "Eric, say to Stacie I am making a sandwich for you". After responding to the request, the experimenter asks Stacie "What would you say/do to your friend?" If the peer 
responds appropriately, verbal praise is provided. If the peer does not respond appropriately, the experimenter models receiving the sandwich, and saying "Thank you, Eric, it's delicious."

Checklist for Stacie

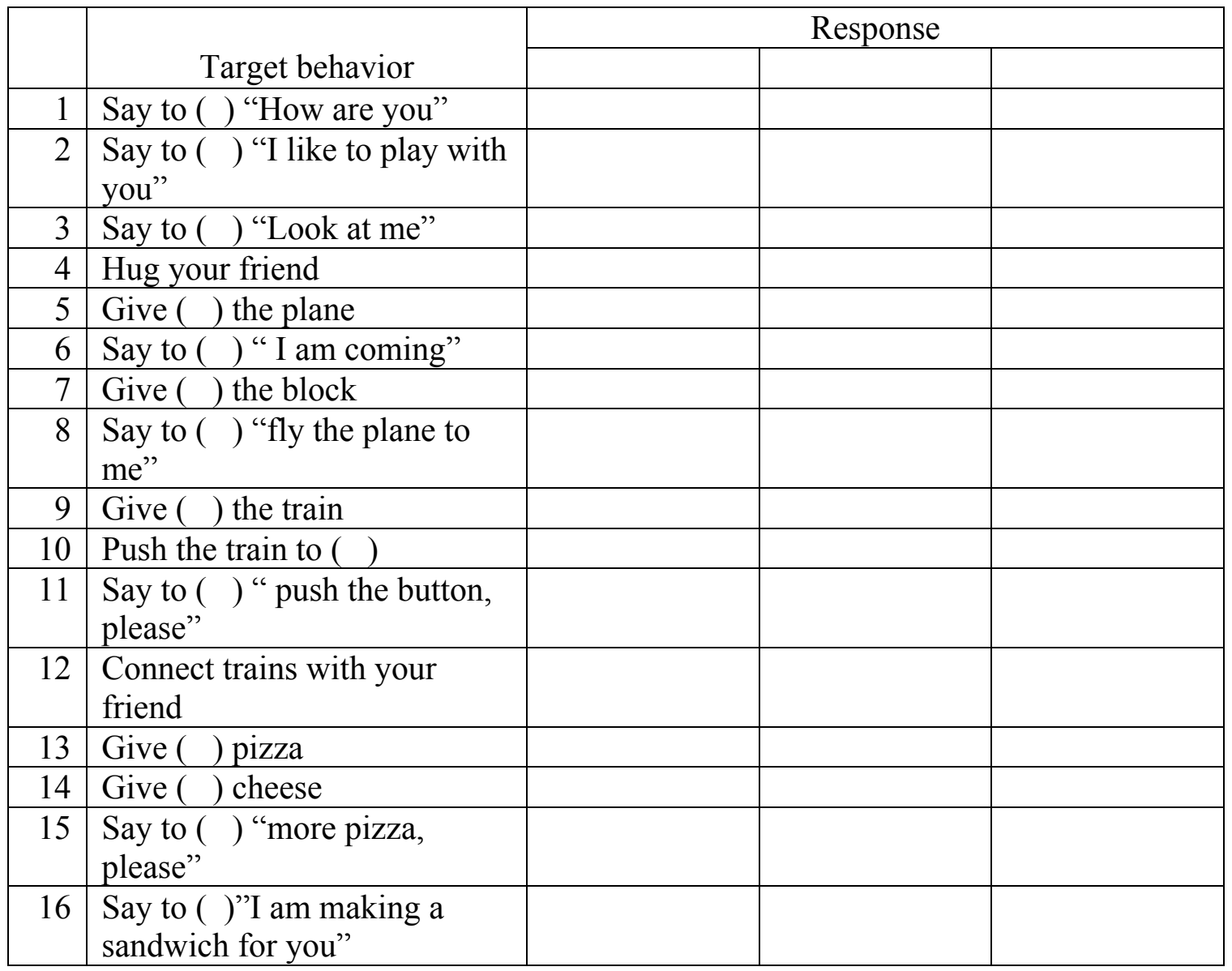

Correct response +

Correct response with prompts \pm

In correct response - 
Training for Paul's peer, Jennifer

Friendship activities

1. The experimenter delivers the low-p request to the second observer "Paul, shake hands with your friend." After responding to the request, the experimenter asks Jennifer "What would you say/do to your friend?" If the peer responds appropriately, verbal praise is provided. If the peer does not respond appropriately, the experimenter models shaking hands with Paul while saying, "Hi, Paul".

2. The experimenter delivers the low-p request to the second observer "Paul, tickle your friend." After responding to the request, the experimenter asks to Jennifer "What would you say/do to your friend?" If the peer responds appropriately, verbal praise is provided. If the peer does not respond appropriately, the experimenter models saying, "I am going to tickle you, too."

3. The experimenter delivers the low-p request to the second observer "Paul, tap your friend". After responding to the request, the experimenter asks Jennifer, "What would you say/do to your friend?" If the peer responds appropriately, verbal praise is provided. If the peer does not respond appropriately, the experimenter models saying " Hi Paul, or good job."

4. The experimenter delivers the low-p request to the second observer "Paul, say to Jennifer, Look at me." The experimenter asks Jennifer "What would you say/do to your friend?" If the peer responds appropriately, verbal praise is provided. If the peer does not respond appropriately, the experimenter models saying " $\mathrm{Hi}$, Paul, "or "High five, Paul."

Blocks and Trucks

5. The experimenter delivers the low-p request to the second observer "Paul, say to Jennifer, make a farm". After responding to the request, the experimenter asks to Jennifer "What would you say/do to your friend?" If the peer responds appropriately, verbal praise is provided. If the peer does not respond appropriately, the experimenter models saying "O.K. Let's make a big farm."

6. The experimenter delivers the low-p request to the second observer "Give Jennifer the cow." After responding to the request, the experimenter asks Jennifer "What would you say/do to your friend?" If the peer responds appropriately, verbal praise is provided. If the peer does not respond appropriately, the experimenter models saying " Thank you, Paul. Let me put it in the farm." 
7. The experimenter delivers the low-p request to the second observer "Paul, say to Jesse, horse please." After responding to the request, the experimenter asks Jennifer, "What would you say/do to your friend?" If the peer responds appropriately, verbal praise is provided. If the peer does not respond appropriately, the experimenter models giving the horse while saying "Here it is, Paul, I like horse, too.”

8. The experimenter delivers the low-p request to the second observer "Paul, push the tractor to Jennifer". After responding to the request, the experimenter asks Jennifer, "What would you say/do to your friend?" If the peer responds appropriately, verbal praise is provided. If the peer does not respond appropriately, the experimenter models receiving the train, and saying "Thank you, Paul, here we go."

Train

9. The experimenter delivers the low-p request to the second observer "Give Jennifer the train." After responding to the request, the experimenter asks Jennifer, "What would you say/do to your friend?" If the peer responds appropriately, verbal praise is provided. If the peer does not respond appropriately, the experimenter models receiving the train, and saying "Thank you, Paul, here is the train, here we go."

10. The experimenter delivers the low-p request to the second observer "Paul, connect trains with Jennifer". After responding to the request, the experimenter asks Jennifer, "What would you do/say to your friend?" If the peer responds appropriately, verbal praise is provided. If the peer does not respond appropriately, the experimenter models receiving the train and saying "Good job, High five, Paul, let's make the long trains".

11. The experimenter delivers the low-p request to the second observer "Paul, say to Jennifer, Come to me, Jennifer". After responding to the request, the experimenter asks Jennifer, "What would you say/do to your friend?" If the peer responds appropriately, verbal praise is provided. If the peer does not respond appropriately, the experimenter models saying "O.K., Paul, I am coming."

12. The experimenter delivers the low-p request to the second observer "Paul, say to Jennifer, Train, please". After responding to the request, the experimenter asks Jennifer, "What would you say/do to your friend?" If the peer responds appropriately, verbal praise is provided. If the peer does not respond appropriately, the experimenter models saying "Here it is, Paul." 


\section{Kitchen}

13. The experimenter delivers the low-p request to the second observer "Paul, give Jennifer the pizza." After responding to the request, the experimenter asks Jennifer, "What would you do/say to your friend?" If the peer responds appropriately, verbal praise is provided. If the peer does not respond appropriately, the experimenter models receiving the pizza, and saying "Thank you, Paul, this is a good pizza."

14. The experimenter delivers the low-p request to the second observer "Paul, say to Jennifer, pizza, please." After responding to the request, the experimenter asks Jennifer, "What would you do/say to your friend?" If the peer responds appropriately, verbal praise is provided. If the peer does not respond appropriately, the experimenter models receiving the pizza, and saying "Here it is, Paul or give him high-five."

15. The experimenter delivers the low-p request to the second observer "Paul, say to Jennifer,Water, please". After responding to the request, the experimenter asks Jennifer, "What would you do/say to your friend?" If the peer responds appropriately, verbal praise is provided. If the peer does not respond appropriately, the experimenter models giving water, and saying "Here it is, Paul."

16. The experimenter delivers the low-p request to the second observer "Paul, put the sandwich on Jennifer's plate." After responding to the request, the experimenter asks Jennifer, "What would you do/say to your friend?" If the peer responds appropriately, verbal praise is provided. If the peer does not respond appropriately, the experimenter models receiving the sandwich, and saying "Thank you, Paul, this is delicious." 
Checklist for peer training

\begin{tabular}{|r|l|l|l|l|}
\hline & \multicolumn{2}{|c|}{ Target behavior } & \multicolumn{2}{c|}{ Response } \\
\cline { 2 - 4 } & Shake hands with your friend & & & \\
\hline 2 & Tickle your friend & & \\
\hline 3 & Tap your friend & & \\
\hline 4 & Say to ( ) "Look at me" & & & \\
\hline 5 & Say to ( ), Make a farm" & & & \\
\hline 6 & Give ( ) the cow & & \\
\hline 7 & Say to ( )"Horse please" & & & \\
\hline 8 & Push the tractor to ( ) & & & \\
\hline 9 & Push the train to ( ) & & & \\
\hline 10 & Connect trains with your friend & & & \\
\hline 11 & Say to ( ) "come to me" & & & \\
\hline 12 & Say to ( ) "Train, please" & & & \\
\hline 13 & Give ( ) pizza & & \\
\hline 14 & Say to ( )"Pizza please" & & & \\
\hline 15 & Say to ( ) "Water please" & & & \\
\hline 16 & Put the sandwich on Jesse's plate & & & \\
\hline
\end{tabular}

Correct response +

Correct response with prompts \pm

In correct response - 
Peer training for Hilary

Friendship activities

1. The experimenter delivers the low-p request to the second observer "Chris, say to Hilary, "Hi, Hilary!" After responding to the request, the experimenter asks Hillary "What would you say/do to your friend?" If the peer responds appropriately, verbal praise is provided. If the peer does not respond appropriately, the experimenter models saying, "Hi, Chris."

2. The experimenter delivers the low-p request to the second observer "Chris, hold your friend's hand" After responding to the request, the experimenter asks Hillary, "What would you do/say to your friend?" If the peer responds appropriately, verbal praise is provided. If the peer does not respond appropriately, the experimenter models holding hands and says, "Hi Chris, nice to see you" or "Hi Chris!"

3. The experimenter delivers the low-p request to the second observer "Chris, tap your friend." After responding to the request, the experimenter asks Hilary, "What would you do/say to your friend?" If the peer responds appropriately, verbal praise is provided. If the peer does not respond appropriately, the experimenter models tapping while saying "Good job, Chris. High five."

4. The experimenter delivers the low-p request to the second observer "Chris, say to Hilary, Good job" After responding to the request, the experimenter asks Hilary, "What would you say/do to your friend?" If the peer responds appropriately, verbal praise is provided. If the peer does not respond appropriately, the experimenter models saying "Thank you, Chris"

Drawing

5. The experimenter delivers the low-p request to the second observer "Chris, give Hilary Slippery soap " After responding to the request, the experimenter asks Hilary, "What would you do/say to your friend?" If the peer responds appropriately, verbal praise is provided. If the peer does not respond appropriately, the experimenter models receiving the slippery soap, saying "Thank you, Chris, look at this, now your turn."

6. The experimenter delivers the low-p request to the second observer "Chris, say to Hilary, Blues's Clues, please." After responding to the request, the experimenter asks Hilary, "What would you do/say to your friend?" If the peer responds 
appropriately, verbal praise is provided. If the peer does not respond appropriately, the experimenter models receiving it and saying "All right, here we go, Chris. Now my turn."

7. The experimenter delivers the low-p request to the second observer "Chris, say to Hilary, Notebook, please". After responding to the request, the experimenter asks Hilary, "What would you do/say to your friend?" If the peer responds appropriately, verbal praise is provided. If the peer does not respond appropriately, the experimenter models receiving the notebook while saying "O.K., Here you go."

8. The experimenter delivers the low-p request to the second observer "Chris, give Hilary the notebook". After responding to the request, the experimenter asks Hilary, "What would you do/say to your friend?" If the peer responds appropriately, verbal praise is provided. If the peer does not respond appropriately, the experimenter models receiving the notebook, saying "Thank you Chris, look at this. Now your turn."

Train

9. The experimenter delivers the low-p request to the second observer "Chris, Give Hillary the train". After responding to the request, the experimenter asks Hilary, "What would you do/say to your friend?" If the peer responds appropriately, verbal praise is provided. If the peer does not respond appropriately, the experimenter models receiving the train and saying "Thank you, Chris, high five"

10. The experimenter delivers the low-p request to the second observer "Chris, push the train to Hilary". After responding to the request, the experimenter asks Hilary, "What would you do/say to your friend?" If the peer responds appropriately, verbal praise is provided. If the peer does not respond appropriately, the experimenter models receiving the train and saying

"Good job, Chris, high five. Here is the train."

11. The experimenter delivers the low-p request to the second observer "Chris, give Hilary the barrel". After responding to the request, the experimenter asks Hilary "What would you do/say to your friend?" If the peer responds appropriately, verbal praise is provided. If the peer does not respond appropriately, the experimenter models saying "Thank you, Chris, push the button, or look at this."

12. The experimenter delivers the low-p request to the second observer "Chris, say to Hilary, Train please". After responding to the request, the experimenter asks Hilary, "What would you do/say to your friend?" If the peer responds appropriately, verbal praise is provided. If the peer does not respond appropriately, the experimenter models giving the train and saying "O.K.Hhere you go. Let's make long trains, Chris." 


\section{Kitchen}

13. The experimenter delivers the low-p request to the second observer "Chris, put the sandwich on Hilary's plate". After responding to the request, the experimenter asks Hilary, "What would you do/say to your friend?" If the peer responds appropriately, verbal praise is provided. If the peer does not respond appropriately, the experimenter models pretending to eat the sandwich, and saying "Thank you, Chris, This is delicious. Here is the sandwich for you."

14. The experimenter delivers the low-p request to the second observer "Chris, give Hilary the pizza". After responding to the request, the experimenter asks Hilary, "What would you do/say to your friend?" If the peer responds appropriately, verbal praise is provided. If the peer does not respond appropriately, the experimenter models receiving the pizza and saying "Thank you, Chris. This is a good pizza. Here is the pizza for you."

15. The experimenter delivers the low-p request to the second observer "Chris, say to Hilary, Pizza please." After responding to the request, the experimenter asks Hilary, "What would you do/say to your friend?" If the peer responds appropriately, verbal praise is provided. If the peer does not respond appropriately, the experimenter models giving pizza, and saying "Here you go, Chris."

16. The experimenter delivers the low-p request to the second observer "Chris, give Hilary, Cheese." After responding to the request, the experimenter asks Hilary, "What would you do/say to your friend?" If the peer responds appropriately, verbal praise is provided. If the peer does not respond appropriately, the experimenter models while receiving the cheese and saying "Thank you, Chris. Here is the cheese for you." 
Checklist for peer training

\begin{tabular}{|c|c|c|c|}
\hline & & Response & \\
\hline & Target behavior & & \\
\hline 1 & Say to ( ) "Hi Hilary" & & \\
\hline 2 & Hold your friend's hand & & \\
\hline 3 & Tap your friend & & \\
\hline 4 & Say to ( ) "Good job" & & \\
\hline 5 & Give ( ) the slippery soap & & \\
\hline 6 & $\begin{array}{l}\text { Say to ( ) "Blues' Clues, } \\
\text { please" }\end{array}$ & & \\
\hline 7 & $\begin{array}{l}\text { Say to ( ) “Notebook } \\
\text { please” }\end{array}$ & & \\
\hline 8 & Give ( ) notebook & & \\
\hline 9 & Give ( ) the train & & \\
\hline 10 & Push the train to () & & \\
\hline 11 & Give ( ) the barrel & & \\
\hline 12 & Say to ( ) "train please" & & \\
\hline 13 & $\begin{array}{l}\text { Put the sandwich on ( )'s } \\
\text { plate }\end{array}$ & & \\
\hline 14 & Give ( ) the pizza & & \\
\hline 15 & Say to ( ) "Pizza, please" & & \\
\hline 16 & Give $($ ) the cheese & & \\
\hline
\end{tabular}

Correct response +

Correct response with prompts \pm In correct response - 